\title{
Feasibility/Treatability Studies for Removal of Heavy Metals from Training Range Soils at the Grafenwöhr Training Area, Germany
}

Energy Systems Division Argonne National Laboratory 


\section{Argonne National Laboratory}

Argonne National Laboratory, with facilities in the states of Illinois and Idaho, is owned by the United States Government, and operated by the University of Chicago under the provisions of a contract with the Department of Energy.

This technical memo is a product of Argonne's Energy Systems (ES) Division.

For information on the division's scientific and engineering activities, contact:

Director, Energy Systems Division

Argonne National Laboratory

Argonne, llinois 60439-4815

Telephone (708) 252-3724

Presented in this technical memo are preliminary results of ongoing work or work that is more limited in scope and depth than that described in formal reports issued by the ES Division.

Publishing support services were provided by Argonne's Information and Publishing Division.

\section{Disclaimer}

This report was prepared as an account of work sponsored by an agency of the United States Government. Neither the United States Government nor any agency thereof, nor any of their employees, makes any warranty, express or implied, or assumes any legal liability or responsibility for the accuracy, completeness, or usefulness of any information, apparatus, product, or process disclosed, or represents that its use would not infringe privately owned rights. Reference herein to any specific commercial product, process, or service by trade name, trademark, manufacturer, or otherwise, does not necessarily constitute or imply its endorsement, recommendation, or favoring by the United States Government or any agency thereof. The views and opinions of authors expressed herein do not necessarily state or reflect those of the United States Government or any agency thereof.

Reproduced directly from the best available copy.

Available to DOE and DOE contractors from the Office of Scientific and Technical Information, P.O. Box 62, Oak Ridge, TN 37831; prices available from (615) 576-8401.

Available to the public from the National Technical Information Service, U.S. Department of Commerce, 5285 Port Royal Road, Springfield, VA 22161. 


\section{DISCLAIMER}

Portions of this document may be illegible in electronic image products. Images are produced from the best available original document. 


\section{Feasibility/Treatability Studies for Removal of Heavy Metals from Training Range Soils at the Grafenwöhr Training Area, Germany}

by R.W. Peters

Waste Management and Bioengineering Section, Energy Systems Division, Argonne National Laboratory, 9700 South Cass Avenue, Argonne, Illinois 60439

May 1995

DISTRIBUTION OF THIS DOCUMENT IS UNLIMITED

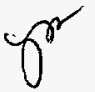

Work sponsored by United States Department of Energy, under contract to the United States Army, 7th Army Training Command 
ה今

This report is printed on recycled paper. 


\section{Contents}

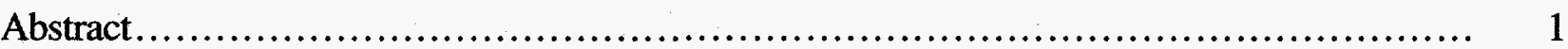

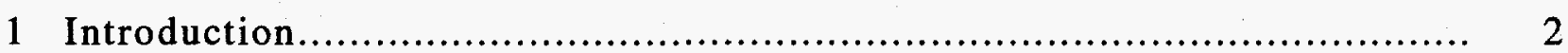

2 Background .................................................................. 3

3 Purpose and Approach....................................................... 6

4 Experimental Procedures.................................................... 7

4.1 Batch Shaker Tests ..................................................... 7

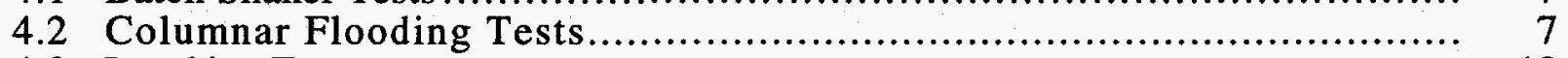

4.3 Leaching Tests............................................................ 10

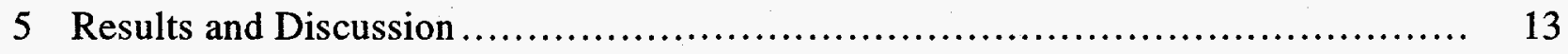

5.1 Characterization of Untreated Soil ..................................... 13

5.2 Characterization of Soil Treated Using Batch Shaker Chelant Extraction ........ 14

5.3 Batch Shaker Tests ............................................................. 23

5.4 Columnar Flooding Tests................................................... 39

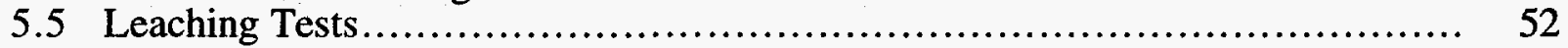

6 Summary and Conclusions.................................................... 87

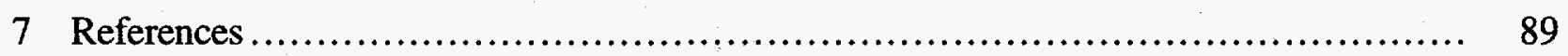

$\begin{array}{ll}\text { Appendix A: } & \text { Batch Shaker Experiment Data: S037, S038, S039, } \\ \text { S041, S044, and S049 } \ldots \ldots \ldots \ldots \ldots \ldots \ldots \ldots \ldots \ldots \ldots \ldots \ldots \ldots \ldots \ldots \ldots \ldots \ldots \ldots \ldots \ldots \ldots \ldots \ldots \ldots \ldots \ldots \ldots \ldots \ldots \ldots \ldots\end{array}$

Appendix B: Amount of Heavy Metals Removed by Columnar Flooding:

$\mathrm{Cd}, \mathrm{Cr}, \mathrm{Cu}, \mathrm{Fe}, \mathrm{Pb}$, and $\mathrm{Zn}$.....

Appendix C: Percent of Heavy Metals Removed by Columnar Flooding:

$\mathrm{Cd}, \mathrm{Cr}, \mathrm{Cu}, \mathrm{Fe}, \mathrm{Pb}$, and $\mathrm{Zn}$.

\section{Figures}

1 Solubilization of Heavy Metals ( $\mathrm{Cd}$ and $\mathrm{Pb}$ ) from Contaminated

Soil Samples S037, S038, S039, S041, S044, and S049,

Using 0.01M Citric Acid and 0.01M EDTA

2 Solubilization of Heavy Metals ( $\mathrm{Ba}, \mathrm{Cu}$, and $\mathrm{Zn}$ ) from Contaminated

Soil Samples S037, S038, S039, S041, S044, and S049, Using

$0.01 \mathrm{M}$ Citric Acid and 0.01M EDTA 


\section{Figures (Cont.)}

3 Initial and Final Heavy Metals Concentrations from Six Soil Samples as a Function of $\mathrm{pH}$ for Batch Chelant Extraction of

$\mathrm{Pb}, \mathrm{Cd}, \mathrm{Cr}, \mathrm{Cu}, \mathrm{Ba}$, and $\mathrm{Zn}$, Using 0.01M Citric Acid

4 Initial and Final Heavy Metals Concentrations from Six Soil Samples as a Function of $\mathrm{pH}$ for Batch Chelant Extraction of

$\mathrm{Pb}, \mathrm{Cd}, \mathrm{Cr}, \mathrm{Cu}, \mathrm{Ba}$, and $\mathrm{Zn}$, Using 0.01M EDTA

5 Columnar Extraction of $\mathrm{Pb}$ from Contaminated Soil, Using

$0.05 \mathrm{M}$ Citric Acid or 0.05M EDTA

6 Columnar Extraction of Cd from Contaminated Soil, Using

$0.05 \mathrm{M}$ Citric Acid or 0.05M EDTA

Columnar Extraction of $\mathrm{Cu}$ from Contaminated Soil, Using

$0.05 \mathrm{M}$ Citric Acid or 0.05M EDTA

8 Columnar Extraction of $\mathrm{Fe}$ from Contaminated Soil, Using

$0.05 \mathrm{M}$ Citric Acid or 0.05M EDTA

9 Columnar Extraction of $\mathrm{Zn}$ from Contaminated Soil, Using

$0.05 \mathrm{M}$ Citric Acid or $0.05 \mathrm{M}$ EDTA

Tables

1 Analytical Procedures/Methods for Determining Physical/Chemical

Characteristics of Soil Samples

2 Physical and Chemical Characteristics of Soil Samples

3 Characterization of the Industrial Well and Drinking Water Well

at Grafenwöhr, Germany

4 Dutch List of Heavy Metals with Category Contamination Levels

for Soil and Groundwater.

5 ICP and TCLP Results from Characterization of Untreated Soils and Groundwater at the Grafenwöhr Training Area

6 Soil Characterization Results for $\mathrm{Pb}$ and $\mathrm{Cu}$ at the

Grafenwöhr Training Area.

7 Soil Characterization Results for $\mathrm{Ca}$ and $\mathrm{Cr}$ at the Grafenwöhr Training Area

8 Soil Characterization Results for $\mathrm{Zn}$ and $\mathrm{Ba}$ at the Grafenwöhr Training Area.

9 Results of Chelant Extraction Soil Treatment - Batch Studies 


\section{Tables (Cont.)}

10 Comparison of Contaminant Concentrations in Treated and

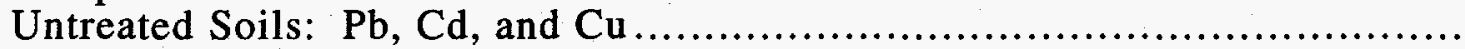

11 Comparison of Contaminant Concentrations in Treated and

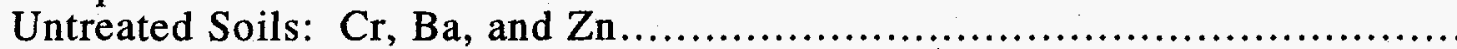




\title{
Feasibility/Treatability Studies for Removal of Heavy Metals from Training Range Soils at the Grafenwöhr Training Area, Germany
}

by

R.W. Peters

\begin{abstract}
A feasibility/treatability study was performed to investigate the leaching potential of heavy metals (particularly lead) from soils at the Grafenwöhr Training Area (GTA) in Germany. The study included an evaluation of the effectiveness of chelant extraction to remediate the heavy-metal-contaminated soils. Batch shaker tests indicated that ethylenediaminetetraacetic acid (EDTA) (0.01M) was more effective than citric acid $(0.01 \mathrm{M})$ at removing cadmium, copper, lead, and zinc. EDTA and citric acid were equally effective in mobilizing chromium and barium from the soil. The batch shaker technique with chelant extraction offers promise as a remediation technique for heavy-metal-contaminated soil at the GTA. Columnar flooding tests conducted as part of the study revealed that deionized water was the least effective leaching solution for mobilization of the heavy metals; the maximum solubilization obtained was $3.72 \%$ for cadmium. EDTA $(0.05 \mathrm{M})$ achieved the greatest removal of lead (average removal of $17.6 \%$ ). The difficulty of extraction using deionized water indicates that all of the heavy metals are very tightly bound to the soil; therefore, they are very stable in the GTA soils and do not pose a serious threat to the groundwater system. Columnar flooding probably does not represent a viable remediation technique for in-situ cleanup of heavy-metal-contaminated soils at the GTA.
\end{abstract}

\section{Introduction}

Military training exercises over the past several decades at the Grafenwöhr Training Area (GTA) in Germany involved firing a wide range of weapons and weapon systems on a number of firing ranges and target areas. The types of weapons used during these live-fire training exercises ranged from small arms and hand grenades to artillery, tanks, and helicopter gun-ships. One environmental consequence of these firing exercises was the deposition of large quantities of heavy metals, such as lead, copper, zinc, and explosive residue, into the soil. Scientists feared that elevated concentrations of some heavy metals could be incorporated into food webs through uptake by vegetation and that significant quantities of heavy metals could be introduced into the local surface waters and/or leached from the soil into groundwater supplies. This could result in heavy metals being transported to surrounding nonmilitary areas, producing significant adverse environmental impacts for the local population. 
The type, degree, and extent of heavy metal and explosive residue contamination from current and past training exercises on the three types of firing ranges and their environs at GTA have already been documented; possible contamination of the local environment by heavy metals introduced into local surface or groundwater supplies was brought up as a potential problem during that study. That part of the investigation is described in a report entitled, Heavy-Metal Contamination on Training Ranges at the Grafenwöhr Training Area, Germany, prepared by S.D. Zellmer and J.F. Schneider (1993).

This report evaluates the effectiveness of chelant extraction for remediation of the heavymetal-laden soils at the GTA and discusses whether heavy metals associated with the various firing ranges have leached into the groundwater system. 


\section{Background}

Three firing ranges were selected for study at GTA:

- Range 122: handgun range

- Range 124: rifle range

- Range 111: hand grenade range

Range 122 includes 10 firing points and a $7-\mathrm{m}$ ( $23-\mathrm{ft})$-high earthen berm located about

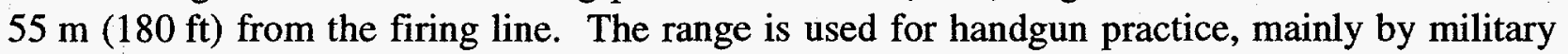
police units. There are nine pop-up targets for each firing point; the first eight at distances ranging from $10 \mathrm{~m}(32.8 \mathrm{ft})$ to $30 \mathrm{~m}(99 \mathrm{ft})$ and the ninth at $50 \mathrm{~m}(165 \mathrm{ft})$ from the firing line. A ditch that runs parallel to the berm between the eighth and ninth targets is designed to remove runoff water from the berm and range. The area around the targets is covered by mowed grass; the ditch and berm are covered by a mixture of grasses and low shrubs. A number of spent slugs are present on the soil surface and on the berm. A tower behind the firing line is used for observation and safety control during firing exercises. The area to both sides and behind the range is forested. The area immediately behind the berm, covered by tall grass and shrub cover, is part of the impact area.

Range 124 is used by combat troops to check the accuracy of their rifle sights before rifle qualification on another range. This range has 10 pads for firing from the prone position and 10 pits for firing from the standing position. The firing pits are located about $5 \mathrm{~m}(16.4 \mathrm{ft})$

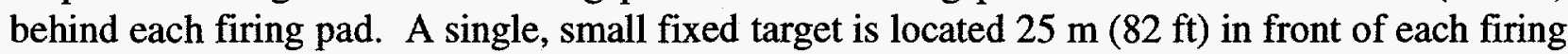
pad. The area between the firing pads and the targets is covered by mowed grass. The 3-m (10-ft) -high earthen berm behind the targets generally lacks vegetative cover. No spent slugs were evident on the soil surface or in the berm soil, but a depression (bullet pocket) was observed in the berm behind each target. A shallow depression between the targets and the base of the berm provides drainage, and a tower behind the firing line is used for observation and safety control during range operations. The area directly behind the berm, to the right of the range, is forested; the Range 126 parking lot is to the left.

Range 111 is used to provide combat troops with practical experience in the use of highexplosive hand grenades. This range consists of an open oval area measuring about $50 \mathrm{~m}(165 \mathrm{ft})$ by $75 \mathrm{~m}(245 \mathrm{ft})$ surrounded by an earthen berm approximately $1 \mathrm{~m}(3 \mathrm{ft})$ high. The area inside the berm is barren and level except for a number of craters, up to $1 \mathrm{~m}$ in depth, resulting from grenade detonations; some of the deeper craters contain standing water. There are two concrete and two log bunkers along the outer edge of the berm to protect the grenadier and the instructor during training exercises. Several other larger concrete structures in the area are for the protection of troops during training exercises. There is some evidence of fragmentation damage to the signs, structures, and trees outside the berm. The area immediately outside the berm is covered by grass; the surrounding area is forested. 
The sample collection protocol is described in the Zellmer and Schneider report (1993). Sampling locations for ranges 122 and 124 were selected to represent different degrees of suspected heavy metal and explosive residue contamination. Sampling locations included berms behind the targets (bullet pockets), other parts of the berm, areas between the firing line and targets, areas behind the firing range and outside the training area, and sediment samples from drainageways in the range. The sampling depths were $0-15 \mathrm{~cm}(0-6$ in.) and $15-30 \mathrm{~cm}$ (6-12 in.). A $2.5-\mathrm{cm}$ soil probe was used to collect the samples.

Fourteen surface soil samples were collected within the berm area for range 111. Sampling locations included the bottoms and sides of the grenade craters and the areas between craters. Only surface samples were collected within the berm area because grenade fragments and explosive residues were not expected to penetrate the soil to an appreciable depth. Samples were collected using a stainless steel spoon. Additional samples were collected from the berm and outside the berm to provide background levels of heavy metals in the native soils. These samples were collected from depths of $0-15 \mathrm{~cm}$ and $15-30 \mathrm{~cm}$ using a soil probe.

Field lead measurements were obtained by using a portable x-ray fluorescence spectrum analyzer at the data collection points. The device, which contains a $0.025-\mathrm{Ci}{ }^{109} \mathrm{Cd}$ sealed source, was calibrated by the manufacturer to measure lead in the soil. The minimum detection limit for lead in soil for this device is approximately $50 \mathrm{mg} / \mathrm{kg}$ using the standard $60-\mathrm{s}$ measurement time. A validation standard was used at the beginning of each day, periodically during the day, and at the end of each day to ensure that the instrument was operating properly in the field (see Zellmer and Schneider 1993 for additional information). Field measurements were made using a 60-s time period to collect the spectrum. Data recorded in the x-ray fluorescence analyzer were transferred to a portable computer, and backup copies of the data were made on a computer disk at the end of each work day.

Vegetation was removed from the data collection point without disturbing the soil surface, then a 60-s measurement was obtained from the cleared area. If the surface measurement indicated that lead was present at a concentration above $50 \mathrm{mg} / \mathrm{kg}$ (the minimum detection limit), several centimeters of soil were removed, and a second measurement was made on the bottom of the excavation. If this reading also indicated lead above $50 \mathrm{mg} / \mathrm{kg}$, additional soil was excavated and another measurement was made. This process was repeated until a reading below $50 \mathrm{mg} / \mathrm{kg}$ was obtained. Throughout the day, multiple readings were taken against validation standards to evaluate the precision of the instrument. These readings, called replicate numbers, were recorded along with the soil readings. The firing range number, transect number (based on a grid laid out by the field team), location on the transect, reading depth, replicate number, and lead concentration of each measurement were recorded in a notebook. More than $200 \mathrm{x}$-ray fluorescence measurements were made; the majority from range 111 were below the instrument detection limit for lead.

Soil samples from both the initial and primary collections were analyzed in two different laboratories at Argonne National Laboratory (ANL) using several different procedures. The Analytical Chemistry Laboratory (ACL) at ANL used the inductively coupled plasma-atomic emission spectroscopy (ICP-AES) procedure to analyze the samples for the following heavy 
metals: barium, cadmium, chromium, cobalt, copper, lead, nickel, tin, and zinc. Samples were also digested by using U.S. Environmental Protection Agency (U.S. EPA) Method 3050A (Acid Digestion of Sediments, Sludges, and Soils), followed by measurement using U.S. EPA Method 6010 for ICP-AES. The analytical laboratory operated by the Reclamation Engineering and Geosciences Section ${ }^{1}$ of the Energy Systems Division at ANL analyzed selected soil samples using the Toxicity Characteristic Leaching Procedure (TCLP); this method was used to characterize the samples for barium, cadmium, chromium, copper, lead, tin, and zinc. The TCLP data were used to group samples that had similar heavy metal concentrations to ensure that adequate sample volumes would be available for the batch shaker and continuous columnar extraction experiments.

${ }^{1}$ Currently called Center for Environmental Restoration Systems. 


\section{Purpose and Approach}

The purpose of this phase of the project was two-fold: (1) to investigate the potential of extracting heavy metals from the contaminated soil using chelating agents or deionized water, and (2) to investigate the leaching potential of lead (and other heavy metals) from soil samples obtained from the GTA. The heavy metal of primary interest was lead; other heavy metals of interest included copper, zinc, cadmium, chromium, barium, and iron.

The extraction study was conducted in two phases: first using a screening technique employing batch shaker tests, then following with columnar flooding tests. The batch shaker study provided initial identification of optimal conditions for the columnar flooding study. During the shaker tests, the effectiveness of the chelating agents, either ethylenediaminetetraacetic acid (EDTA) or citric acid, on heavy-metal-contaminated soil was evaluated. Water was used as the leachant in the columnar flooding tests to determine the mobility of the lead (and other heavy metals) in GTA soils. Analyses of the test solutions were performed using atomic absorption spectroscopy (AAS). 


\section{Experimental Procedures}

\subsection{Batch Shaker Tests}

The analytical procedures used to characterize the soil samples collected from the GTA are listed in Table 1. Table 2 summarizes characteristics of the soils used in this study. The soil characterization indicated that the soil was generally slightly alkaline, had a low organic carbon content (less than $2.2 \%$ ) and a low cation exchange capacity (CEC), and was generally sandy.

Several batches (approximately $200 \mathrm{~g}$ each) of contaminated soil obtained from the GTA were air dried in the hood. After drying, the bulk batch samples were subdivided into nominal 5-g portions and placed in plastic shaker containers (with lids) for testing. A 50-mL chelant solution (either $0.01 \mathrm{M}$ EDTA or $0.01 \mathrm{M}$ citric acid) was then added. In total, 108 soil samples, plus approximately $25 \%$ additional spot replicates, were tested.

Samples were shaken for approximately 3 hours at the low setting on an Eberbach shaker table; this time requirement was determined during a previous study to be adequate to achieve equilibrium (Peters and Shem 1992). Following agitation, the samples were centrifuged in plastic Nalgene centrifuge tubes equipped with snap-on caps, filtered using No. 42 Whatman filter paper, and stored in glass vials maintained at a pH of less than 2 (prepped using ultrapure $\mathrm{HNO}_{3}$ ) to await AAS analysis. A sample volume of at least $10 \mathrm{~mL}$ was collected for the analysis. The tests were calibrated using AAS standards for lead, cadmium, copper, chromium, zinc, barium, and iron, and performed in accordance with the procedures described in Standard Methods for the Examination of Water and Wastewater (American Public Health Association 1992).

The TCLP data from the Zellmer and Schneider report (1993) provided the initial heavy metal concentrations for each soil sample. This information was used to determine which soil samples were to be employed in the tests. The TCLP information was also used in conjunction with the AAS measurements to determine the percentage of heavy metal removal.

Data collected from the batch shaker tests included the following: operating temperature, extractant type and concentration, heavy metals concentration on the soil before treatment (and after treatment - as determined by calculation), heavy metals concentration in the extract solution after treatment, $\mathrm{pH}$ of the solution before and after treatment, and batch shaking time.

\subsection{Columnar Flooding Tests}

Because a columnar flow test involves the use of approximately $300 \mathrm{~g}$ of material, various soil samples had to be grouped together in order to obtain a sufficient quantity of sample. TCLP data from the Zellmer and Schneider report (1993) provided the information used for grouping samples to obtain the required sample volume. 
TABLE 1 Analytical Procedures/Methods for Determining

Physical/Chemical Characteristics of Soil Samples

Soil Parameter

Method

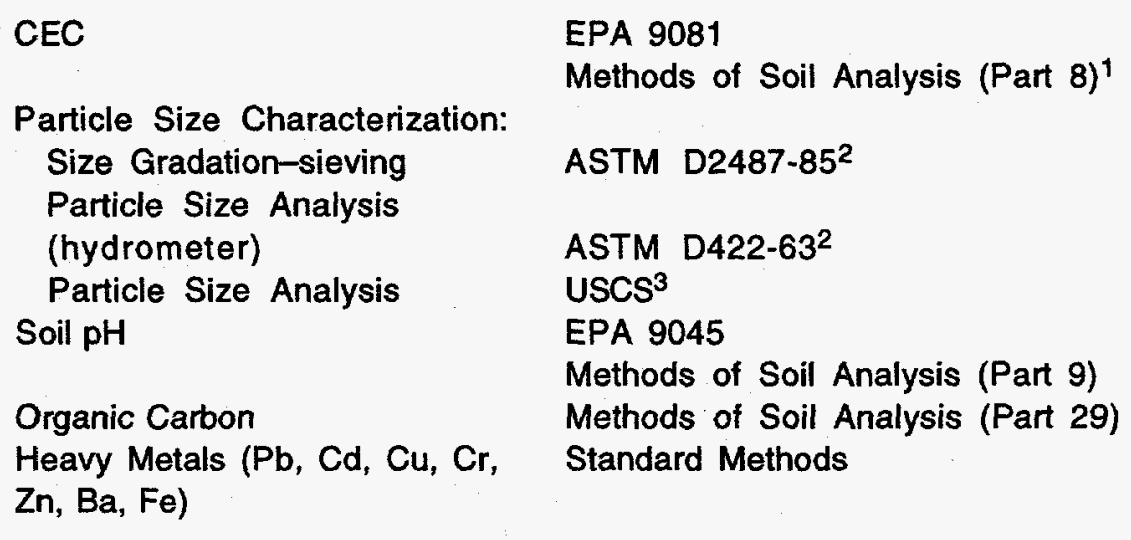

1 American Society of Agronomy and Soil Science Society of America 1982.

2 American Society for Testing Materials (1987a, 1987b).

3 Particle size classification is in accordance with the Unified Soil Classification System.

TABLE 2 Physical and Chemical Characteristics of Soil Samples ${ }^{1}$

\begin{tabular}{|c|c|c|c|c|c|c|c|c|}
\hline \multirow[b]{2}{*}{$\begin{array}{l}\text { Range } \\
\text { (R) }\end{array}$} & \multirow[b]{2}{*}{$\begin{array}{l}\text { Depth } \\
(\mathrm{cm})\end{array}$} & \multirow[b]{2}{*}{$\begin{array}{l}\text { Soil } \\
\mathrm{pH}\end{array}$} & \multirow{2}{*}{$\begin{array}{c}\text { Organic } \\
\text { Carbon } \\
(\%)\end{array}$} & \multirow[b]{2}{*}{$\begin{array}{c}\text { CEC } \\
(\mathrm{gmol} / \mathrm{kg})\end{array}$} & \multicolumn{3}{|c|}{ Soil Texture $(\mathrm{g} / \mathrm{kg})$} & \multirow[b]{2}{*}{$\begin{array}{c}\text { Textural } \\
\text { Class }\end{array}$} \\
\hline & & & & & Sand & Silt & Clay & \\
\hline 122 & 0 & 5.8 & 1.99 & 12.43 & 750 & 180 & 70 & Sandy Loam \\
\hline 124 & 15 & 7.1 & 2.20 & 17.57 & 690 & 210 & 100 & Sandy Loam \\
\hline 124 & 7 & 7.4 & 0.78 & 7.47 & 770 & 160 & 70 & Sandy Loam \\
\hline 124 & 0 & 7.1 & 1.19 & 6.23 & 810 & 120 & 70 & Loamy Sand \\
\hline 124 & 60 & 7.7 & 0.23 & 1.69 & 800 & 130 & 70 & Loamy Sand \\
\hline 111 & 0 & 8.7 & 0.31 & 4.85 & 750 & 130 & 120 & Sandy Loam \\
\hline 111 & 10 & 8.0 & 0.37 & 4.69 & 800 & 130 & 70 & Loamy Sand \\
\hline Detection & Limits & 0.1 & 0.01 & 0.05 & 10 & 10 & 10 & \\
\hline
\end{tabular}

1 Samples analyzed by the Reclamation Engineering and Geosciences Laboratory at ANL. 
Aluminum columns with a fixed-glass wall were hand-packed with dry soil from the GTA firing ranges. The soil had been passed through an $850-\mu \mathrm{m}$ sieve (American Society for Testing Materials [ASTM] mesh \#20) and retained by a 75- $\mu \mathrm{m}$ sieve (ASTM mesh \#200). Soil that passed through the $75-\mu \mathrm{m}$ sieve was discarded; the fine soil might otherwise plug the flow through the soil columns. The weight of the soil contained in each soil column was measured and recorded.

The packed soil columns were flooded with deionized water to saturate the soil and the deionized water was nominally adjusted to be in the $\mathrm{pH}$ range of 3 to 7 to simulate rainfall conditions.

Solutions were pumped through the columns in an upflow mode using a Cole-Parmer Masterflex pump. The volume of solution necessary to initially saturate the soil was noted; this volume was assumed to approximate one pore volume of liquid in the column. Finally, five pore volumes of deionized water were pumped through the columns.

The resulting leachate was drained, collected, and analyzed by using AAS (after prepping with $\mathrm{HNO}_{3}$ ) for lead, cadmium, chromium, copper, iron, and zinc. For the soil portions used in performing the column experiment, the heavy metal concentrations were determined by mass balance calculations. Flushing the deionized water column during the experiment enabled researchers to identify the easily desorbed portion of the lead (and other heavy metals) from the soil and provided an indication of how readily lead could leach into the groundwater supply.

After flushing with deionized water, the contaminated soil columns were flushed with a wash solution (again in an upflow mode). The solution contained one chelant (either EDTA or citric acid) at a concentration of $0.05 \mathrm{M}$. (The chelant solution concentration was increased to $0.05 \mathrm{M}$ to improve the efficiency of removal of heavy metals from soils.) Each pore volume of liquid was collected, preserved in acid, stored, and analyzed by AAS using standard procedures. Five to eight pore volumes of chelating agent solution were used for each sample.

The TCLP data available from the Zellmer and Schneider report (1993) provided the initial heavy metal concentrations for each soil sample. This information was used to determine which soil samples were to be used for the tests. The TCLP information was also used in conjunction with the AAS measurements to determine the amount and percentage of heavy metal removal, as a function of pore volume throughput.

Data collected from the columnar flooding tests included the following: columnar solution feed flow rates, operating temperature, extractant type and concentration, $\mathrm{pH}$ (before and after treatment), heavy metals removed from the soil (determined by mass balance on the soil and total heavy metals concentration in the eluate solution), pore volume, and efficiency of heavy metals removal from the soil column. 


\subsection{Leaching Tests}

Previously collected data on the local groundwater provided information on contaminants. Table 3 presents the characteristics of the industrial well (well no. 118) and drinking water well (well no.6) at Grafenwöhr, Germany. As shown, the groundwater is slightly acidic, has a low conductivity, and a low total organic carbon concentration. The drinking water well also showed no major heavy metal contamination (with the possible exception of a higher concentration of manganese, which may be due to natural background levels).

The column flooding experiments with deionized water were used to determine how readily lead and other heavy metals could be leached into the groundwater. 
TABLE 3 Characterization of the Industrial Well and Drinking Water Well at Grafenwöhr, Germany ${ }^{1}$

Concentration

Contaminant

Industrial Water

Drinking Water

Well No. 118

Well No. 6

Organics (mg/L):

Dichloromethane

trans-1,2-Dichloroethene

$N^{2}$

ND

cis-1,2-Dichloroethene

ND

ND

Trichloromethane

ND

ND

1,2-Dichloroethane

0.0024

ND

1,1,1-Trichloroethane

ND

ND

1,2,2-Trichloroethane

ND

ND

1,2,3-Trichloroethane

Tetrachloromethane

1,2-Dichloropropane

Trichloroethylene

ND

ND

ND

ND

ND

ND

ND

ND

ND

Tetrachloroethylene

ND

ND

1, 1, 1,2-Tetrachloroethane

ND

ND

1,1,2,2-Tetrachloroethane

ND

ND

Hexachloroethane

ND

ND

Inorganics (mg/L):

Iron

0.14

0.02

Manganese

Mercury

0.01

5.3

Chromium

ND

4

Cadmium

0.001

Nickel

ND

Lead

Copper

0.01

0.08

Zinc

0.08

ND

ND

Arsenic

ND

Boron

0.10

0.008

Sodium

Potassium

Calcium

Magnesium

226

0.01

ND

ND

0.54

ND

$4 \quad 14$

$5 \quad 110$

2

Anions (mg/L):

Chloride

Fluoride

Sulfate

Phosphate

Cyanide

Nitrate

Nitrite

Ammonium $\left(\mathrm{NH}_{4}-\mathrm{N}\right)$

5

ND

18

ND

ND

4

0.02

0.1
28

0.22

4

24

ND

190

ND

ND

49

0.02

20 
TABLE 3 (Cont.)

\begin{tabular}{lcc}
\hline & \multicolumn{2}{c}{ Concentration } \\
\cline { 2 - 3 } \multicolumn{1}{c}{ Contaminant } & $\begin{array}{c}\text { Industrial Water } \\
\text { Well No. } 118\end{array}$ & $\begin{array}{c}\text { Drinking Water } \\
\text { Well No. } 6\end{array}$ \\
& & \\
\hline & & \\
Other Characteristics (mg/L except as noted): & 6.18 \\
pH (dimensionless) & 5.27 & 12.7 \\
Conductivity ( $\mu$ s/cm) & 13.0 & 18 \\
Total Organic Carbon & 0.4 & 5.0 \\
BOD ${ }_{5}^{3}$ & 1.8 & 37 \\
$\mathrm{KMnO}_{4}$ Demand & 1.1 & 11 \\
Total Suspended Solids & 6 & 740 \\
Total Dissolved Solids & 25 & 445 \\
Residue & 5 & 2.9 \\
Buffer Capacity (mmol/L) & 0.15 & \\
\hline
\end{tabular}

1 Adapted from Dames \& Moore International 1992.

2 ND $=$ Not Detected.

${ }^{3} \mathrm{BOD}_{5}=$ Biological Oxygen Demand.

${ }^{4} \mathrm{KMnO}_{4}=$ Potassium Permanganate. 


\section{Results and Discussion}

\subsection{Characterization of Untreated Soil}

Several national governments, including the U.S. government, have developed guidelines and/or regulations defining hazardous levels of heavy metals contamination in soils and groundwater. In 1988, the Netherlands published the "Dutch List," which presented three categories of heavy metal concentrations: Category A (Baseline Concentration), Category B (Detailed Investigation Needed), and Category C (Remedial Investigation Needed). As of this date, Germany has not established national standards or cleanup levels for heavy-metalcontaminated soils and groundwater. However, the Bavarian state government has generally adopted the Dutch List as its guidelines for assessing heavy metals contamination. Table 4 lists the three Dutch List concentration category values (soil and groundwater) for heavy metals that were included in this investigation.

Prior to performing the chelant extraction experiment, the untreated soil was characterized using ICP, AAS, and TCLP methods. Results of the ICP and TCLP analyses from the untreated

TABLE 4 Dutch List of Heavy Metals with Category Contamination Levels for Soil and Groundwater

\begin{tabular}{|c|c|c|c|c|c|c|}
\hline \multirow[b]{2}{*}{ Heavy Metal } & \multicolumn{3}{|c|}{$\begin{array}{c}\text { Concentration in Soil } \\
(\mathrm{mg} / \mathrm{kg})\end{array}$} & \multicolumn{3}{|c|}{$\begin{array}{c}\text { Concentration in Groundwater } \\
(\mathrm{mg} / \mathrm{L})\end{array}$} \\
\hline & $\begin{array}{c}\text { Category } \\
\text { A }\end{array}$ & $\begin{array}{c}\text { Category } \\
\text { B }\end{array}$ & $\begin{array}{l}\text { Category } \\
\text { C }\end{array}$ & $\begin{array}{c}\text { Category } \\
\text { A }\end{array}$ & $\begin{array}{c}\text { Category } \\
\text { B }\end{array}$ & $\begin{array}{l}\text { Category } \\
\text { C }\end{array}$ \\
\hline Arsenic (As) & - & 30 & 50 & $\cdots$ & 30 & 100 \\
\hline Barium (Ba) & 200 & 400 & 2000 & 50 & 100 & 500 \\
\hline Cadmium (Cd) & $\cdots$ & 5 & 20 & -- & 2.5 & 10 \\
\hline Chromium (Cr) & -- & 250 & 800 & -- & 50 & 200 \\
\hline Cobalt (Co) & 20 & 50 & 300 & 20 & 50 & 200 \\
\hline Copper (Cu) & - & 100 & 500 & -- & 50 & 200 \\
\hline Lead $(\mathrm{Pb})$ & $\cdots$ & 150 & 600 & -- & 50 & 200 \\
\hline Mercury $(\mathrm{Hg})$ & $\cdots$ & 2 & 10 & -- & 0.5 & 2 \\
\hline Nickel (Ni) & - & 100 & 500 & - & 50 & 150 \\
\hline $\operatorname{Tin}(S n)$ & 20 & 50 & 300 & 10 & 30 & 150 \\
\hline Zinc $(Z n)$ & $\ldots$ & 500 & 3000 & - - & 200 & 800 \\
\hline
\end{tabular}

Reference: Straatsuitgevrij's-Grevenhage (1988)

Category A: Baseline Concentration

Category B: Detailed Investigation Needed

Category C: Remedial Investigation Needed 
contaminated soils are listed in Table 5 for the elements of interest for this investigation phase (lead, copper, cadmium, chromium, barium, and zinc). The Dutch list standards (Categories A, $\mathrm{B}$, and $\mathrm{C}$ ) are also included in Table 5 for comparison. The numbers marked in boldface exceed Category C standards; underlined numbers exceed Category B standards. Table 5 indicates that the samples exhibit lead, copper, cadmium, and zinc contamination. Tables 6 through 8 summarize the ICP and TCLP results for the untreated soils at GTA.

\subsection{Characterization of Soil Treated Using Batch Shaker Chelant Extraction}

Results of the AAS analyses of contaminated soils treated using batch shaker chelant extraction (either $0.01 \mathrm{M}$ citric acid or $0.01 \mathrm{M}$ EDTA) are listed in Table 9 for lead, copper, cadmium, chromium, barium, and zinc. Table 9 also compares chelation results with the Dutch List standards. Numbers marked in boldface exceed Category $\mathrm{C}$ standards; underlined numbers exceed Category B standards. The data indicate that the most severe treatment problem involves cadmium contamination; lesser problems are presented by barium and zinc contamination. The residual concentrations were calculated by subtracting the amount of heavy metal contained in the chelant solution after treatment (determined by AAS analyses) from the initial heavy metal concentration of the untreated soil (determined by ICP analyses and listed in Table 5). Because grab samples were used to determine the residual concentrations in the untreated and treated soils, several samples contained higher estimated quantities of heavy metals extracted into the chelant solution than the quantities initially reported to be present in the soil (based upon the ICP results presented in Table 5). For those cases, the residual concentrations were arbitrarily assigned a value of approximately zero $(\sim 0) \mathrm{mg} / \mathrm{kg}$.

The results presented are for the case of a chelant concentration of $0.01 \mathrm{M}$. Due to limited funding and time constraints, no attempt was made to identify the most effective chelant concentration. Rather, the goal of these studies was to determine whether chelant extraction would offer potential as a cleanup technique. In order to assess this potential, the residual metal concentrations (before and after chelant extraction treatment) were compared. Table 10 presents the results for lead, cadmium, and copper; Table 11 presents the results for chromium, barium, and zinc.

The results listed in Tables 10 and 11 indicate that, while the chelant extraction technique did not reduce heavy metals concentrations to meet all the Dutch List standards, it did reduce the heavy metal concentrations in these soils quite effectively. Very few soils would fall under Class C criteria after treatment. The concentrations of heavy metals in the soils were substantially lower in the chelant-extracted soils than in the untreated soils. The two major heavy metals of concern are cadmium and barium. Treatments for these elements did not effectively reduce concentrations to meet the Dutch List guidelines, although the concentrations were indeed lowered. Again, it should be pointed out that no attempt was made to optimize the concentration of chelant to obtain the maximum removal of heavy metals. The concentration of citric acid and EDTA was maintained at $0.01 \mathrm{M}$. To achieve maximum removal of heavy metals from solution, chelant concentrations in the range of $0.05-0.10 \mathrm{M}$ should be investigated. 
TABLE 5 ICP and TCLP Results from Characterization of Untreated Soils and Groundwater at the Grafenwöhr Training Area

\begin{tabular}{|c|c|c|c|c|c|c|c|}
\hline \multirow{2}{*}{\multicolumn{2}{|c|}{ Sample No. }} & \multicolumn{6}{|c|}{ Concentration $(\mathrm{mg} / \mathrm{kg})$} \\
\hline & & $\mathrm{Pb}$ & Cd & $\mathrm{Cu}$ & $\mathrm{Cr}$ & $\mathrm{Ba}$ & $\mathrm{Zn}$ \\
\hline \multicolumn{8}{|c|}{$\begin{array}{l}\text { Dutch List Standards } \\
\text { Soils }(\mathrm{mg} / \mathrm{kg})\end{array}$} \\
\hline \multirow{3}{*}{\multicolumn{2}{|c|}{$\begin{array}{l}\text { Category A } \\
\text { Category B } \\
\text { Category C }\end{array}$}} & $\cdots$ & -- & $\cdots$ & $\cdots$ & 200 & - \\
\hline & & 150 & 5.0 & 100 & 250 & 400 & 500 \\
\hline & & 600 & 20 & 500 & 800 & 2,000 & 3,000 \\
\hline \multirow[t]{7}{*}{ R124 } & $-S 003$ & 7,870 & 1.2 & 271 & 7.5 & 51.8 & 77.6 \\
\hline & $-S 004$ & 126,000 & $\underline{7.6}$ & 798 & 5.6 & 37. & 125 \\
\hline & -5007 & 4,800 & 0.97 & 6,420 & 7.2 & 57.3 & 700 \\
\hline & -S009 & 13,600 & 2.1 & 13,200 & 10.1 & 53.7 & 1.350 \\
\hline & $-S 014$ & 1,800 & 0.98 & 29.9 & 6.6 & 28.9 & 105 \\
\hline & -S015 & 684 & 0.96 & 35.0 & 6.0 & 34.4 & 39.6 \\
\hline & $-S 016$ & 398 & 0.99 & 146 & 7.9 & 63.2 & 48.2 \\
\hline \multirow{5}{*}{ R122 } & $-S 017$ & 41.2 & 0.98 & 28.6 & 4.6 & 63.3 & 23.8 \\
\hline & -5022 & 123 & 0.97 & 57.0 & 3.0 & 83.4 & 30.2 \\
\hline & $-S 026$ & 55.0 & 0.95 & 51.1 & 3.5 & 48.6 & 23.0 \\
\hline & $-S 029$ & 31.6 & 0.97 & 23.7 & 5.5 & 71.6 & 72.7 \\
\hline & -5030 & 314 & 1.00 & 32.6 & 39.2 & 97.9 & 2.120 \\
\hline \multirow[t]{6}{*}{ R111 } & -5037 & 112 & 31.1 & $\underline{276}$ & 34.8 & 97.3 & $\overline{5,680}$ \\
\hline & -5038 & 152 & 32.3 & $\underline{370}$ & 41.8 & 115 & $\underline{691}$ \\
\hline & -S039 & 90.6 & 94.6 & $1, \overline{560}$ & 27.7 & 94.8 & 976 \\
\hline & $-S 041$ & 70.1 & 32.5 & 364 & 44.4 & 164 & $\underline{703}$ \\
\hline & -S044 & 70.7 & 73.6 & 322 & 25.8 & 92.0 & 48.6 \\
\hline & $-\$ 049$ & 26.0 & 1.0 & 11.0 & 16.3 & 61.0 & $\cdots$ \\
\hline \multicolumn{8}{|c|}{$\begin{array}{l}\text { Dutch List Standards } \\
\text { Groundwater (mg/L) }\end{array}$} \\
\hline \multirow{3}{*}{\multicolumn{2}{|c|}{$\begin{array}{l}\text { Category A } \\
\text { Category B } \\
\text { Category C }\end{array}$}} & - & - & - & - & 50 & - \\
\hline & & 50 & 2.5 & 50 & 50 & 100 & 200 \\
\hline & & 200 & 10.0 & 200 & 200 & 500 & 800 \\
\hline \multirow[t]{3}{*}{ R124 } & -5003 & 194 & 0.028 & - - & 0.007 & 0.113 & - - \\
\hline & $-S 007$ & 53.4 & 0.036 & -- & 0.008 & 0.120 & - - \\
\hline & -S014 & 37.7 & 0.015 & $\ldots$ & 0.031 & 0.092 & $\ldots$ \\
\hline \multirow[t]{3}{*}{ R122 } & -S016 & 3.62 & 0.006 & - - & 0.008 & 0.092 & $\cdots$ \\
\hline & $-\$ 022$ & 1.92 & 0.005 & -- & 0.007 & 0.092 & -- \\
\hline & $-\$ 029$ & 0.06 & 0.005 & -- & 0.007 & 0.092 & $\cdots$ \\
\hline \multirow[t]{3}{*}{ R111 } & $-\$ 037$ & 0.25 & 0.815 & -- & 0.033 & 0.098 & - \\
\hline & -S039 & 0.53 & 3.490 & -- & 0.051 & 0.218 & $\cdots$ \\
\hline & $-S 049$ & 0.06 & 0.021 & -- & 0.007 & 0.092 & - \\
\hline
\end{tabular}

Boldface Numbers: Exceed Category C Standards

Underlined Numbers: Exceed Category B Standards

$R=$ Range

$\mathrm{S}=$ Soil Sample 
TABLE 6 Soil Characterization Results for $\mathrm{Pb}$ and $\mathrm{Cu}$ at the Grafenwöhr Training Area

\begin{tabular}{|c|c|c|c|c|c|c|c|}
\hline \multirow{3}{*}{\multicolumn{2}{|c|}{ Sample No. }} & \multicolumn{3}{|c|}{$\mathrm{Pb}$ Concentration } & \multicolumn{3}{|c|}{ Cu Concentration } \\
\hline & & \multicolumn{2}{|c|}{ Soil } & \multirow[b]{2}{*}{$\begin{array}{c}\mathrm{TCLP} \\
\mathrm{mg} / \mathrm{L}^{2}\end{array}$} & \multicolumn{2}{|c|}{ Soil } & \multirow[b]{2}{*}{$\begin{array}{c}\mathrm{TCLP} \\
\mathrm{mg} / \mathrm{L}^{2}\end{array}$} \\
\hline & & $\mathrm{mg} / \mathrm{kg}^{1}$ & $\mathrm{mg} / \mathrm{kg}^{2}$ & & $\mathrm{mg} / \mathrm{kg}^{1}$ & $\mathrm{mg} / \mathrm{kg}^{2}$ & \\
\hline \multirow[t]{19}{*}{$\mathrm{R} 124$} & $-S 001$ & & 0.50 & 0.03 & & 0.50 & 0.03 \\
\hline & $-\mathrm{S} 002$ & & 0.50 & 0.03 & & 0.25 & 0.01 \\
\hline & -5003 & 7,870 & $4,441.0$ & 246.9 & 271.0 & 35.90 & 1.89 \\
\hline & -5004 & 126,000 & $13,553.1$ & 753.5 & 798.0 & 96.93 & 5.10 \\
\hline & $-S 005$ & & $7,330.2$ & 407.6 & & 44.57 & 2.35 \\
\hline & (dup) & & $3,532.5$ & 196.4 & & 41.35 & 2.18 \\
\hline & -5006 & & $3,539.7$ & 196.8 & & 23.52 & 1.24 \\
\hline & $-S 007$ & 4,800 & $7,213.0$ & 401.0 & 6,420 & 80.22 & 4.22 \\
\hline & $\begin{array}{l}-5008 \\
\text { (dup) }\end{array}$ & & $\begin{array}{l}4,985.5 \\
5,024.6\end{array}$ & $\begin{array}{l}277.2 \\
279.4\end{array}$ & & $\begin{array}{l}67.84 \\
67.35\end{array}$ & $\begin{array}{l}3.57 \\
3.55\end{array}$ \\
\hline & -5009 & 13,600 & $9,010.5$ & 501.0 & 13,200 & 72.55 & 3.82 \\
\hline & $-S 010$ & & $7,811.7$ & 434.3 & & 66.85 & 3.52 \\
\hline & (dup) & & $7,365.7$ & 409.5 & & 81.33 & 4.28 \\
\hline & $-S 011$ & & $10,143.8$ & 564.0 & & 77.99 & 4.11 \\
\hline & $-S 012$ & & $6,353.3$ & 353.2 & & 61.90 & 3.26 \\
\hline & $-S 013$ & & $1,051.3$ & 58.45 & & 8.17 & 0.43 \\
\hline & (dup) & & $1,193.8$ & 66.37 & & 15.85 & 0.83 \\
\hline & -So14 & 1,800 & $1,023.9$ & 56.93 & 29.9 & 8.76 & 0.46 \\
\hline & $-S 015$ & 684.0 & 254.6 & 14.16 & 35.0 & 3.22 & 0.17 \\
\hline & $\ldots$ & $\ldots$ & $\ldots$ & $\ldots$ & $\cdots$ & $\cdots$ & $\ldots$ \\
\hline \multirow[t]{18}{*}{ R122 } & $-S 016$ & 398.0 & 37.72 & 2.10 & 146.0 & 8.42 & 0.44 \\
\hline & $-S 017$ & 41.2 & 0.50 & 0.03 & 28.6 & 0.75 & 0.04 \\
\hline & -5018 & & 0.50 & 0.03 & & 2.97 & 0.16 \\
\hline & -5019 & & 0.50 & 0.03 & & 0.25 & 0.01 \\
\hline & $-S 020$ & & $1,778.7$ & 98.89 & & 116.4 & 6.13 \\
\hline & -5021 & & 254.6 & 14.16 & & 9.66 & 0.51 \\
\hline & (dup) & & 61.70 & 3.43 & & 6.44 & 0.34 \\
\hline & -5022 & 123.0 & 20.16 & 1.12 & 57.0 & 7.68 & 0.40 \\
\hline & $-\mathrm{S} 023$ & & 0.50 & 0.03 & & 1.49 & 0.08 \\
\hline & $-S 024$ & & 350.4 & 19.48 & & 42.09 & 2.22 \\
\hline & (dup) & & 332.2 & 18.47 & & 43.08 & 2.27 \\
\hline & $-S 025$ & & 6.29 & 0.35 & & 2.73 & 0.14 \\
\hline & -5026 & 55.0 & 0.50 & 0.03 & 51.1 & 4.46 & 0.23 \\
\hline & -5027 & & 0.50 & 0.03 & & 1.49 & 0.08 \\
\hline & (dup) & & 0.50 & 0.03 & & 1.49 & 0.08 \\
\hline & $-\$ 028$ & & 0.50 & 0.03 & & 0.25 & 0.01 \\
\hline & -5029 & 31.6 & 0.50 & 0.03 & 23.7 & 0.25 & 0.01 \\
\hline & $-\mathrm{S} 030$ & 314.0 & 11.16 & 0.62 & 32.6 & 1.20 & 0.06 \\
\hline
\end{tabular}


TABLE 6 (Cont.)

\begin{tabular}{|c|c|c|c|c|c|c|c|}
\hline \multirow{3}{*}{\multicolumn{2}{|c|}{ Sample No. }} & \multicolumn{3}{|c|}{$\mathrm{Pb}$ Concentration } & \multicolumn{3}{|c|}{ Cu Concentration } \\
\hline & & \multicolumn{2}{|c|}{ Soil } & \multirow{2}{*}{$\begin{array}{c}\text { TCLP } \\
\mathrm{mg} / \mathrm{L}^{2}\end{array}$} & \multicolumn{2}{|c|}{ Soil } & \multirow{2}{*}{$\begin{array}{l}\text { TCLP } \\
\mathrm{mg} / \mathrm{L}^{2}\end{array}$} \\
\hline & & $\mathrm{mg} / \mathrm{kg}^{1}$ & $\mathrm{mg} / \mathrm{kg}^{2}$ & & $\mathbf{m g} / \mathbf{k g}^{1}$ & $\mathrm{mg} / \mathrm{kg}^{2}$ & \\
\hline \multirow[t]{23}{*}{ R111 } & $-S 031$ & & 0.50 & 0.03 & & 1.49 & 0.08 \\
\hline & $-S 032$ & & 0.50 & 0.03 & & 4.71 & 0.25 \\
\hline & -5033 & & 1.25 & 0.07 & & 12.14 & 0.64 \\
\hline & $-S 034$ & & 0.50 & 0.03 & & 10.65 & 0.56 \\
\hline & $-S 035$ & & 5.98 & 0.33 & & 12.94 & 0.68 \\
\hline & $-\$ 036$ & & 12.45 & 0.69 & & 30.40 & 1.60 \\
\hline & -5037 & 112.0 & 12.45 & 0.69 & 276.0 & 18.93 & 1.00 \\
\hline & -5038 & 152.0 & 15.04 & 0.84 & 370.0 & 25.45 & 1.34 \\
\hline & -5039 & 90.6 & 15.04 & 0.84 & 1,560 & 73.42 & 3.87 \\
\hline & $-S 040$ & & 22.75 & 1.26 & & 37.44 & 1.97 \\
\hline & (dup) & & 25.46 & 1.42 & & 33.79 & 1.78 \\
\hline & $-S 041$ & 70.1 & 2.51 & 0.14 & 364.0 & 14.61 & 0.77 \\
\hline & $-S 042$ & & 0.50 & 0.03 & & 21.05 & 1.11 \\
\hline & $-S 043$ & & 0.50 & 0.03 & & 9.16 & 0.48 \\
\hline & $-S 044$ & 70.7 & 3.77 & 0.21 & 322.0 & 7.68 & 0.40 \\
\hline & $-S 045$ & & 0.50 & 0.03 & & 7.68 & 0.40 \\
\hline & (dup) & & 0.50 & 0.03 & & 9.41 & 0.50 \\
\hline & $-S 046$ & & 0.50 & 0.03 & & 4.21 & 0.22 \\
\hline & (dup) & & 0.50 & 0.03 & & 3.22 & 0.17 \\
\hline & -S047 & & 15.04 & 0.84 & & 2.77 & 0.15 \\
\hline & $-S 048$ & & 0.50 & 0.03 & & 0.99 & 0.05 \\
\hline & (dup) & & 0.50 & 0.03 & & 0.99 & 0.05 \\
\hline & -S049 & 26.0 & 0.50 & 0.03 & 11.0 & 0.75 & 0.04 \\
\hline
\end{tabular}

1 Determined by the Argonne ACL using ICP-AES.

2 Determined by the Argonne Reclamation Engineering and Geosciences Laboratory using AAS and TCLP.

Notes: $\begin{aligned} R=\text { Range } \\ \\ S=\text { Soil Sample } \\ \text { dup = duplicate }\end{aligned}$ 
TABLE 7 Soil Characterization Results for $\mathrm{Cd}$ and $\mathrm{Cr}$ at the Grafenwöhr Training Area

\begin{tabular}{|c|c|c|c|c|c|c|c|}
\hline \multirow{3}{*}{\multicolumn{2}{|c|}{ Sample No. }} & \multicolumn{3}{|c|}{ Cd Concentration } & \multicolumn{3}{|c|}{ Cr Concentration } \\
\hline & & \multicolumn{2}{|c|}{ Soil } & \multirow{2}{*}{$\begin{array}{l}\text { TCLP } \\
\mathrm{mg} / \mathrm{L}^{2}\end{array}$} & \multicolumn{2}{|c|}{ Soil } & \multirow{2}{*}{$\begin{array}{l}\text { TCLP } \\
\mathrm{mg} / \mathrm{L}^{2}\end{array}$} \\
\hline & & $\mathrm{mg} / \mathrm{kg}^{1}$ & $\mathrm{mg} / \mathrm{kg}^{2}$ & & $\mathrm{mg} / \mathrm{kg}^{1}$ & $\mathrm{mg} / \mathrm{kg}^{2}$ & \\
\hline \multirow[t]{19}{*}{ R124 } & $-S 001$ & & 0.38 & 0.02 & & 0.20 & 0.01 \\
\hline & $-S 002$ & & 0.03 & 0.00 & & 0.20 & 0.01 \\
\hline & -5003 & 1.2 & 0.38 & 0.02 & 7.5 & 0.20 & 0.01 \\
\hline & $-S 004$ & 7.6 & 0.38 & 0.02 & 5.6 & 0.20 & 0.01 \\
\hline & -5005 & & 0.03 & 0.00 & & 0.20 & 0.01 \\
\hline & (dup) & & 0.38 & 0.02 & & 0.20 & 0.01 \\
\hline & -5006 & & 0.03 & 0.00 & & 0.20 & 0.01 \\
\hline & $-\$ 007$ & 0.97 & 0.01 & 0.00 & 7.2 & 0.20 & 0.01 \\
\hline & -5008 & & 0.01 & 0.00 & & 0.20 & 0.01 \\
\hline & (dup) & & 0.01 & 0.00 & & 0.20 & 0.01 \\
\hline & -5009 & 2.1 & 0.03 & 0.00 & 10.1 & 0.20 & 0.01 \\
\hline & -5010 & & 0.03 & 0.00 & & 0.20 & 0.01 \\
\hline & (dup) & & 0.01 & 0.00 & & 0.20 & 0.01 \\
\hline & -5011 & & 0.03 & 0.00 & & 0.20 & 0.01 \\
\hline & $-S 012$ & & 0.03 & 0.00 & & 0.20 & 0.01 \\
\hline & $-S 013$ & & 0.38 & 0.02 & & 0.20 & 0.01 \\
\hline & (dup) & . & 0.03 & 0.00 & & 0.20 & 0.01 \\
\hline & -5014 & 0.98 & 1.25 & 0.06 & 6.6 & 0.20 & 0.01 \\
\hline & $-S 015$ & 0.96 & 0.01 & 0.00 & 6.0 & 0.20 & 0.01 \\
\hline & $\ldots$ & $\therefore \ldots$ & $\ldots$ & $\ldots$ & $\ldots$ & $\ldots$ & $\ldots$ \\
\hline \multirow[t]{18}{*}{ R122 } & $-S 016$ & 0.99 & 0.01 & 0.00 & 7.9 & 0.20 & 0.01 \\
\hline & $-S 017$ & 0.98 & 0.01 & 0.00 & 4.6 & 0.20 & 0.01 \\
\hline & $-S 018$ & & 0.03 & 0.00 & & 0.20 & 0.01 \\
\hline & -5019 & & 0.03 & 0.00 & & 0.20 & 0.01 \\
\hline & -5020 & & 0.01 & 0.00 & & 0.20 & 0.01 \\
\hline & $-S 021$ & & 0.01 & 0.00 & & 0.20 & 0.01 \\
\hline & (dup) & & 0.01 & 0.00 & & 0.20 & 0.01 \\
\hline & $-S 022$ & 0.97 & 0.01 & 0.00 & 3.0 & 0.20 & 0.01 \\
\hline & $-\mathrm{S} 023$ & & 0.01 & 0.00 & & 0.20 & 0.01 \\
\hline & $-S 024$ & & 0.01 & 0.00 & & 0.20 & 0.01 \\
\hline & (dup) & & 0.01 & 0.00 & & 0.20 & 0.01 \\
\hline & -5025 & & 0.01 & 0.00 & & 0.20 & 0.01 \\
\hline & -5026 & 0.95 & 0.01 & 0.00 & 3.5 & 0.20 & 0.01 \\
\hline & $-S 027$ & & 0.01 & 0.00 & & 0.20 & 0.01 \\
\hline & (dup) & & 0.01 & 0.00 & & 0.20 & 0.01 \\
\hline & -5028 & & 0.01 & 0.00 & & 0.20 & 0.01 \\
\hline & $-S 029$ & 0.97 & 0.01 & 0.00 & 5.5 & 0.20 & 0.01 \\
\hline & -5030 & 1.00 & 1.61 & 0.08 & 39.2 & 0.20 & 0.01 \\
\hline
\end{tabular}


TABLE 7 (Cont.)

\begin{tabular}{|c|c|c|c|c|c|c|c|}
\hline \multirow{3}{*}{\multicolumn{2}{|c|}{ Sample No. }} & \multicolumn{3}{|c|}{ Cd Concentration } & \multicolumn{3}{|c|}{$\mathrm{Cr}$ Concentration } \\
\hline & & \multicolumn{2}{|c|}{ Soil } & \multirow[b]{2}{*}{$\begin{array}{l}\mathrm{TCLP} \\
\mathrm{mg} / \mathrm{L}^{2}\end{array}$} & \multicolumn{2}{|c|}{ Soil } & \multirow[b]{2}{*}{$\begin{array}{l}\text { TCLP } \\
\mathrm{mg} / \mathrm{L}^{2}\end{array}$} \\
\hline & & $\mathrm{mg} / \mathrm{kg}^{1}$ & $\mathrm{mg} / \mathbf{k g}^{2}$ & & $\mathbf{m g} / \mathbf{k g}^{1}$ & $\mathrm{mg} / \mathrm{kg}^{2}$ & \\
\hline \multirow[t]{23}{*}{ R111 } & $-S 031$ & & 1.77 & 0.09 & & 0.20 & 0.01 \\
\hline & $-S 032$ & & 12.15 & 0.63 & & 0.20 & 0.01 \\
\hline & $-\mathrm{S} 033$ & & 59.92 & 3.10 & & 0.20 & 0.01 \\
\hline & $-\mathrm{S} 034$ & & 54.73 & 2.83 & & 0.20 & 0.01 \\
\hline & $-S 035$ & & 40.30 & 2.08 & & 0.20 & 0.01 \\
\hline & $-S 036$ & & 62.79 & 3.25 & & 0.20 & 0.01 \\
\hline & $-S 037$ & 31.1 & 21.68 & 1.12 & 34.8 & 0.43 & 0.02 \\
\hline & $-S 038$ & 32.3 & 25.72 & 1.33 & 41.8 & 0.43 & 0.02 \\
\hline & $-\$ 039$ & 94.6 & 79.98 & 4.14 & 27.7 & 0.43 & 0.02 \\
\hline & $-S 040$ & & 41.92 & 2.17 & & 0.43 & 0.02 \\
\hline & (dup) & & 42.73 & 2.21 & & 0.20 & 0.01 \\
\hline & $-S 041$ & 32.5 & 50.75 & 2.62 & 44.4 & 0.20 & 0.01 \\
\hline & $-S 042$ & & 17.26 & 0.89 & & 0.20 & 0.01 \\
\hline & .5043 & & 21.93 & 1.13 & & 0.20 & 0.01 \\
\hline & $-S 044$ & 73.6 & 17.26 & 0.89 & 25.8 & 0.20 & 0.01 \\
\hline & $-S 045$ & & 6.27 & 0.32 & & 0.20 & 0.01 \\
\hline & (dup) & & 5.92 & 0.31 & & 0.20 & 0.01 \\
\hline & -5046 & & 14.57 & 0.75 & & 0.20 & 0.01 \\
\hline & (dup) & & 14.57 & 0.75 & & 0.20 & 0.01 \\
\hline & -5047 & & 6.65 & 0.34 & & 0.20 & 0.01 \\
\hline & $-S 048$ & & 2.46 & 0.13 & & 0.20 & 0.01 \\
\hline & (dup) & & 1.42 & 0.07 & & 0.20 & 0.01 \\
\hline & -5049 & 1.0 & 0.38 & 0.02 & 16.3 & 0.20 & 0.01 \\
\hline
\end{tabular}

1 Determined by the Argonne ACL using ICP-AES.

2 Determined by the Argonne Reclamation Engineering and Geosciences Laboratory using AAS and TCLP.

Notes: $\begin{aligned} & R=\text { Range } \\ & S=\text { Soil Sample } \\ & \text { dup = duplicate }\end{aligned}$ 
TABLE 8 Soil Characterization Results for $\mathrm{Zn}$ and $\mathrm{Ba}$ at the Grafenwöhr Training Area

\begin{tabular}{|c|c|c|c|c|c|c|c|}
\hline \multirow{3}{*}{\multicolumn{2}{|c|}{ Sample No. }} & \multicolumn{3}{|c|}{ Zn Concentration } & \multicolumn{3}{|c|}{ Ba Concentration } \\
\hline & & \multicolumn{2}{|c|}{ Soil } & \multirow[b]{2}{*}{$\begin{array}{c}\mathrm{TCLP} \\
\mathrm{mg} / \mathrm{L}^{2}\end{array}$} & \multicolumn{2}{|c|}{ Soil } & \multirow[b]{2}{*}{$\begin{array}{c}\text { TCLP } \\
\mathrm{mg} / \mathrm{L}^{2}\end{array}$} \\
\hline & & $\mathrm{mg} / \mathrm{kg}^{1}$ & $\mathrm{mg} / \mathrm{kg}^{2}$ & & $\mathrm{mg} / \mathrm{kg}^{1}$ & $\mathrm{mg} / \mathrm{kg}^{2}$ & \\
\hline \multirow[t]{19}{*}{ R124 } & $-S 001$ & & 0.61 & 0.03 & & 804.8 & 36.04 \\
\hline & -5002 & & 0.31 & 0.02 & & 228.4 & 10.23 \\
\hline & -5003 & 77.6 & 13.74 & 0.74 & 51.8 & 607.4 & 27.20 \\
\hline & $-S 004$ & 125.0 & 23.59 & 1.27 & 37.1 & 369.0 & 16.52 \\
\hline & $-S 005$ & & 9.62 & 0.52 & & 332.1 & 14.87 \\
\hline & (dup) & & 9.01 & 0.48 & & 339.1 & 15.18 \\
\hline & -5006 & & 7.94 & 0.43 & & 478.7 & 21.44 \\
\hline & $-S 007$ & 700.0 & 14.66 & 0.79 & 57.3 & 282.2 & 12.64 \\
\hline & -5008 & & 14.05 & 0.76 & & 258.3 & 11.57 \\
\hline & (dup) & & 14.05 & 0.76 & & 299.2 & 13.40 \\
\hline & -5009 & 1,350 & 16.79 & 0.90 & 53.7 & 439.8 & 19.69 \\
\hline & $-S 010$ & & 14.96 & 0.80 & & 247.3 & 11.07 \\
\hline & (dup) & & 13.59 & 0.73 & & 232.4 & 10.40 \\
\hline & $-S 011$ & & 18.93 & 1.02 & & 460.8 & 20.63 \\
\hline & -5012 & & 11.91 & 0.64 & & 327.1 & 14.65 \\
\hline & -5013 & & 5.80 & 0.31 & & 683.2 & 30.59 \\
\hline & (dup) & & 6.87 & 0.37 & & 688.1 & 30.81 \\
\hline & -5014 & 105.0 & 8.57 & 0.46 & 28.9 & 903.6 & 40.46 \\
\hline & $-S 015$ & 39.6 & 1.07 & 0.05 & 34.4 & 34.89 & 1.56 \\
\hline & $\ldots$ & $\ldots$ & $\ldots$ & $\ldots$ & $\ldots$ & $\ldots$ & $\ldots$ \\
\hline \multirow[t]{18}{*}{$\mathrm{R} 122$} & -5016 & 48.2 & 5.19 & 0.26 & 63.2 & 304.2 & 13.62 \\
\hline & -5017 & 23.8 & 0.31 & 0.02 & 63.3 & 59.82 & 2.68 \\
\hline & -5018 & & 1.53 & 0.08 & & 107.7 & 4.82 \\
\hline & -5019 & & 0.46 & 0.02 & & 1.98 & 0.09 \\
\hline & $-S 020$ & & 19.39 & 1.04 & & 0.50 & 0.02 \\
\hline & -5021 & & 2.60 & 0.14 & & 0.50 & 0.02 \\
\hline & (dup) & & 2.44 & 0.12 & & 0.50 & 0.02 \\
\hline & -5022 & 30.2 & 2.75 & 0.14 & 83.4 & 9.96 & 0.45 \\
\hline & -5023 & & 0.31 & 0.02 & & 0.50 & 0.02 \\
\hline & -5024 & & 7.94 & 0.43 & & 84.76 & 3.80 \\
\hline & (dup) & & 8.09 & 0.43 & & 18.93 & 0.85 \\
\hline & $-S 025$ & & 2.44 & 0.13 & & 0.50 & 0.02 \\
\hline & -5026 & 23.0 & 2.60 & 0.14 & 48.6 & 0.50 & 0.02 \\
\hline & -5027 & & 1.38 & 0.07 & & 0.50 & 0.02 \\
\hline & (dup) & & 1.07 & 0.06 & & 0.50 & 0.02 \\
\hline & -5028 & & 0.15 & 0.01 & & 76.78 & 3.44 \\
\hline & -5029 & 72.7 & 0.15 & 0.01 & 71.6 & 78.77 & 3.53 \\
\hline & -5030 & 2120 & 1.04 & 0.06 & 97.9 & $1,032.2$ & 46.22 \\
\hline
\end{tabular}


TABLE 8 (Cont.)

\begin{tabular}{|c|c|c|c|c|c|c|c|}
\hline \multirow{3}{*}{\multicolumn{2}{|c|}{ Sample No. }} & \multicolumn{3}{|c|}{$\mathrm{Zn}$ Concentration } & \multicolumn{3}{|c|}{ Ba Concentration } \\
\hline & & \multicolumn{2}{|c|}{ Soil } & \multirow{2}{*}{$\begin{array}{l}\text { TCLP } \\
\mathrm{mg} / \mathrm{L}^{2}\end{array}$} & \multicolumn{2}{|c|}{ Soil } & \multirow{2}{*}{$\begin{array}{l}\text { TCLP } \\
\mathrm{mg} / \mathrm{L}\end{array}$} \\
\hline & & $\mathrm{mg} / \mathrm{kg}^{1}$ & $\mathrm{mg} / \mathrm{kg}^{2}$ & & $\mathrm{mg} / \mathrm{kg}^{1}$ & $\mathrm{mg} / \mathrm{kg}^{2}$ & \\
\hline \multirow[t]{23}{*}{ R111 } & -5031 & & 7.63 & 0.41 & & 361.0 & 16.17 \\
\hline & -S032 & & 103.7 & 5.57 & & 703.1 & 31.48 \\
\hline & $-\mathrm{SO} 033$ & & 63.66 & 3.42 & & 740.0 & 33.14 \\
\hline & $-S 034$ & & 70.53 & 3.79 & & 708.1 & 31.71 \\
\hline & $-S 035$ & & 121.9 & 6.10 & & 712.1 & 31.89 \\
\hline & -5036 & & 359.6 & 17.98 & & $1,062.1$ & 47.56 \\
\hline & $-S 037$ & 5,680 & 975.7 & 52.46 & 97.3 & 980.4 & 43.90 \\
\hline & -5038 & 691.0 & $1,523.4$ & 81.90 & 115.0 & $1,050.2$ & 47.03 \\
\hline & $-\$ 039$ & 976.0 & 662.1 & 35.60 & 94.8 & $1,032.2$ & 46.22 \\
\hline & $-S 040$ & & 220.9 & 11.88 & & 464.7 & 20.81 \\
\hline & (dup) & & 209.1 & 11.24 & & 525.6 & 23.53 \\
\hline & -5041 & 703.0 & 193.6 & 10.41 & 164.0 & 728.0 & 32.60 \\
\hline & -5042 & & 94.19 & 5.06 & & 514.6 & 23.04 \\
\hline & -5043 & & 368.7 & 19.82 & & 765.9 & 34.30 \\
\hline & -5044 & 48.6 & 400.1 & 21.51 & 92.0 & 803.8 & 35.99 \\
\hline & -5045 & & 349.7 & 18.80 & & 726.0 & 32.51 \\
\hline & (dup) & & 449.1 & 24.15 & & 752.0 & 33.67 \\
\hline & -5046 & & 136.8 & 7.35 & & 686.2 & 30.72 \\
\hline & (dup) & & 79.68 & 4.28 & & 696.1 & 31.17 \\
\hline & -5047 & & 567.5 & 30.51 & & $1,059.2$ & 47.43 \\
\hline & -5048 & & 6.41 & 0.34 & r & 76.78 & 3.44 \\
\hline & (dup) & & 4.73 & 0.25 & & 71.79 & 3.21 \\
\hline & -5049 & & 1.68 & 0.09 & 61.0 & 19.93 & 0.89 \\
\hline
\end{tabular}

1 Determined by the Argonne ACL using ICP-AES.

2 Determined by the Argonne Reclamation Engineering and Geosciences Laboratory using AAS and TCLP.

Notes: $R=$ Range

$S=$ Soil Sample

dup $=$ duplicate 
TABLE 9 Results of Chelant Extraction Soil Treatment - Batch Studies

Element Concentration $(\mathrm{mg} / \mathrm{kg})$

$\begin{array}{llllllll}\text { Sample No. } & \mathrm{pH} & \mathrm{Pb} & \mathrm{Cd} & \mathrm{Cu} & \mathrm{Cr} & \mathrm{Ba} & \mathrm{Zn}\end{array}$

Dutch List Standards

Soils $(\mathrm{mg} / \mathrm{kg})$

Category A

Category B

Category C

$\begin{array}{lrl}-- & - \\ \cdots & 150 \\ - & 600\end{array}$

5

5
20

$\begin{array}{rr}\cdots & -- \\ 100 & 250 \\ 500 & 800\end{array}$

200
400

500

2,000

3,000

Citric Acid:

\begin{tabular}{|c|c|c|c|c|c|c|c|c|}
\hline \multirow[t]{3}{*}{ R111 } & -5037 & 5.915 & 9.06 & 17.27 & $\sim 0$ & 0.140 & 203.7 & 901.6 \\
\hline & & 6.409 & 10.20 & 19.42 & $\sim 0$ & 0.140 & 637.1 & 623.9 \\
\hline & & 7.698 & 10.21 & 21.05 & $\sim 0$ & 0.139 & $\underline{684.1}$ & 780.1 \\
\hline \multirow[t]{3}{*}{ R111 } & -5038 & 6.237 & 8.04 & 17.83 & $\sim 0$ & 0.140 & 118.7 & 1.381 .2 \\
\hline & & 6.736 & 12.78 & 22.04 & $\sim 0$ & 0.140 & $\underline{531.5}$ & 1.478 .4 \\
\hline & & 7.734 & 12.80 & 25.09 & $\sim 0$ & 0.139 & 665.0 & 1.345 .2 \\
\hline \multirow[t]{3}{*}{ R111 } & $-\$ 039$ & 6.304 & 10.44 & 31.63 & $\sim 0$ & 0.140 & 338.2 & 413.4 \\
\hline & & 6.321 & 10.47 & 46.32 & $\sim 0$ & 0.139 & $\underline{617.7}$ & $\underline{562.3}$ \\
\hline & & 7.421 & 9.31 & 62.88 & $\sim 0$ & 0.139 & 718.0 & $\underline{568.1}$ \\
\hline \multirow[t]{3}{*}{ R111 } & $-S 041$ & 5.861 & $\sim 0$ & 3.08 & $\sim 0$ & $\sim 0$ & $\sim 0$ & 140.9 \\
\hline & & 6.498 & 0.26 & 39.85 & $\sim 0$ & $\sim 0$ & 490.0 & 128.5 \\
\hline & & 7.601 & 0.28 & 40.21 & $\sim 0$ & $\sim 0$ & $\overline{534.2}$ & 109.1 \\
\hline \multirow[t]{3}{*}{ R111 } & $-S 044$ & 6.432 & 1.51 & 11.71 & $\sim 0$ & -0 & 118.9 & 152.9 \\
\hline & & 6.747 & 1.51 & 15.48 & $\sim 0$ & $\sim 0$ & 498.5 & 299.6 \\
\hline & & 7.261 & 0.28 & 13.95 & $\sim 0$ & $\sim 0$ & 347.9 & 4.82 \\
\hline \multirow[t]{3}{*}{ R111 } & -5049 & 3.257 & $\sim 0$ & $\sim 0$ & $\sim 0$ & $\sim 0$ & 16.16 & $\sim 0$ \\
\hline & & 5.163 & $\sim 0$ & $\sim 0$ & $\sim 0$ & $\sim 0$ & 17.67 & $\sim 0$ \\
\hline & & 7.093 & $\sim 0$ & $\sim 0$ & $\sim 0$ & $\sim 0$ & 15.70 & $\sim 0$ \\
\hline
\end{tabular}

EDTA:

\begin{tabular}{|c|c|c|c|c|c|c|c|c|}
\hline \multirow[t]{3}{*}{$\mathrm{R} 111$} & -5037 & 6.715 & $\sim 0$ & 11.16 & $\sim 0$ & 0.140 & 242.6 & 861.3 \\
\hline & & 7.113 & $\sim 0$ & 11.34 & $\sim 0$ & 0.140 & 633.1 & 902.0 \\
\hline & & 7.229 & $\sim 0$ & 15.39 & $\sim 0$ & 0.140 & 612.7 & 905.5 \\
\hline \multirow[t]{3}{*}{ R111 } & -5038 & 6.884 & $\sim 0$ & 10.93 & $\sim 0$ & 0.139 & 233.2 & $1,387.0$ \\
\hline & & 6.982 & $\sim 0$ & 15.11 & $\sim 0$ & 0.140 & $\underline{597.5}$ & 465.1 \\
\hline & & 7.204 & $\sim 0$ & 15.04 & $\sim 0$ & 0.139 & 797.1 & 997.0 \\
\hline \multirow[t]{3}{*}{ R111 } & $-\$ 039$ & 6.401 & $\sim 0$ & 0.48 & $\sim 0$ & 0.139 & 46.70 & 222.6 \\
\hline & & 6.854 & $\sim 0$ & 10.79 & $\sim 0$ & 0.138 & 550.0 & 342.5 \\
\hline & & 7.186 & $\sim 0$ & 16.66 & $\sim 0$ & 0.139 & $\underline{627.5}$ & 380.5 \\
\hline \multirow[t]{3}{*}{ R111 } & $-S 041$ & 6.214 & $\sim 0$ & $\sim 0$ & $\sim 0$ & $\sim 0$ & 30.63 & $\sim 0$ \\
\hline & & 6.887 & $\sim 0$ & $\sim 0$ & $\sim 0$ & $\sim 0$ & 246.0 & $\sim 0$ \\
\hline & & 7.431 & -0 & 3.02 & $\sim 0$ & $\sim 0$ & 416.5 & $\sim 0$ \\
\hline
\end{tabular}


TABLE 9 (Cont.)

\begin{tabular}{|c|c|c|c|c|c|c|c|}
\hline \multirow[b]{2}{*}{ Sample No. } & \multicolumn{7}{|c|}{ Element Concentration $(\mathrm{mg} / \mathrm{kg}$ ) } \\
\hline & $\mathrm{pH}$ & $\mathrm{Pb}$ & Cd & $\mathrm{Cu}$ & $\mathrm{Cr}$ & $\mathrm{Ba}$ & $\mathrm{Zn}$ \\
\hline \multicolumn{8}{|l|}{ EDTA: (Cont.) } \\
\hline R111 -S044 & 6.701 & -0 & 2.96 & $\sim 0$ & $\sim 0$ & 121.0 & $\sim 0$ \\
\hline & 7.321 & $\sim 0$ & 7.79 & $\sim 0$ & $\sim 0$ & 339.6 & 29.66 \\
\hline & 7.847 & $\sim 0$ & 9.44 & $\sim 0$ & $\sim 0$ & 473.8 & 83.48 \\
\hline \multirow[t]{3}{*}{$R 111-S 049$} & 3.183 & $\sim 0$ & $\sim 0$ & $\sim 0$ & $\sim 0$ & 15.02 & -0 \\
\hline & 5.076 & -0 & $\sim 0$ & $\sim 0$ & $\sim 0$ & 17.69 & $\sim 0$ \\
\hline & 7.101 & $\sim 0$ & $\sim 0$ & $\sim 0$ & $\sim 0$ & 0.70 & $\sim 0$ \\
\hline
\end{tabular}

Boldface Numbers: Exceed Category C Standards

Underlined Numbers: Exceed Category B Standards

$R=$ Range

$S=$ Soil Sample

TABLE 10 Comparison of Contaminant Concentrations in Treated and Untreated Soils: $\mathrm{Pb}, \mathrm{Cd}$, and $\mathrm{Cu}$

\begin{tabular}{|c|c|c|c|c|c|c|c|}
\hline \multirow[b]{3}{*}{ Sample No. } & \multirow[b]{3}{*}{$\mathrm{pH}$} & \multicolumn{6}{|c|}{ Element Concentration $(\mathrm{mg} / \mathrm{kg})$} \\
\hline & & \multicolumn{2}{|c|}{$\mathrm{Pb}$} & \multicolumn{2}{|c|}{$\mathrm{Cd}$} & \multicolumn{2}{|c|}{$\mathrm{Cu}$} \\
\hline & & Untreated & Treated & Untreated & Treated & Untreated & Treated \\
\hline
\end{tabular}

Dutch List Standards

Soils $(\mathrm{mg} / \mathrm{kg})$

Category A

Category B

Category $\mathrm{C}$

$\begin{array}{ll}\cdots & \cdots \\ \cdots & 150 \\ \cdots & 600\end{array}$

$\cdots$
150
600

-
5
20

--
5
20

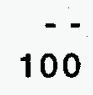

100

$600 \quad 20$

20

500

500

Citric Acid:

\begin{tabular}{|c|c|c|c|c|c|c|c|c|}
\hline \multirow[t]{3}{*}{ R111 } & $-S 037$ & 5.915 & 112 & 9.06 & 31.1 & 17.27 & 276 & $\sim 0$ \\
\hline & & 6.409 & 112 & 10.20 & 31.1 & 19.42 & $\underline{276}$ & $\sim 0$ \\
\hline & & 7.698 & 112 & 10.21 & 31.1 & 21.05 & $\underline{276}$ & $\sim 0$ \\
\hline \multirow[t]{3}{*}{$\mathrm{R} 111$} & -5038 & 6.237 & 152 & 8.04 & 32.3 & 17.83 & 370 & $\sim 0$ \\
\hline & & 6.736 & 152 & 12.78 & 32.3 & 22.04 & $\underline{370}$ & $\sim 0$ \\
\hline & & 7.734 & 152 & 12.80 & 32.3 & 25.09 & $\underline{370}$ & $\sim 0$ \\
\hline \multirow[t]{3}{*}{ R111 } & $-\$ 039$ & 6.304 & 90.6 & 10.44 & 94.6 & 31.63 & 1,560 & $\sim 0$ \\
\hline & & 6.321 & 90.6 & 10.47 & 94.6 & 46.32 & 1,560 & $\sim 0$ \\
\hline & & 7.421 & 90.6 & 9.31 & 94.6 & 62.88 & 1,560 & $\sim 0$ \\
\hline
\end{tabular}


TABLE 10 (Cont.)

TABLE 10 (Cont)

Element Concentration $(\mathrm{mg} / \mathrm{kg})$

$\mathrm{Pb}$

$\mathrm{Cd}$

Cu

Sample No. $\quad \mathrm{pH} \quad$ Untreated Treated Untreated Treated Untreated Treated

Citric Acid: (Cont.)

$\begin{array}{lllllllll}\text { R111 } & \text {-S041 } & 5.861 & 70.1 & \sim 0 & 32.5 & 3.08 & \underline{364} & \sim 0 \\ & & 6.498 & 70.1 & 0.26 & \mathbf{3 2 . 5} & \mathbf{3 9 . 8 5} & \underline{\mathbf{3 6 4}} & \sim 0 \\ \mathrm{R} 111 & \text {-S044 } & \mathbf{7 . 6 0 1} & 70.1 & 0.28 & \mathbf{3 2 . 5} & \mathbf{4 0 . 2 1} & \underline{\mathbf{3 6 4}} & \sim 0 \\ & & 6.432 & 70.7 & 1.51 & \mathbf{7 3 . 6} & \underline{11.71} & \underline{\mathbf{3 2 2}} & \sim 0 \\ & & 6.747 & 70.7 & 1.51 & \mathbf{7 3 . 6} & \underline{15.48} & \underline{322} & \sim 0 \\ \mathrm{R} 111 & \text {-S049 } & 7.261 & 70.7 & 0.28 & \mathbf{7 3 . 6} & 13.95 & \underline{322} & \sim 0 \\ & & 3.257 & 26.0 & \sim 0 & 1.0 & \sim 0 & 11.0 & \sim 0 \\ & & 5.163 & 26.0 & \sim 0 & 1.0 & \sim 0 & 11.0 & \sim 0 \\ & & 7.093 & 26.0 & \sim 0 & 1.0 & \sim 0 & 11.0 & \sim 0\end{array}$

EDTA:

\begin{tabular}{|c|c|c|c|c|c|c|c|c|}
\hline \multirow[t]{3}{*}{ R111 } & -5037 & 6.715 & 112 & $\sim 0$ & 31.1 & 11.16 & $\underline{276}$ & $\sim 0$ \\
\hline & & 7.113 & 112 & -0 & 31.1 & 11.34 & $\underline{276}$ & $\sim 0$ \\
\hline & & 7.229 & 112 & $\sim 0$ & 31.1 & 15.39 & $\underline{276}$ & $\sim 0$ \\
\hline \multirow[t]{3}{*}{ R111 } & -5038 & 6.884 & 152 & $\sim 0$ & 32.3 & 10.93 & $\overline{370}$ & $\sim 0$ \\
\hline & & 6.982 & 152 & $\sim 0$ & 32.3 & 15.11 & $\underline{370}$ & $\sim 0$ \\
\hline & & 7.204 & 152 & $\sim 0$ & 32.3 & 15.04 & $\underline{370}$ & $\sim 0$ \\
\hline \multirow[t]{3}{*}{ R111 } & -5039 & 6.401 & 90.6 & $\sim 0$ & 94.6 & 0.48 & 1,560 & $\sim 0$ \\
\hline & & 6.854 & 90.6 & $\sim 0$ & 94.6 & 10.79 & 1,560 & $\sim 0$ \\
\hline & & 7.186 & 90.6 & $\sim 0$ & 94.6 & 16.66 & 1,560 & $\sim 0$ \\
\hline \multirow[t]{3}{*}{ R111 } & $-S 041$ & 6.214 & 70.1 & $\sim 0$ & 32.5 & $\sim 0$ & $\underline{364}$ & $\sim 0$ \\
\hline & & 6.887 & 70.1 & $\sim 0$ & 32.5 & $\sim 0$ & 364 & $\sim 0$ \\
\hline & & 7.431 & 70.1 & $\sim 0$ & 32.5 & 3.02 & 364 & $\sim 0$ \\
\hline \multirow[t]{3}{*}{ R111 } & $-S 044$ & 6.701 & 70.7 & $\sim 0$ & 73.6 & 2.96 & 322 & $\sim 0$ \\
\hline & & 7.321 & 70.7 & $\sim 0$ & 73.6 & 7.79 & 322 & -0 \\
\hline & & 7.847 & 70.7 & $\sim 0$ & 73.6 & 9.44 & 322 & $\sim 0$ \\
\hline \multirow[t]{3}{*}{ R111 } & $-\$ 049$ & 3.183 & 26.0 & $\sim 0$ & 1.0 & $\sim 0$ & 11.0 & $\sim 0$ \\
\hline & & 5.076 & 26.0 & $\sim 0$ & 1.0 & $\sim 0$ & 11.0 & $\sim 0$ \\
\hline & & 7.101 & 26.0 & $\sim 0$ & 1.0 & $\sim 0$ & 11.0 & $\sim 0$ \\
\hline
\end{tabular}

Boldface Numbers: Exceed Category C Standards

Underlined Numbers: Exceed Category B Standards

$\mathrm{R}=$ Range

$S=$ Soil Sample 
TABLE 11 Comparison of Contaminant Concentrations in Treated and Untreated Soils: $\mathrm{Cr}, \mathrm{Ba}$, and $\mathrm{Zn}$

\begin{tabular}{|c|c|c|c|c|c|c|c|}
\hline \multirow[b]{3}{*}{ Sample No. } & \multirow[b]{3}{*}{$\mathrm{pH}$} & \multicolumn{6}{|c|}{ Element Concentration $(\mathrm{mg} / \mathrm{kg})$} \\
\hline & & \multicolumn{2}{|c|}{$\mathrm{Cr}$} & \multicolumn{2}{|c|}{$\mathrm{Ba}$} & \multicolumn{2}{|c|}{$\mathrm{Zn}$} \\
\hline & & Untreated & Treated & Untreated & Treated & Untreated & Treated \\
\hline \multicolumn{8}{|c|}{$\begin{array}{l}\text { Dutch List Standards } \\
\text { Soils }(\mathrm{mg} / \mathrm{kg})\end{array}$} \\
\hline Category $\mathrm{A}$ & - & - & $\cdots$ & 200 & 200 & - &.- \\
\hline Category B & - & 250 & 250 & 400 & 400 & 500 & 500 \\
\hline Category C & -- & 800 & 800 & 2,000 & 2,000 & 3,000 & 3,000 \\
\hline
\end{tabular}

Citric Acid:

\begin{tabular}{|c|c|c|c|c|c|c|c|c|}
\hline \multirow[t]{3}{*}{ R111 } & -5037 & 5.915 & 34.8 & 0.140 & 97.3 & 203.7 & 5,680 & 901.6 \\
\hline & & 6.409 & 34.8 & 0.140 & 97.3 & 637.1 & 5,680 & 623.9 \\
\hline & & 7.698 & 34.8 & 0.139 & 97.3 & 684.1 & 5,680 & 780.1 \\
\hline \multirow[t]{3}{*}{ R111 } & -5038 & 6.237 & 41.8 & 0.140 & 115 & 118.7 & 691 & 1.381 .0 \\
\hline & & 6.736 & 41.8 & 0.140 & 115 & 531.5 & 691 & 1.478 .2 \\
\hline & & 7.734 & 41.8 & 0.139 & 115 & 665.0 & 691 & 1.345 .2 \\
\hline \multirow[t]{3}{*}{ R111 } & $-\$ 039$ & 6.304 & 27.7 & 0.140 & 94.8 & 338.2 & 976 & 413.4 \\
\hline & & 6.321 & 27.7 & 0.139 & 94.8 & 617.7 & 976 & 562.3 \\
\hline & & 7.421 & 27.7 & 0.139 & 94.8 & 718.0 & 976 & 568.1 \\
\hline \multirow[t]{3}{*}{ R111 } & $-S 041$ & 5.861 & 44.4 & $\sim 0$ & 164 & $\sim 0$ & 703 & $\overline{140.9}$ \\
\hline & & 6.498 & 44.4 & $\sim 0$ & 164 & 490.0 & 703 & 128.5 \\
\hline & & 7.601 & 44.4 & $\sim 0$ & 164 & 534.2 & 703 & 109.1 \\
\hline \multirow[t]{3}{*}{ R111 } & $-S 044$ & 6.432 & 25.8 & $\sim 0$ & 92.0 & 118.9 & 48.6 & 152.9 \\
\hline & & 6.747 & 25.8 & $\sim 0$ & 92.0 & 498.5 & 48.6 & 299.6 \\
\hline & & 7.261 & 25.8 & -0 & 92.0 & 347.9 & 48.6 & 4.82 \\
\hline \multirow[t]{3}{*}{ R111 } & $-S 049$ & 3.257 & 16.3 & $\sim 0$ & 61.0 & 16.16 & -- & $\sim 0$ \\
\hline & & 5.163 & 16.3 & $\sim 0$ & 61.0 & 17.67 & - & $\sim 0$ \\
\hline & & 7.093 & 16.3 & $\sim 0$ & 61.0 & 15.70 & - & $\sim 0$ \\
\hline
\end{tabular}

EDTA:

\begin{tabular}{|c|c|c|c|c|c|c|c|c|}
\hline \multirow[t]{3}{*}{ R111 } & -5037 & 6.715 & 34.8 & 0.140 & 97.3 & 242.6 & 5,680 & 861.3 \\
\hline & & 7.113 & 34.8 & 0.140 & 97.3 & 633.1 & 5,680 & 902.0 \\
\hline & & 7.229 & 34.8 & 0.140 & 97.3 & 612.7 & 5,680 & 905.5 \\
\hline \multirow[t]{3}{*}{ R111 } & -5038 & 6.884 & 41.8 & 0.139 & 115 & 233.2 & 691. & 1.387 .0 \\
\hline & & 6.982 & 41.8 & 0.140 & 115 & $\overline{597.5}$ & 691 & 465.1 \\
\hline & & 7.204 & 41.8 & 0.139 & 115 & 797.1 & 691 & 997.0 \\
\hline \multirow[t]{3}{*}{ R111 } & -5039 & 6.401 & 27.7 & 0.139 & 94.8 & 46.70 & 976 & 222.6 \\
\hline & & 6.854 & 27.7 & 0.138 & 94.8 & 550.0 & 976 & 342.5 \\
\hline & & 7.186 & 27.7 & 0.139 & 94.8 & 627.5 & 976 & 380.5 \\
\hline
\end{tabular}


TABLE 11 (Cont.)

\begin{tabular}{|c|c|c|c|c|c|c|c|}
\hline & \multirow[b]{3}{*}{$\mathrm{pH}$} & \multicolumn{6}{|c|}{ Element Concentration $(\mathrm{mg} / \mathrm{kg})$} \\
\hline & & C & & B & & Z & \\
\hline Sample No. & & Untreated & Treated & Untreated & Treated & Untreated & Treated \\
\hline \multicolumn{8}{|l|}{ EDTA: (Cont.) } \\
\hline$R 111-S 041$ & 6.214 & 44.4 & -0 & 164 & 30.63 & 703 & $\sim 0$ \\
\hline & 6.887 & 44.4 & $\sim 0$ & 164 & 246.0 & 703 & $\sim 0$ \\
\hline & 7.431 & 44.4 & $\sim 0$ & 164 & 416.5 & 703 & $\sim 0$ \\
\hline R111 -S044 & 6.701 & 25.8 & $\sim 0$ & 92.0 & 121.0 & 48.6 & $\sim 0$ \\
\hline & 7.321 & 25.8 & $\sim 0$ & 92.0 & $\underline{339.6}$ & 48.6 & 29.66 \\
\hline & 7.847 & 25.8 & $\sim 0$ & 92.0 & 473.8 & 48.6 & 83.48 \\
\hline \multirow{3}{*}{ R111 $-S 049$} & 3.183 & 16.3 & $\sim 0$ & 61.0 & 15.02 & $\cdots$ & $\sim 0$ \\
\hline & 5.076 & 16.3 & $\sim 0$ & 61.0 & 17.69 & $\cdots$ & $\sim 0$ \\
\hline & 7.101 & 16.3 & $\sim 0$ & 61.0 & 0.70 & -- & $\sim 0$ \\
\hline
\end{tabular}

Boldface Numbers: Exceed Category C Standards

Underlined Numbers: Exceed Category B Standards

$R=$ Range

$S=$ Soil Sample

\subsection{Batch Shaker Tests}

Figure 1 presents the solubilization data for cadmium and lead extracted into solution by using either 0.01M citric acid or 0.01M EDTA for samples S037, S038, S039, S041, S044, and S049. Figure 2 presents the solubilization data for barium, copper, and zinc extracted by using the same two chelant solutions for the same six samples. ${ }^{2}$ The chelant concentration was held constant at $0.01 \mathrm{M}$ during these experiments. The soil tested was collected from the hand grenade range (range R111). Data concerning the individual batch shaker experiments are summarized in Appendix A for each of the heavy metals of interest (barium, cadmium, chromium, copper, iron, lead, and zinc).

Figures 1 and 2 indicate that EDTA was about 10 times more effective than citric acid at mobilizing lead, nearly four times more effective at mobilizing cadmium, nearly five times more effective at mobilizing zinc, and two to ten times more effective at mobilizing copper. EDTA and citric acid were nearly equally effective at removing barium and chromium from the soil. The results presented in Figures 1 and 2 generally indicate that, as the $\mathrm{pH}$ is lowered, the solubilization

2 Chromium results are not graphically displayed because they exhibited a consistent two-level plot caused by concentrations near the lower limit of detection. 


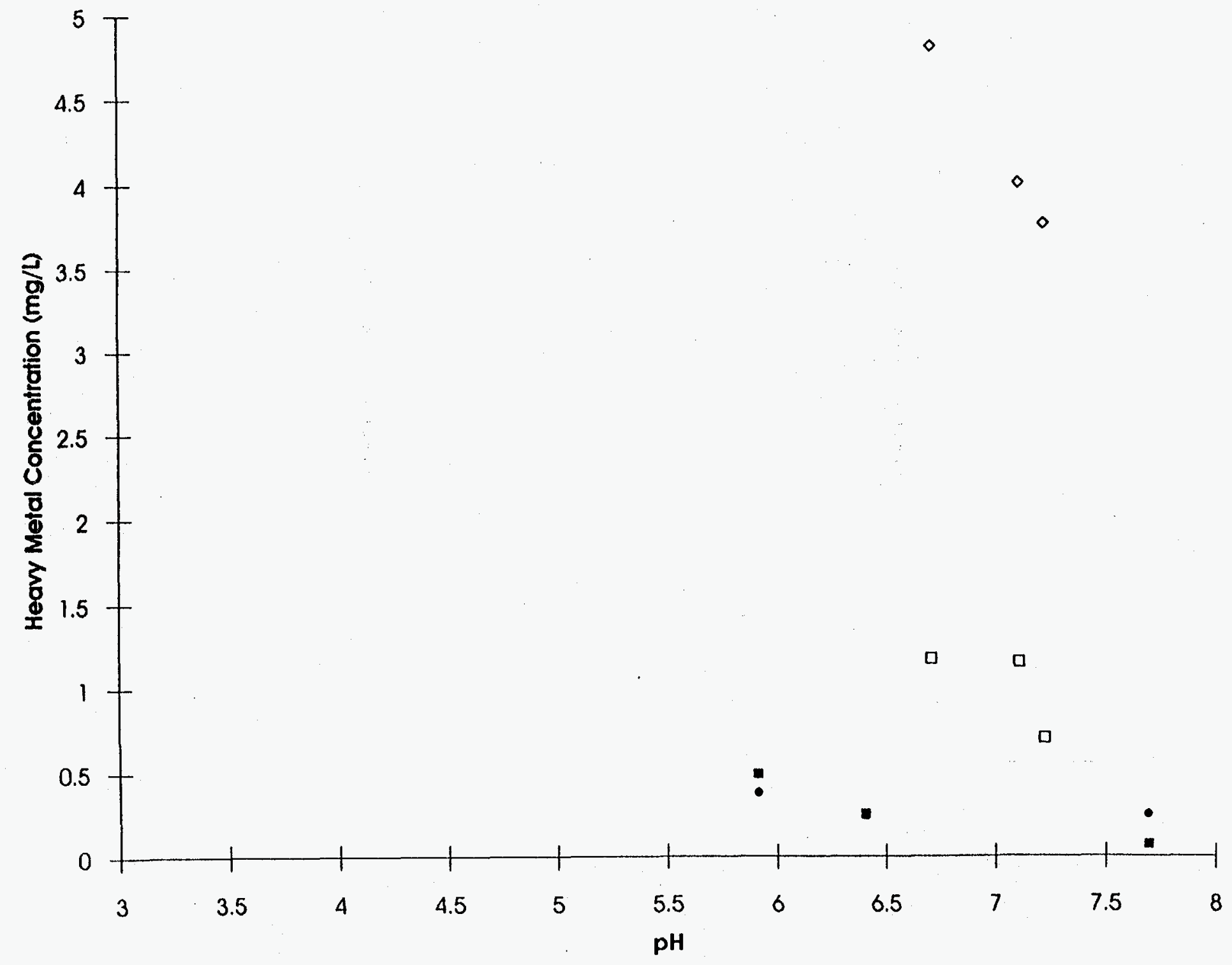

FIGURE 1 Solubilization of Heavy Metals (Cd and Pb) from Contaminated Soil Samples S037, S038, S039, S041, S044, and S049, Using 0.01M Citric Acid and 0.01M EDTA 


$$
\begin{aligned}
& \text { 응 웅 응 } \\
& \text { 萦 } \\
& \text { 명 영 : } \\
& \text { - } \quad \text { - } 0
\end{aligned}
$$

0

0

$\circ$

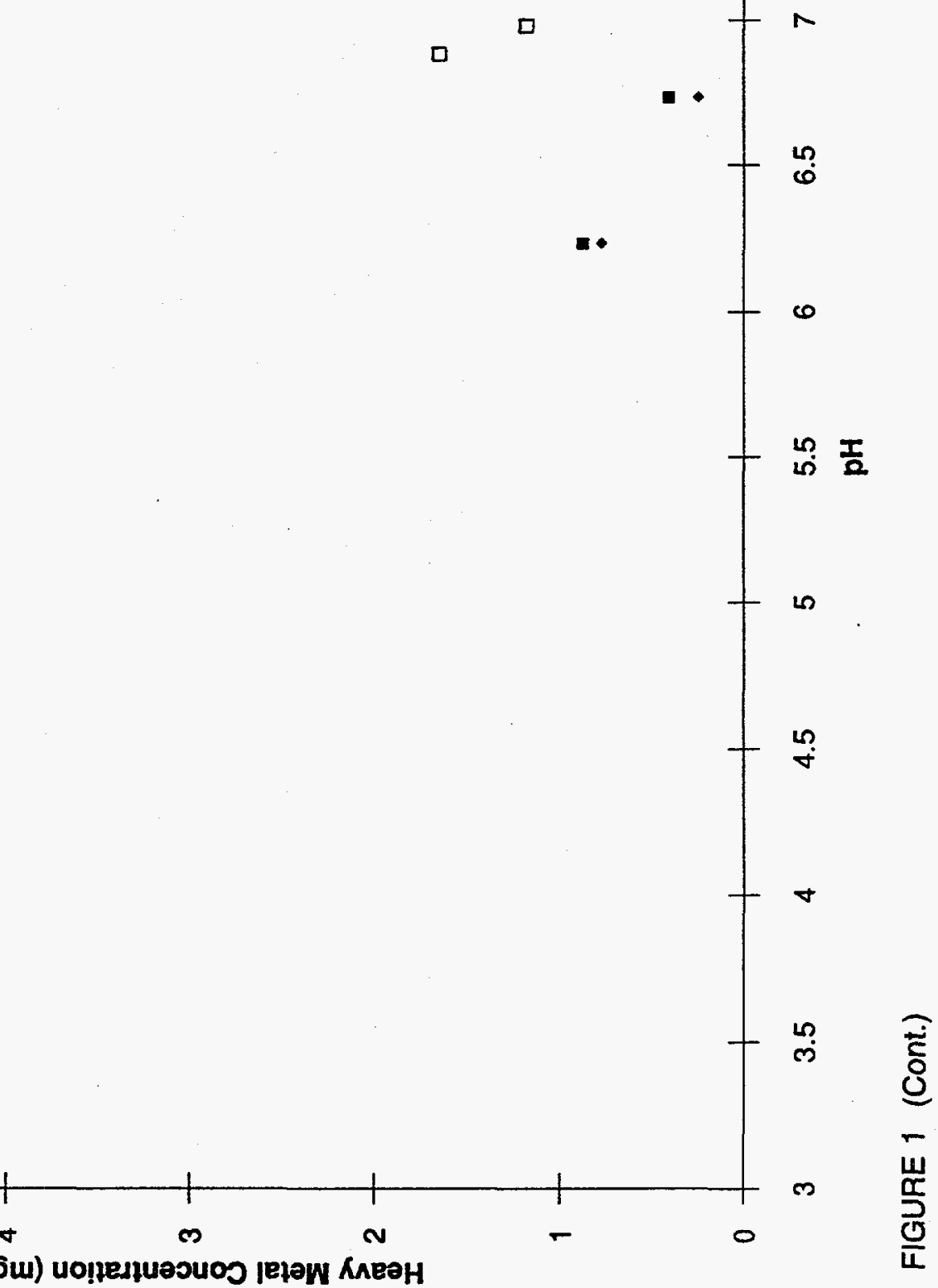




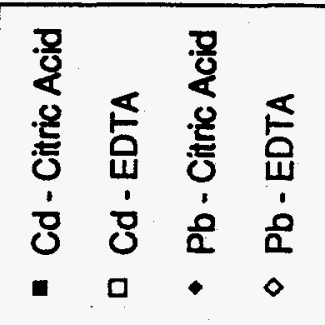

ㅁ

-

○

口

0

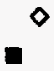

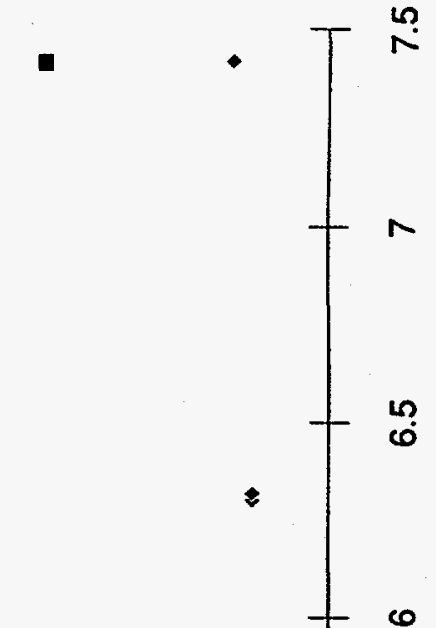

I

ก

م

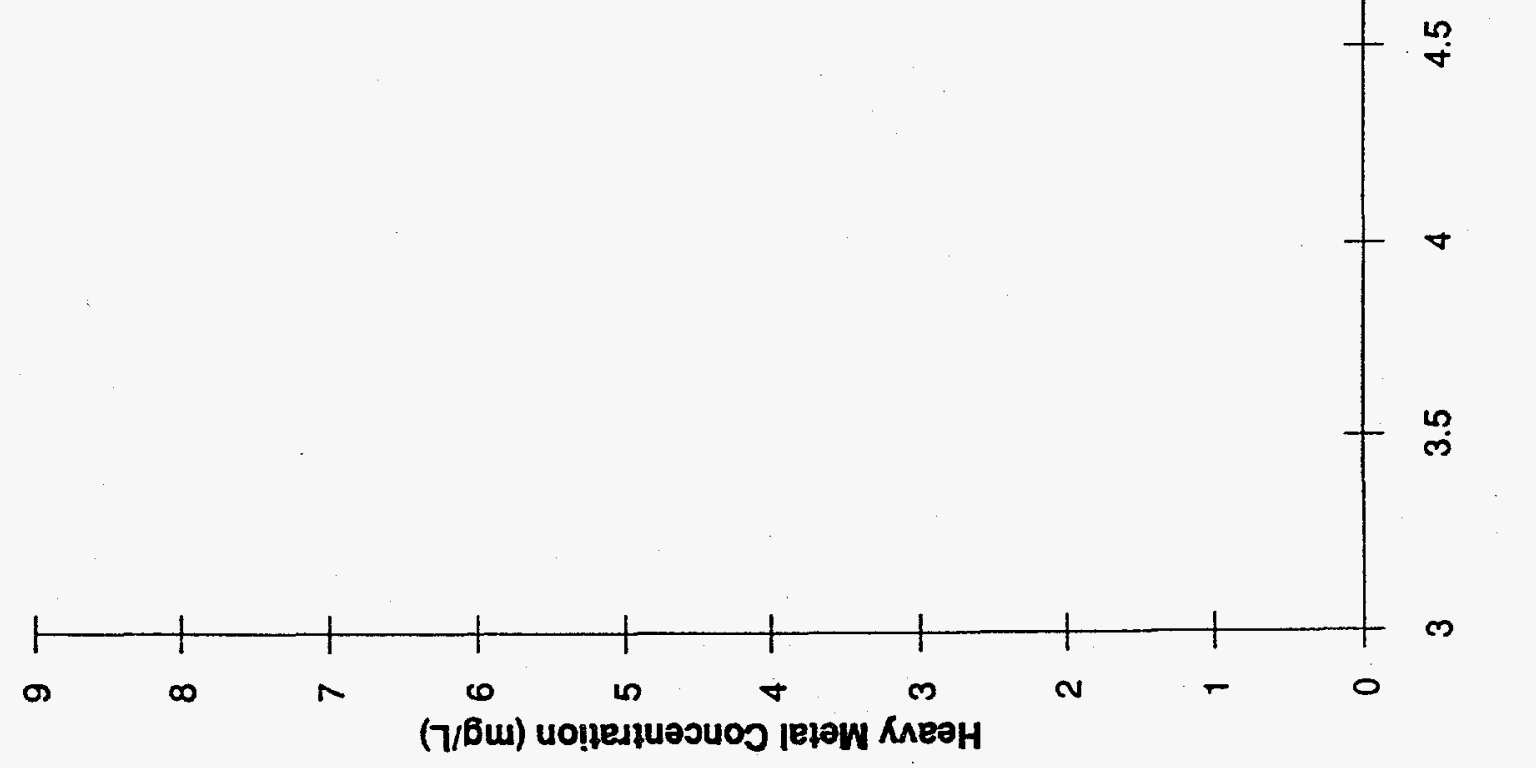

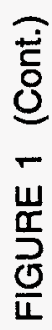




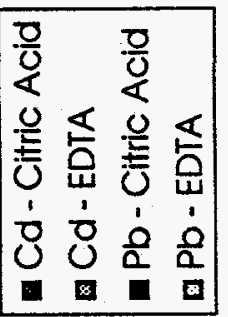

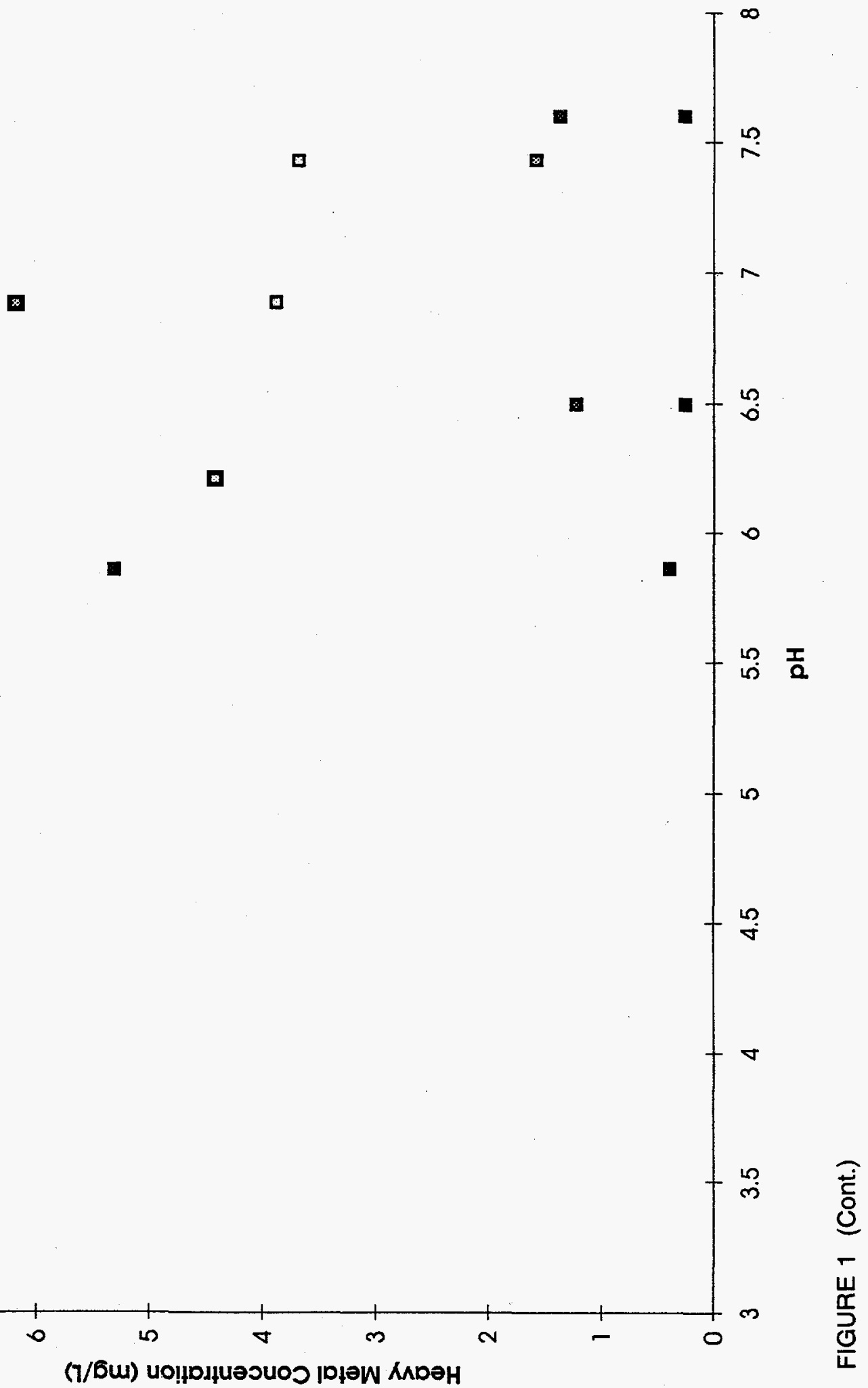




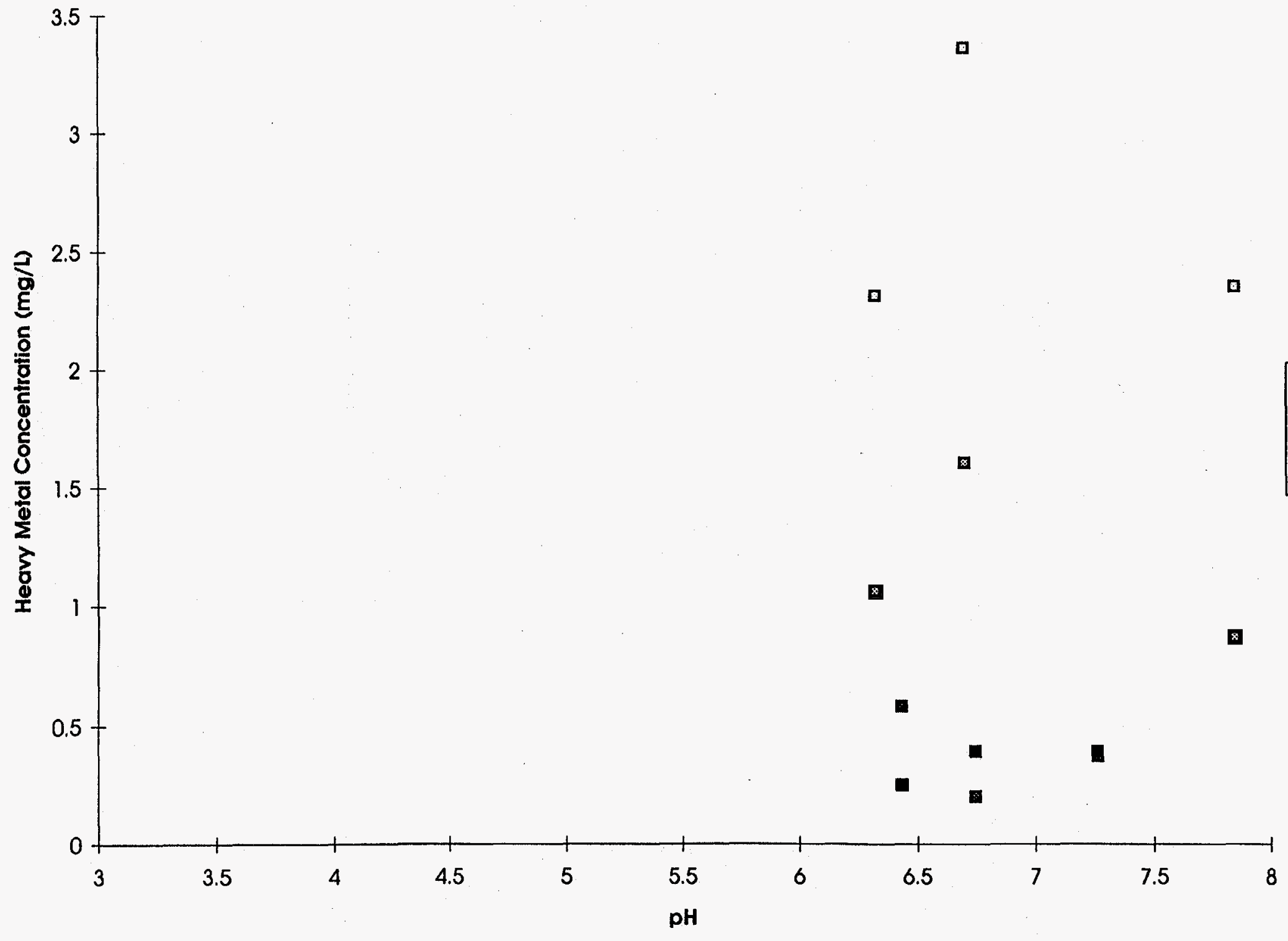

FIGURE 1 (Cont.) 


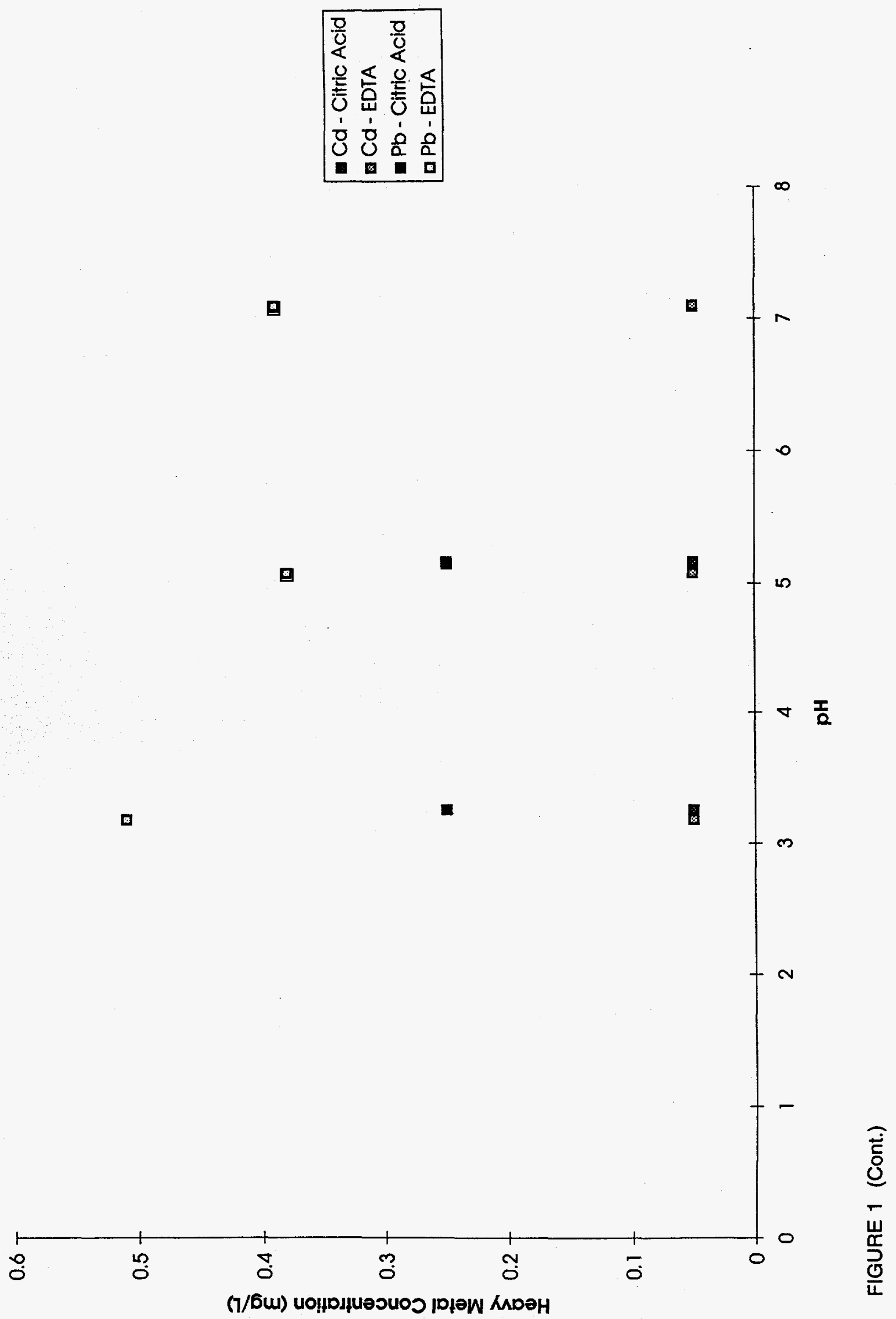




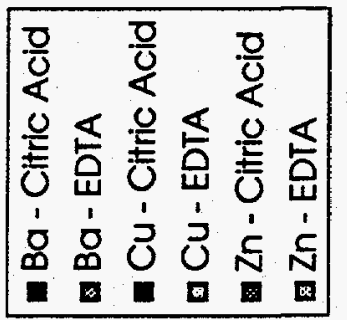

D

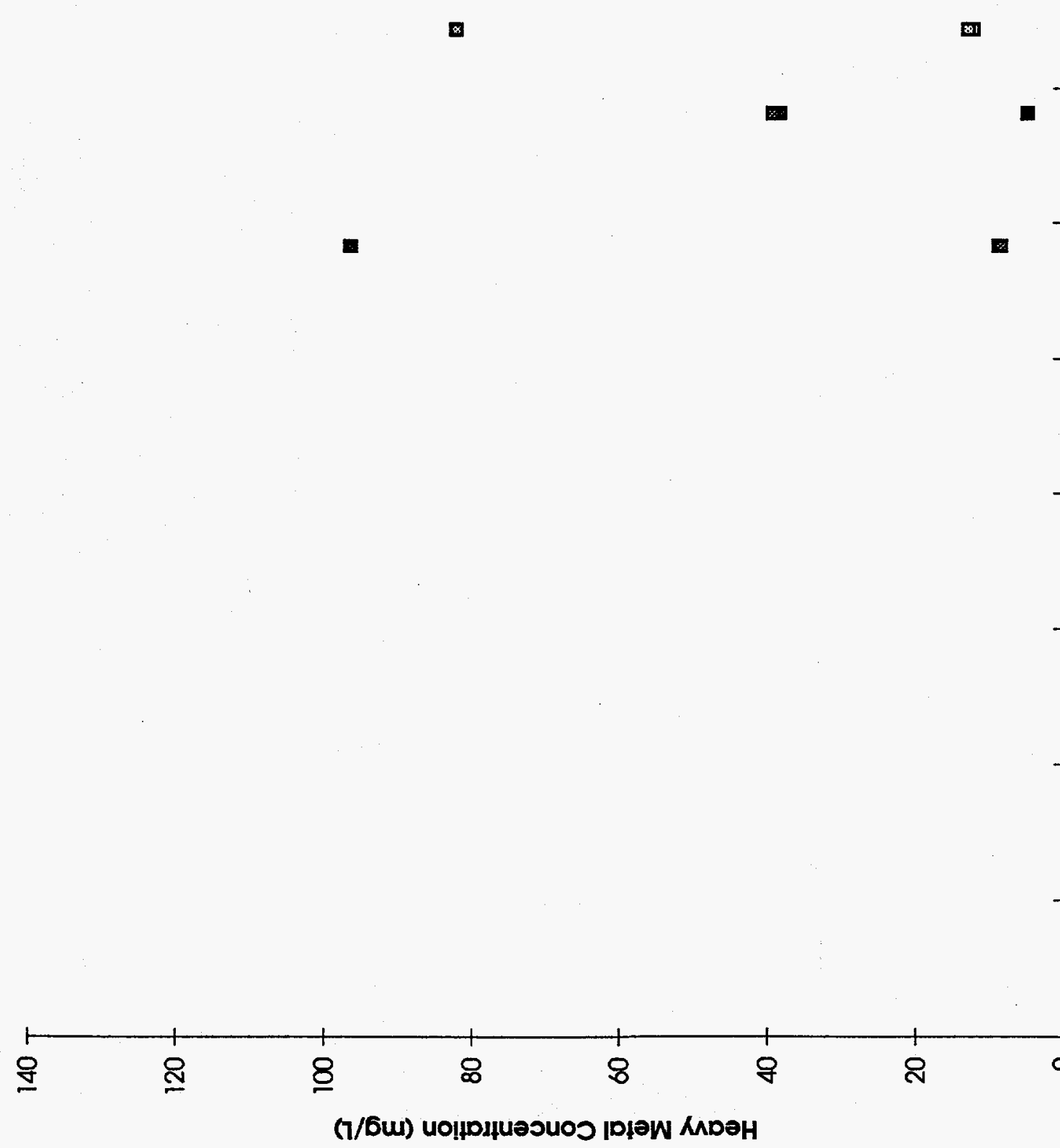

듬

导

๑

ㅁ

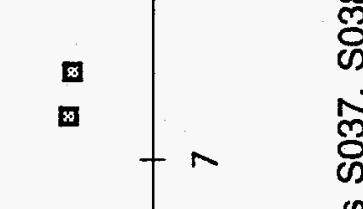

$+\quad \overline{\overline{0}}$

i 10 동

돈

은

10 క 怘占

$\stackrel{\infty}{\sim} \quad \frac{\infty}{\mathbb{N}} \frac{\Sigma}{0}$

$\sum 0$

乐号

$\checkmark \quad \stackrel{\oplus}{1} \div$

훙

등 은

品 $\quad$ 츨응

๙

N $\frac{5}{9}$

山

㟧

ㅁํㄴ 


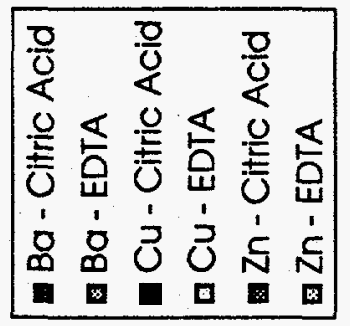

D

๘

ช

주

a

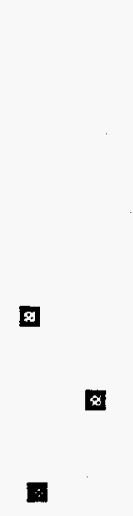

$\operatorname{lin}_{10} \frac{T}{0}$

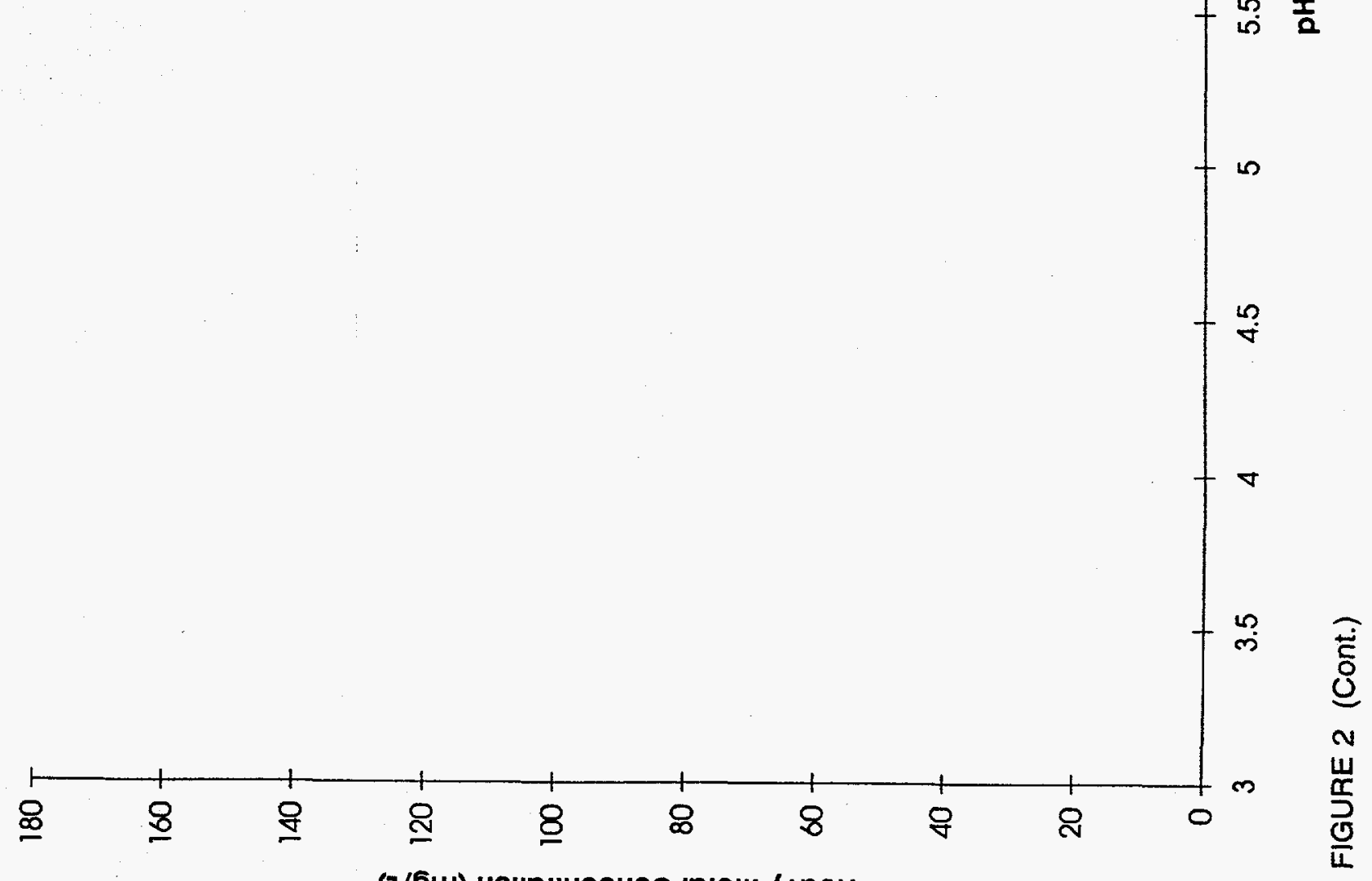

(7/6w) Uo!̣pגuəouos jofəw MDәH 


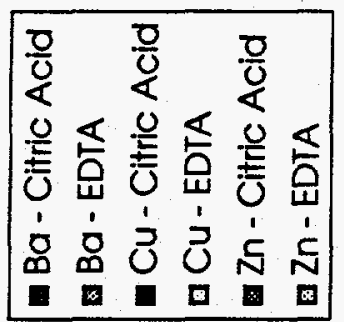

-

口

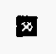

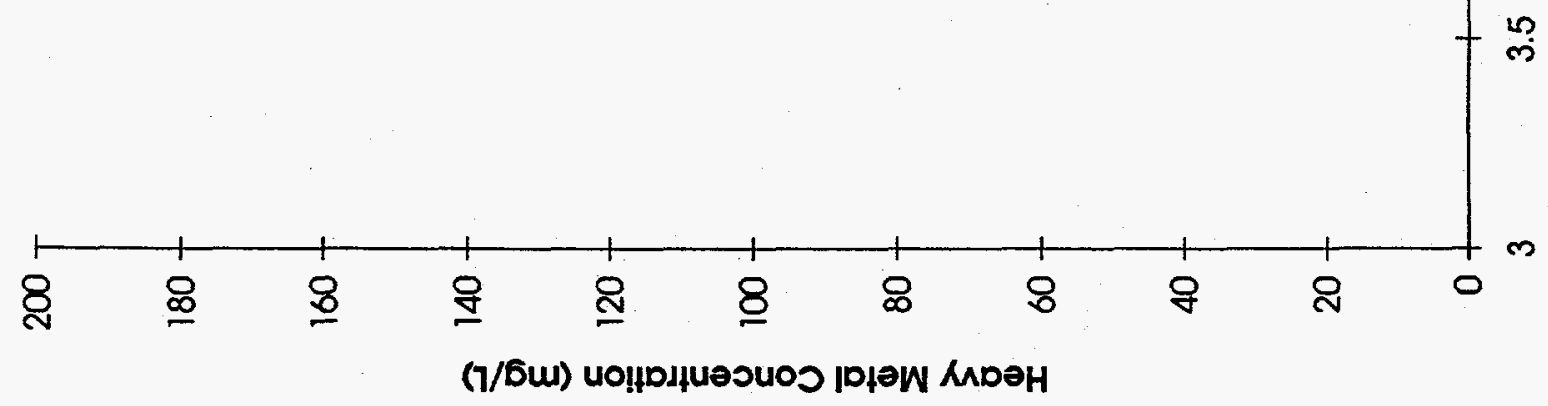

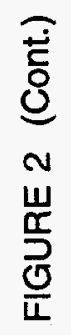




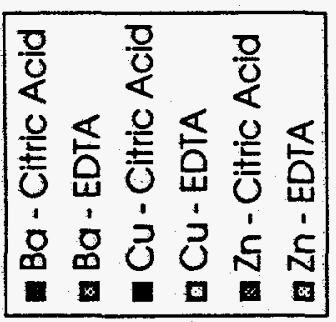

ธ
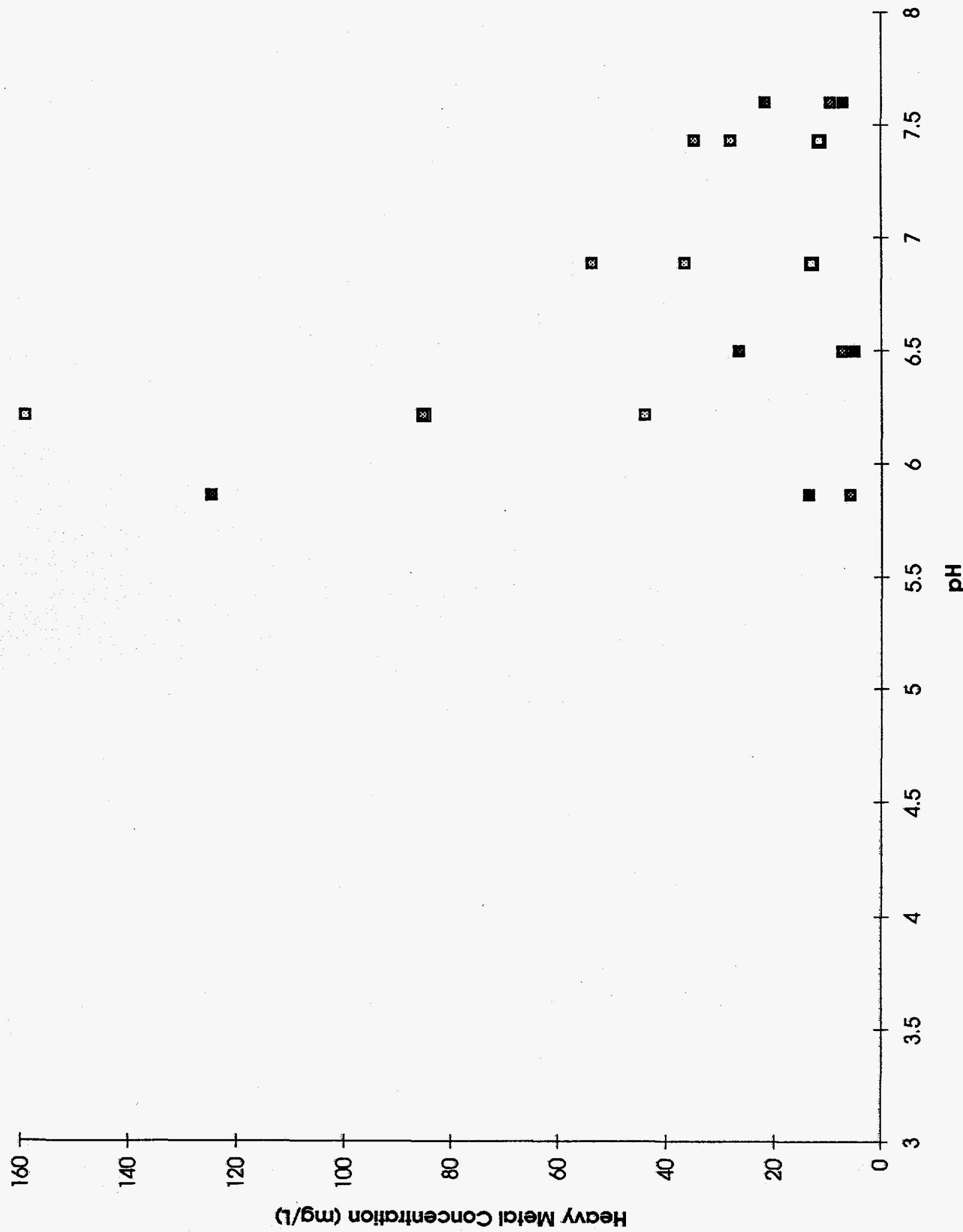

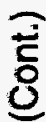

논 


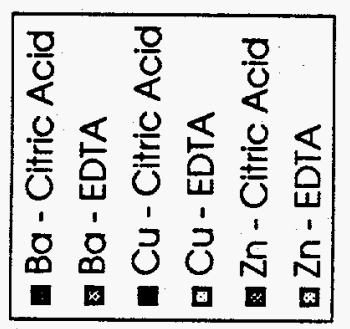

w

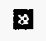

田

a

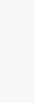




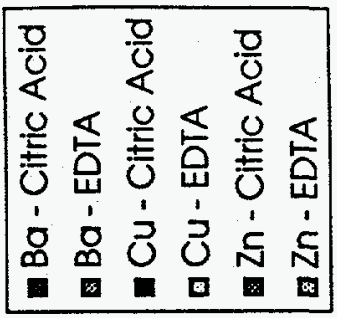

口

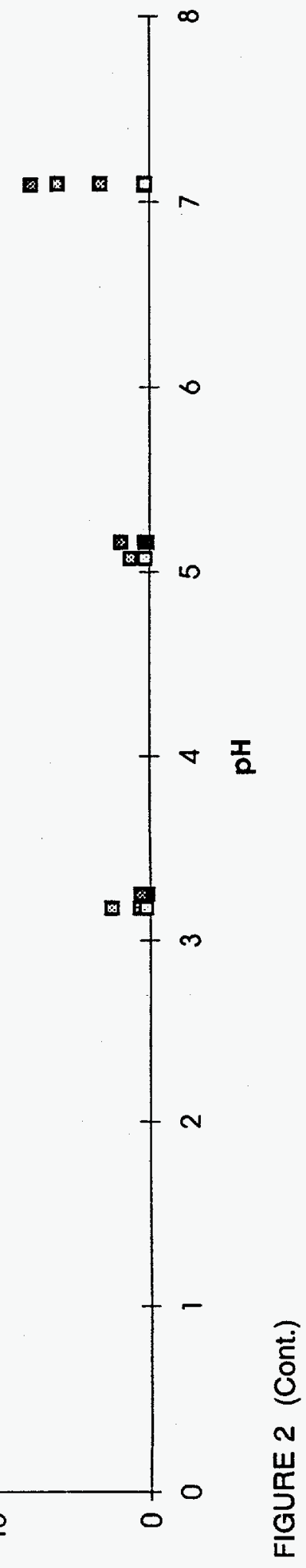

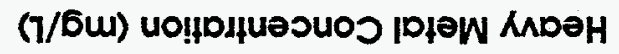


of the heavy metals increases. The data also indicate the following trends in terms of the solubilization of the heavy metals of interest:

$$
\begin{array}{ll}
\text { Citric Acid: } & \mathrm{Ba}>\mathrm{Zn}>\mathrm{Cu}>\mathrm{Cd}>\mathrm{Pb}>\mathrm{Cr} \\
\text { EDTA: } & \mathrm{Ba} \approx \mathrm{Cu}>\mathrm{Zn}>\mathrm{Pb}>\mathrm{Cd}>\mathrm{Cr}
\end{array}
$$

The amount of heavy metal solubilized was determined based upon the AAS analyses and the volume of the chelant solution applied to the soil samples in the batch shaker tests. The initial and final concentrations of heavy metals contained in samples from the hand grenade range (R111) are shown in Figures 3 and 4 (for soil samples S037, S038, S039, S041, S044, and S049) for citric acid and EDTA extraction, respectively. The data shown in Figures 3 and 4 (and listed in Appendix A) reveal the following heavy metal mobilization information, over the entire $\mathrm{pH}$ range

\begin{tabular}{|c|c|c|c|c|c|c|c|c|c|c|c|c|}
\hline \multirow[b]{2}{*}{ Analyses } & \multicolumn{6}{|c|}{ Citric Acid Extraction } & \multicolumn{6}{|c|}{ EDTA Extraction } \\
\hline & $\mathrm{Pb}$ & $\mathrm{Cd}$ & $\mathrm{Cr}$ & $\mathrm{Cu}$ & $\mathrm{Ba}$ & $\mathrm{Zn}$ & $\mathrm{Pb}$ & $\mathrm{Cd}$ & $\mathrm{Cr}$ & $\mathrm{Cu}$ & $\mathrm{Ba}$ & $\mathrm{Zn}$ \\
\hline \multicolumn{13}{|l|}{ Maximum Metal } \\
\hline $\begin{array}{r}\text { Removed, \% } \\
\text { Minimum Metal }\end{array}$ & 100 & 100 & 100 & 100 & 100 & 100 & 100 & 100 & 100 & 100 & 100 & 100 \\
\hline $\begin{array}{l}\text { Removed, \% } \\
\text { Average Metal }\end{array}$ & 15 & 2 & 69 & 100 & 11 & 3 & 100 & 22 & 70 & 100 & 11 & 7 \\
\hline $\begin{array}{l}\text { Removal, \% } \\
\text { Mean Removal at Low }\end{array}$ & 57 & 39 & 85 & 100 & 52 & 42 & 100 & 69 & 85 & 100 & 56 & 65 \\
\hline $\begin{array}{l}\mathrm{pH}(\mathrm{pH}<6), \% \\
\text { Mean Removal at High }\end{array}$ & 61 & 56 & 85 & 100 & 75 & 41 & 100 & 81 & 85 & 100 & 77 & 64 \\
\hline $\mathrm{pH}(\mathrm{pH}>7), \%$ & 59 & 14 & 85 & 100 & 47 & 48 & 100 & 54 & 85 & 100 & 36 & 61 \\
\hline
\end{tabular}
studied:

These data confirm the information presented earlier. EDTA extraction generally performed slightly better than citric acid extraction, with average heavy metal removal rates ranging from 56 to $100 \%$ for EDTA extraction and 39 to $100 \%$ for citric acid extraction. The data shown in Figures 3 and 4 indicate that batch shaker chelant extraction does offer promise as a technique to clean up heavy-metal-contaminated soils. However, the proper chelant concentration needs to be determined from optimization studies to achieve maximum heavy metal removal.

\subsection{Columnar Flooding Tests}

In the columnar flooding studies, deionized water and chelating agent solution were percolated through the soil columns. As mentioned earlier, five pore volumes of deionized water were first passed through the soil column, then approximately eight pore volumes of chelant 


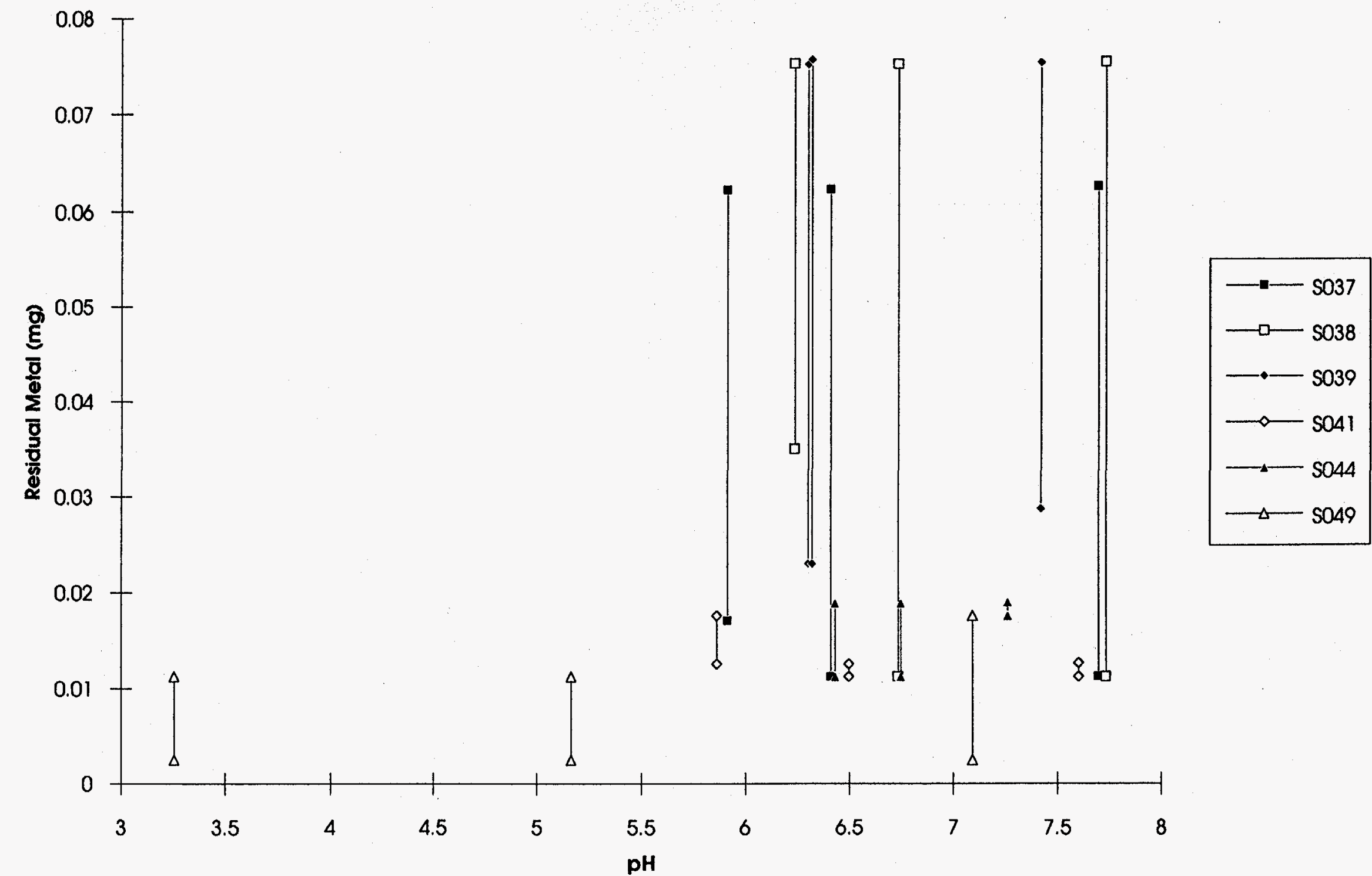

FIGURE 3 Initial and Final Heavy Metals Concentrations from Six Soil Samples as a Function of pH for Batch Chelant Extraction of $\mathrm{Pb}, \mathrm{Cd}, \mathrm{Cr}, \mathrm{Cu}, \mathrm{Ba}$, and $\mathrm{Zn}$, Using 0.01M Citric Acid 


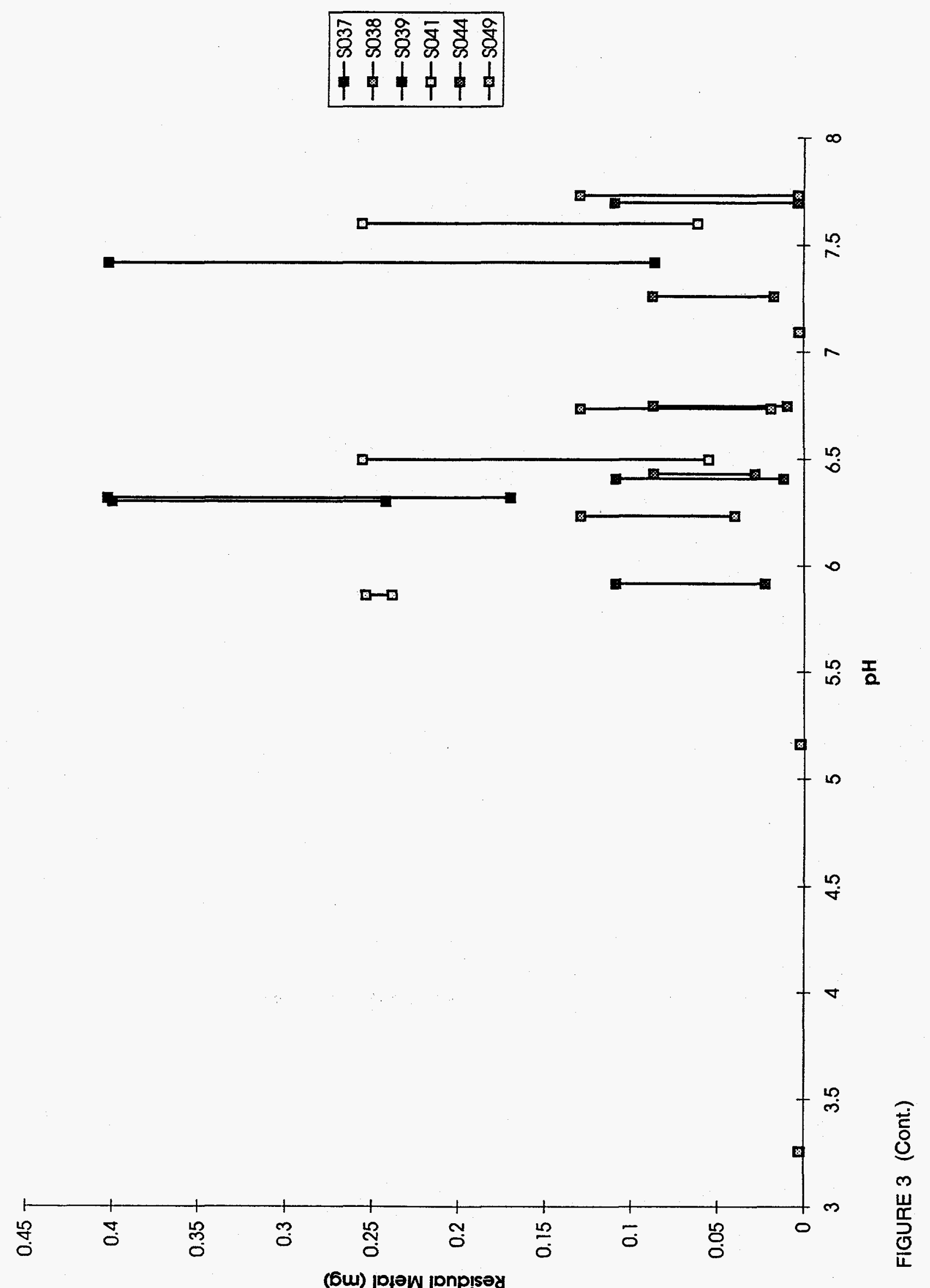



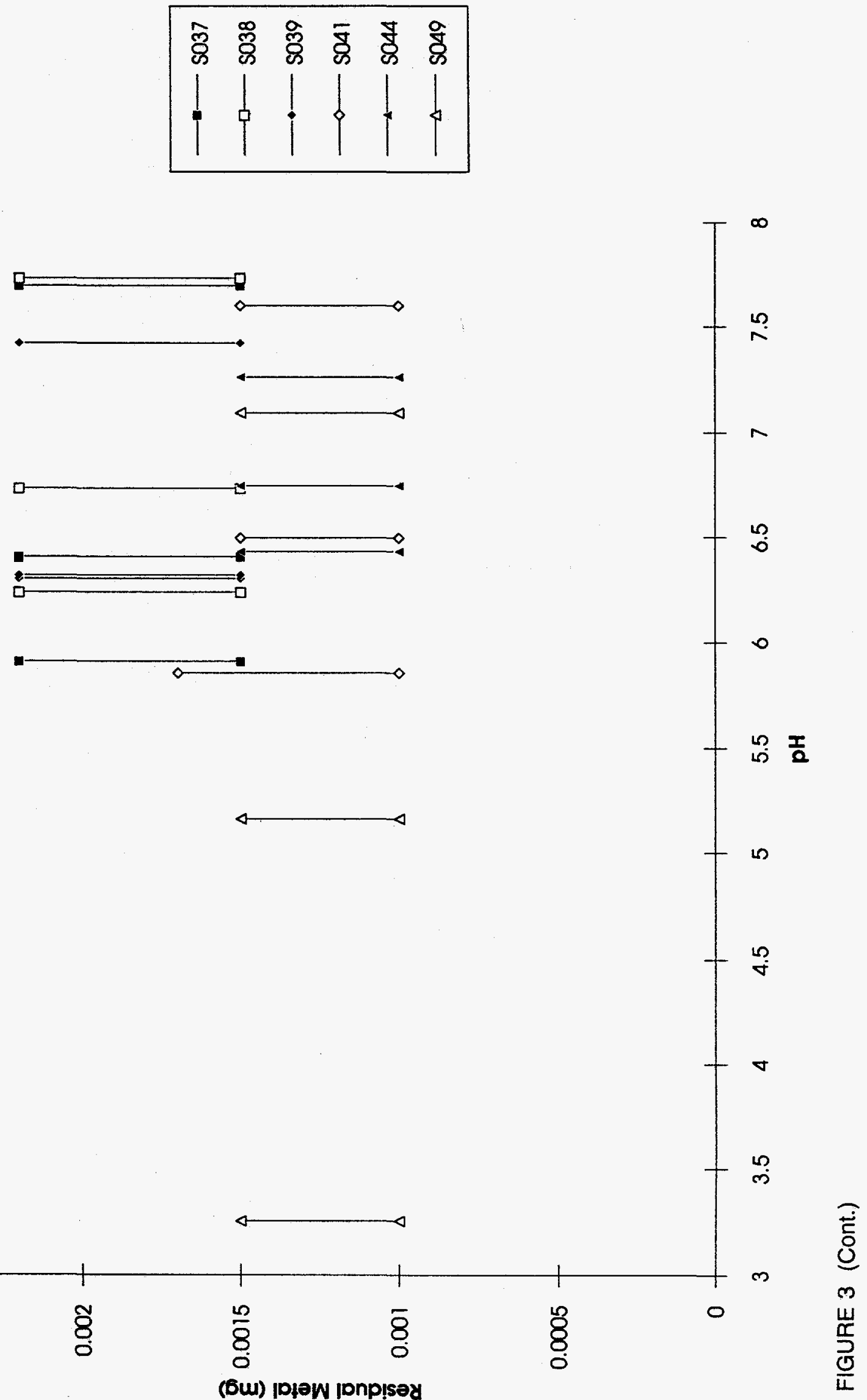

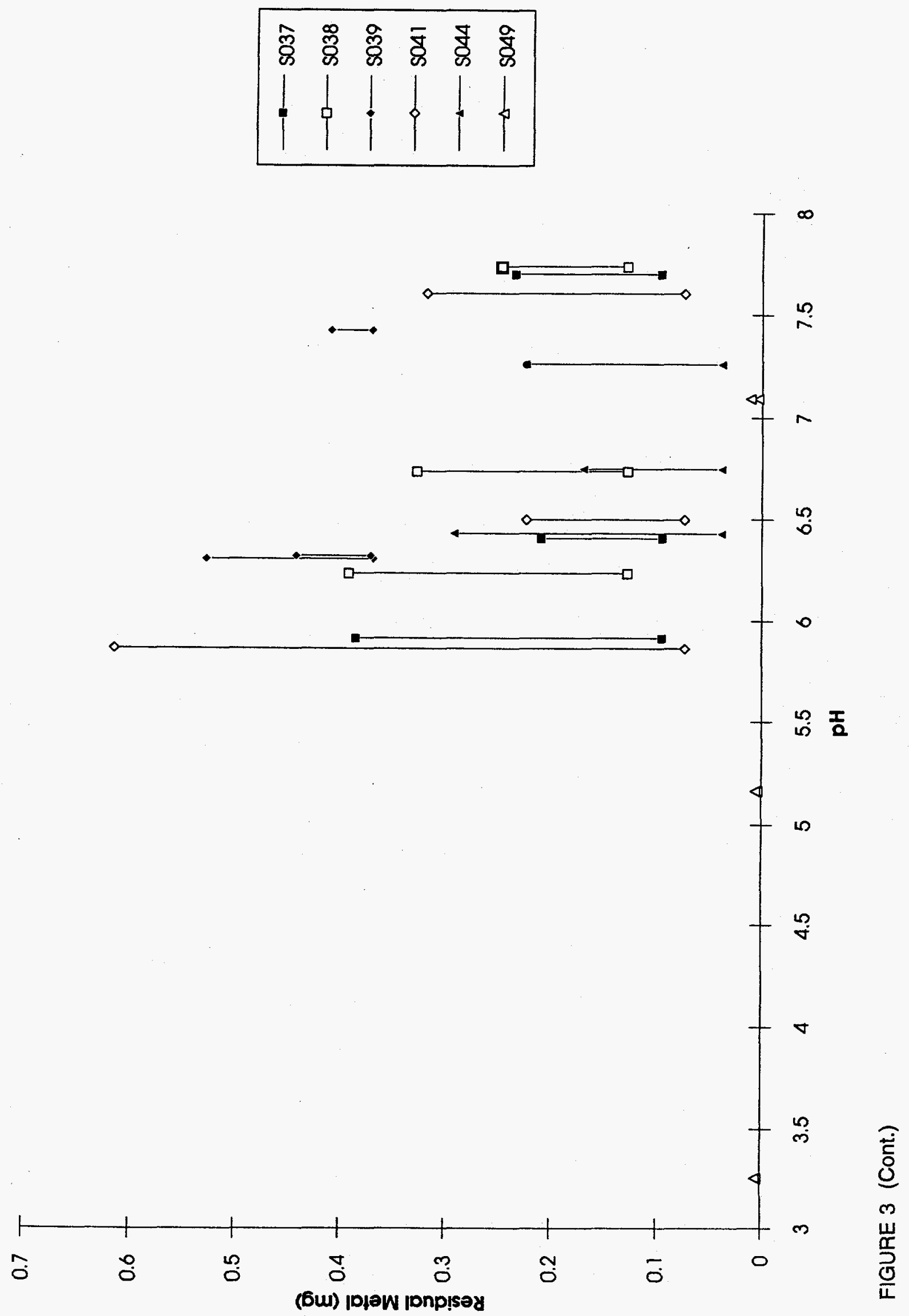

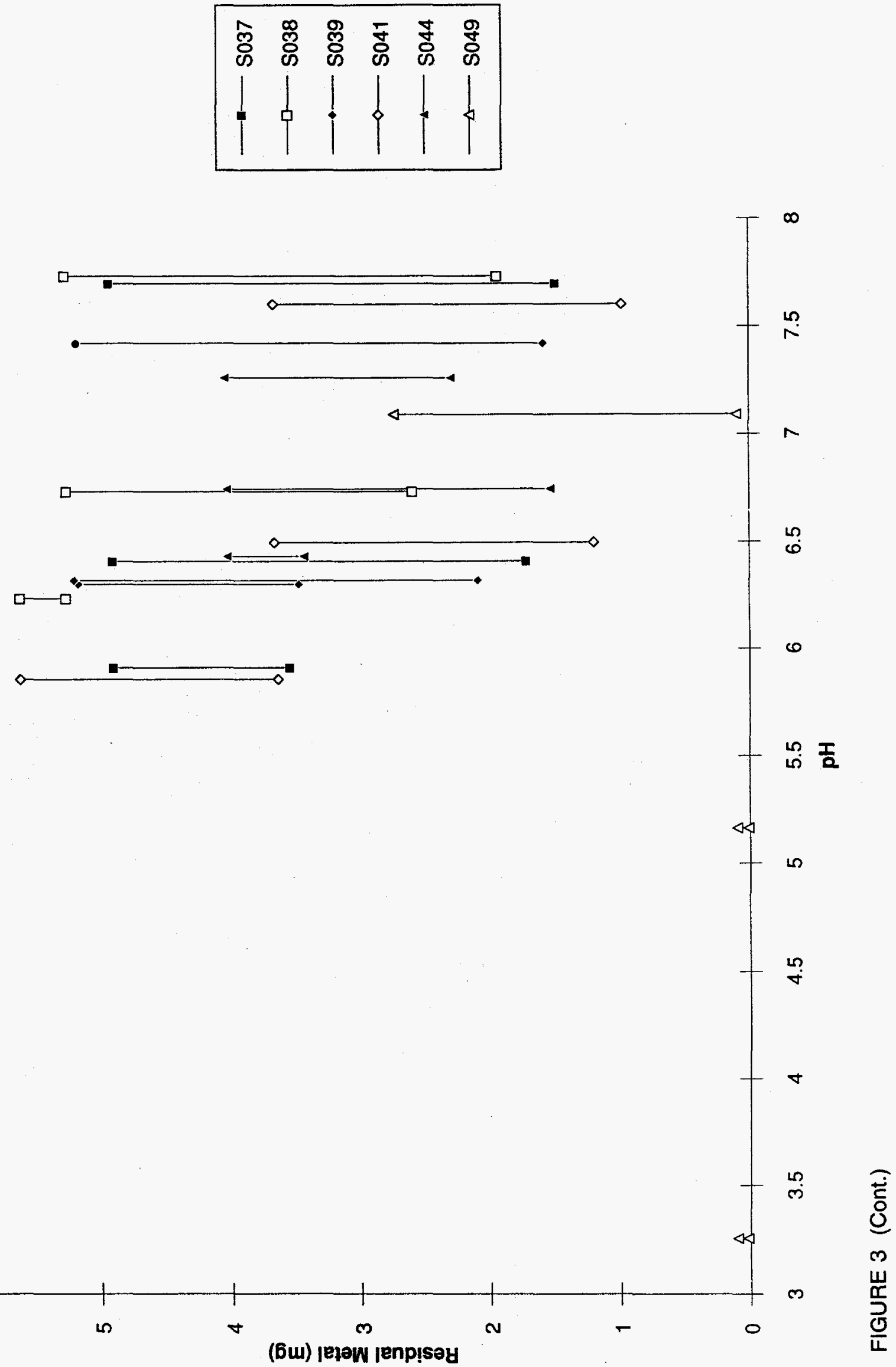

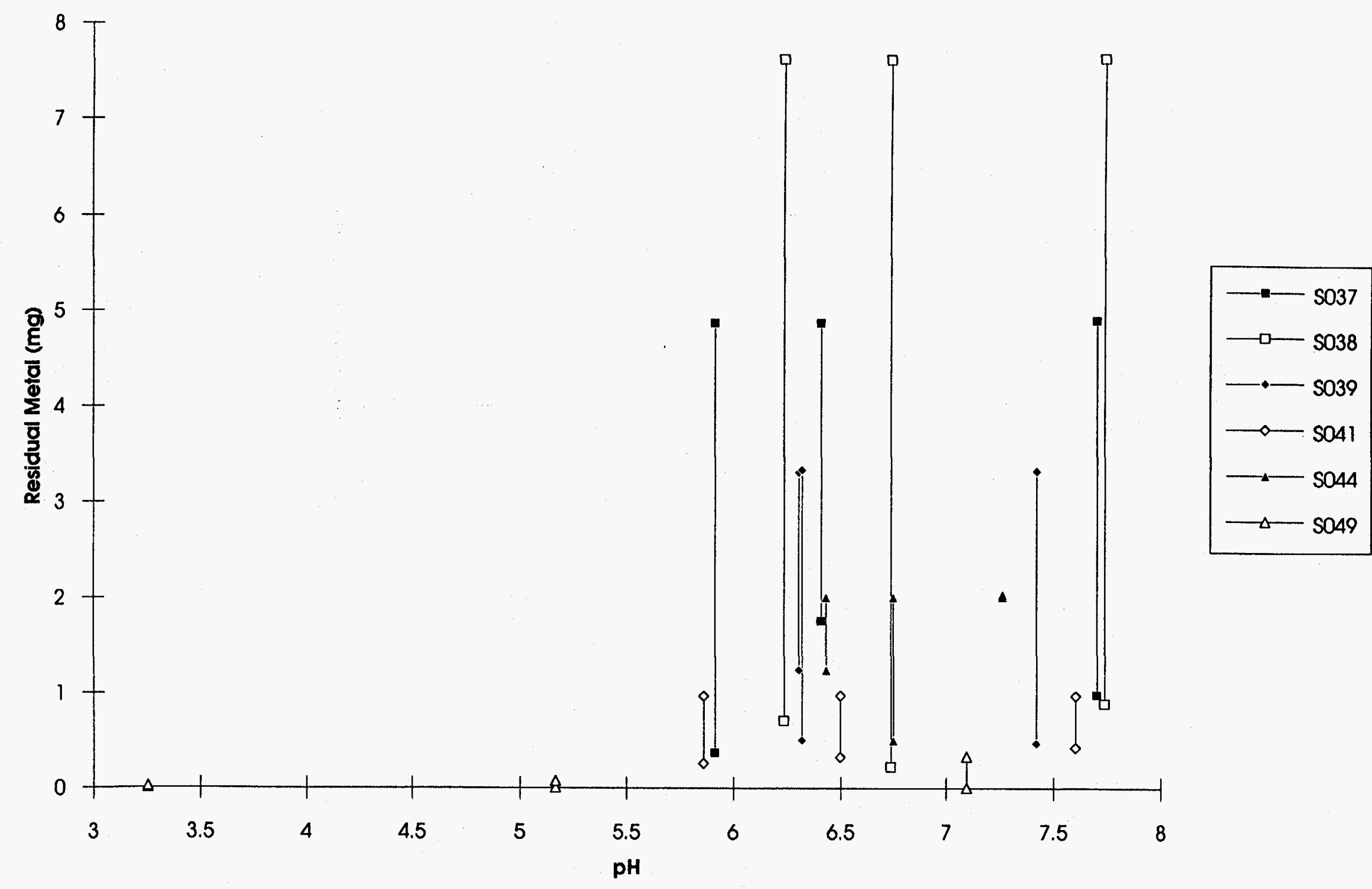

FIGURE 3 (Cont.) 


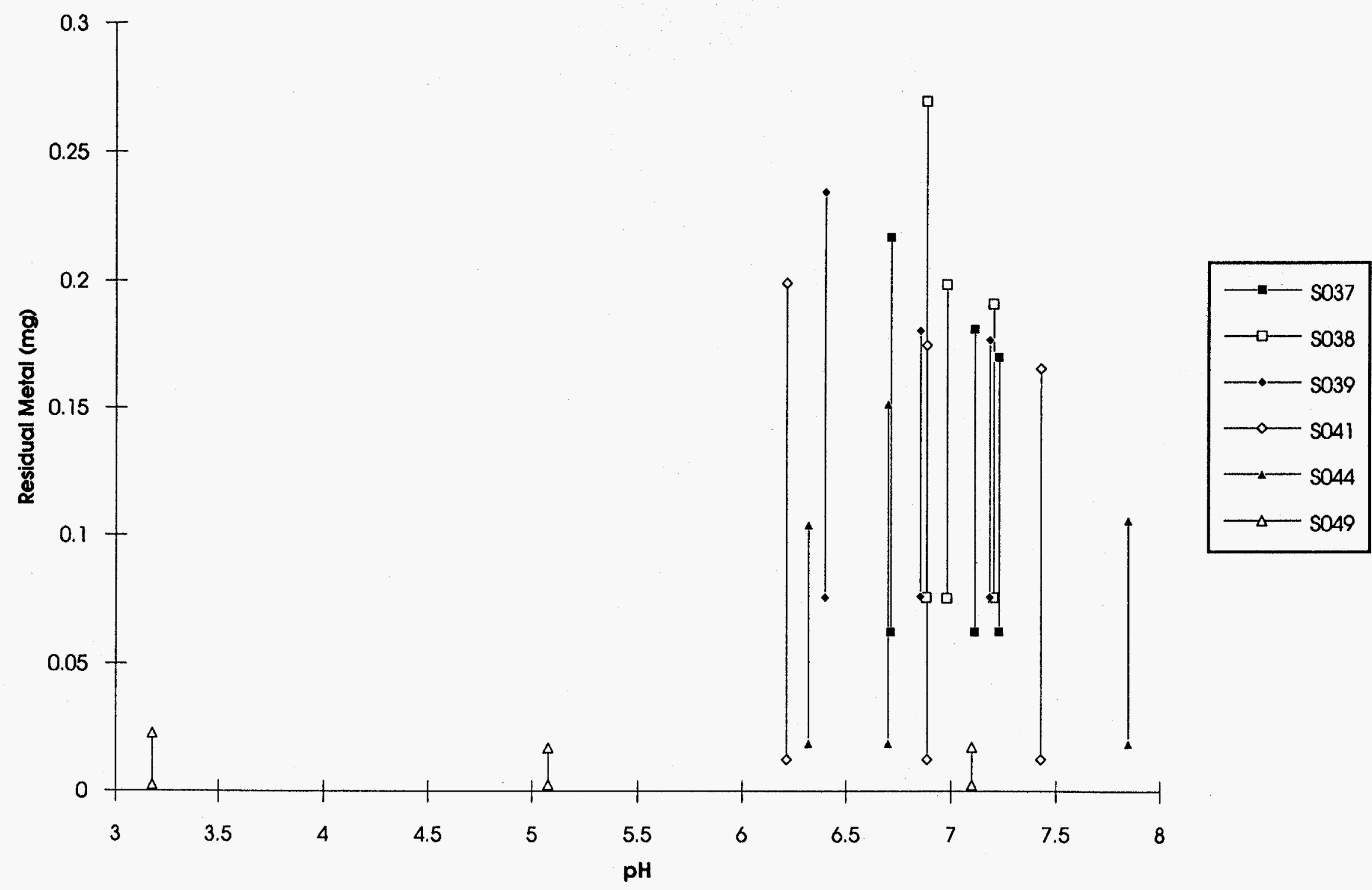

FIGURE 4 Initial and Final Heavy Metals Concentrations from Six Soil Samples as a Function of pH for Batch Chelant Extraction of $\mathrm{Pb}, \mathrm{Cd}, \mathrm{Cr}, \mathrm{Cu}, \mathrm{Ba}$, and $\mathrm{Zn}$, Using 0.01M EDTA 


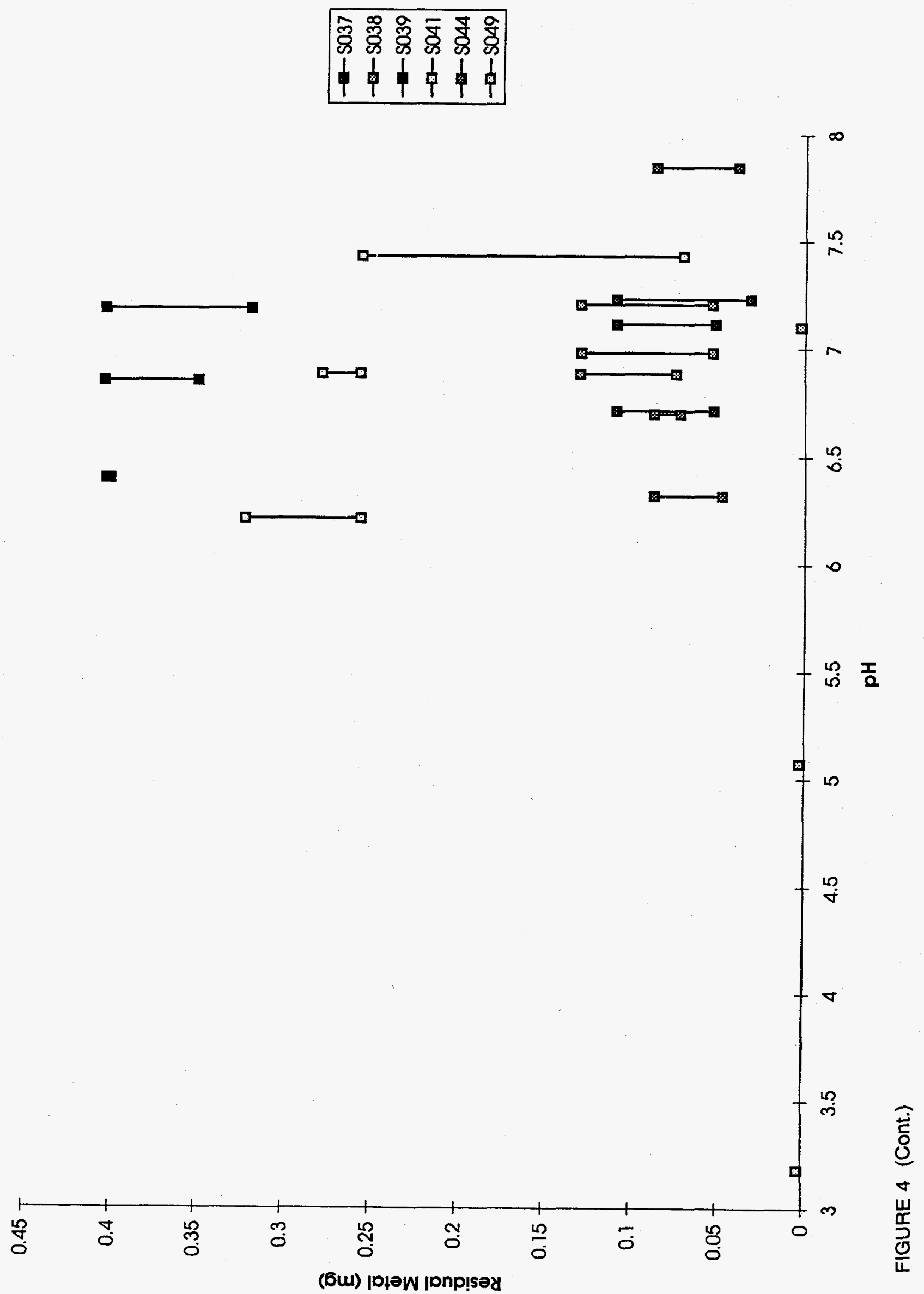




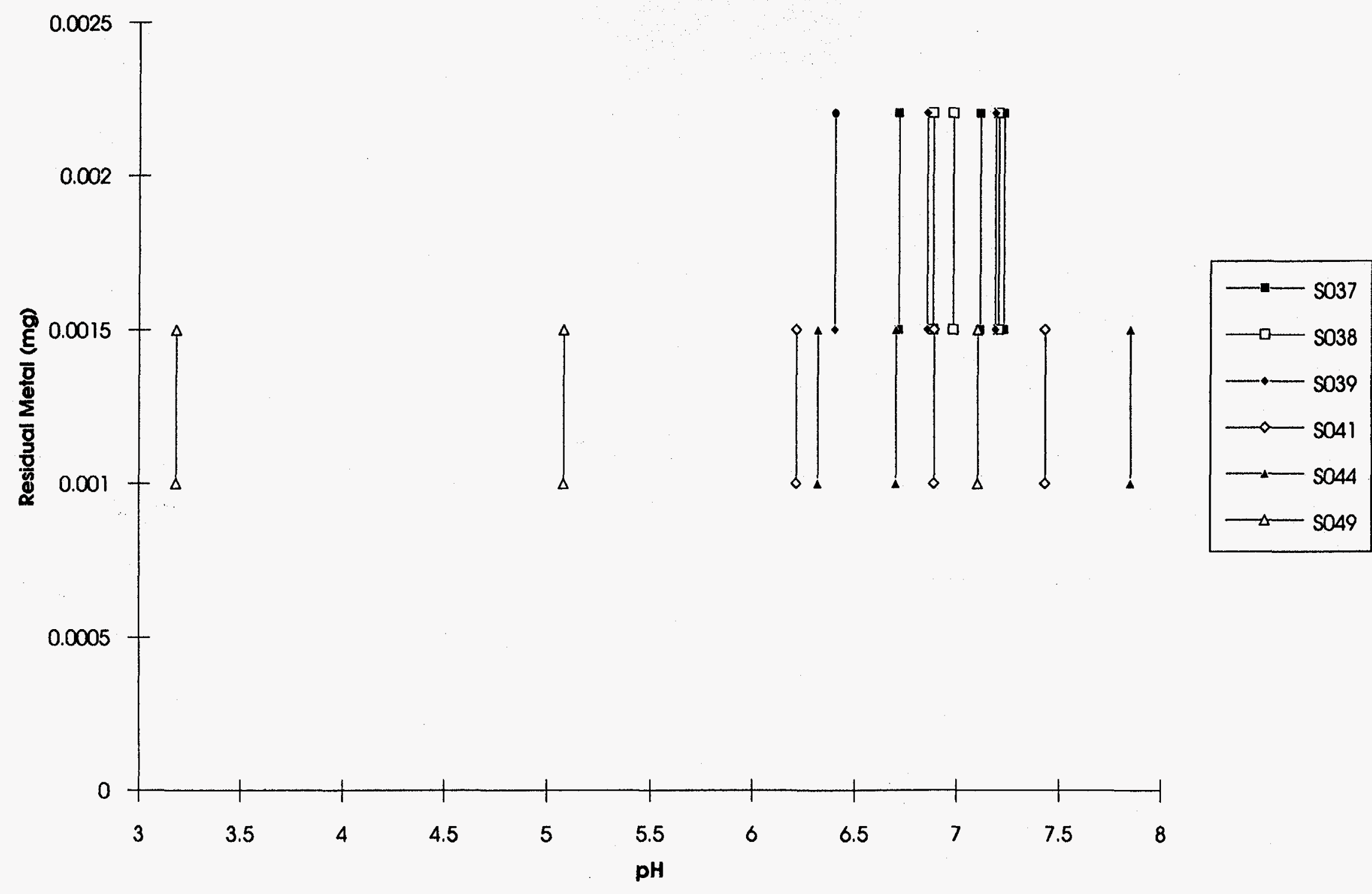

FIGURE 4 (Cont.) 

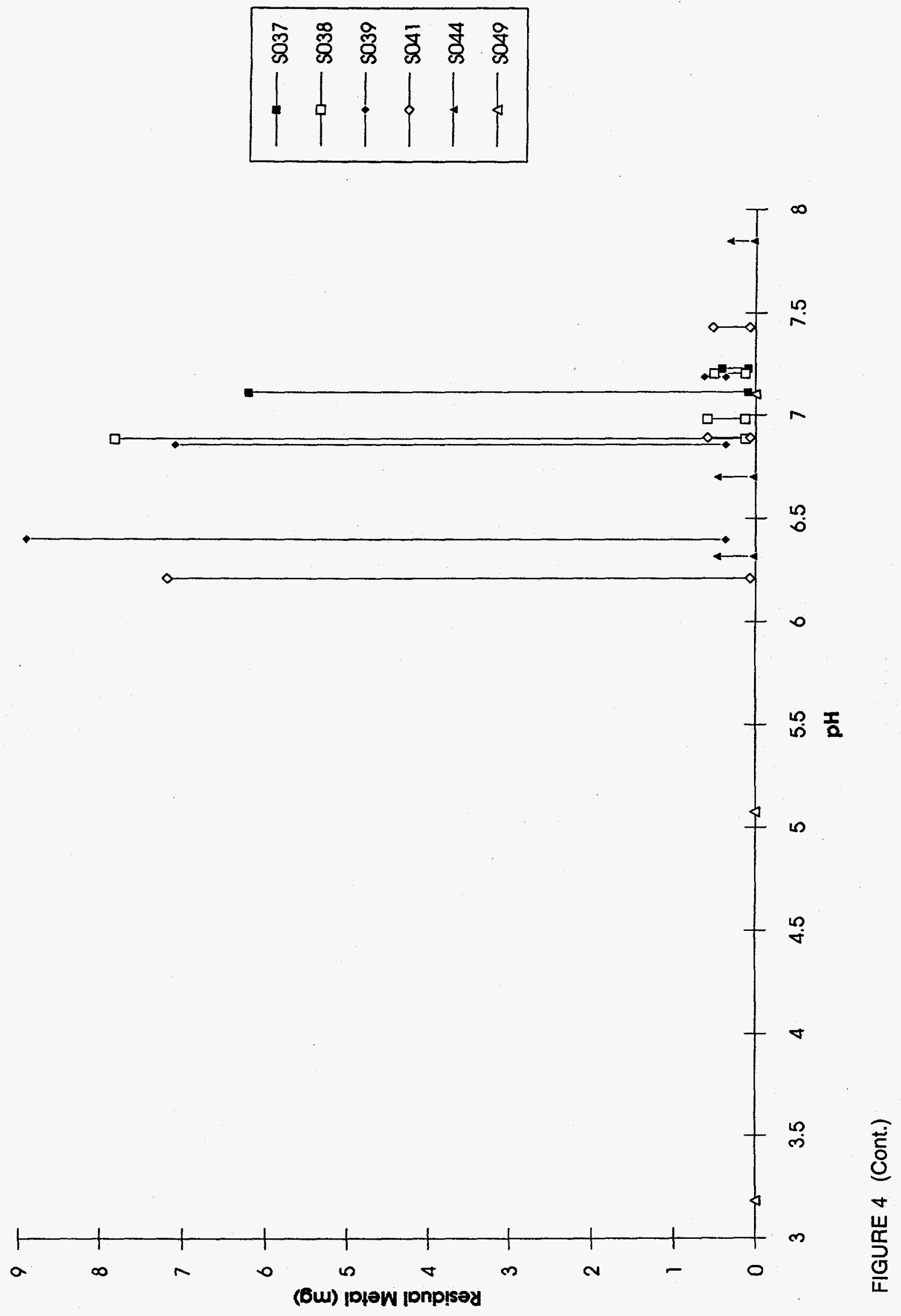

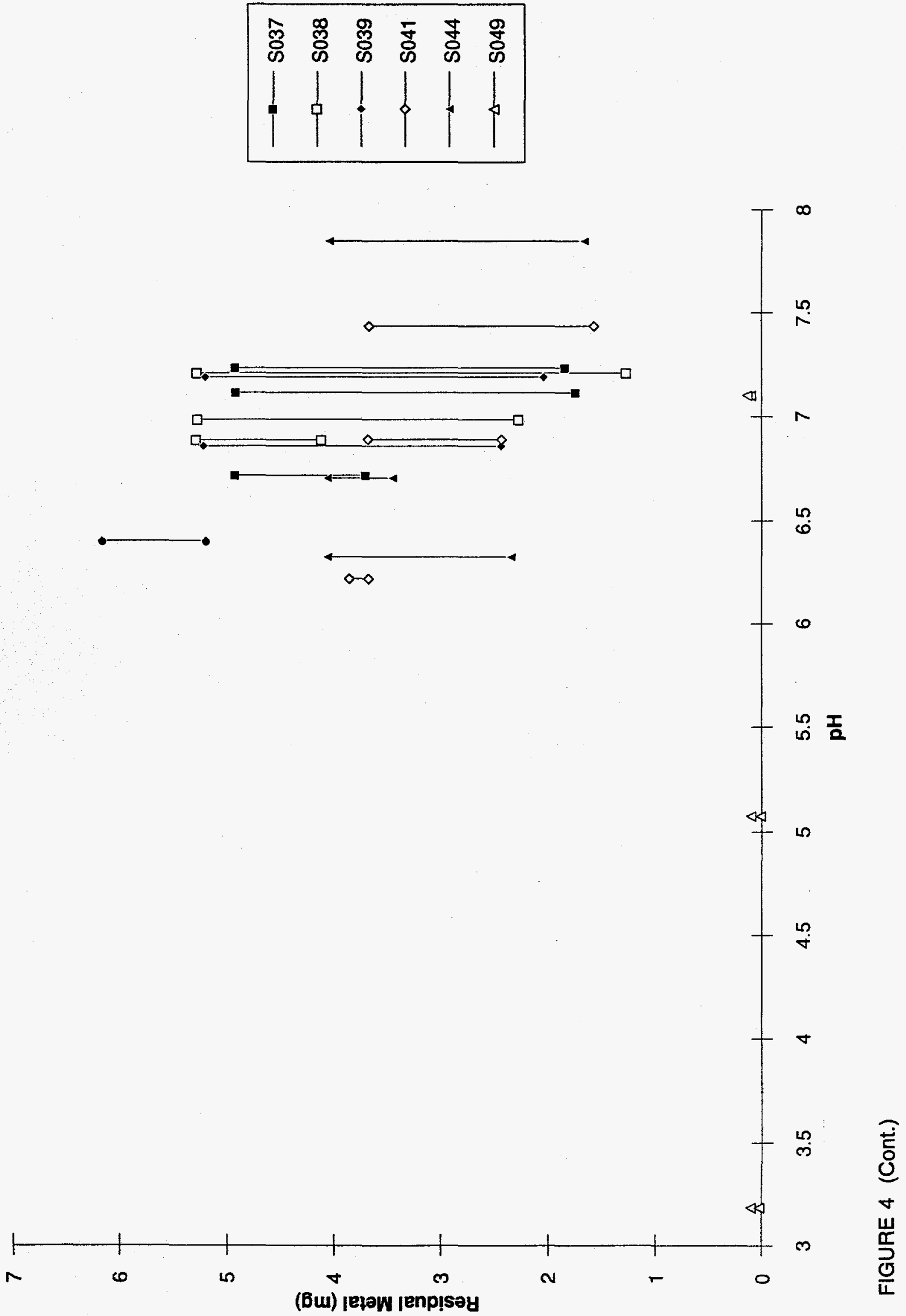

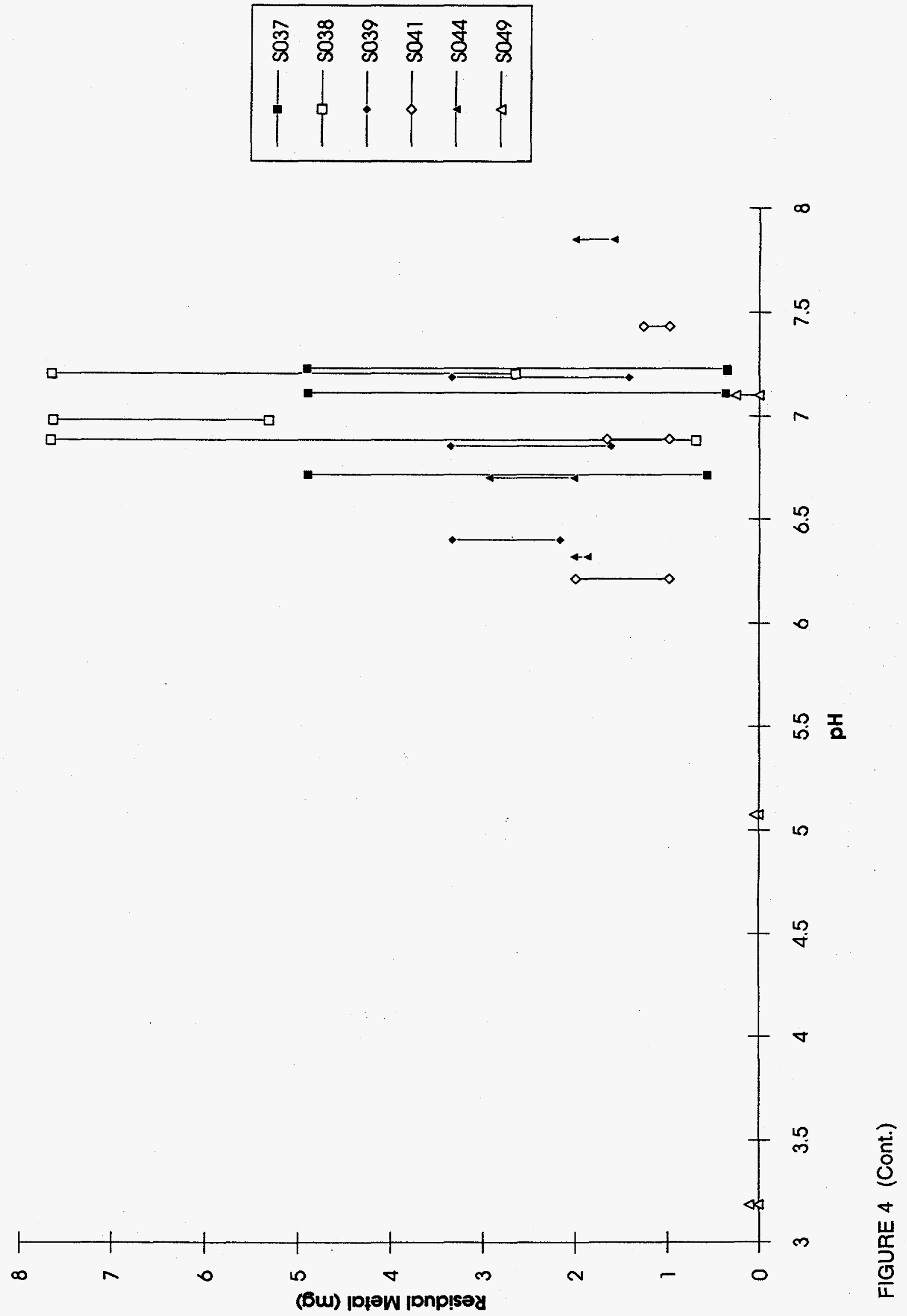
solution $(0.05 \mathrm{M})$ were passed through. Because of the limited number of soil samples available, several samples were combined in order to provide the approximately $300 \mathrm{~g}$ of soil needed to perform the columnar flow experiment. Results of the columnar flow studies are shown in Figures 5 through 9 for lead, cadmium, copper, iron, and zinc, respectively. ${ }^{3}$ Results from these experiments are summarized below:

\begin{tabular}{lcccccc}
\hline & \multicolumn{7}{c}{ Heavy Metal } \\
\cline { 2 - 7 } \multicolumn{1}{c}{ Analyses } & $\mathrm{Pb}$ & $\mathrm{Cd}$ & $\mathrm{Cr}$ & $\mathrm{Cu}$ & $\mathrm{Fe}$ & $\mathrm{Zn}$ \\
\hline & & & & & & \\
Average Removal, \% & & & & & & \\
Deionized Water & 0.31 & 3.72 & 1.60 & 3.72 & 0.03 & 1.69 \\
Citric Acid & 4.25 & 11.1 & 2.37 & 8.96 & 0.39 & 10.6 \\
EDTA & 17.6 & 13.0 & 2.80 & 1.41 & 0.51 & 4.87 \\
Removal Range, \% & $0.0-$ & $0.1-$ & $0.5-$ & $0.0-$ & $0.0-$ & $0.5-$ \\
& 50.6 & 34.7 & 6.6 & 16.0 & 0.5 & 24.0 \\
Most Effective & EDTA & $(\mathrm{a})$ & (a) & CIT & $(\mathrm{a})$ & $\mathrm{CIT}$ \\
Treatment Method & & & & & & \\
\hline
\end{tabular}

Notes: (a) denotes that both EDTA and citric acid (CIT) are equally effective at removing this heavy metal.

Appendix $B$ gives detailed information on the amounts of heavy metals removed.

Appendix $\mathrm{C}$ gives detailed information on the percentages of heavy metals removed.

\subsection{Leaching Tests}

As noted earlier (Table 3), the groundwater in the Grafenwöhr, Germany, area showed no major heavy metal contamination.

Extraction with deionized water indicated that all of the heavy metals are very tightly bound to the soil. The quantity of heavy metals leached into solution was generally less than $1.7 \%$ of the total amount of heavy metals contained in the soil sample.

The deionized water extraction results indicate that the heavy metals are very stable in the soils at the GTA and do not represent a serious threat to the groundwater system.

3 Chromium results are not graphically displayed because they exhibited a consistent two-level plot caused by concentrations near the lower limit of detection. 


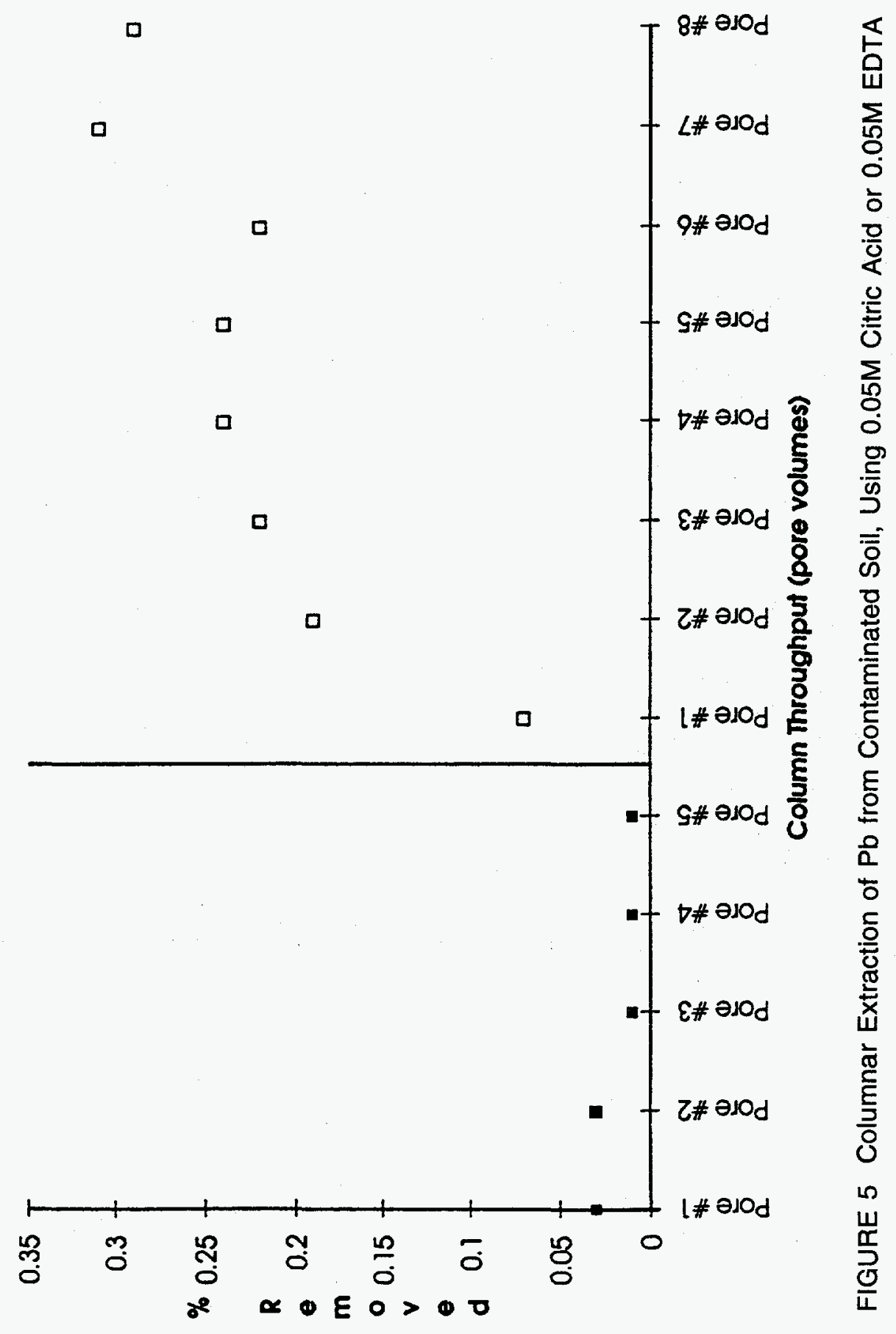



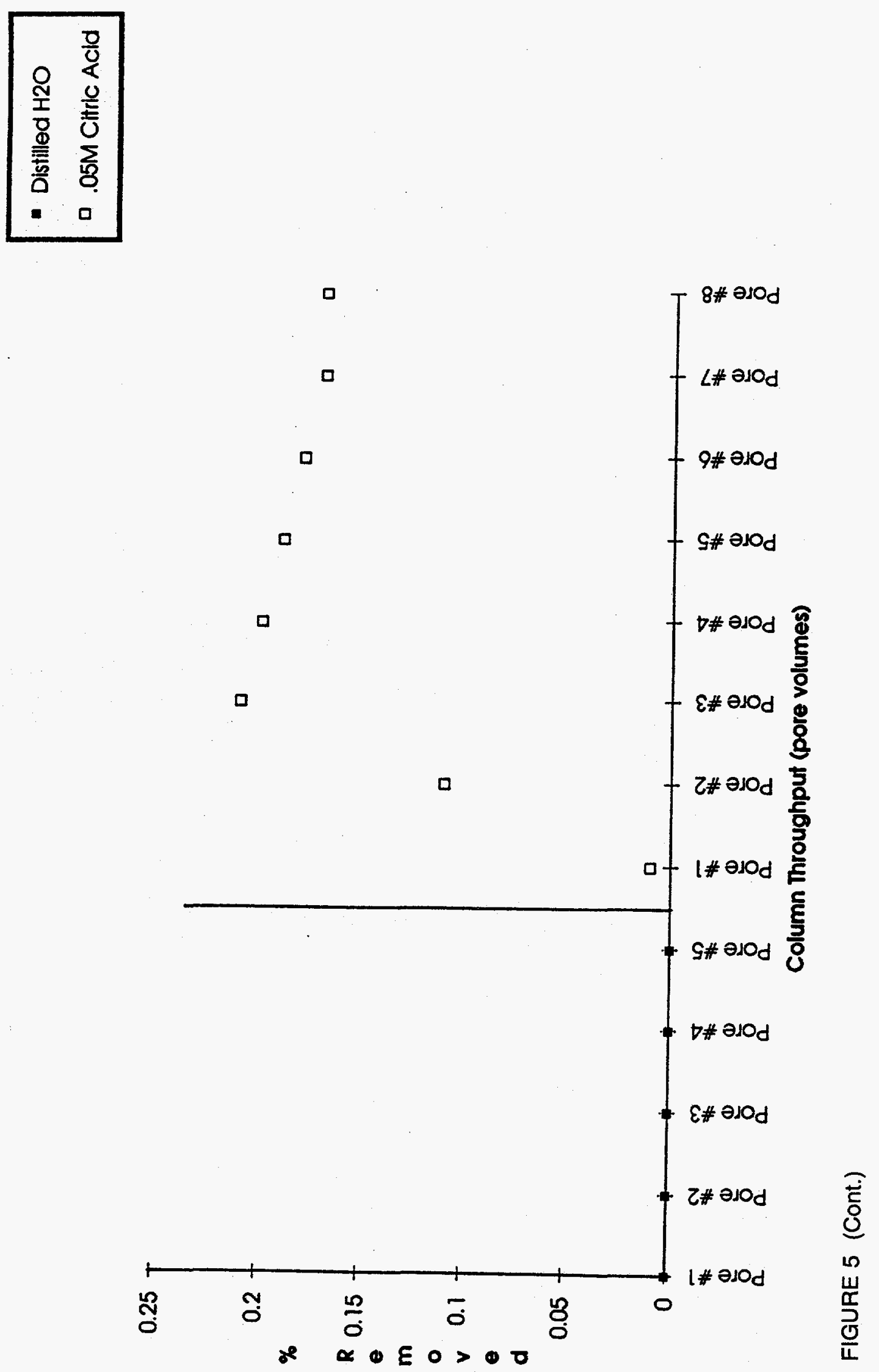

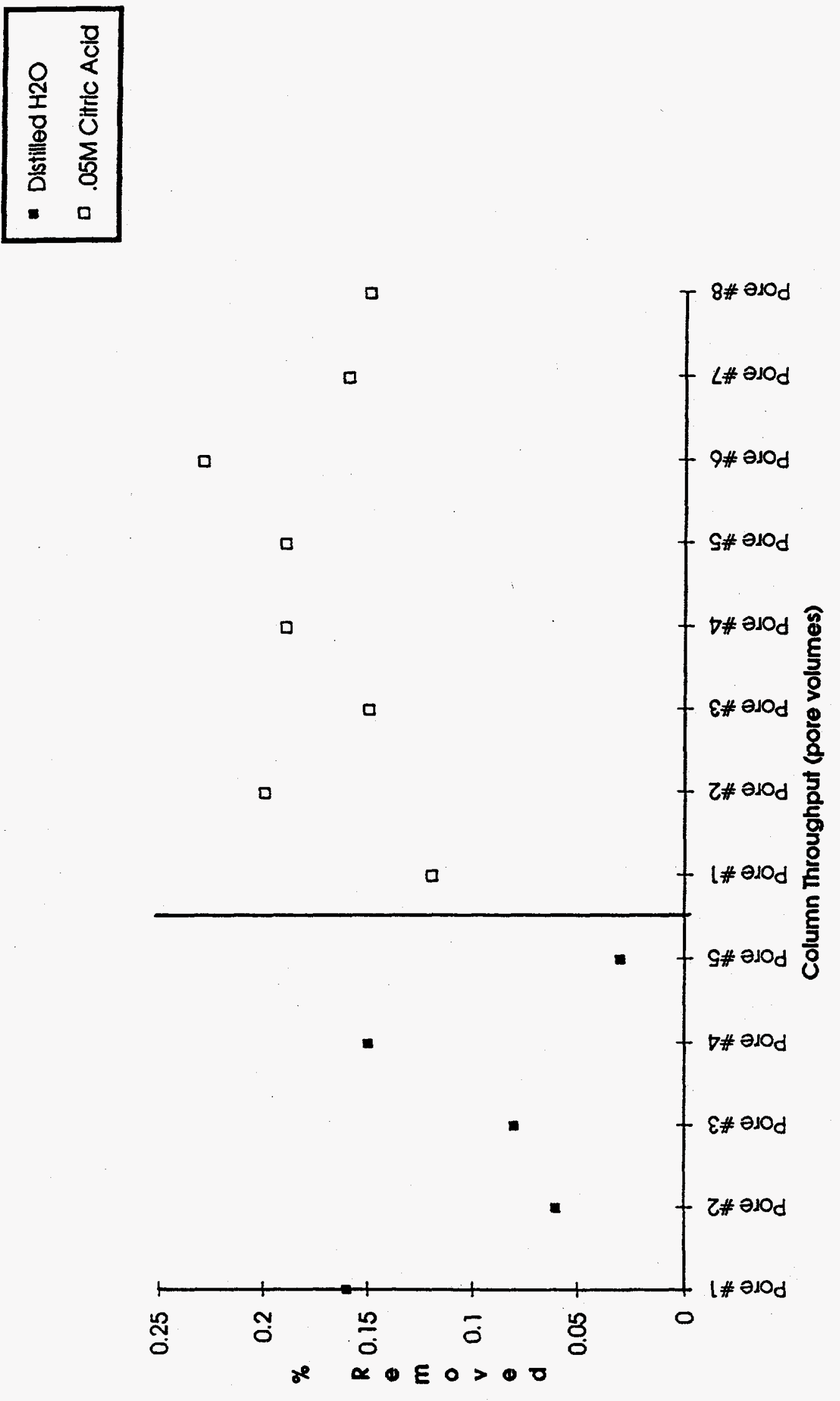

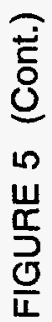



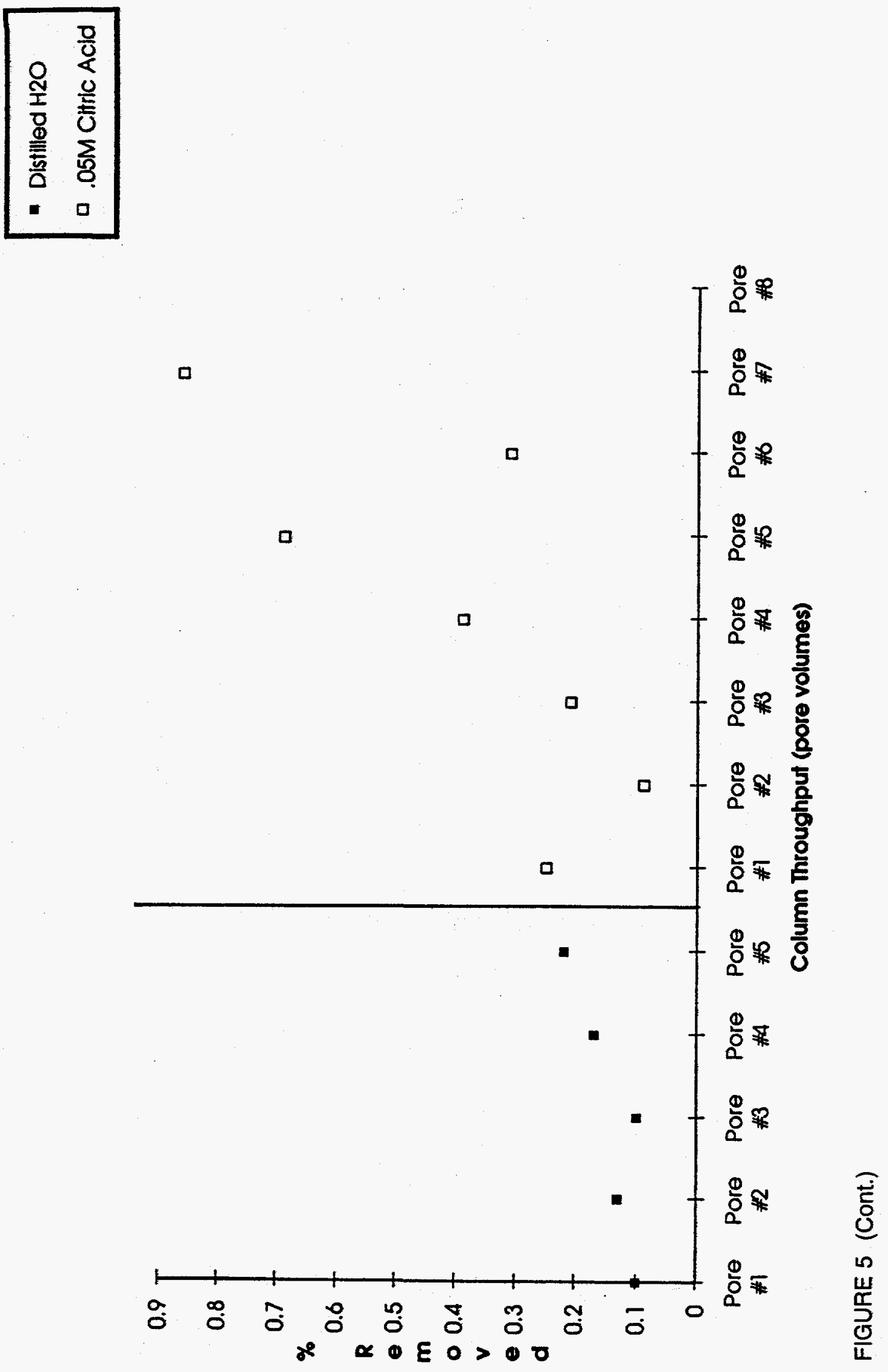

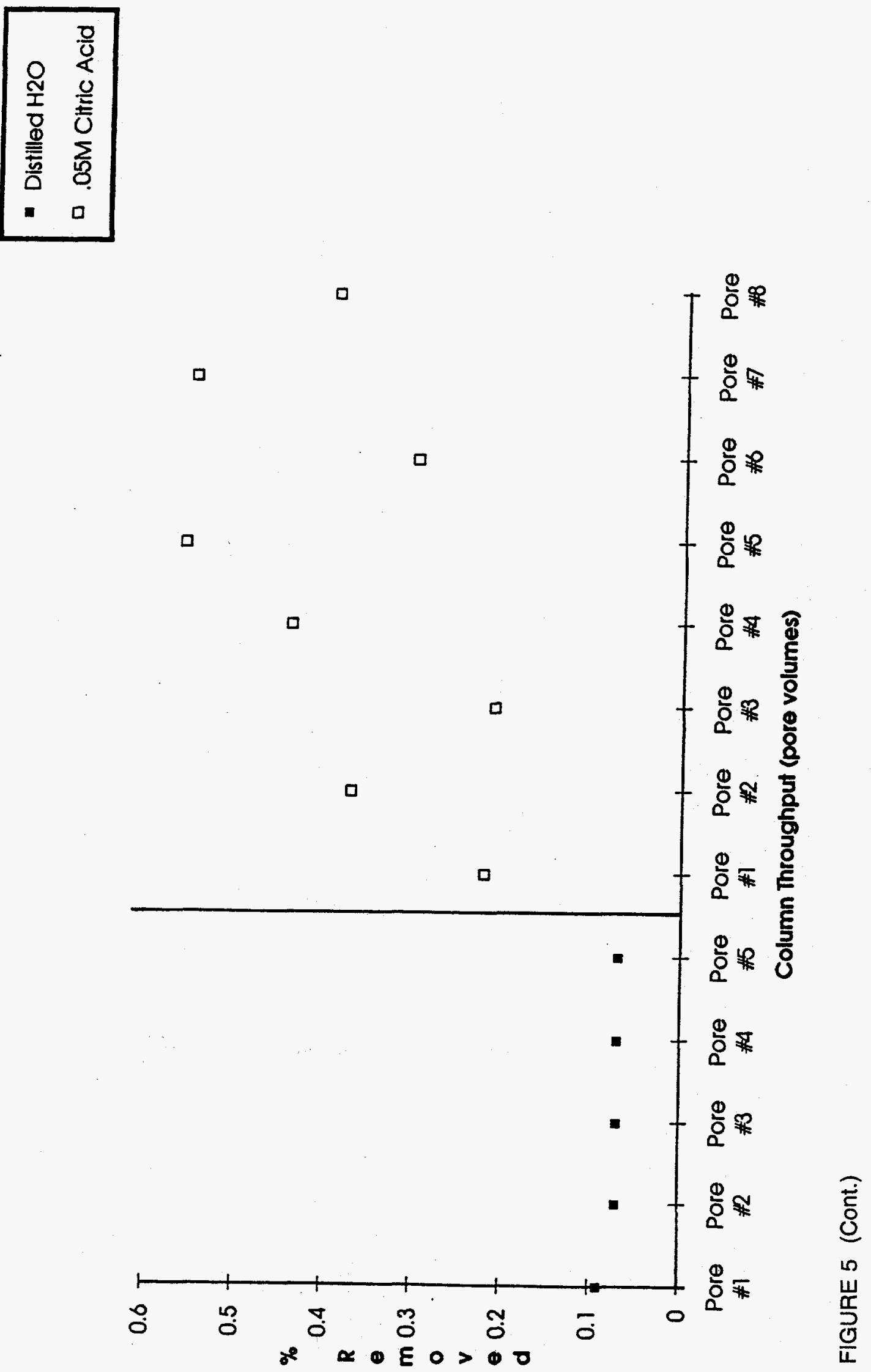


\section{- Distilled H2O \\ 口. O5M EDTA}

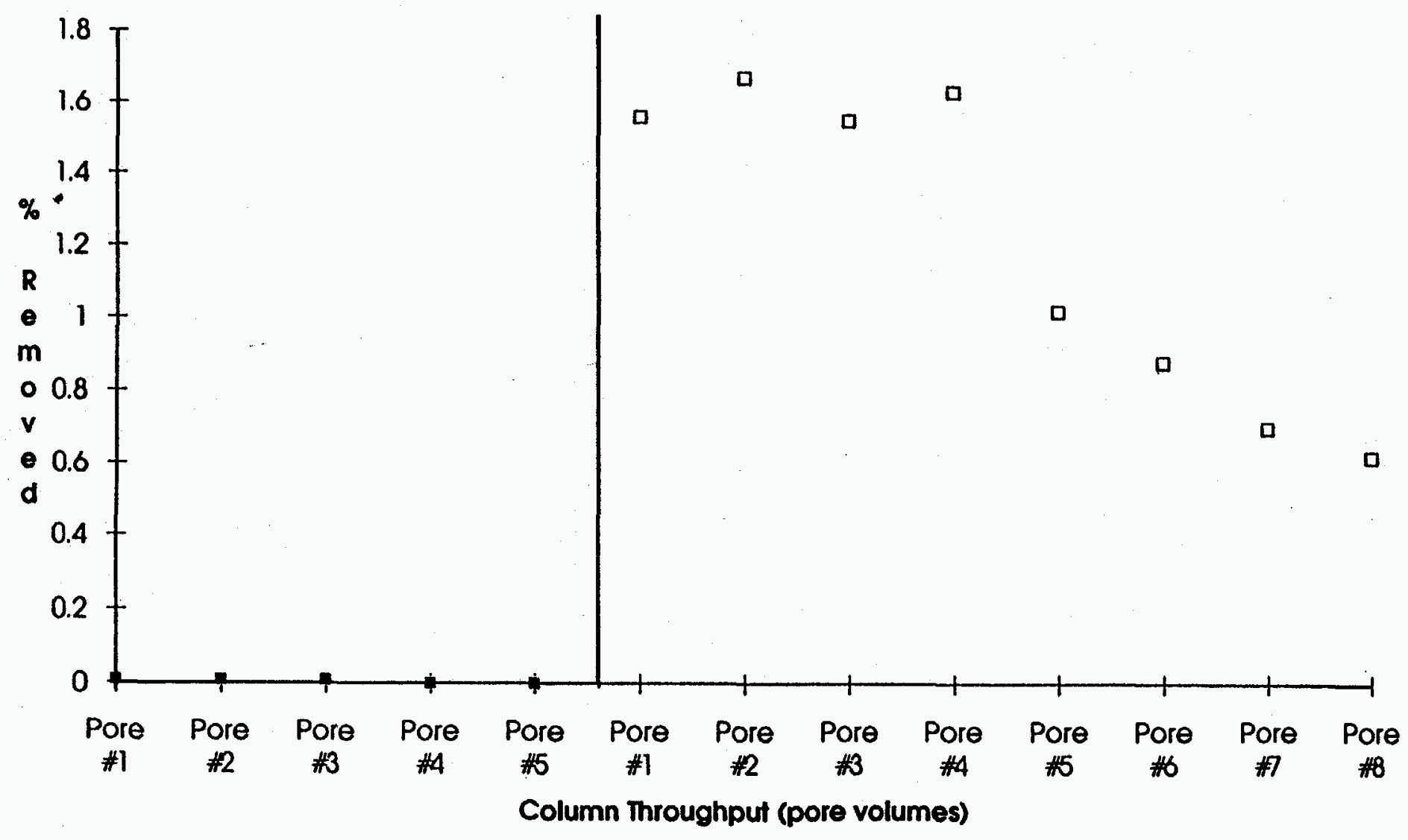

FIGURE 5 (Cont.) 

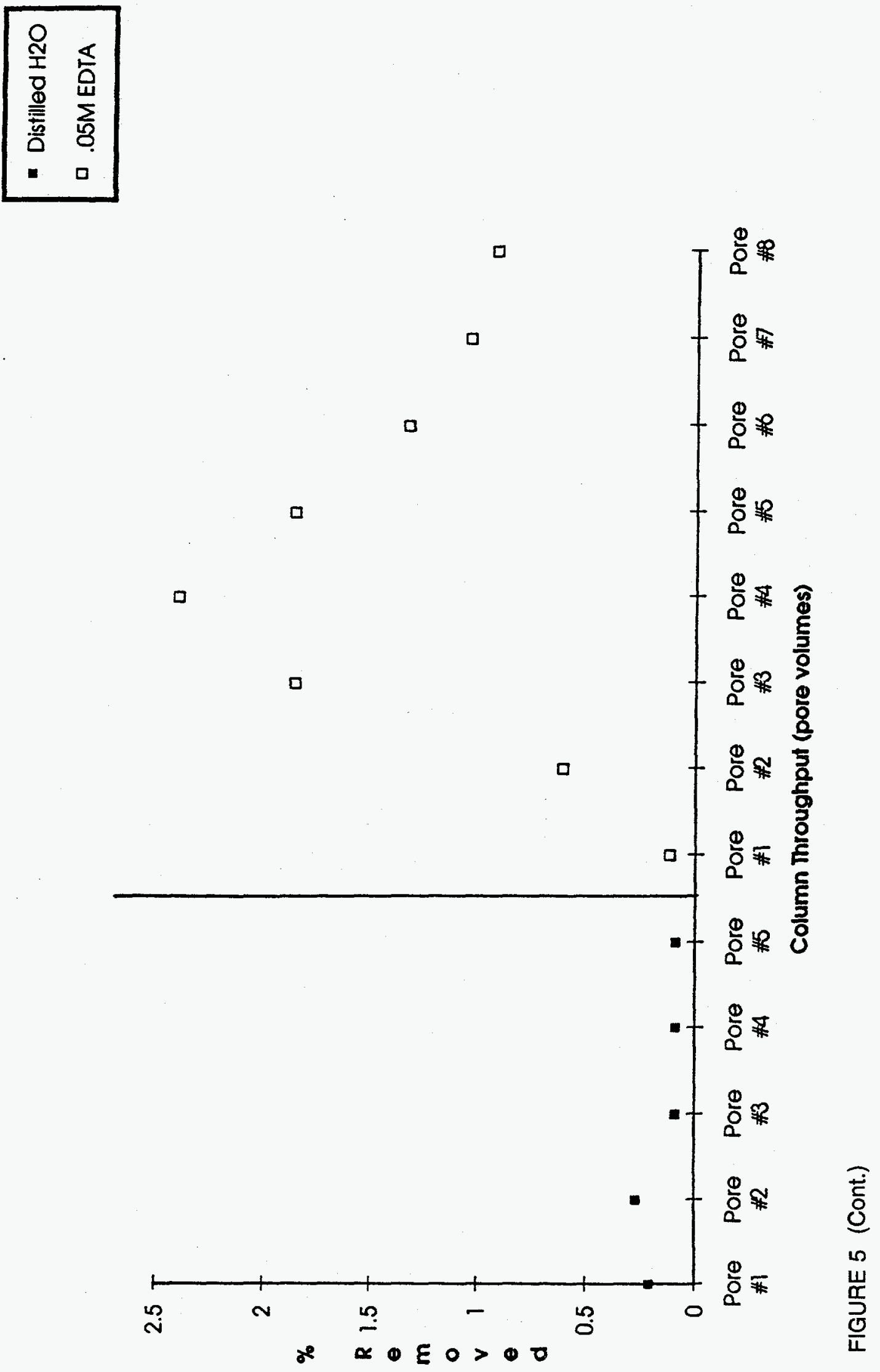

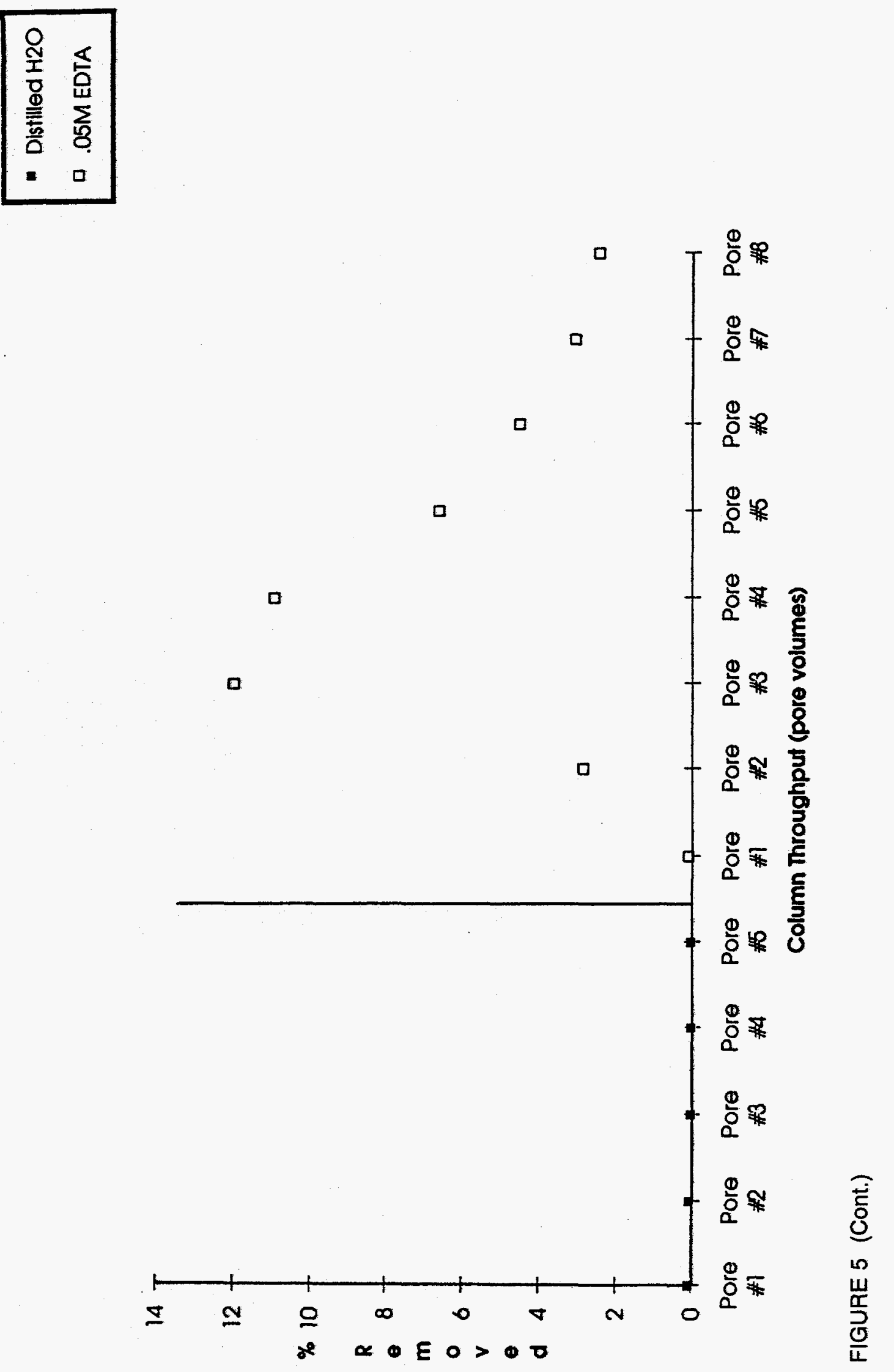

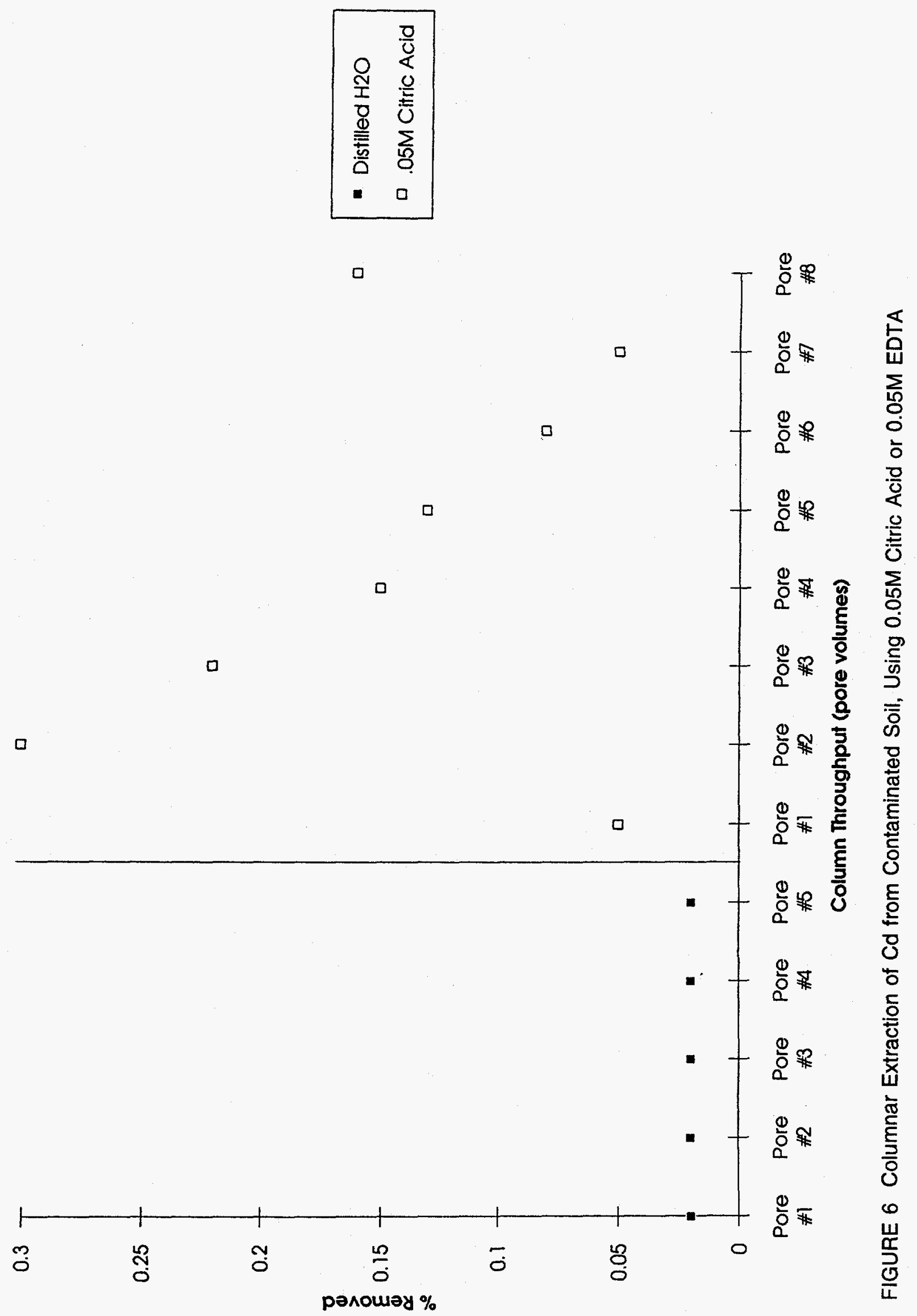


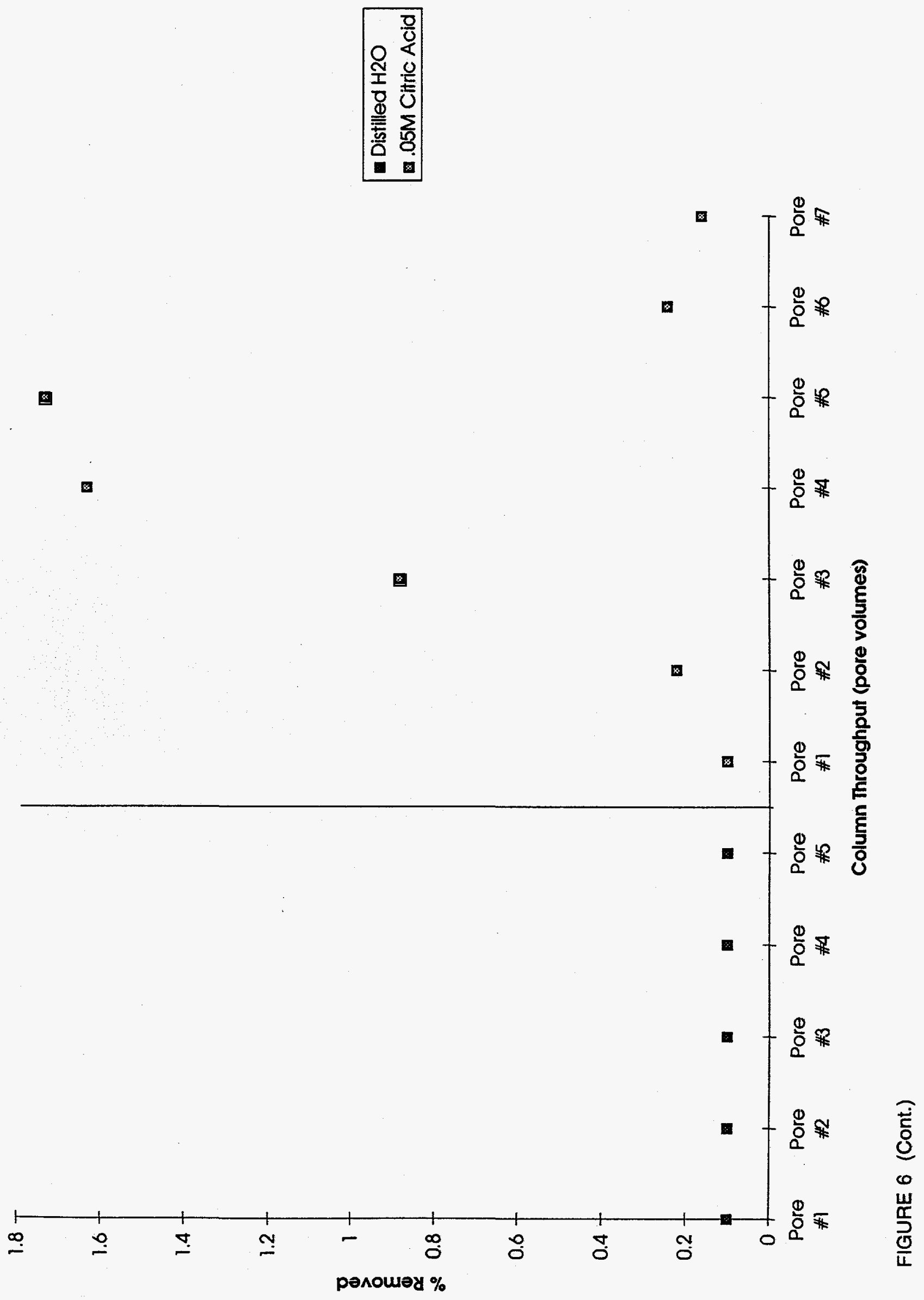




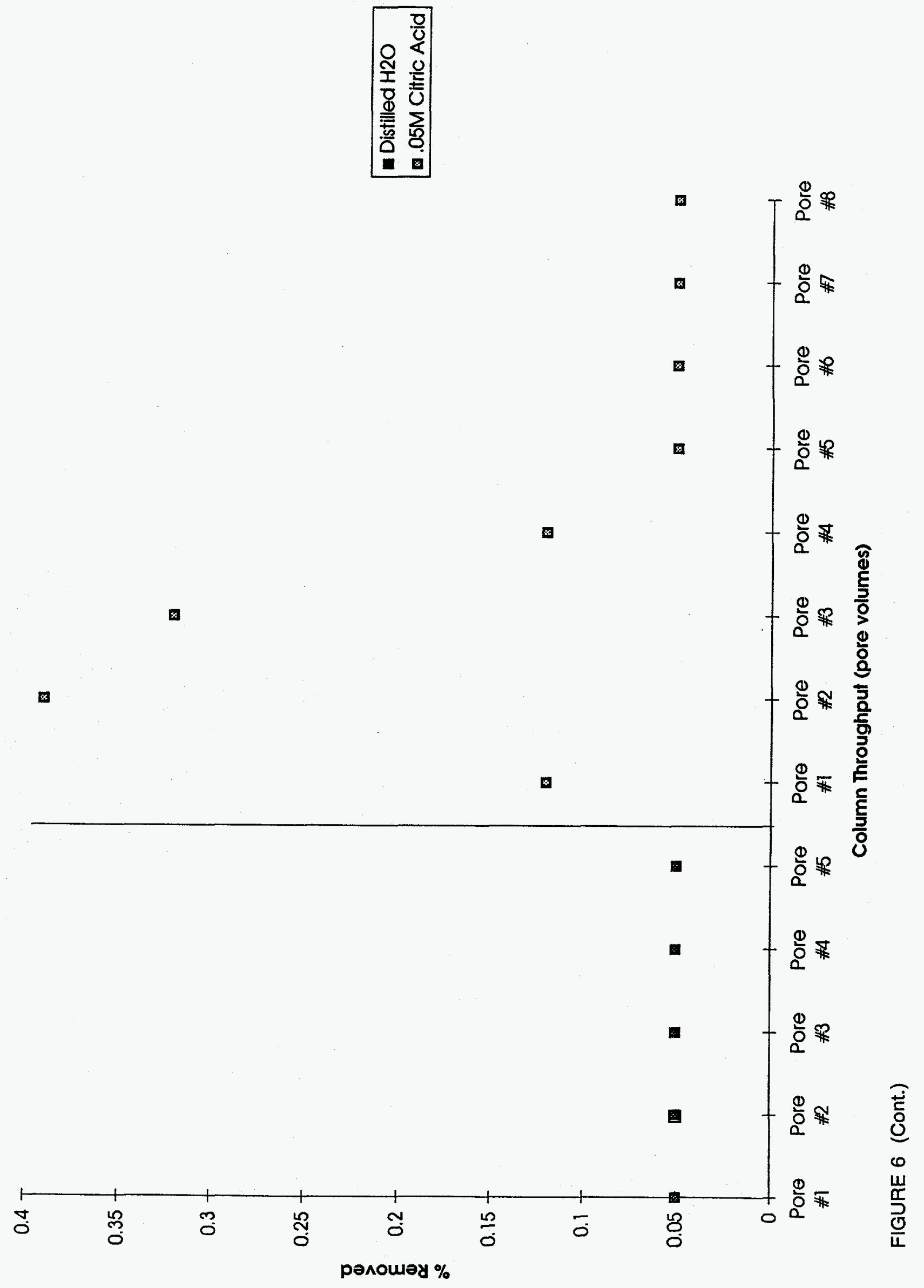




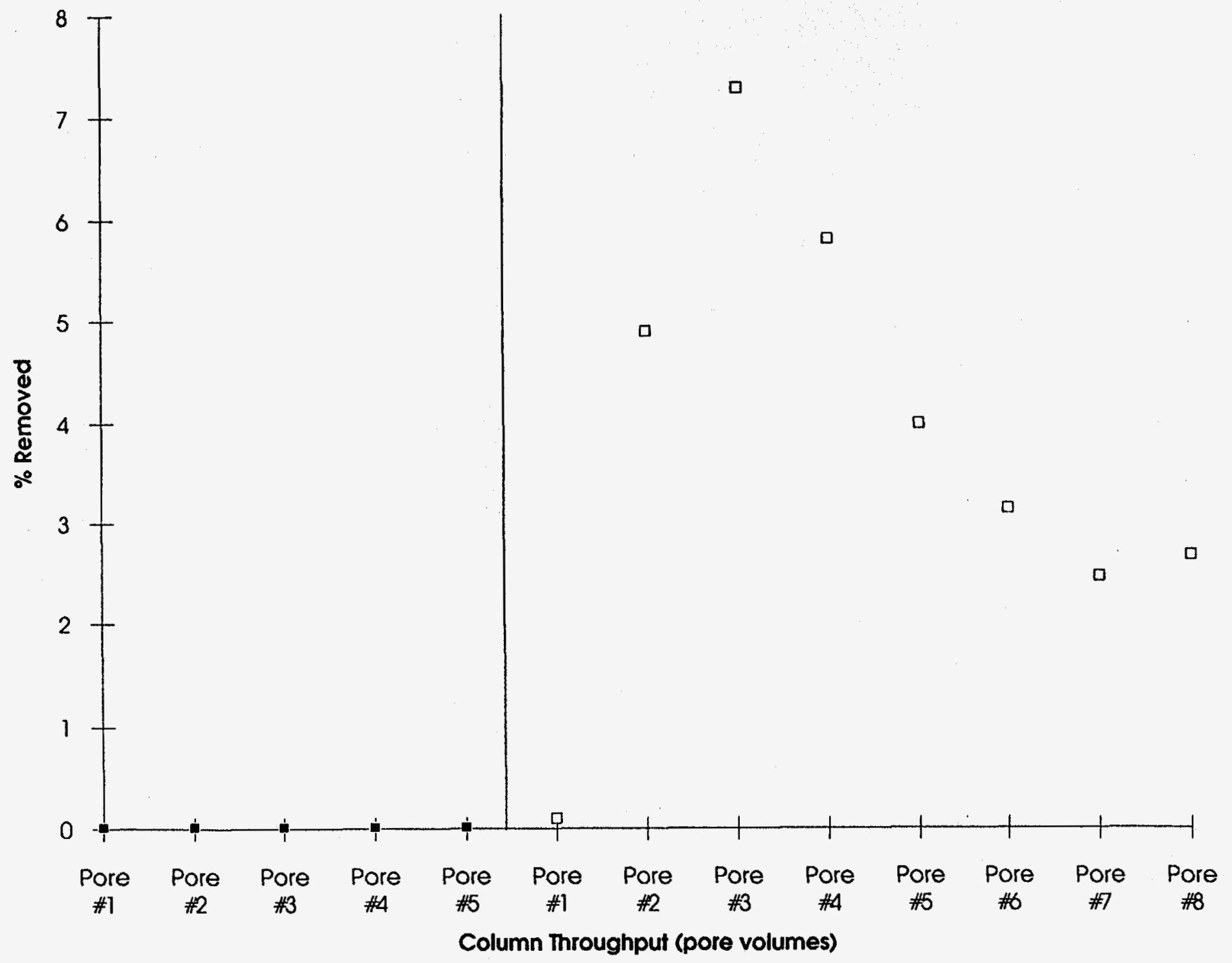

- Distilled $\mathrm{H} 2 \mathrm{O}$

口. .05M Citric Acid

FIGURE 6 (Cont.) 


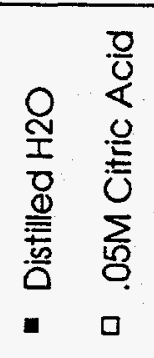

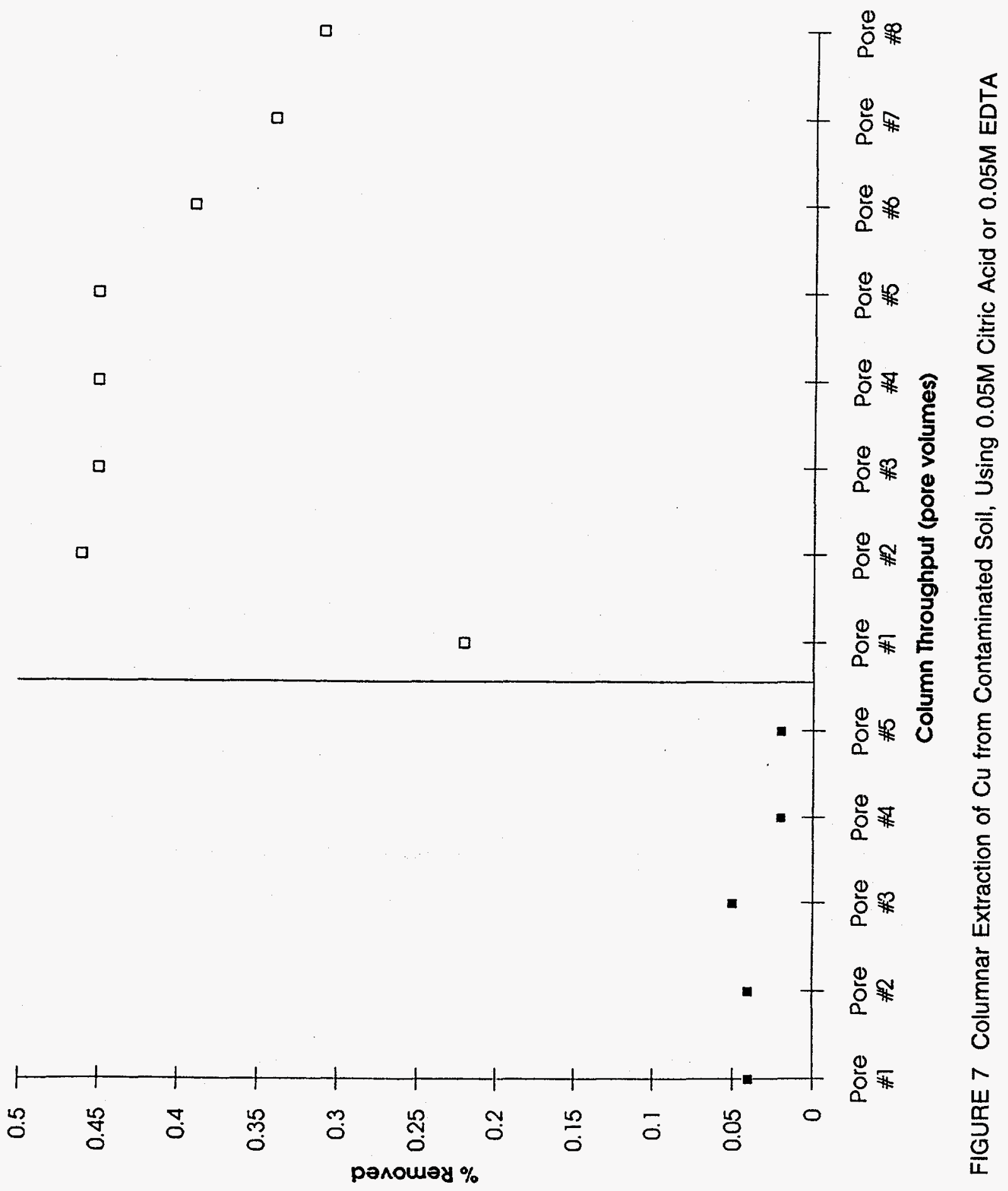




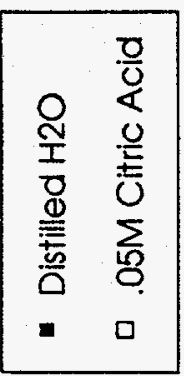

ㅁ

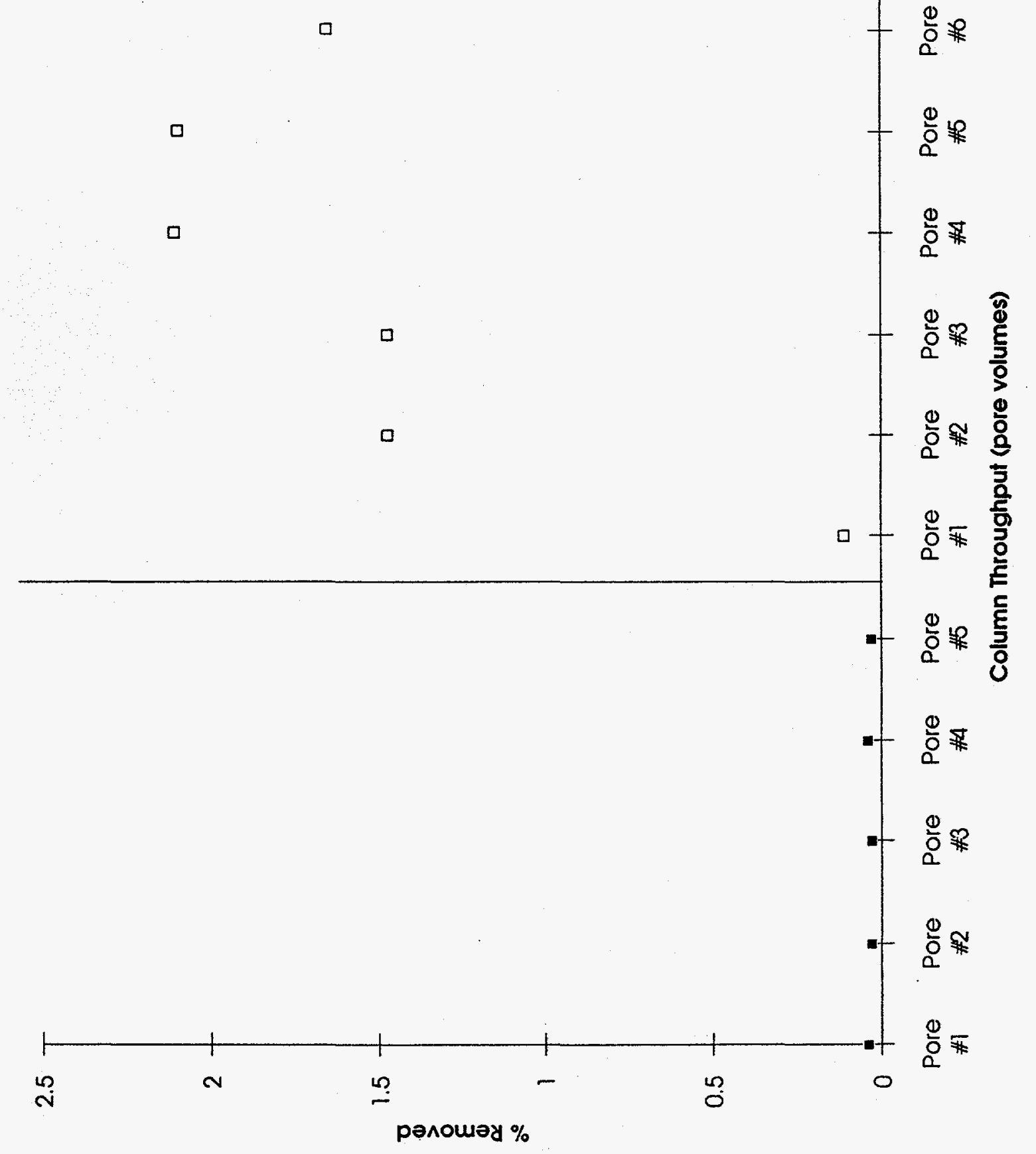

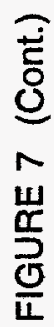



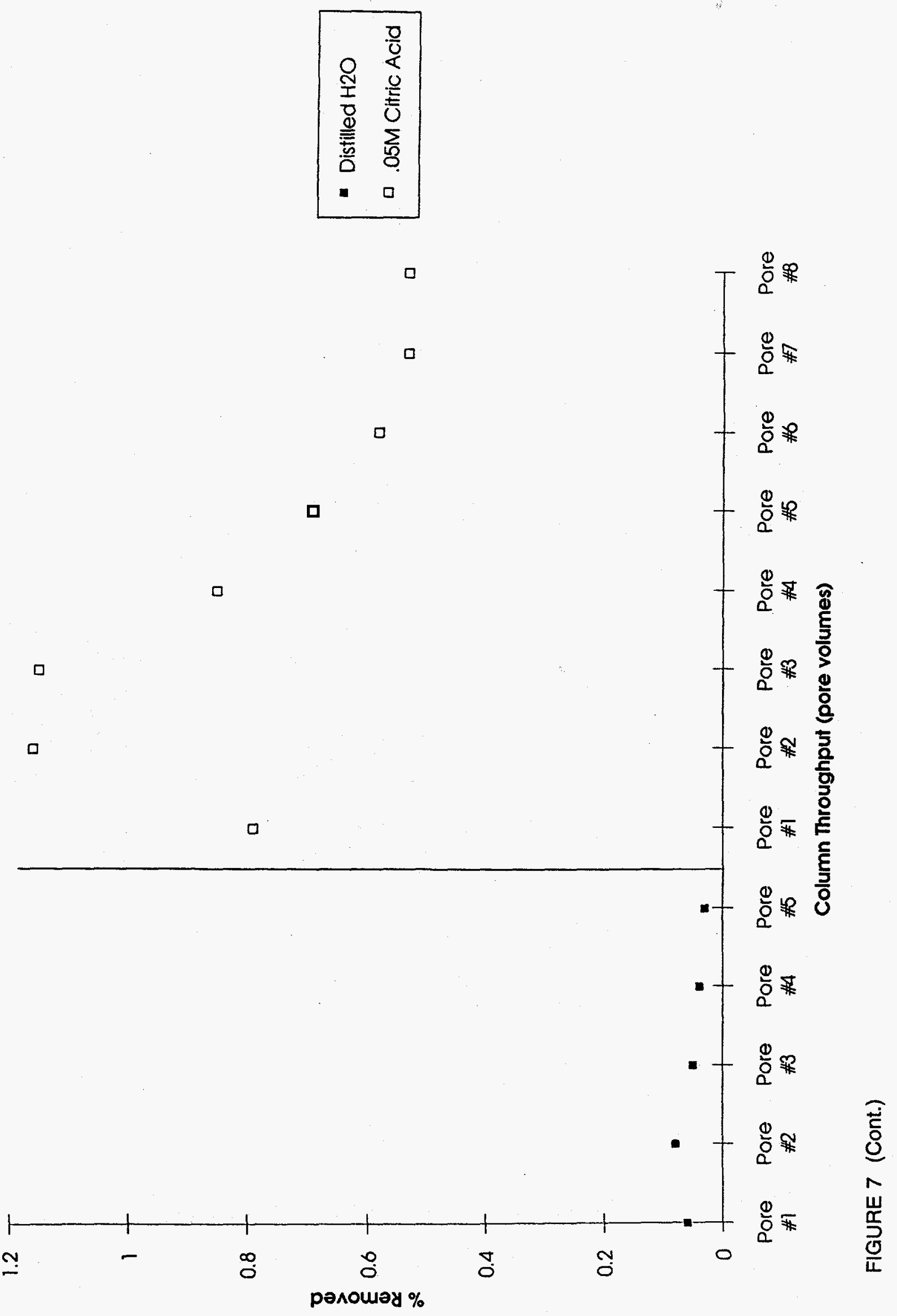


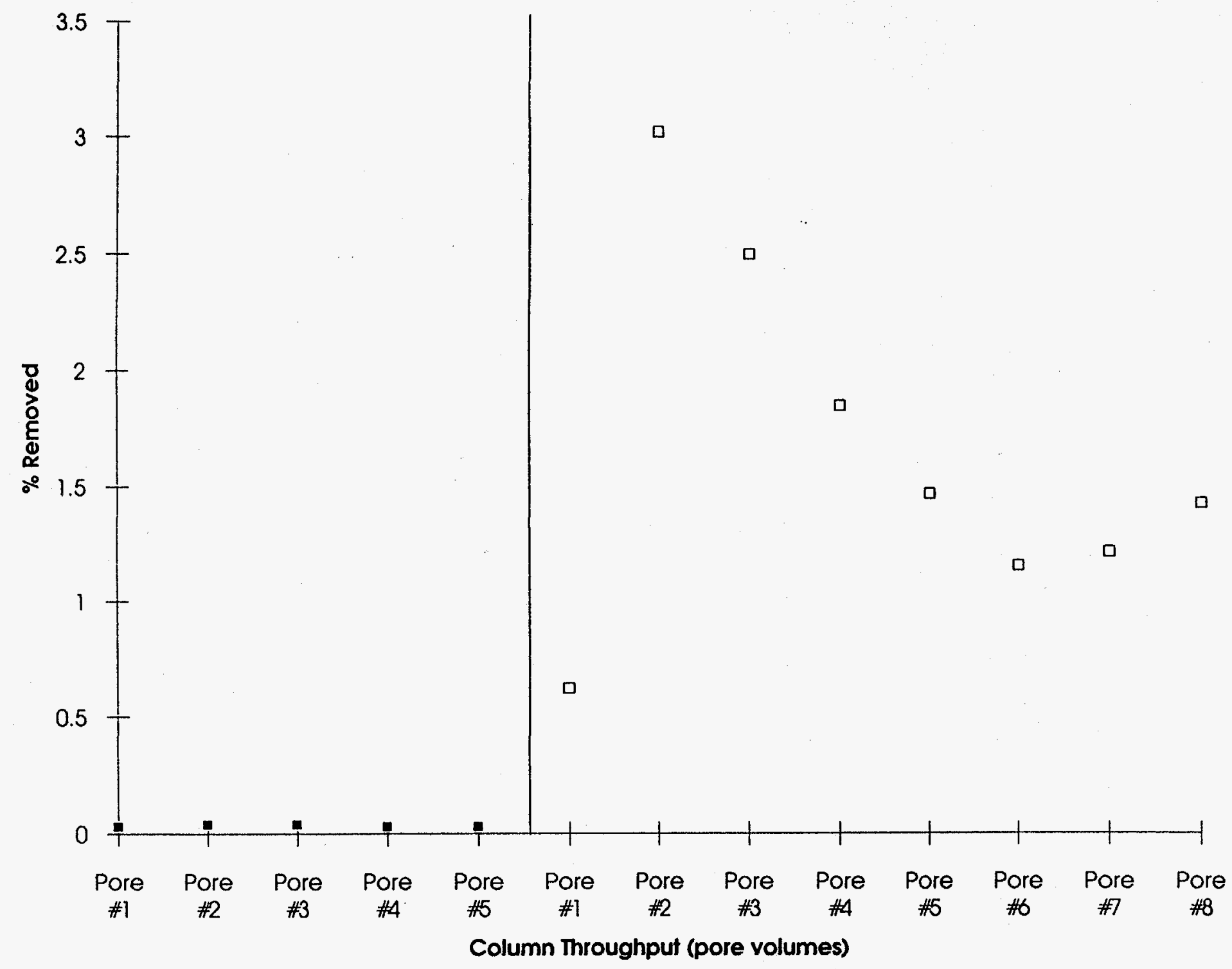

- Distilled H2O

口 .05M Citric Acid

FIGURE 7 (Cont.) 

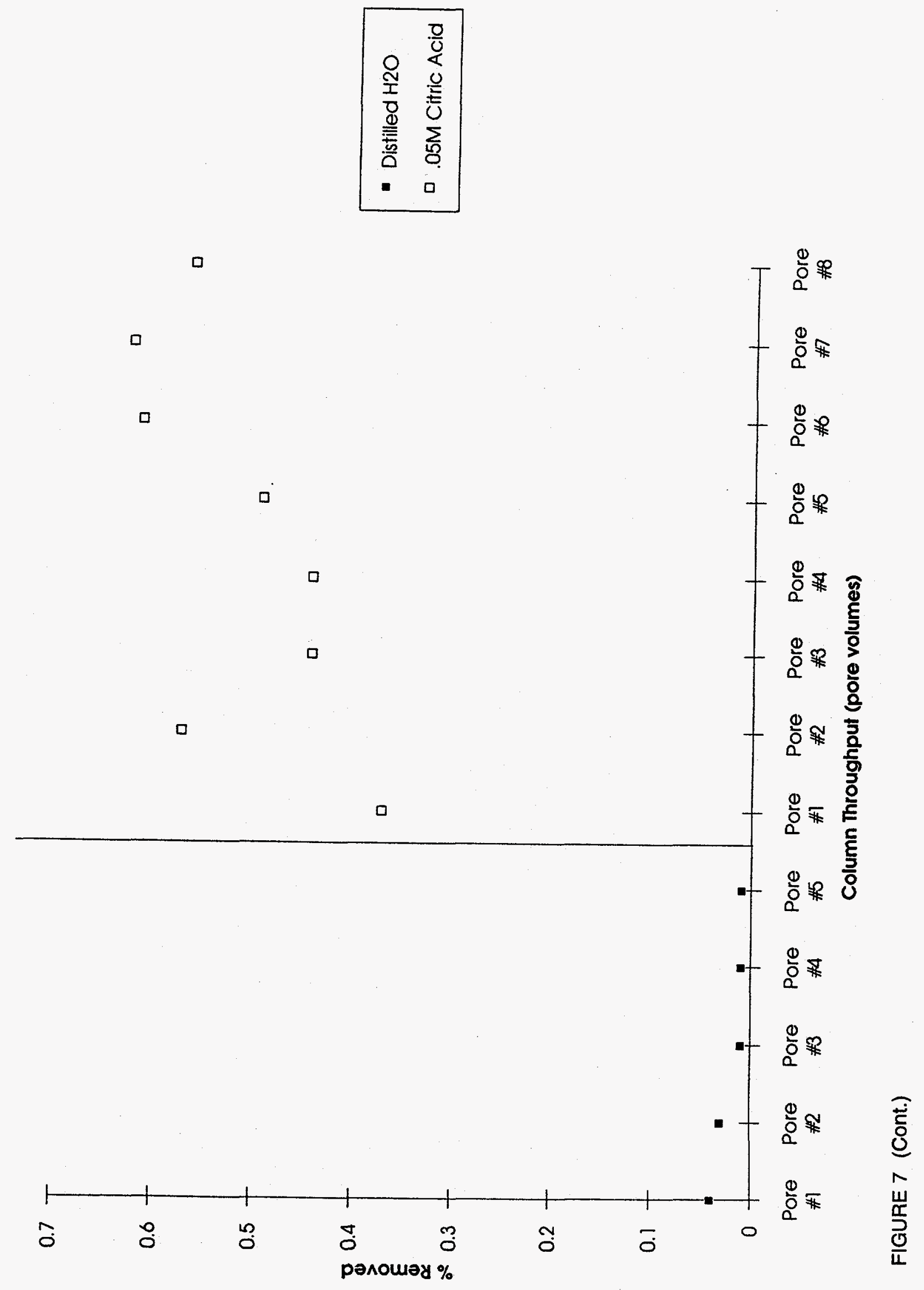


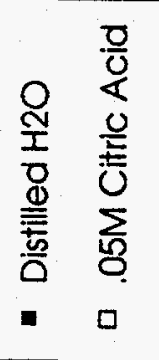

$\square$

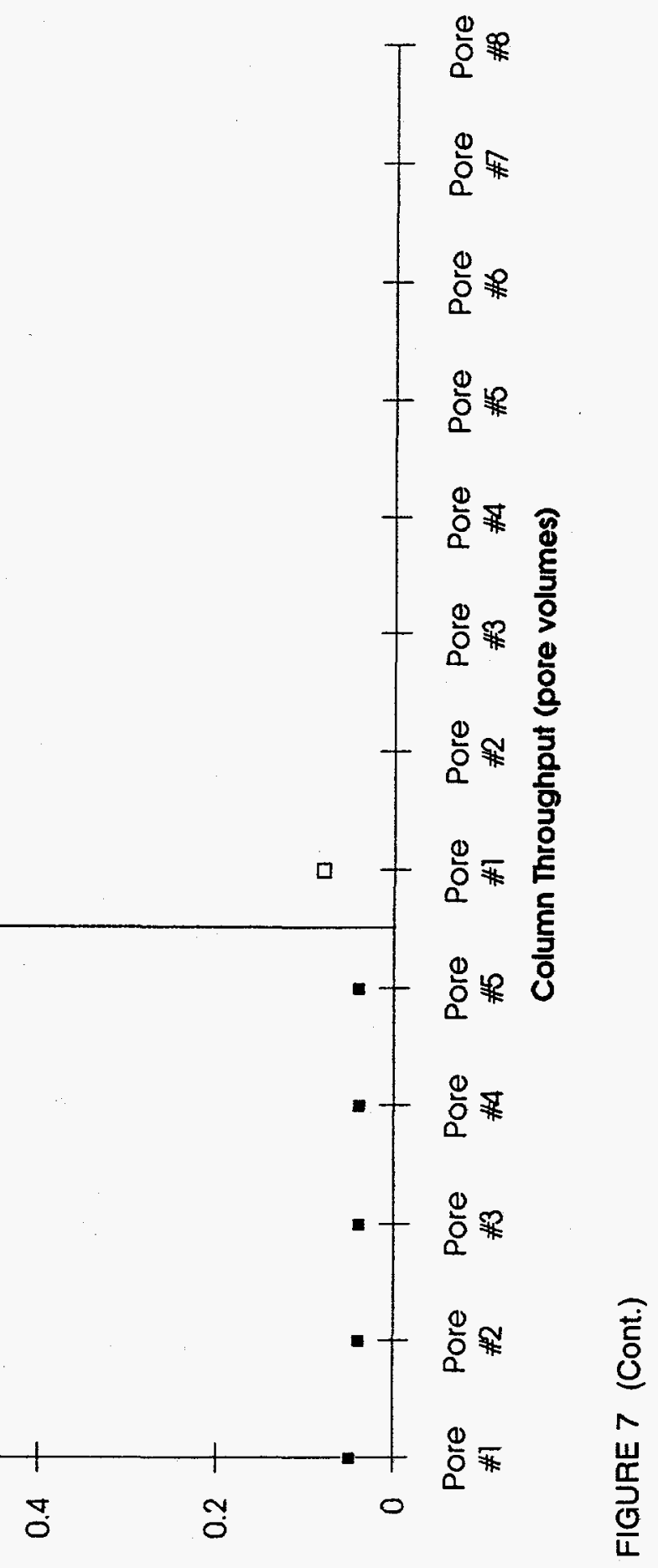

pə^ошеу \% 

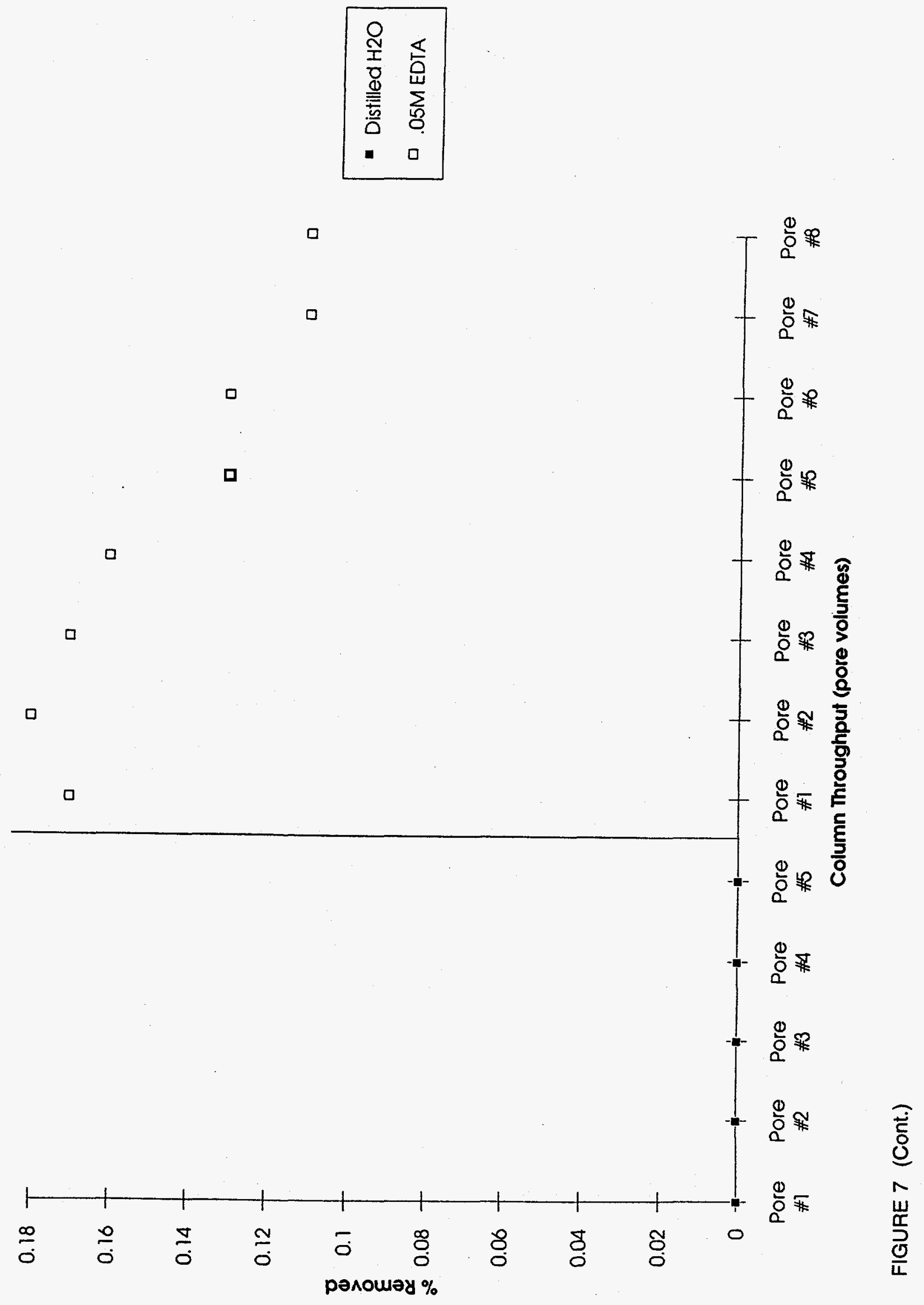


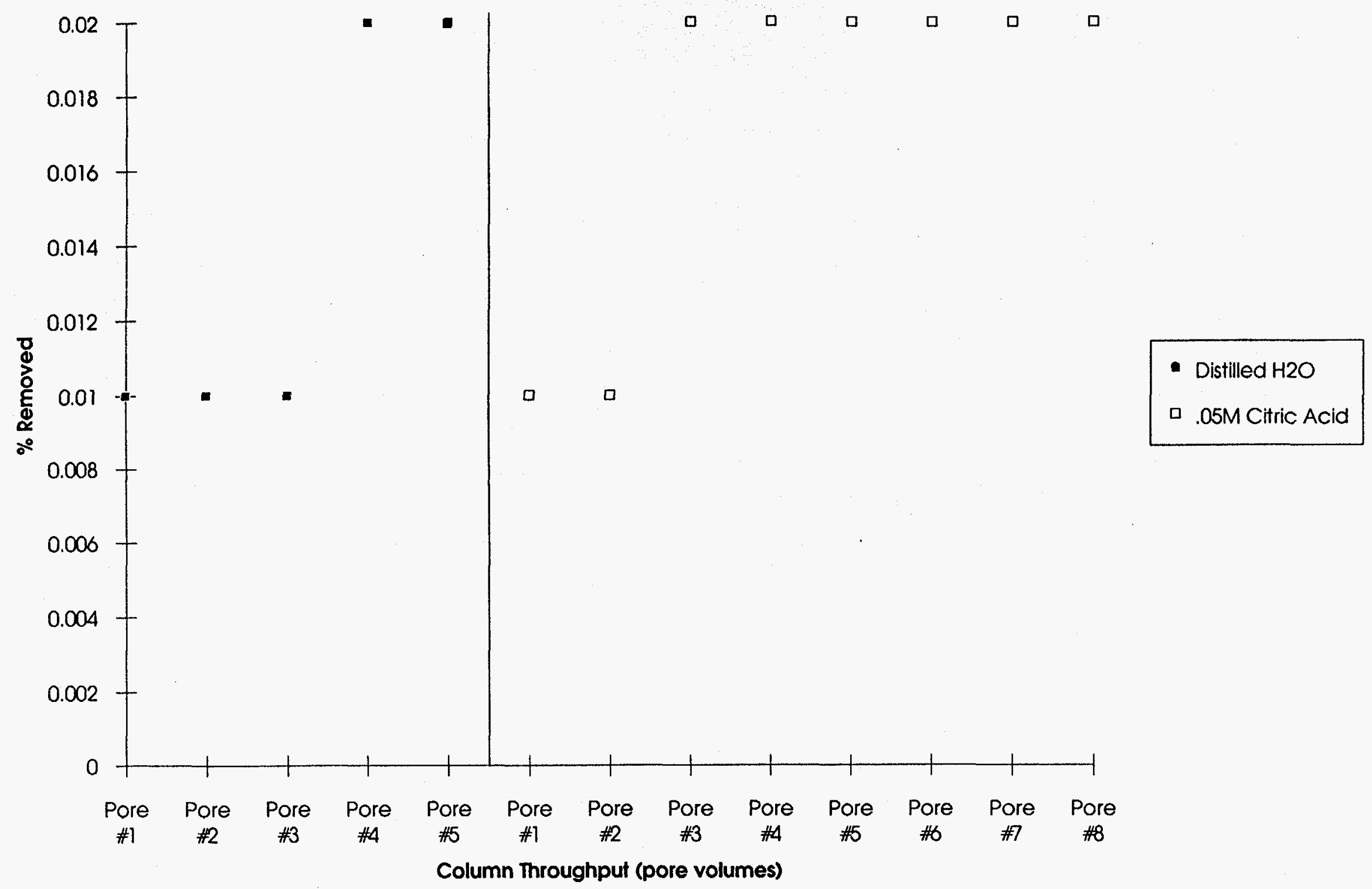

FIGURE 8 Columnar Extraction of Fe from Contaminated Soil, Using 0.05M Citric Acid or 0.05M EDTA 

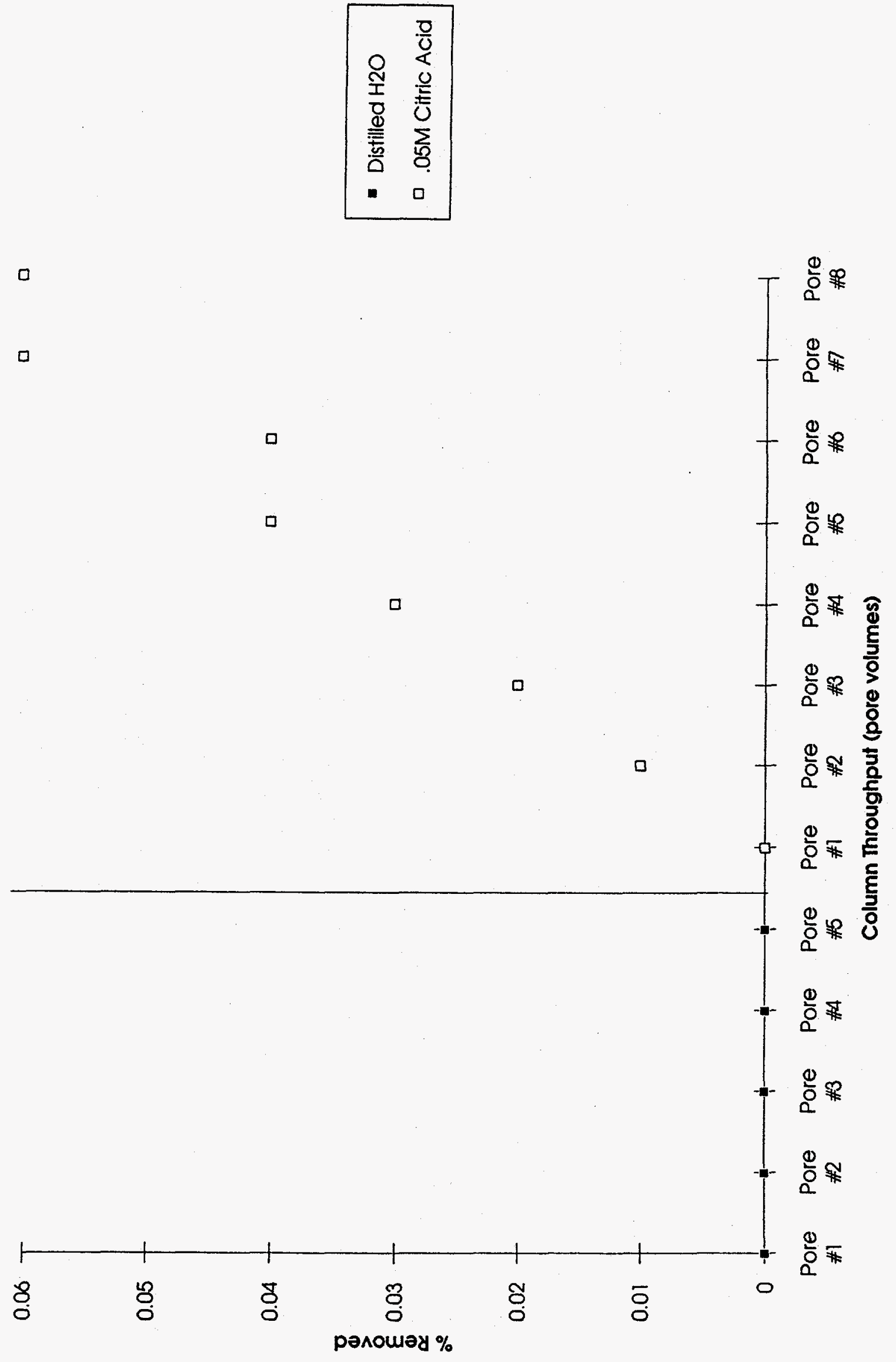


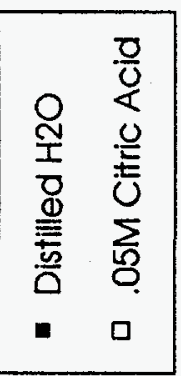

口

ㅁ

ㅁ

ㅁ

ㅁ

ㅁ
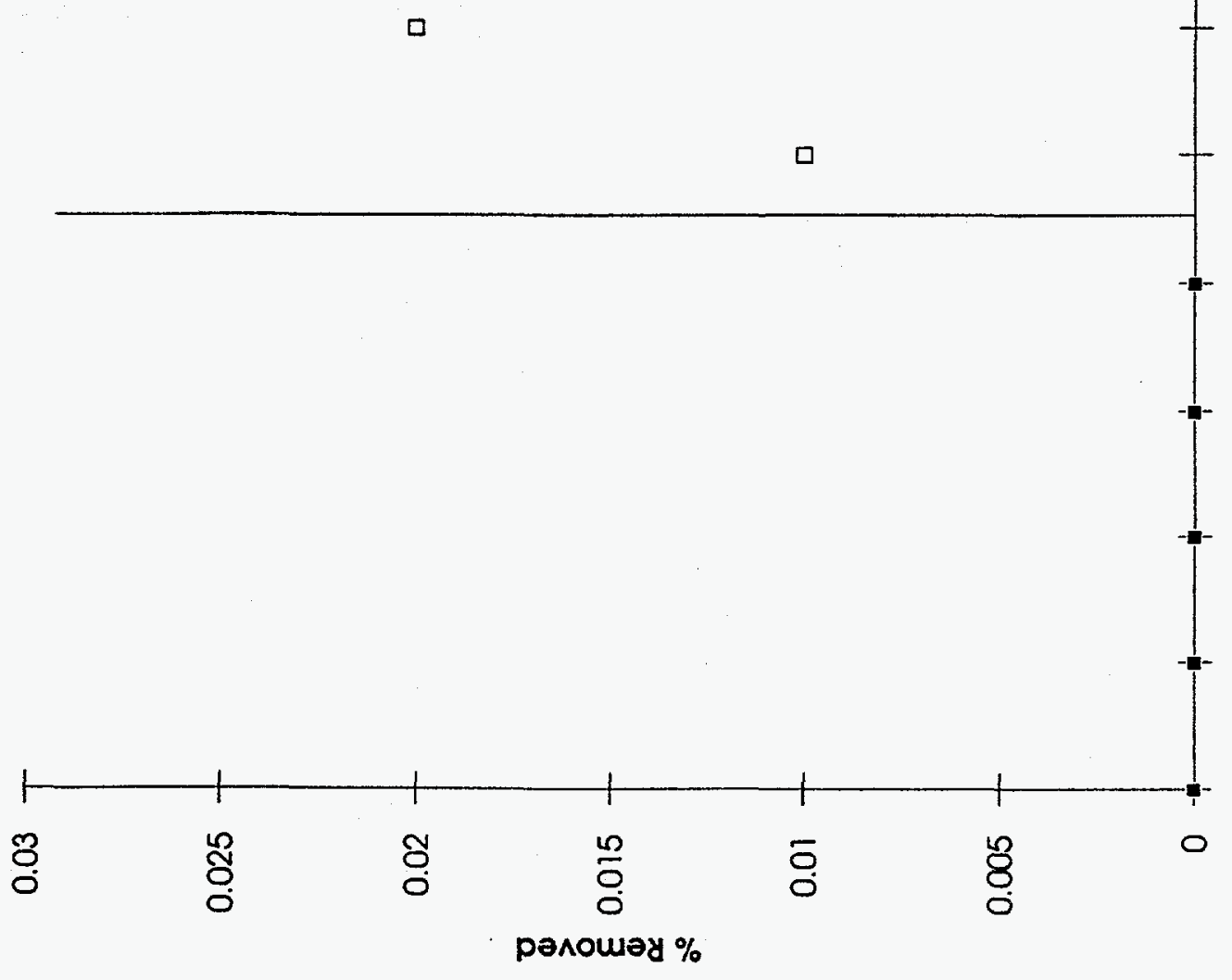

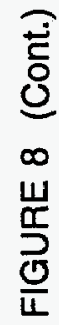



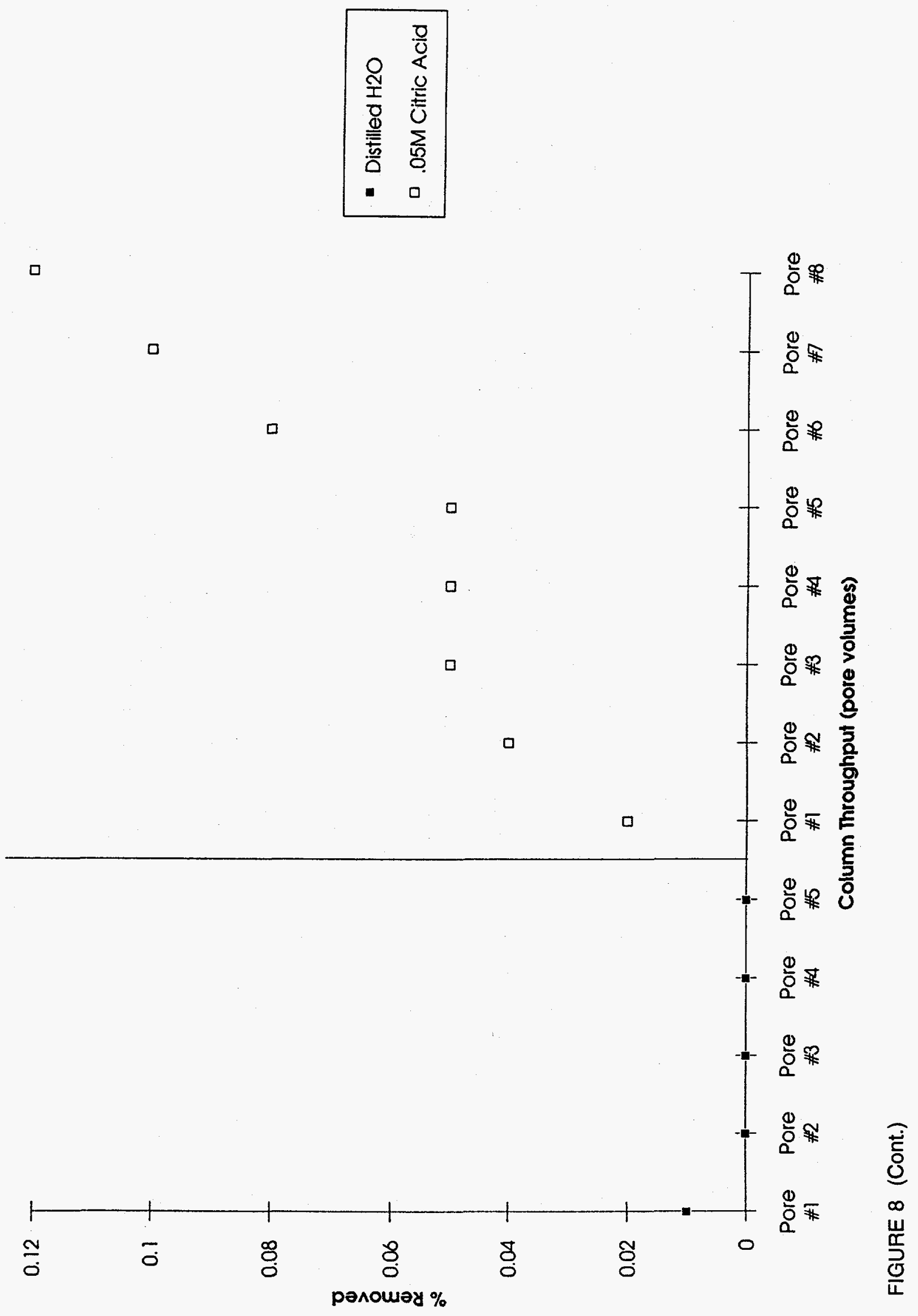

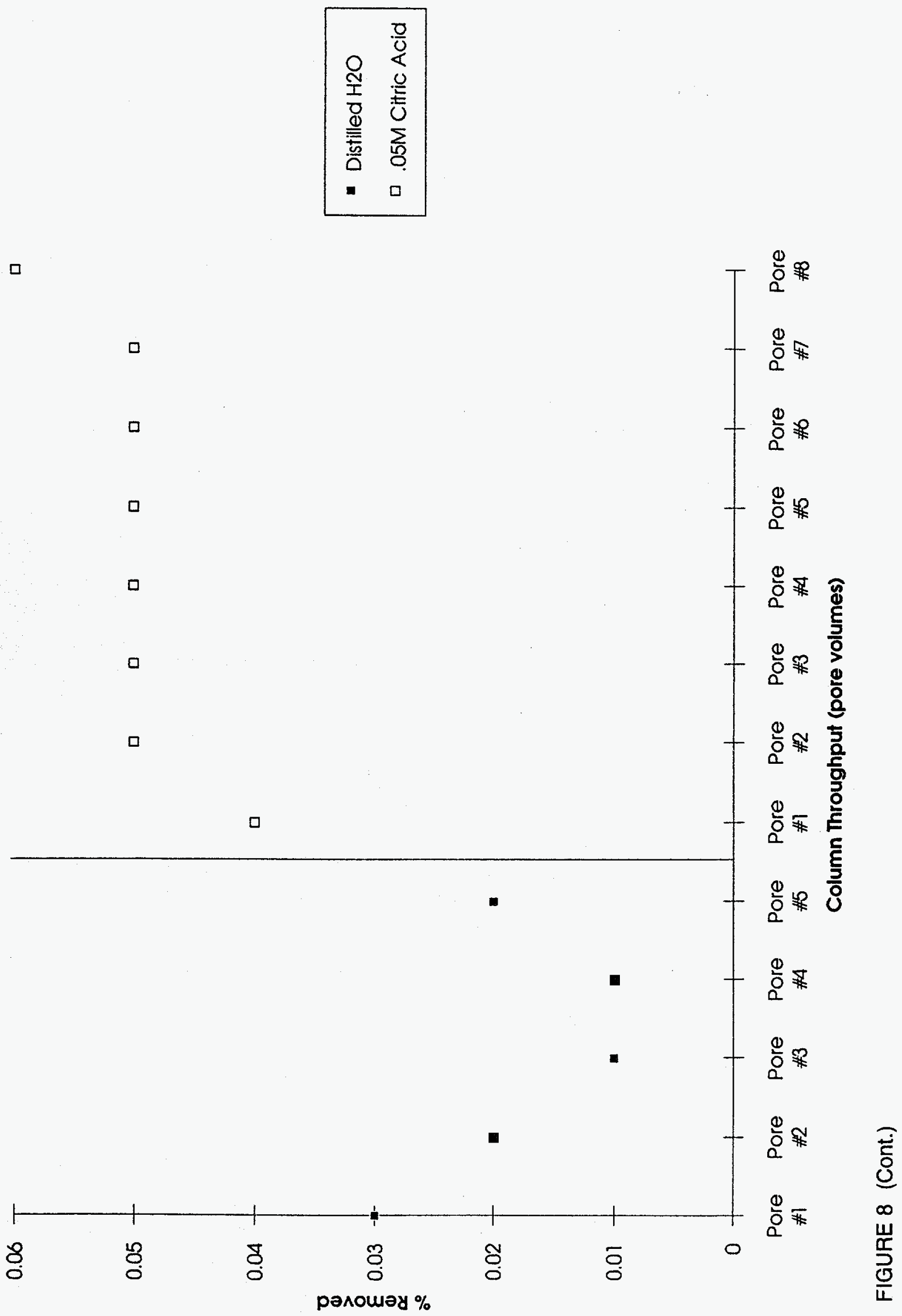

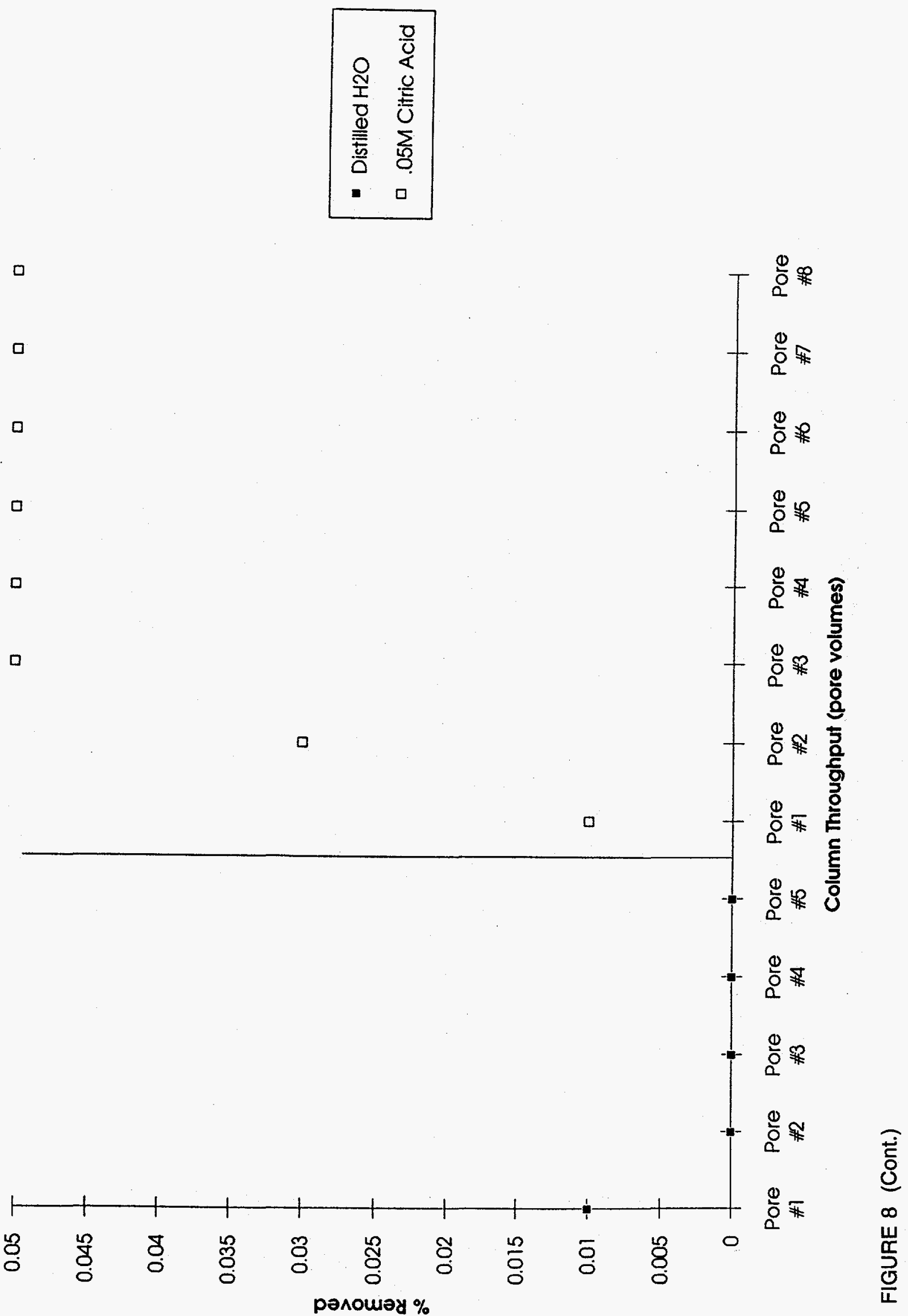

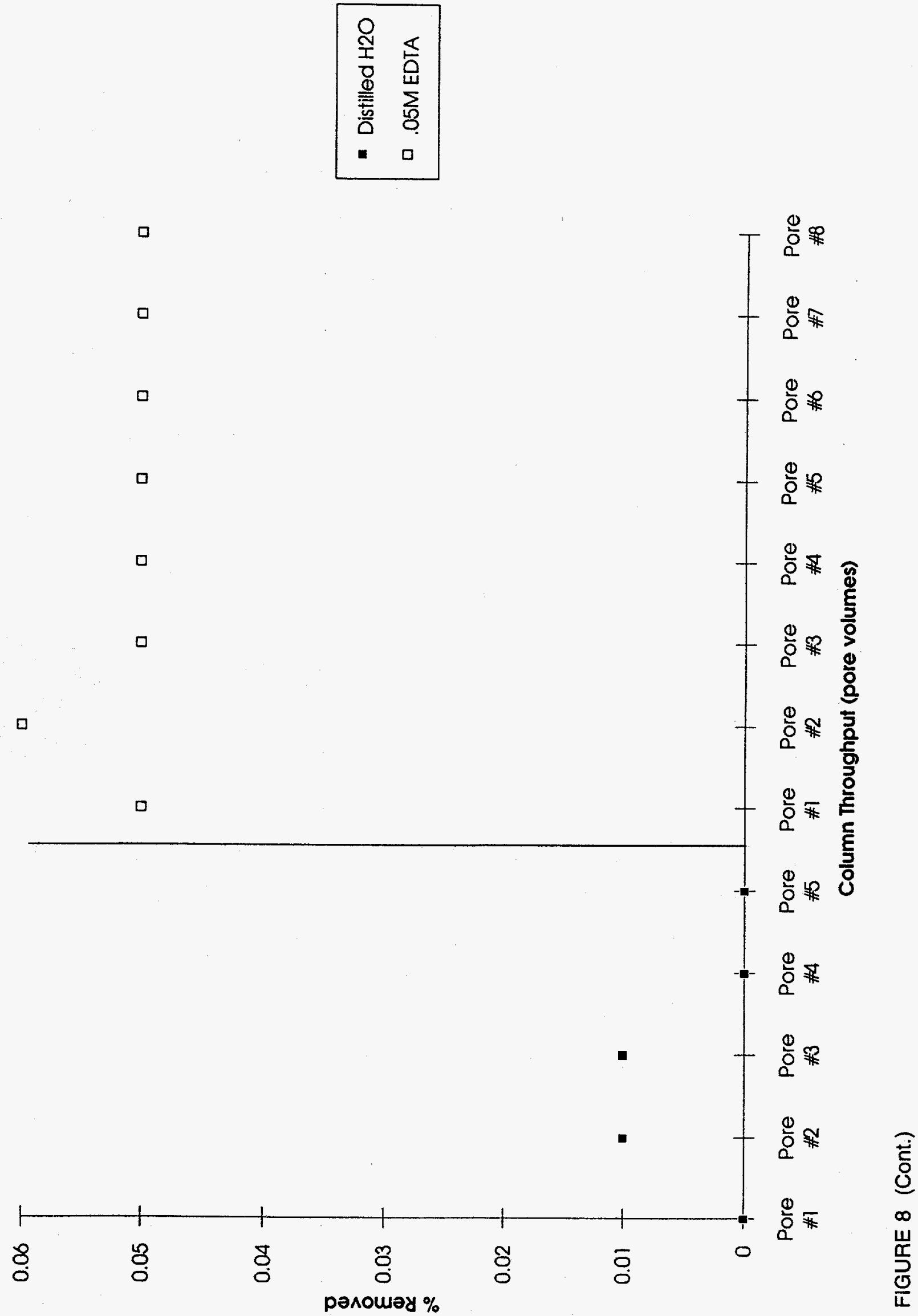


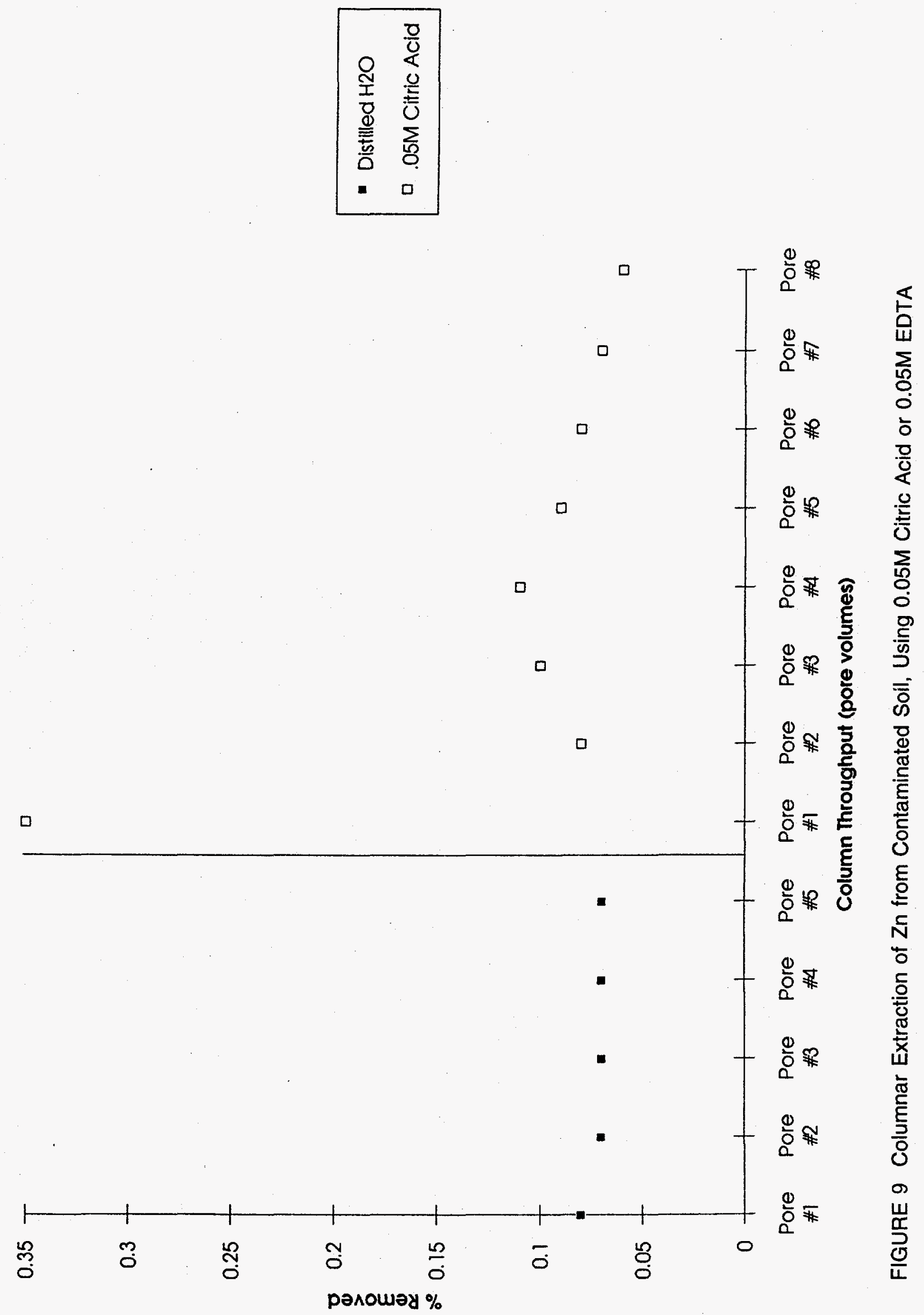



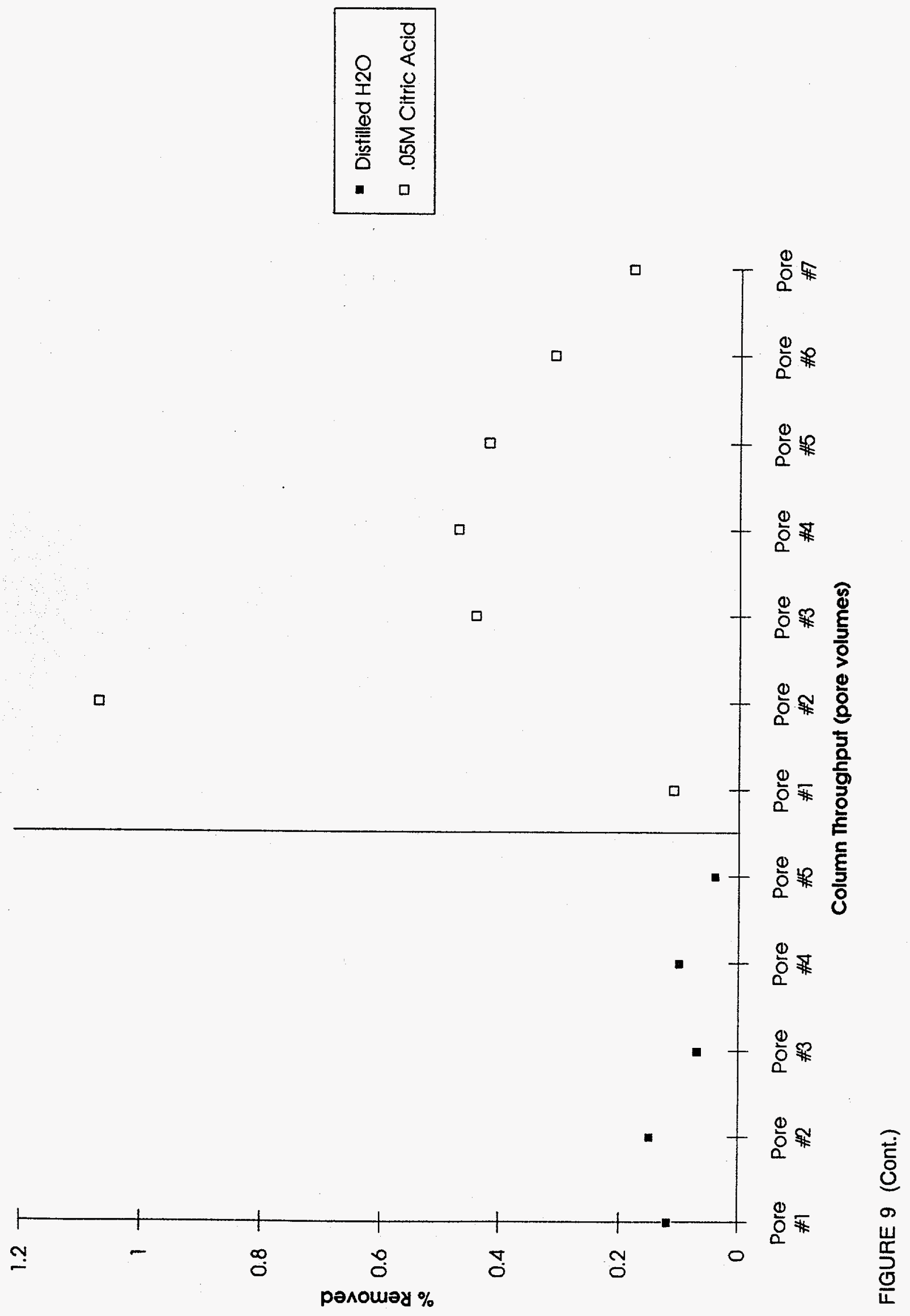


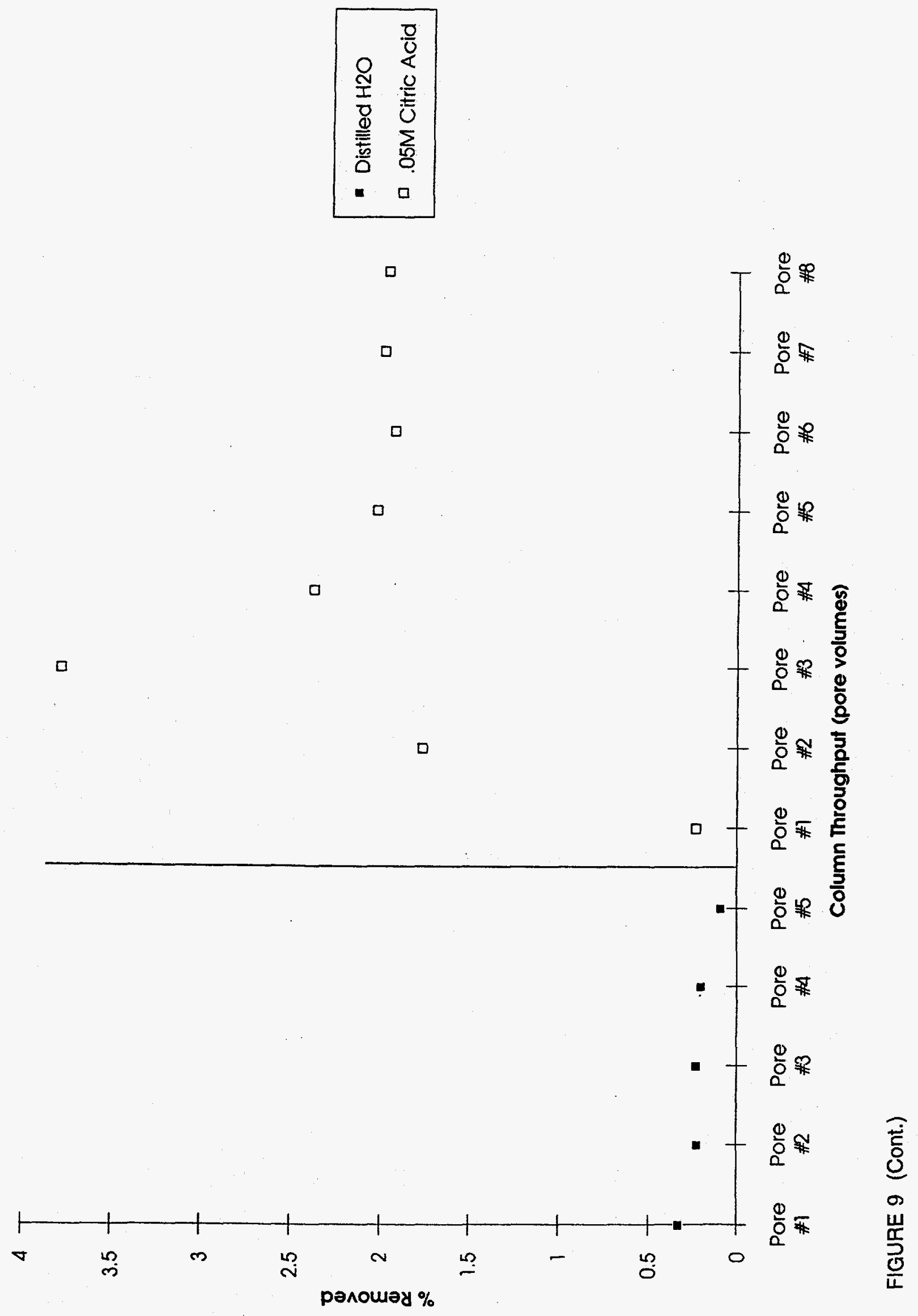



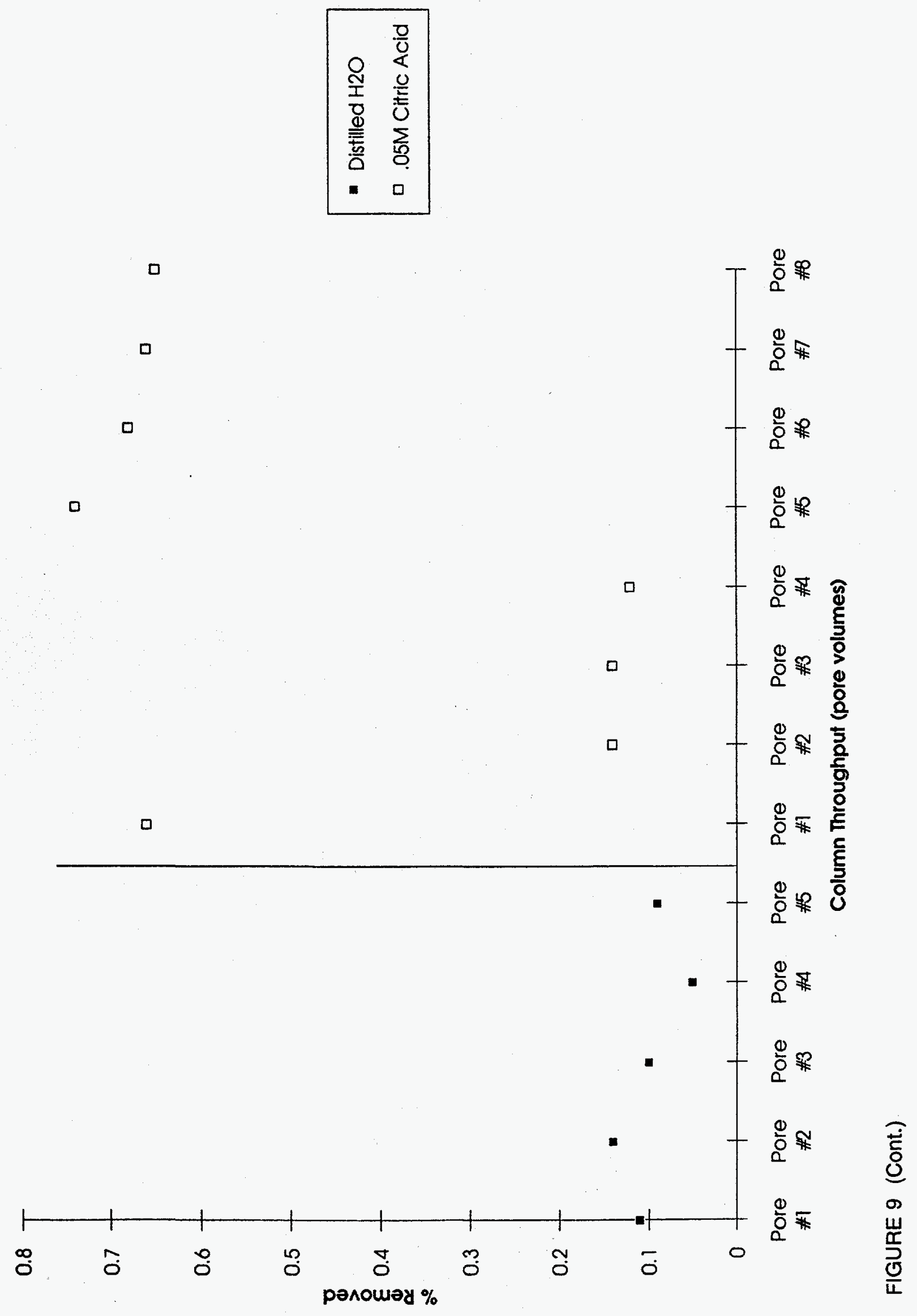


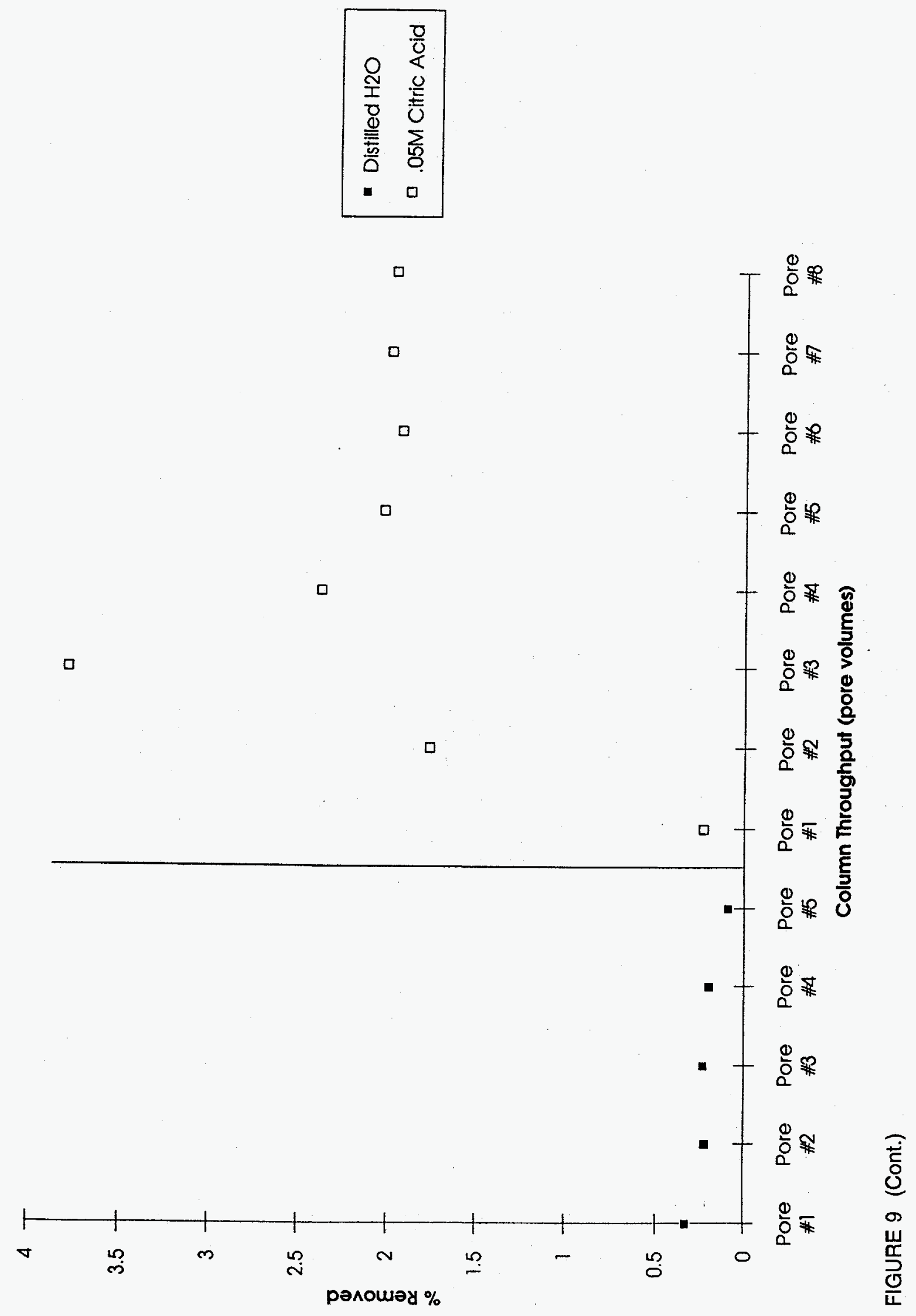



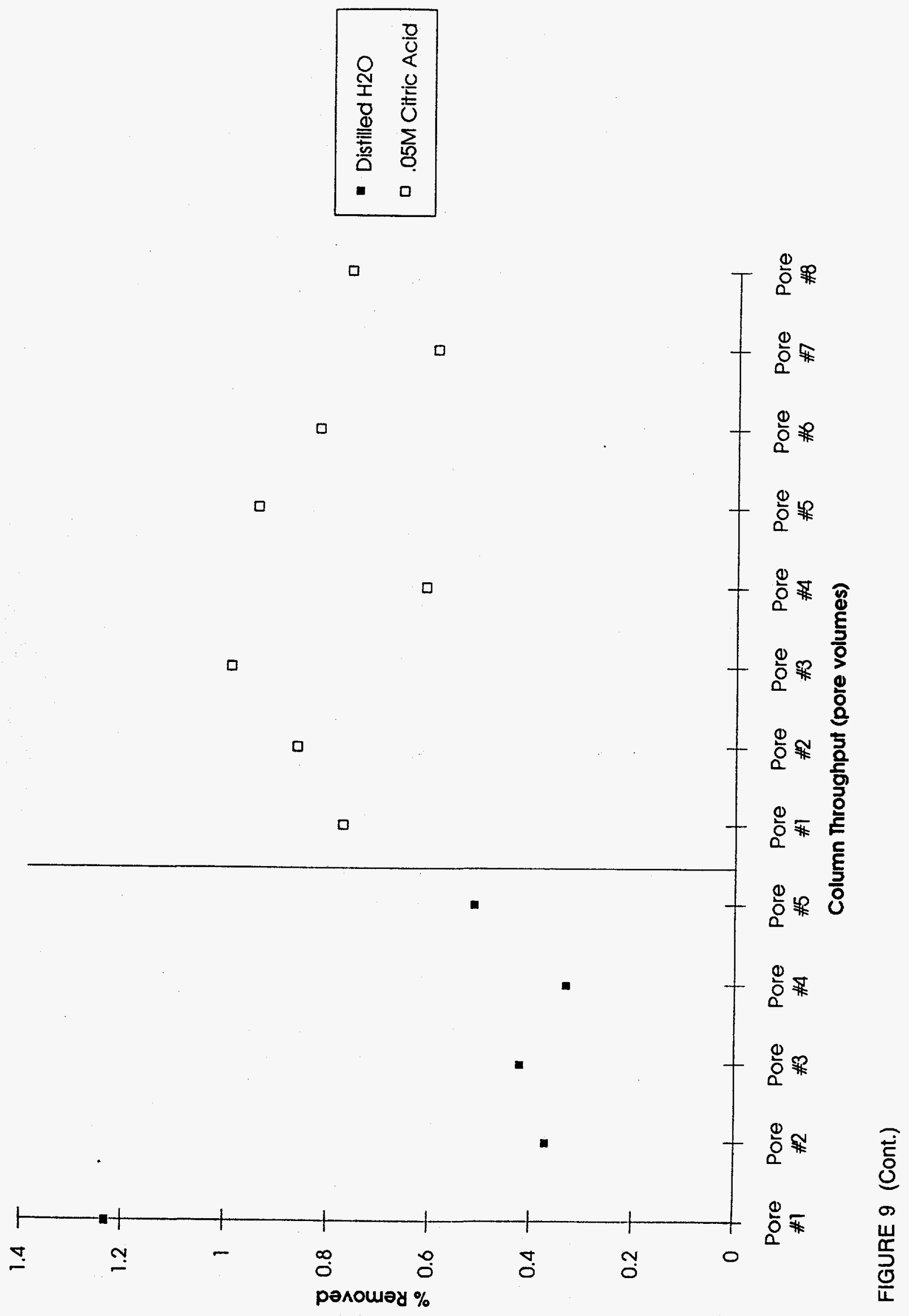

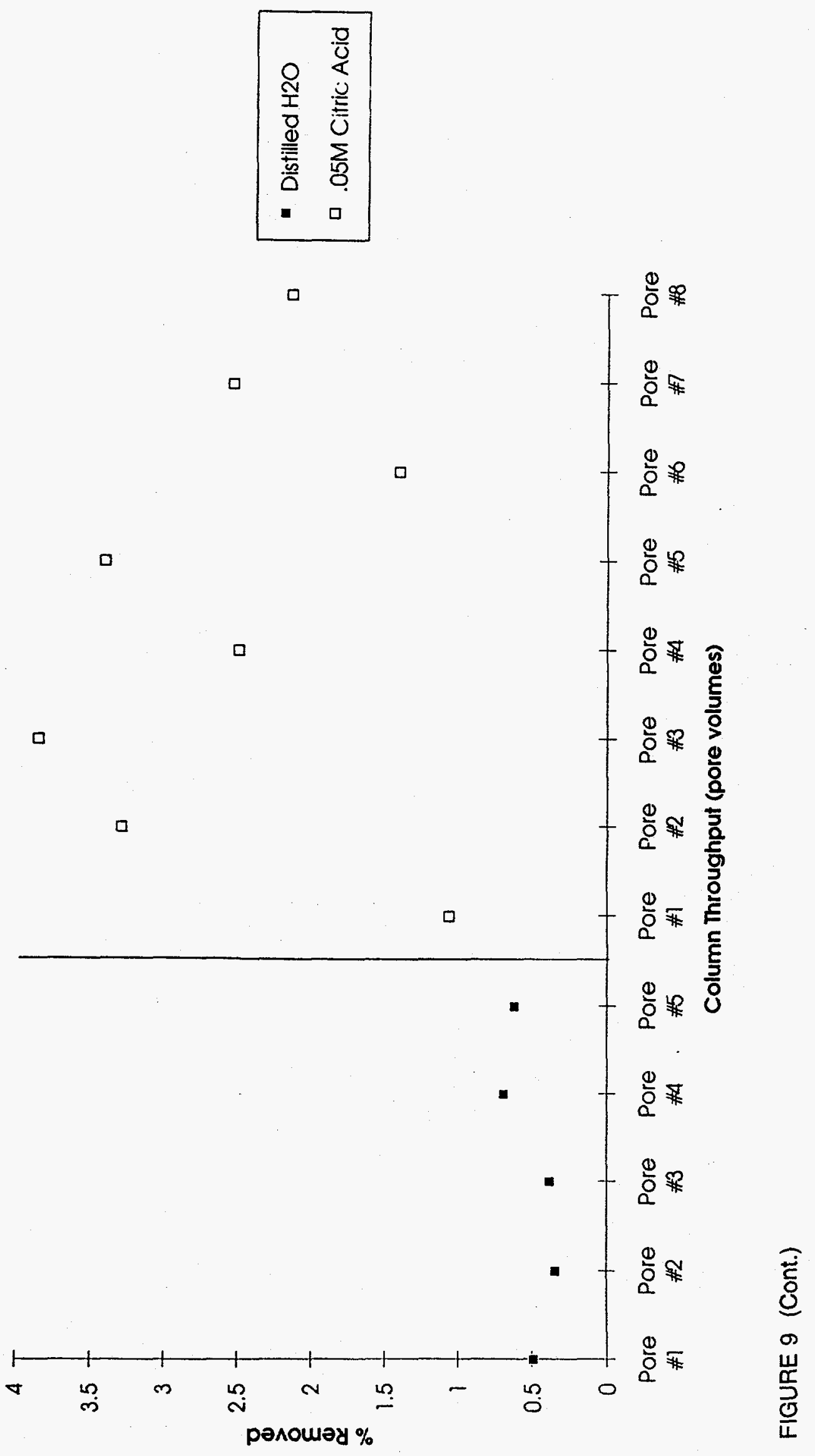

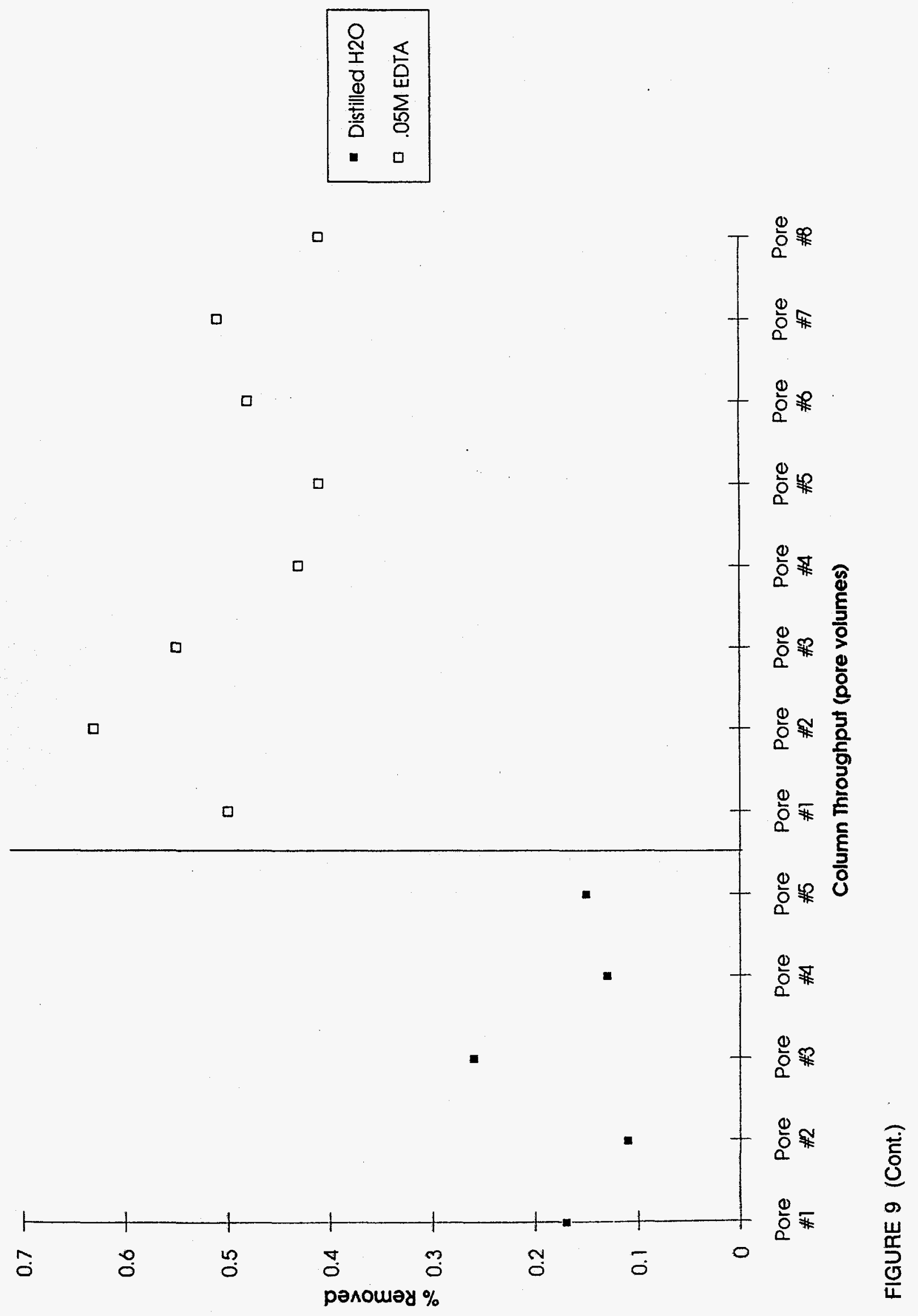


\section{Summary and Conclusions}

The results of this feasibility/treatability study are indicated below.

\section{Batch Shaker Studies:}

- EDTA (0.01M) was more effective than citric acid $(0.01 \mathrm{M})$ at removing cadmium, copper, lead, and zinc.

- EDTA (0.01M) and citric acid (0.01M) were equally effective for mobilizing chromium and barium from the soil.

- Heavy metals removal was slightly greater with a pH in the range of 5 to 6 than it was with a $\mathrm{pH}$ greater than 7 .

- The batch shaker chelant extraction technique offers promise as a remediation technique for on-site cleanup of heavy-metal-contaminated soil at the GTA.

\section{Columnar Flooding Studies:}

- Deionized water was the least effective leaching solution used in terms of mobilization of the heavy metals; the maximum solubilization obtained was $3.72 \%$ for cadmium.

- Extraction with deionized water indicated that all of the heavy metals tested are very tightly bound to the soil. The quantity of heavy metals leached into solution was generally less than $1.7 \%$ of the total amount of heavy metals contained in the soil sample.

- The deionized water extraction results indicated that the heavy metals are very stable in the soils at the GTA and do not represent a serious threat to the groundwater system.

- EDTA (0.05M) treatment resulted in the greatest removal of lead; a maximum removal of $50.6 \%$ and an average removal of $17.6 \%$ were achieved.

- EDTA (0.05M) treatment was more effective than citric acid $(0.05 \mathrm{M})$ or distilled water at removing cadmium, chromium, and iron. The average removal rates in columnar extractions using EDTA $(0.05 \mathrm{M})$ were $13 \%$ for cadmium, $2.8 \%$ for chromium, and $0.5 \%$ for iron. 
- Citric acid $(0.05 \mathrm{M})$ was more effective than either EDTA $(0.05 \mathrm{M})$ or deionized water at mobilizing copper and zinc in columnar extractions. The average removal rates using citric acid $(0.05 \mathrm{M})$ were $8.96 \%$ for copper and $10.59 \%$ for zinc.

- The amount of heavy metals mobilized from these soils constitutes a relatively low percentage (typically less than $20 \%$ ).

- Because of the relatively small percentage of heavy metals mobilized in the columnar flooding chelation extraction study, this technique probably does not offer promise for in-situ remediation of heavy-metal-contaminated soil at the GTA. 


\section{References}

American Public Health Association, 1992, Standard Methods for the Examination of Water and Wastewater, 18th Ed., A.E. Greenberg, L.S. Clesceri, and A.D. Eaton (editors), American Public Health Association, Washington, D.C.

American Society for Testing and Materials, 1987a, "ASTM D2487-85: Standard Test Method for Classification of Soils for Engineering Purposes," in 1987 Annual Book of ASTM Standards, Sec. 4, Vol. 04.08, American Society for Testing and Materials, Philadelphia, Penn.

American Society for Testing and Materials, 1987b, "ASTM D422-63: Standard Method for Particle-Size Analysis of Soils," in 1987 Annual Book of ASTM Standards, Sec. 4, Vol. 04, American Society for Testing and Materials, Philadelphia, Penn.

American Society of Agronomy and Soil Science Society of America, 1982, Methods of Soil Analysis, Part 2: Chemical and Microbiological Properties, 2nd Edition, A.L. Page, R.H. Miller, and D.R. Keeney (editors), American Society of Agronomy and Soil Science Society of America, Madison, Wis.

Dames \& Moore International, 1992, Grafenwöhr MILCOM Ground-Water Sampling, 2nd Sampling Round, Project No. 17846-055-420, Contract No. DACA90-91-D-0015, Feb.

Peters, R.W., and L. Shem, 1992, Use of Chelating Agents for Remediation of Heavy Metal Contaminated Soil, ACS Symposium, Series 509 on Environmental Remediation: Removing Organic and Metal Ion Pollutants, 509:70-84.

Zellmer, S.D., and J.F. Schneider, 1993, Heavy-Metal Contamination on Training Ranges at the Grafenwöhr Training Area, Germany, ANL/ESD/TM-59, Argonne National Laboratory, Argonne, Ill. 
Appendix A:

Batch Shaker Experiment Data:

S037, S038, S039, SO41, S044, and S049 
Ba Removed by Batch Shaker Method

\begin{tabular}{|c|c|c|c|c|c|c|c|c|}
\hline & $\overline{\mathrm{Ba}}$ & Wt. of Soil & $\mathrm{Ba}$ in & $\mathrm{Ba}$ & Ba in & $\% \mathrm{Ba}$ & $\mathrm{pH}$ of & Ba Remaining \\
\hline SAMPLE \# & $(\mathbf{m g} / \mathbf{k g})$ & (g) & Soil (mg) & $(\mathrm{mg} / \mathrm{L})$ & sample (mg) & Removed & Sample & in Soil ( $\mathrm{mg} / \mathrm{kg})$ \\
\hline R111-S037-.01 CIT-3 & 980.36 & 5.003 & 4.905 & 28.230 & 1.270 & $26 \%$ & 5.915 & 726.442 \\
\hline R111-S037-.01 CIT-3-F & 980.36 & 5.003 & 4.905 & 78.890 & 3.550 & $72 \%$ & 5.915 & 270.776 \\
\hline R111-S037-.01 CIT-3-F/C & 980.36 & 5.003 & 4.905 & 86.350 & 3.886 & $79 \%$ & 5.915 & 203.676 \\
\hline R111-S037-.01 CIT-3-F-DUP & 980.36 & 5.003 & 4.905 & 82.010 & 3.690 & $75 \%$ & 5.915 & 242.713 \\
\hline R111-S037-.01 CIT-5 & 980.36 & 5.010 & 4.912 & 45.750 & 2.059 & $42 \%$ & 6.409 & 569.432 \\
\hline R111-S037-.01 CIT-5-F & 980.36 & 5.010 & 4.912 & 40.420 & 1.819 & $37 \%$ & 6.409 & 617.306 \\
\hline R111-S037-.01 CIT-5-F/C & 980.36 & 5.010 & 4.912 & 38.220 & 1.720 & $35 \%$ & 6.409 & 637.067 \\
\hline R111-S037-.01 CIT-5-F-DUP & 980.36 & 5.010 & 4.912 & 32.890 & 1.480 & $30 \%$ & 6.409 & 684.941 \\
\hline R111-S037-.01 CIT-7 & 980.36 & 5.036 & 4.937 & 41.070 & 1.848 & $37 \%$ & 7.698 & 613.372 \\
\hline R111-S037-.01 CIT-7-F & 980.36 & 5.036 & 4.937 & 30.210 & 1.359 & $28 \%$ & 7.698 & 710.414 \\
\hline R111-S037-.01 CIT-7-F/C & 980.36 & 5.036 & 4.937 & 33.090 & 1.489 & $30 \%$ & 7.698 & 684.679 \\
\hline R111-S037-.01 CIT-7-F-DUP & 980.36 & 5.036 & 4.937 & 26.000 & 1.170 & $24 \%$ & 7.698 & 748.033 \\
\hline R111-S038-.01 CIT-3 & 1050.17 & 5.014 & 5.266 & 108.290 & 4.873 & $93 \%$ & 6.237 & 78.281 \\
\hline R111-S038-.01 CIT-3-F & 1050.17 & 5.014 & 5.266 & 102.070 & 4.593 & $87 \%$ & 6.237 & 134.105 \\
\hline R111-S038-.01 ClT-3-F/C & 1050.17 & 5.014 & 5.266 & 124.890 & 5.620 & $107 \%$ & 6.237 & -70.702 \\
\hline R111-S038-.01 CIT-3-F-DUP & 1050.17 & 5.014 & 5.266 & 103.790 & 4.671 & $89 \%$ & 6.237 & 118.668 \\
\hline R111-S038-.01 CIT-5 & 1050.17 & 5.014 & 5.266 & 47.900 & 2.156 & $41 \%$ & 6.736 & 620.274 \\
\hline R111-S038-.01 CIT-5-F & 1050.17 & 5.014 & 5.266 & 54.360 & 2.446 & $46 \%$ & 6.736 & 562.296 \\
\hline R111-S038-.01 CIT-5-F/C & 1050.17 & 5.014 & 5.266 & 57.790 & 2.601 & $49 \%$ & 6.736 & 531.512 \\
\hline R111-S038-.01 CIT-5-F-DUP & 1050.17 & 5.014 & 5.266 & 46.100 & 2.075 & $39 \%$ & 6.736 & 636.428 \\
\hline R111-S038-.01 CIT-7 & 1050.17 & 5.030 & 5.282 & 42.600 & 1.917 & $36 \%$ & 7.734 & 669.057 \\
\hline R111-S038-.01 CIT-7-F & 1050.17 & 5.030 & 5.282 & 41.920 & 1.886 & $36 \%$ & 7.734 & 675.140 \\
\hline R111-S038-.01 CIT-7-F/C & 1050.17 & 5.030 & 5.282 & 43.060 & 1.938 & $37 \%$ & 7.734 & 664.941 \\
\hline R111-S038-.01 CIT-7-F-DUP & 1050.17 & 5.030 & 5.282 & 38.230 & 1.720 & $33 \%$ & 7.734 & 708.152 \\
\hline R111-S039-.01 ClT-3 & 1032.22 & 5.008 & 5.169 & 70.230 & 3.160 & $61 \%$ & 6.304 & 401.160 \\
\hline R111-S039-.01 CIT-3-F & 1032.22 & 5.008 & 5.169 & 72.400 & 3.258 & $63 \%$ & 6.304 & 381.661 \\
\hline R111-S039-.01 CIT-3-F/C & 1032.22 & 5.008 & 5.169 & 77.240 & 3.476 & $67 \%$ & 6.304 & 338.170 \\
\hline R111-S039-.01 CIT-3-F-DUP & 1032.22 & 5.008 & 5.169 & 70.230 & 3.160 & $61 \%$ & 6.304 & 401.160 \\
\hline R111-S039-.01 CIT-5 & 1032.22 & 5.041 & 5.203 & 39.280 & 1.768 & $34 \%$ & 6.321 & 681.575 \\
\hline R111-S039-.01 CIT-5-F & 1032.22 & 5.041 & 5.203 & 41.260 & 1.857 & $36 \%$ & 6.321 & 663.900 \\
\hline R111-S039-.01 CIT-5-F/C & 1032.22 & 5.041 & 5.203 & 46.440 & 2.090 & $40 \%$ & 6.321 & 617.659 \\
\hline R111-S039-.01 CIT-5-F-DUP & 1032.22 & 5.041 & 5.203 & 41.680 & 1.876 & $36 \%$ & 6.321 & 660.151 \\
\hline R111-S039-.01 CIT-7 & 1032.22 & 5.029 & 5.191 & 39.640 & 1.784 & $34 \%$ & 7.421 & 677.517 \\
\hline R111-S039-.01 ClT-7-F & 1032.22 & 5.029 & 5.191 & 33.710 & 1.517 & $29 \%$ & 7.421 & 730.580 \\
\hline R111-S039-.01 CIT-7-F/C & 1032.22 & 5.029 & 5.191 & 35.120 & 1.580 & $30 \%$ & 7.421 & 717.963 \\
\hline
\end{tabular}


Ba Removed by Batch Shaker Method

\begin{tabular}{|c|c|c|c|c|c|c|c|c|}
\hline & $\mathrm{Ba}$ & Wt. of Soil & Ba in & $\mathrm{Ba}$ & Ba in & $\% \mathrm{Ba}$ & $\mathrm{pH}$ of & Ba Remaining \\
\hline SAMPLE \# & $(\mathbf{m g} / \mathbf{k g})$ & (g) & Soil (mg) & $(\mathrm{mg} / \mathrm{L})$ & sample (mg) & Removed & Sample & in Soil (mg/kg) \\
\hline R111-S039-.01 CIT-7-F-DUP & 1032.22 & 5.029 & 5.191 & 28.510 & 1.283 & $25 \%$ & 7.421 & 777.110 \\
\hline R1t1-S041-.01 CIT-3 & 728.04 & 5.002 & 3.642 & 117.530 & 5.289 & $145 \%$ & 5.861 & -329.307 \\
\hline R111-S041-.01 CIT-3-F & 728.04 & 5.002 & 3.642 & 108.940 & 4.902 & $135 \%$ & 5.861 & -252.028 \\
\hline $\mathrm{R} 111-\mathrm{S} 041-.01 \mathrm{CIT}-3-\mathrm{F} / \mathrm{C}$ & 728.04 & 5.002 & 3.642 & 124.810 & 5.616 & $154 \%$ & 5.861 & -394.801 \\
\hline R111-S041-.01 CIT-3-F-DUP & 728.04 & 5.002 & 3.642 & 98.780 & 4.445 & $122 \%$ & 5.861 & -160.625 \\
\hline R111-S041-.01 CIT-5 & 728.04 & 5.036 & 3.666 & 49.700 & 2.237 & $61 \%$ & 6.498 & 283.938 \\
\hline R111-S041-.01 CIT-5-F & 728.04 & 5.036 & 3.666 & 23.780 & 1.070 & $29 \%$ & 6.498 & 515.550 \\
\hline R111-S041-.01 CIT-5-F/C & 728.04 & 5.036 & 3.666 & 26.640 & 1.199 & $33 \%$ & 6.498 & 489.994 \\
\hline R111-S041-.01 CIT-5-F-DUP & 728.04 & 5.036 & 3.666 & 22.860 & 1.029 & $28 \%$ & 6.498 & 523.771 \\
\hline R111-S041-.01 CIT-7 & 728.04 & 5.041 & 3.670 & 43.970 & 1.979 & $54 \%$ & 7.601 & 335.529 \\
\hline R111-S041-.01 CIT-7-F & 728.04 & 5.041 & 3.670 & 23.250 & 1.046 & $29 \%$ & 7.601 & 520.492 \\
\hline R111-S041-.01 CIT-7-F/C & 728.04 & 5.041 & 3.670 & 21.710 & 0.977 & $27 \%$ & 7.601 & 534.239 \\
\hline R111-S04t-.01 CIT-7-F-DUP & 728.04 & 5.041 & 3.670 & 18.790 & 0.846 & $23 \%$ & 7.601 & 560.305 \\
\hline R111-S044-.01 CIT-3 & 803.63 & 5.021 & 4.036 & 80.060 & 3.603 & $89 \%$ & 6.432 & 86.304 \\
\hline R111-S044-.01 CIT-3-F & 803.83 & 5.021 & 4.036 & 66.520 & 2.993 & $74 \%$ & 6.432 & 207.654 \\
\hline R111-S044-.01 CIT-3-F/C & 803.83 & 5.021 & 4.036 & 76.420 & 3.439 & $85 \%$ & 6.432 & 118.927 \\
\hline R111-S044-.01 CIT-3-F-DUP & 803.83 & 5.021 & 4.036 & 65.720 & 2.957 & $73 \%$ & 6.432 & 214.824 \\
\hline R111-S044-.01 CIT-5 & 803.83 & 5.021 & 4.036 & 32.170 & 1.448 & $36 \%$ & 6.747 & 515.511 \\
\hline R111-S044-.01 ClT-5-F & 803.83 & 5.021 & 4.036 & 34.910 & 1.571 & $39 \%$ & 6.747 & 490.954 \\
\hline R111-S044-.01 CIT-5-F/C & 803.83 & 5.021 & 4.036 & 34.070 & 1.533 & $38 \%$ & 6.747 & 498.482 \\
\hline R111-S044-.01 CIT-5-F-DUP & 803.83 & 5.021 & 4.036 & 32.680 & 1.471 & $36 \%$ & 6.747 & 510.940 \\
\hline R1+1-S044-.01 CIT-7 & 803.83 & 5.041 & 4.052 & 37.970 & 1.709 & $42 \%$ & 7.261 & 464.879 \\
\hline Ri11-S044-.01 ClT-7-F & 803.83 & 5.041 & 4.052 & 17.190 & 0.774 & $19 \%$ & 7.261 & 650.378 \\
\hline Ri111-S044-.01 CIT-7-F/C & 803.83 & 5.041 & 4.052 & 51.080 & 2.299 & $57 \%$ & 7.261 & 347.849 \\
\hline R111-S044-.01 CIT-7-F-DUP & 803.83 & 5.041 & 4.052 & 16.390 & 0.738 & $18 \%$ & 7.261 & 657.520 \\
\hline Rt11-S049-.01 CIT-3 & 19.93 & 5.030 & 0.100 & 0.400 & 0.018 & $18 \%$ & 3.257 & 16.351 \\
\hline A11t-S049-.01 CIT-3-F & 19.93 & 5.030 & 0.100 & 0.260 & 0.012 & $12 \%$ & $3: 257$ & 17.604 \\
\hline R111-S049-.01 CIT-3-F/C & 19.93 & 5.030 & 0.100 & 0.420 & 0.019 & $19 \%$ & 3.257 & 16.173 \\
\hline R111-S049-.01 CIT-3-F-DUP & 19.93 & 5.030 & 0.100 & 0.250 & 0.011 & $11 \%$ & 3.257 & 17.693 \\
\hline Ri11-S049-.01 CIT-5 & 19.93 & 5.009 & 0.100 & 0.580 & 0.026 & $26 \%$ & 5.163 & 14.719 \\
\hline R111-S049-.01 GIT-5-F & 19.93 & 5.009 & 0.100 & 0.250 & 0.011 & $11 \%$ & 5.163 & 17.684 \\
\hline Rt111-S049-.01 CIT-5-F/C & 19.93 & 5.009 & 0.100 & 0.250 & 0.011 & $11 \%$ & 5.163 & 17.684 \\
\hline R111-S049-.01 CIT-5-F-DUP & 19.93 & 5.009 & 0.100 & 0.250 & 0.011 & $11 \%$ & 5.163 & 17.684 \\
\hline Rt11-S049-.01 CIT-7 & 19.93 & 5.008 & 0.100 & 0.870 & 0.039 & $39 \%$ & 7.093 & 12.113 \\
\hline R111-S049-01 CIT-7-F & 19.93 & 5.008 & 0.100 & 1.330 & 0.060 & $60 \%$ & 7.093 & 7.979 \\
\hline
\end{tabular}


Ba Removed by Batch Shaker Method

\begin{tabular}{|c|c|c|c|c|c|c|c|c|}
\hline & $\mathrm{Ba}$ & Wt. of Soil & Ba in & $\mathrm{Ba}$ & Ba in & $\% \mathbf{B a}$ & pH of & Ba Remaining \\
\hline SAMPLE \# & $(\mathbf{m g} / \mathbf{k g})$ & (g) & Soil (mg) & $(\mathrm{mg} / \mathrm{L})$ & sample (mg) & Removed & Sample & in Soil $(\mathrm{mg} / \mathrm{kg})$ \\
\hline R111-S049-.01 CIT-7-F/C & 19.93 & 5.008 & 0.100 & 60.920 & 2.741 & $2747 \%$ & 7.093 & -527.474 \\
\hline R111-S049-.01 CIT-7-F-DUP & 19.93 & 5.008 & 0.100 & 0.470 & 0.021 & $21 \%$ & 7.093 & 15.707 \\
\hline R111-S037-.01 EDTA-3 & 980.36 & 5.008 & 4.910 & 96.350 & 4.336 & $88 \%$ & 6.715 & 114.595 \\
\hline R111-S037-.01 EDTA-3-F & 980.36 & 5.008 & 4.910 & 80.030 & 3.601 & $73 \%$ & 6.715 & 261.241 \\
\hline R111-S037-.01 EDTA-3-F/C & 980.36 & 5.008 & 4.910 & 82.100 & 3.695 & $75 \%$ & 6.715 & 242.640 \\
\hline R111-S037-.01 EDTA-3-F-DUP & 980.36 & 5.008 & 4.910 & 77.720 & 3.497 & $71 \%$ & 6.715 & 281.997 \\
\hline R111-S037-.01 EDTA-5 & 980.36 & 5.007 & 4.909 & 42.580 & 1.916 & $39 \%$ & 7.113 & 597.676 \\
\hline R111-S037-.01 EDTA-5-F & 980.36 & 5.007 & 4.909 & 39.800 & 1.791 & $36 \%$ & 7.113 & 622.661 \\
\hline R111-S037-.01 EDTA-5-F/C & 980.36 & 5.007 & 4.909 & 38.640 & 1.739 & $35 \%$ & 7.113 & 633.086 \\
\hline R111-S037-.01 EDTA-5-F-DUP & 980.36 & 5.007 & 4.909 & 38.900 & 1.751 & $36 \%$ & 7.113 & 630.749 \\
\hline R111-S037-.01 EDTA-7 & 980.36 & 5.010 & 4.912 & 37.700 & 1.697 & $35 \%$ & 7.229 & 641.737 \\
\hline R111-S037-.01 EDTA-7-F & 980.36 & 5.010 & 4.912 & 30.450 & 1.370 & $28 \%$ & 7.229 & 706.857 \\
\hline R111-S037-.01 EDTA-7-F/C & 980.36 & 5.010 & 4.912 & 40.930 & 1.842 & $37 \%$ & 7.229 & 612.725 \\
\hline R111-S037-.01 EDTA-7-F-DUP & 980.36 & 5.010 & 4.912 & 29.940 & 1.347 & $27 \%$ & 7.229 & 711.438 \\
\hline R111-S038-.01 EDTA-3 & 1050.17 & 5.024 & 5.276 & 102.020 & 4.591 & $87 \%$ & 6.884 & 136.376 \\
\hline R111-S038-.01 EDTA-3-F & 1050.17 & 5.024 & 5.276 & 91.610 & 4.122 & $78 \%$ & 6.884 & 229.619 \\
\hline R111-S038-.01 EDTA-3-F/C & 1050.17 & 5.024 & 5.276 & 91.210 & 4.104 & $78 \%$ & 6.884 & 233.201 \\
\hline R111-S038-.01 EDTA-3-F-DUP & 1050.17 & 5.024 & 5.276 & 84.030 & 3.781 & $72 \%$ & 6.884 & 297.513 \\
\hline R111-S038-.01 EDTA-5 & 1050.17 & 5.009 & 5.260 & 51.090 & 2.299 & $44 \%$ & 6.982 & 591.186 \\
\hline R111-S038-.01 EDTA-5-F & 1050.17 & 5.009 & 5.260 & 49.750 & 2.239 & $43 \%$ & 6.982 & 603.225 \\
\hline R111-S038-.01 EDTA-5-F/C & 1050.17 & 5.009 & 5.260 & 50.390 & 2.268 & $43 \%$ & 6.982 & 597.475 \\
\hline R111-S038-.01 EDTA-5-F-DUP & 1050.17 & 5.009 & 5.260 & 41.950 & 1.888 & $36 \%$ & 6.982 & 673.298 \\
\hline R111-S038-.01 EDTA-7 & 1050.17 & 5.019 & 5.271 & 40.960 & 1.843 & $35 \%$ & 7.204 & 682.926 \\
\hline R111-S038-.01 EDTA-7-F & 1050.17 & 5.019 & 5.271 & 35.400 & 1.593 & $30 \%$ & 7.204 & 732.776 \\
\hline$R 111-5038-.01$ EDTA-7-F/C & 1050.17 & 5.019 & 5.271 & 28.230 & 1.270 & $24 \%$ & 7.204 & 797.062 \\
\hline R111-S038-.01 EDTA-7-F-DUP & 1050.17 & 5.019 & 5.271 & 29.880 & 1.345 & $26 \%$ & 7.204 & 782.268 \\
\hline R111-S039-.01 EDTA-3 & 1032.22 & 5.026 & 5.188 & 135.550 & 6.100 & $118 \%$ & 6.401 & -181.419 \\
\hline R111-S039-.01 EDTA-3-F & 1032.22 & 5.026 & 5.188 & 99.610 & 4.482 & $86 \%$ & 6.401 & 140.368 \\
\hline R111-S039-.01 EDTA-3-F/C & 1032.22 & 5.026 & 5.188 & 136.690 & 6.151 & $119 \%$ & 6.401 & -191.626 \\
\hline R111-S039-.01 EDTA-3-F-DUP & 1032.22 & 5.026 & 5.188 & 110.070 & 4.953 & $95 \%$ & 6.401 & 46.715 \\
\hline R111-S039-.01 EDTA-5 & 1032.22 & 5.041 & 5.203 & 57.200 & 2.574 & $49 \%$ & 6.854 & 521.607 \\
\hline R111-S039-.01 EDTA-5-F & 1032.22 & 5.041 & 5.203 & 46.220 & 2.080 & $40 \%$ & 6.854 & 619.623 \\
\hline R111-S039-.01 EDTA-5-F/C & 1032.22 & 5.041 & 5.203 & 54.020 & 2.431 & $47 \%$ & 6.854 & 549.994 \\
\hline R111-S039-.01 EDTA-5-F-DUP & 1032.22 & 5.041 & 5.203 & 46.820 & 2.107 & $40 \%$ & 6.854 & 614.267 \\
\hline B111-S039-.01 EDTA-7 & 1032.22 & 5.031 & 5.193 & 35.870 & 1.614 & $31 \%$ & 7.186 & 711.379 \\
\hline
\end{tabular}


Ba Removed by Batch Shaker Method

\begin{tabular}{|c|c|c|c|c|c|c|c|c|}
\hline & $\mathrm{Ba}$ & Wt. of Soil & Ba in & $\mathbf{B a}$ & Ba in & $\% \mathbf{B a}$ & $\mathrm{pH}$ of & Ba Remaining \\
\hline SAMPLE \# & $(\mathbf{m g} / \mathbf{k g})$ & (g) & Soil (mg) & $(\mathrm{mg} / \mathrm{L})$ & sample (mg) & Removed & Sample & in Soil $(\mathrm{mg} / \mathrm{kg})$ \\
\hline R111-S039-.01 EDTA-7-F & 1032.22 & 5.031 & 5.193 & 46.110 & 2.075 & $40 \%$ & 7.186 & 619.787 \\
\hline R111-S039-.01 EDTA-7-F/C & 1032.22 & 5.031 & 5.193 & 45.250 & 2.036 & $39 \%$ & 7.186 & 627.479 \\
\hline R111-S039-.01 EDTA-7-F-DUP & 1032.22 & 5.031 & 5.193 & 33.930 & 1.527 & $29 \%$ & 7.186 & 728.732 \\
\hline R111-S041-.01 EDTA-3 & 728.04 & 5.031 & 3.663 & 82.660 & 3.720 & $102 \%$ & 6.214 & -11.316 \\
\hline R111-S041-.01 EDTA-3-F & 728.04 & 5.031 & 3.663 & 87.910 & 3.956 & $108 \%$ & 6.214 & -58.275 \\
\hline R111-S041-.01 EDTA-3-F/C & 728.04 & 5.031 & 3.663 & 85.390 & 3.843 & $105 \%$ & 6.214 & $-\mathbf{3 5 . 7 3 5}$ \\
\hline R111-S041-.01 EDTA-3-F-DUP & 728.04 & 5.031 & 3.663 & 77.970 & 3.509 & $96 \%$ & 6.214 & 30.634 \\
\hline R111-S041-.01 EDTA-5 & 728.04 & 5.036 & 3.666 & 51.390 & 2.313 & $63 \%$ & 6.887 & 268.836 \\
\hline R111-S041-.01 EDTA-5-F & 728.04 & 5.036 & 3.666 & 52.770 & 2.375 & $65 \%$ & 6.887 & 256.505 \\
\hline R111-S041-.01 EDTA-5-F/C & 728.04 & 5.036 & 3.666 & 53.950 & 2.428 & $66 \%$ & 6.887 & 245.961 \\
\hline R111-S041-.01 EDTA-5-F-DUP & 728.04 & 5.036 & 3.666 & 49.290 & 2.218 & $60 \%$ & 6.887 & 287.601 \\
\hline R111-S041-.01 EDTA-7 & 728.04 & 5.027 & 3.660 & 30.090 & 1.354 & $37 \%$ & 7.431 & 458.685 \\
\hline R111-S041-.01 EDTA-7-F & 728.04 & 5.027 & 3.660 & 35.020 & 1.576 & $43 \%$ & 7.431 & 414.553 \\
\hline R111-S041-.01 EDTA-7-F/C & 728.04 & 5.027 & 3.660 & 34.800 & 1.566 & $43 \%$ & 7.431 & 416.522 \\
\hline R111-S041-.01 EDTA-7-F-DUP & 728.04 & 5.027 & 3.660 & 29.200 & 1.314 & $36 \%$ & 7.431 & 466.651 \\
\hline R111-S044-.01 EDTA-3 & 803.83 & 5.036 & 4.048 & 71.390 & 3.213 & $79 \%$ & 6.701 & 165.913 \\
\hline R111-S044-.01 EDTA-3-F & 803.83 & 5.036 & 4.048 & 79.820 & 3.592 & $89 \%$ & 6.701 & 90.585 \\
\hline R111-S044-.01 EDTA-3-F/C & 803.83 & 5.036 & 4.048 & 76.420 & 3.439 & $85 \%$ & 6.701 & 120.967 \\
\hline R111-S044-.01 EDTA-3-F-DUP & 803.83 & 5.036 & 4.048 & 77.370 & 3.482 & $86 \%$ & 6.701 & 112.478 \\
\hline R111-S044-.01 EDTA-5 & 803.83 & 5.034 & 4.046 & 47.250 & 2.126 & $53 \%$ & 6.321 & 381.452 \\
\hline R111-S044-.01 EDTA-5-F & 803.83 & 5.034 & 4.046 & 59.970 & 2.699 & $67 \%$ & 6.321 & 267.745 \\
\hline R111-S044-.01 EDTA-5-F/C & 803.83 & 5.034 & 4.046 & 51.930 & 2.337 & $58 \%$ & 6.321 & 339.617 \\
\hline R111-S044-.01 EDTA-5-F-DUP & 803.83 & 5.034 & 4.046 & 48.780 & 2.195 & $54 \%$ & 6.321 & 367.775 \\
\hline R111-S044-.01 EDTA-7 & 803.83 & 5.013 & 4.030 & 34.660 & 1.560 & $39 \%$ & 7.847 & 492.699 \\
\hline R111-S044-.01 EDTA-7-F & 803.83 & 5.013 & 4.030 & 39.350 & 1.771 & $44 \%$ & 7.847 & 450.598 \\
\hline R111-S044-.01 EDTA-7-F/C & 803.83 & 5.013 & 4.030 & 36.770 & 1.655 & $41 \%$ & 7.847 & 473.758 \\
\hline R111-S044-.01 EDTA-7-F-DUP & 803.83 & 5.013 & 4.030 & 29.810 & 1.341 & $33 \%$ & 7.847 & 536.236 \\
\hline R111-S049-.01 EDTA-3 & 19.93 & 5.041 & 0.100 & 0.250 & 0.011 & $11 \%$ & 3.183 & 17.698 \\
\hline R111-S049-.01 EDTA-3-F & 19.93 & 5.041 & 0.100 & 0.260 & 0.012 & $12 \%$ & 3.183 & 17.609 \\
\hline R111-S049-.01 EDTA-3-F/C & 19.93 & 5.041 & 0.100 & 0.550 & 0.025 & $25 \%$ & 3.183 & 15.020 \\
\hline R111-S049-.01 EDTA-3-F-DUP & 19.93 & 5.041 & 0.100 & 0.250 & 0.011 & $11 \%$ & 3.183 & 17.698 \\
\hline R111-S049-.01 EDTA-5 & 19.93 & 5.027 & 0.100 & 0.320 & 0.014 & $14 \%$ & 5.076 & 17.065 \\
\hline R111-S049-.01 EDTA-5-F & 19.93 & 5.027 & 0.100 & 0.290 & 0.013 & $13 \%$ & 5.076 & 17.334 \\
\hline R111-S049-.01 EDTA-5-F/C & 19.93 & 5.027 & 0.100 & 0.250 & 0.011 & $11 \%$ & 5.076 & 17.692 \\
\hline R111-S049-.01 EDTA-5-F-DUP & 19.93 & 5.027 & 0.100 & 0.250 & 0.011 & $11 \%$ & 5.076 & 17.692 \\
\hline
\end{tabular}


Ba Removed by Batch Shaker Method

\begin{tabular}{|l|c|c|c|c|c|c|c|c|}
\hline & Ba & Wt. of Soil & Ba in & Ba & Ba in & $\%$ Ba & pH of & Ba Remaining \\
\hline \multicolumn{1}{|c|}{ SAMPLE\# } & $(\mathbf{m g} / \mathbf{k g})$ & $(\mathbf{g})$ & Soil $(\mathbf{m g})$ & $(\mathbf{m g} / \mathbf{L})$ & sample $(\mathbf{m g})$ & Removed & Sample & in Soil (mg/kg) \\
\hline & & & & & & & & \\
\hline R111-S049-.01 EDTA-7 & 19.93 & 5.033 & 0.100 & 2.090 & 0.094 & $94 \%$ & 7.101 & 1.243 \\
\hline R111-S049-.01 EDTA-7-F & 19.93 & 5.033 & 0.100 & 2.150 & 0.097 & $96 \%$ & 7.101 & 0.707 \\
\hline R111-S049-.01 EDTA-7-F/C & 19.93 & 5.033 & 0.100 & 3.050 & 0.137 & $137 \%$ & 7.101 & -7.340 \\
\hline R111-S049-.01 EDTA-7-F-DUP & 19.93 & 5.033 & 0.100 & 1.110 & 0.050 & $50 \%$ & 7.101 & 10.006 \\
\hline
\end{tabular}




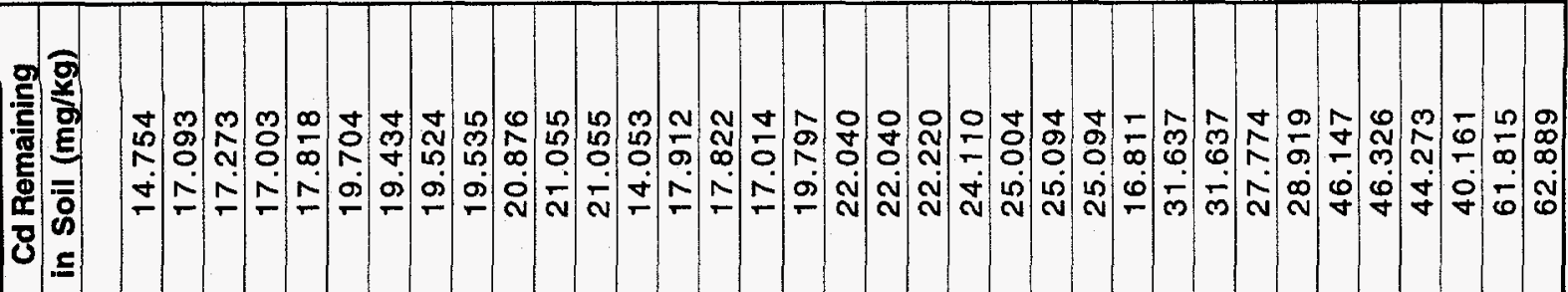

ப은

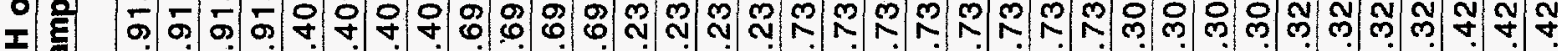
产

8 రె口 。

की

을

(5)

น

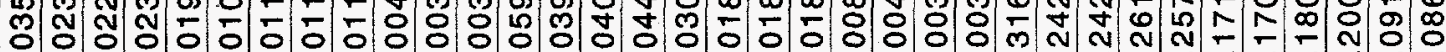

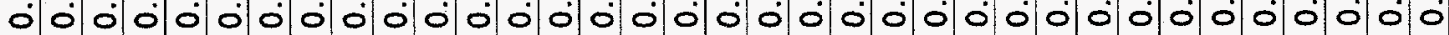
के

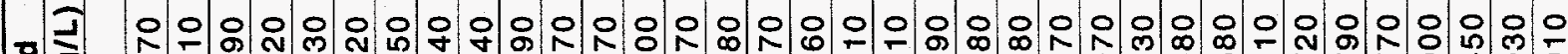

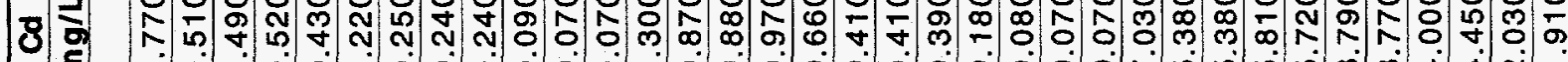

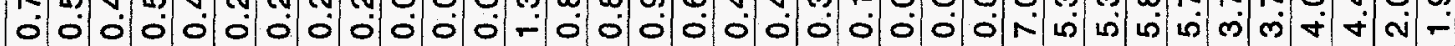

\section{돌 몰}

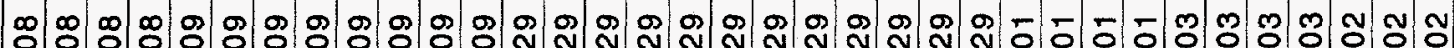

$8 \%$

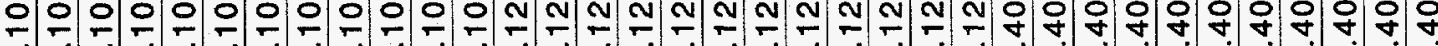

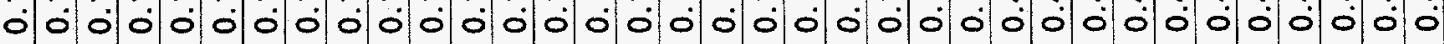

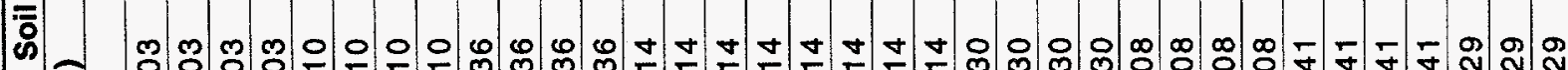
कृ

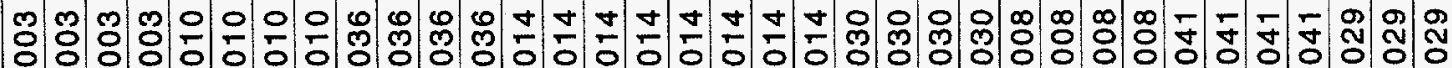
3

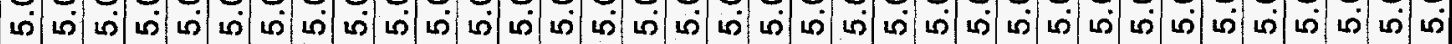

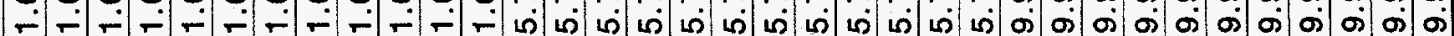

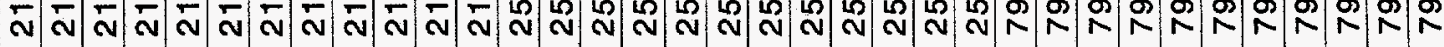

4

$\frac{1}{2}$

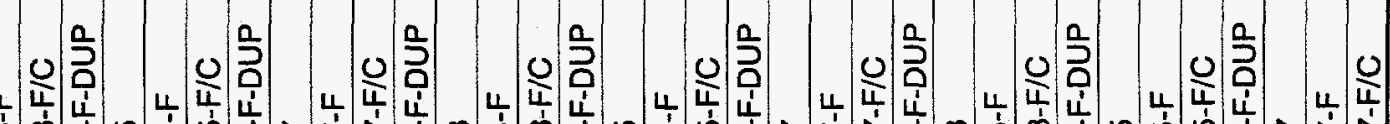

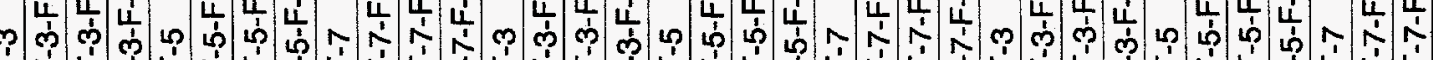

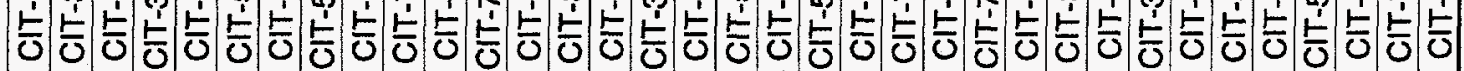
б б 穴

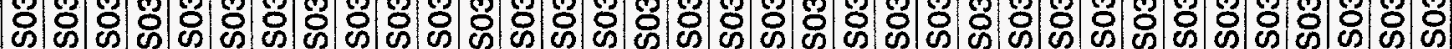

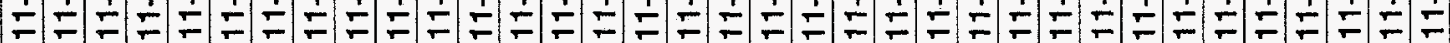

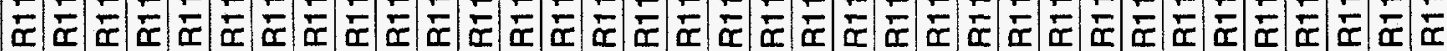


Cd Removed by Batch Shaker Method

\begin{tabular}{|c|c|c|c|c|c|c|c|c|}
\hline & Cd & Wt. of Soil & Cd in & $\mathrm{Cd}$ & Cd in & $\% \mathbf{C d}$ & $\mathrm{pH}$ of & Cd Remaining \\
\hline SAMPLE \# & $(\mathbf{m g} / \mathbf{k g})$ & (g) & Soil (mg) & (mg/L) & Sample (mg) & Removed & Sample & in Soil ( $\mathbf{m g} / \mathbf{k g})$ \\
\hline R111-S039-.01 CIT-7-F-DUP & 79.98 & 5.029 & 0.402 & 2.120 & 0.095 & $24 \%$ & 7.421 & 61.010 \\
\hline $\mathrm{R} 111-\mathrm{S} 041-.01 \mathrm{CIT}-3$ & 50.75 & 5.002 & 0.254 & 6.600 & 0.297 & $117 \%$ & 5.861 & -8.626 \\
\hline R111-S041-.01 CIT-3-F & 50.75 & 5.002 & 0.254 & 5.080 & 0.229 & $90 \%$ & 5.861 & 5.048 \\
\hline R111-S041-.01 CIT-3-F/C & 50.75 & 5.002 & 0.254 & 5.300 & 0.239 & $94 \%$ & 5.861 & 3.069 \\
\hline R111-S041-.01 CIT-3-F-DUP & 50.75 & 5.002 & 0.254 & 5.490 & 0.247 & $97 \%$ & 5.861 & 1.360 \\
\hline R111-S041-.01 CIT-5 & 50.75 & 5.036 & 0.256 & 3.750 & 0.169 & $66 \%$ & 6.498 & 17.241 \\
\hline R111-S041-.01 CIT-5-F & 50.75 & 5.036 & 0.256 & 1.160 & 0.052 & $20 \%$ & 6.498 & 40.385 \\
\hline R111-S041-.01 CIT-5-F/C & 50.75 & 5.036 & 0.256 & 1.220 & 0.055 & $21 \%$ & 6.498 & 39.848 \\
\hline R111-S041-.01 CIT-5-F-DUP & 50.75 & 5.036 & 0.256 & 1.180 & 0.053 & $21 \%$ & 6.498 & 40.206 \\
\hline R111-S041-.01 CIT-7 & 50.75 & 5.041 & 0.256 & 4.260 & 0.192 & $75 \%$ & 7.601 & 12.722 \\
\hline R111-S041-.01 CIT-7-F & 50.75 & 5.041 & 0.256 & 1.280 & 0.058 & $23 \%$ & 7.601 & 39.324 \\
\hline R111-S041-.01 CIT-7-F/C & 50.75 & 5.041 & 0.256 & 1.360 & 0.061 & $24 \%$ & 7.601 & 38.610 \\
\hline R111-S041-.01 CIT-7-F-DUP & 50.75 & 5.041 & 0.256 & 1.190 & 0.054 & $21 \%$ & 7.601 & 40.127 \\
\hline R111-S044-.01 CIT-3 & 17.26 & 5.021 & 0.087 & 1.130 & 0.051 & $59 \%$ & 6.432 & 7.133 \\
\hline R111-S044-.01 CIT-3-F & 17.26 & 5.021 & 0.087 & 0.580 & 0.026 & $30 \%$ & 6.432 & 12.062 \\
\hline R111-S044-.01 CIT-3-F/C & 17.26 & 5.021 & 0.087 & 0.620 & 0.028 & $32 \%$ & 6.432 & 11.703 \\
\hline R111-S044-.01 CIT-3-F-DUP & 17.26 & 5.021 & 0.087 & 0.630 & 0.028 & $33 \%$ & 6.432 & 11.614 \\
\hline R111-S044-.01 CIT-5 & 17.26 & 5.021 & 0.087 & 0.400 & 0.018 & $21 \%$ & 6.747 & 13.675 \\
\hline R111-S044-.01 CIT-5-F & 17.26 & 5.021 & 0.087 & 0.190 & 0.009 & $10 \%$ & 6.747 & 15.557 \\
\hline R111-S044-.01 CIT-5-F/C & 17.26 & 5.021 & 0.087 & 0.200 & 0.009 & $10 \%$ & 6.747 & 15.468 \\
\hline R111-S044-.01 CIT-5-F-DUP & 17.26 & 5.021 & 0.087 & 0.190 & 0.009 & $10 \%$ & 6.747 & 15.557 \\
\hline R111-S044-.01 CIT-7 & 17.26 & 5.041 & 0.087 & 0.790 & 0.036 & $41 \%$ & 7.261 & 10.208 \\
\hline R111-S044-.01 CIT-7-F & 17.26 & 5.041 & 0.087 & 0.340 & 0.015 & $18 \%$ & 7.261 & 14.225 \\
\hline R111-S044-.01 CIT-7-F/C & 17.26 & 5.041 & 0.087 & 0.370 & 0.017 & $19 \%$ & 7.261 & 13.957 \\
\hline R111-S044-.01 CIT-7-F-DUP & 17.26 & 5.041 & 0.087 & 0.320 & 0.014 & $17 \%$ & 7.261 & 14.403 \\
\hline R111-S049-.01 CIT-3 & 0.38 & 5.030 & 0.002 & 0.05 & 0.002 & $118 \%$ & 3.257 & -0.067 \\
\hline R111-S049-.01 CIT-3-F & 0.38 & 5.030 & 0.002 & 0.05 & 0.002 & $118 \%$ & 3.257 & -0.067 \\
\hline R111-S049-.01 CIT-3-F/C & 0.38 & 5.030 & 0.002 & 0.05 & 0.002 & $118 \%$ & 3.257 & -0.067 \\
\hline R111-S049-.01 CIT-3-F-DUP & 0.38 & 5.030 & 0.002 & 0.05 & 0.002 & $118 \%$ & 3.257 & -0.067 \\
\hline R111-S049-.01 CIT-5 & 0.38 & 5.009 & 0.002 & 0.05 & 0.002 & $118 \%$ & 5.163 & -0.069 \\
\hline R111-S049-.01 CIT-5-F & 0.38 & 5.009 & 0.002 & 0.05 & 0.002 & $118 \%$ & 5.163 & -0.069 \\
\hline R111-S049-.01 CIT-5-F/C & 0.38 & 5.009 & 0.002 & 0.05 & 0.002 & $118 \%$ & 5.163 & -0.069 \\
\hline R111-S049-.01 CIT-5-F-DUP & 0.38 & 5.009 & 0.002 & 0.05 & 0.002 & $118 \%$ & 5.163 & -0.069 \\
\hline R111-S049-.01 CIT-7 & 0.38 & 5.008 & 0.002 & 0.05 & 0.002 & $118 \%$ & 7.093 & -0.069 \\
\hline R111-S049-.01 CIT-7-F & 0.38 & 5.008 & 0.002 & 0.05 & 0.002 & $118 \%$ & 7.093 & -0.069 \\
\hline
\end{tabular}


Cd Removed by Batch Shaker Method

\begin{tabular}{|c|c|c|c|c|c|c|c|c|}
\hline & Cd & Wt. of Soil & Cd in & Cd & Cd in & $\% \mathbf{C d}$ & pH of & Cd Remaining \\
\hline SAMPLE\# & $(\mathbf{m g} / \mathbf{k g})$ & (g) & Soil (mg) & $(\mathrm{mg} / \mathrm{L})$ & Sample (mg) & Removed & Sample & in Soil $(\mathrm{mg} / \mathrm{kg})$ \\
\hline R111-S049-.01 CIT-7-F/C & 0.38 & 5.008 & 0.002 & 0.05 & 0.002 & $118 \%$ & 7.093 & -0.069 \\
\hline R111-S049-.01 CIT-7-F-DUP & 0.38 & 5.008 & 0.002 & 0.05 & 0.002 & $118 \%$ & 7.093 & -0.069 \\
\hline R111-S037-.01 EDTA-3 & 21.68 & 5.008 & 0.109 & 1.160 & 0.052 & $48 \%$ & 6.715 & 11.257 \\
\hline R111-S037-.01 EDTA-3-F & 21.68 & 5.008 & 0.109 & 1.080 & 0.049 & $45 \%$ & 6.715 & 11.976 \\
\hline R111-S037-.01 EDTA-3-F/C & 21.68 & 5.008 & 0.109 & 1.170 & 0.053 & $48 \%$ & 6.715 & 11.167 \\
\hline R111-S037-.01 EDTA-3-F-DUP & 21.68 & 5.008 & 0.109 & 1.130 & 0.051 & $47 \%$ & 6.715 & 11.526 \\
\hline R111-S037-.01 EDTA-5 & 21.68 & 5.007 & 0.109 & 1.000 & 0.045 & $41 \%$ & 7.113 & 12.693 \\
\hline R111-S037-.01 EDTA-5-F & 21.68 & 5.007 & 0.109 & 1.080 & 0.049 & $45 \%$ & 7.113 & 11.974 \\
\hline R111-S037-.01 EDTA-5-F/C & 21.68 & 5.007 & 0.109 & 1.150 & 0.052 & $48 \%$ & 7.113 & 11.344 \\
\hline R111-S037-.01 EDTA-5-F-DUP & 21.68 & 5.007 & 0.109 & 1.200 & 0.054 & $50 \%$ & 7.113 & 10.895 \\
\hline R111-S037-.01 EDTA-7 & 21.68 & 5.010 & 0.109 & 0.680 & 0.031 & $28 \%$ & 7.229 & 15.572 \\
\hline R111-S037-.01 EDTA-7-F & 21.68 & 5.010 & 0.109 & 0.710 & 0.032 & $29 \%$ & 7.229 & 15.303 \\
\hline R111-S037-.01 EDTA-7-F/C & 21.68 & 5.010 & 0.109 & 0.700 & 0.032 & $29 \%$ & 7.229 & 15.393 \\
\hline R111-S037-.01 EDTA-7-F-DUP & 21.68 & 5.010 & 0.109 & 0.710 & 0.032 & $29 \%$ & 7.229 & 15.303 \\
\hline R111-S038-.01 EDTA-3 & 25.72 & 5.024 & 0.129 & 1.810 & 0.081 & $63 \%$ & 6.884 & 9.508 \\
\hline R111-S038-.01 EDTA-3-F & 25.72 & 5.024 & 0.129 & 1.750 & 0.079 & $61 \%$ & 6.884 & 10.045 \\
\hline R111-S038-.01 EDTA-3-F/C & 25.72 & 5.024 & 0.129 & 1.650 & 0.074 & $57 \%$ & 6.884 & 10.941 \\
\hline R111-S038-.01 EDTA-3-F-DUP & 25.72 & 5.024 & 0.129 & 1.760 & 0.079 & $61 \%$ & 6.884 & 9.956 \\
\hline R111-S038-.01 EDTA-5 & 25.72 & 5.009 & 0.129 & 1.160 & 0.052 & $41 \%$ & 6.982 & 15.299 \\
\hline R111-S038-.01 EDTA-5-F & 25.72 & 5.009 & 0.129 & 1.210 & 0.054 & $42 \%$ & 6.982 & 14.850 \\
\hline R111-S038-.01 EDTA-5-F/C & 25.72 & 5.009 & 0.129 & 1.180 & 0.053 & $41 \%$ & 6.982 & 15.119 \\
\hline R111-S038-.01 EDTA-5-F-DUP & 25.72 & 5.009 & 0.129 & 1.330 & 0.060 & $46 \%$ & 6.982 & 13.772 \\
\hline R111-S038-.01 EDTA-7 & 25.72 & 5.019 & 0.129 & 0.940 & 0.042 & $33 \%$ & 7.204 & 17.292 \\
\hline R111-S038-.01 EDTA-7-F & 25.72 & 5.019 & 0.129 & 1.070 & 0.048 & $37 \%$ & 7.204 & 16.126 \\
\hline R111-S038-.01 EDTA-7-F/C & 25.72 & 5.019 & 0.129 & 1.190 & 0.054 & $41 \%$ & 7.204 & 15.051 \\
\hline R111-S038-.01 EDTA-7-F-DUP & 25.72 & 5.019 & 0.129 & 1.030 & 0.046 & $36 \%$ & 7.204 & 16.485 \\
\hline R111-S039-.01 EDTA-3 & 79.98 & 5.026 & 0.402 & 8.940 & 0.402 & $100 \%$ & 6.401 & -0.064 \\
\hline R111-S039-.01 EDTA-3-F & 79.98 & 5.026 & 0.402 & 8.590 & 0.387 & $96 \%$ & 6.401 & 3.070 \\
\hline R111-S039-.01 EDTA-3-F/C & 79.98 & 5.026 & 0.402 & 8.880 & 0.400 & $99 \%$ & 6.401 & 0.473 \\
\hline R111-S039-.01 EDTA-3-F-DUP & 79.98 & 5.026 & 0.402 & 9.260 & 0.417 & $104 \%$ & 6.401 & -2.929 \\
\hline R111-S039-.01 EDTA-5 & 79.98 & 5.041 & 0.403 & 7.730 & 0.348 & $86 \%$ & 6.854 & 10.976 \\
\hline R111-S039-.01 EDTA-5-F & 79.98 & 5.041 & 0.403 & 7.500 & 0.338 & $84 \%$ & 6.854 & 13.029 \\
\hline R111-S039-.01 EDTA-5-F/C & 79.98 & 5.041 & 0.403 & 7.750 & 0.349 & $87 \%$ & 6.854 & 10.797 \\
\hline R111-S039-.01 EDTA-5-F-DUP & 79.98 & 5.041 & 0.403 & 8.400 & 0.378 & $94 \%$ & 6.854 & 4.995 \\
\hline R111-S039-.01 EDTA-7 & 79.98 & 5.031 & 0.402 & 6.890 & 0.310 & $77 \%$ & 7.186 & 18.352 \\
\hline
\end{tabular}




\section{Cd Removed by Batch Shaker Method}

\begin{tabular}{|c|c|c|c|c|c|c|c|c|}
\hline & $\mathbf{C d}$ & Wt. of Soil & Cd in & $\mathrm{Cd}$ & Cd in & $\% \mathbf{C d}$ & $\mathrm{pH}$ of & Cd Remaining \\
\hline SAMPLE\# & $(\mathrm{mg} / \mathrm{kg})$ & (g) & Soil (mg) & $(\mathrm{mg} / \mathrm{L})$ & Sample (mg) & Removed & Sample & in Soil $(\mathrm{mg} / \mathrm{kg})$ \\
\hline R111-S039-.01 EDTA-7-F & 79.98 & 5.031 & 0.402 & 7.570 & 0.341 & $85 \%$ & 7.186 & 12.270 \\
\hline R111-S039-.01 EDTA-7-F/C & 79.98 & 5.031 & 0.402 & 7.080 & 0.319 & $79 \%$ & 7.186 & 16.653 \\
\hline R111-S039-.01 EDTA-7-F-DUP & 79.98 & 5.031 & 0.402 & 7.010 & 0.315 & $78 \%$ & 7.186 & 17.279 \\
\hline R111-S041-.01 EDTA-3 & 50.75 & 5.031 & 0.255 & 7.690 & 0.346 & $136 \%$ & 6.214 & -18.034 \\
\hline R111-S041-.01 EDTA-3-F & 50.75 & 5.031 & 0.255 & 6.900 & 0.311 & $122 \%$ & 6.214 & -10.967 \\
\hline R111-S041-.01 EDTA-3-F/C & 50.75 & 5.031 & 0.255 & 7.150 & 0.322 & $126 \%$ & 6.214 & -13.203 \\
\hline R111-S041-.01 EDTA-3-F-DUP & 50.75 & 5.031 & 0.255 & 7.340 & 0.330 & $129 \%$ & 6.214 & -14.903 \\
\hline R111-S041-.01 EDTA-5 & 50.75 & 5.036 & 0.256 & 5.730 & 0.258 & $101 \%$ & 6.887 & -0.451 \\
\hline R111-S041-.01 EDTA-5-F & 50.75 & 5.036 & 0.256 & 5.750 & 0.259 & $101 \%$ & 6.887 & -0.630 \\
\hline R111-S041-.01 EDTA-5-F/C & 50.75 & 5.036 & 0.256 & 6.170 & 0.278 & $109 \%$ & 6.887 & -4.383 \\
\hline R111-S041-.01 EDTA-5-F-DUP & 50.75 & 5.036 & 0.256 & 6.340 & 0.285 & $112 \%$ & 6.887 & -5.902 \\
\hline R111-S041-.01 EDTA-7 & 50.75 & 5.027 & 0.255 & 5.540 & 0.249 & $98 \%$ & 7.431 & 1.158 \\
\hline R111-S041-.01 EDTA-7-F & 50.75 & 5.027 & 0.255 & 5.330 & 0.240 & $94 \%$ & 7.431 & 3.038 \\
\hline R111-S041-.01 EDTA-7-F/C & 50.75 & 5.027 & 0.255 & 1.570 & 0.071 & $28 \%$ & 7.431 & 36.696 \\
\hline R111-S041-.01 EDTA-7-F-DUP & 50.75 & 5.027 & 0.255 & 5.670 & 0.255 & $100 \%$ & 7.431 & -0.006 \\
\hline R111-S044-.01 EDTA-3 & 17.26 & 5.036 & 0.087 & 1.570 & 0.071 & $81 \%$ & 6.701 & 3.231 \\
\hline R111-S044-.01 EDTA-3-F & 17.26 & 5.036 & 0.087 & 1.510 & 0.068 & $78 \%$ & 6.701 & 3.767 \\
\hline R111-S044-.01 EDTA-3-F/C & 17.26 & 5.036 & 0.087 & 1.600 & 0.072 & $83 \%$ & 6.701 & 2.963 \\
\hline R111-S044-.01 EDTA-3-F-DUP & 17.26 & 5.036 & 0.087 & 1.660 & 0.075 & $86 \%$ & 6.701 & 2.427 \\
\hline R111-S044-.01 EDTA-5 & 17.26 & 5.034 & 0.087 & 1.070 & 0.048 & $55 \%$ & 6.321 & 7.695 \\
\hline R111-S044-.01 EDTA-5-F & 17.26 & 5.034 & 0.087 & 1.020 & 0.046 & $53 \%$ & 6.321 & 8.142 \\
\hline R111-S044-.01 EDTA-5-F/C & 17.26 & 5.034 & 0.087 & 1.060 & 0.048 & $55 \%$ & 6.321 & 7.784 \\
\hline R111-S044-.01 EDTA-5-F-DUP & 17.26 & 5.034 & 0.087 & 1.060 & 0.048 & $55 \%$ & 6.321 & 7.784 \\
\hline R111-S044-.01 EDTA-7 & 17.26 & 5.013 & 0.087 & 0.720 & 0.032 & $37 \%$ & 7.847 & 10.797 \\
\hline R111-S044-.01 EDTA-7-F & 17.26 & 5.013 & 0.087 & 0.860 & 0.039 & $45 \%$ & 7.847 & 9.540 \\
\hline R111-S044-.01 EDTA-7-F/C & 17.26 & 5.013 & 0.087 & 0.870 & 0.039 & $45 \%$ & 7.847 & 9.450 \\
\hline R111-S044-.01 EDTA-7-F-DUP & 17.26 & 5.013 & 0.087 & 0.810 & 0.036 & $42 \%$ & 7.847 & 9.989 \\
\hline R111-S049-.01 EDTA-3 & 0.38 & 5.041 & 0.002 & 0.05 & 0.002 & $117 \%$ & 3.183 & -0.066 \\
\hline R111-S049-.01 EDTA-3-F & 0.38 & 5.041 & 0.002 & 0.05 & 0.002 & $117 \%$ & 3.183 & -0.066 \\
\hline R111-S049-.01 EDTA-3-F/C & 0.38 & 5.041 & 0.002 & 0.05 & 0.002 & $117 \%$ & 3.183 & -0.066 \\
\hline R111-S049-.01 EDTA-3-F-DUP & 0.38 & 5.041 & 0.002 & 0.05 & 0.002 & $117 \%$ & 3.183 & -0.066 \\
\hline R111-S049-.01 EDTA-5 & 0.38 & 5.027 & 0.002 & 0.05 & 0.002 & $118 \%$ & 5.076 & -0.068 \\
\hline R111-S049-.01 EDTA-5-F & 0.38 & 5.027 & 0.002 & 0.05 & 0.002 & $118 \%$ & 5.076 & -0.068 \\
\hline R111-S049-.01 EDTA-5-F/C & 0.38 & 5.027 & 0.002 & 0.05 & 0.002 & $118 \%$ & 5.076 & -0.068 \\
\hline R111-S049-.01 EDTA-5-F-DUP & 0.38 & 5.027 & 0.002 & 0.05 & 0.002 & $118 \%$ & 5.076 & -0.068 \\
\hline
\end{tabular}


Cd Removed by Batch Shaker Method

\begin{tabular}{|c|c|c|c|c|c|c|c|c|}
\hline & Cd & Wt. of Soil & Cd in & Cd & Cd in & $\%$ Cd & $\mathrm{pH}$ of & Cd Remaining \\
\hline SAMPLE \# & $(\mathbf{m g} / \mathbf{k g})$ & (g) & Soil (mg) & $(\mathrm{mg} / \mathrm{L})$ & Sample (mg) & Removed & Sample & in Soil (mg/kg) \\
\hline R111-S049-.01 EDTA-7 & 0.38 & 5.033 & 0.002 & 0.05 & 0.002 & $118 \%$ & 7.101 & -0.067 \\
\hline R111-S049-.01 EDTA-7-F & 0.38 & 5.033 & 0.002 & 0.05 & 0.002 & $118 \%$ & 7.101 & -0.067 \\
\hline R111-S049-.01 EDTA-7-F/C & 0.38 & 5.033 & 0.002 & 0.05 & 0.002 & $118 \%$ & 7.101 & -0.067 \\
\hline R111-S049-.01 EDTA-7-F-DUP & 0.38 & 5.033 & 0.002 & 0.05 & 0.002 & $118 \%$ & 7.101 & -0.067 \\
\hline
\end{tabular}


Cr Removed by Batch Shaker Method

\begin{tabular}{|c|c|c|c|c|c|c|c|c|}
\hline & $\mathrm{Cr}$ & Wt. of Soil & Cr in & $\mathrm{Cr}$ & Crin & $\% \mathrm{Cr}$ & $\mathrm{pH}$ of & Cr Remaining \\
\hline SAMPLE\# & $(\mathrm{mg} / \mathrm{kg})$ & (g) & Soil (mg) & $(\mathrm{mg} / \mathrm{L})$ & Sample (mg) & Removed & Sample & in Soil ( $\mathrm{mg} / \mathrm{kg}$ ) \\
\hline R111-S037-.01 CIT-3 & 0.43 & 5.003 & 0.002 & 0.150 & 0.002 & $70 \%$ & 5.915 & 0.130 \\
\hline R111-S037-.01 ClT-3-F & 0.43 & 5.003 & 0.002 & 0.150 & 0.002 & $70 \%$ & 5.915 & 0.130 \\
\hline R111-S037-.01 CIT-3-F/C & 0.43 & 5.003 & 0.002 & 0.150 & 0.002 & $70 \%$ & 5.915 & 0.130 \\
\hline R111-S037-.01 CIT-3-F-DUP & 0.43 & 5.003 & 0.002 & 0.150 & 0.002 & $70 \%$ & 5.915 & 0.130 \\
\hline R111-S037-.01 CIT-5 & 0.43 & 5.010 & 0.002 & 0.150 & 0.002 & $70 \%$ & 6.409 & 0.131 \\
\hline R111-S037-.01 CIT-5-F & 0.43 & 5.010 & 0.002 & 0.150 & 0.002 & $70 \%$ & 6.409 & 0.131 \\
\hline R111-S037-.01 CIT-5-F/C & 0.43 & 5.010 & 0.002 & 0.150 & 0.002 & $70 \%$ & 6.409 & 0.131 \\
\hline R111-S037-.01 CIT-5-F-DUP & 0.43 & 5.010 & 0.002 & 0.150 & 0.002 & $70 \%$ & 6.409 & 0.131 \\
\hline R111-S037-.01 ClT-7 & 0.43 & 5.036 & 0.002 & 0.150 & 0.002 & $69 \%$ & 7.698 & 0.132 \\
\hline R111-S037-.01 CIT-7-F & 0.43 & 5.036 & 0.002 & 0.150 & 0.002 & $69 \%$ & 7.698 & 0.132 \\
\hline R111-S037-.01 CIT-7-F/C & 0.43 & 5.036 & 0.002 & 0.150 & 0.002 & $69 \%$ & 7.698 & 0.132 \\
\hline R111-S037-.01 CIT-7-F-DUP & 0.43 & 5.036 & 0.002 & 0.150 & 0.002 & $69 \%$ & 7.698 & 0.132 \\
\hline R111-S038-.01 CIT-3 & 0.43 & 5.014 & 0.002 & 0.150 & 0.002 & $70 \%$ & 6.237 & 0.131 \\
\hline R111-S038-.01 CIT-3-F & 0.43 & 5.014 & 0.002 & 0.150 & 0.002 & $70 \%$ & 6.237 & 0.131 \\
\hline R111-S038-.01 C/T-3-F/C & 0.43 & 5.014 & 0.002 & 0.150 & 0.002 & $70 \%$ & 6.237 & 0.131 \\
\hline R111-S038-.01 CIT-3-F-DUP & 0.43 & 5.014 & 0.002 & 0.150 & 0.002 & $70 \%$ & 6.237 & 0.131 \\
\hline R111-S038-.01 CIT-5 & 0.43 & 5.014 & 0.002 & 0.150 & 0.002 & $70 \%$ & 6.736 & 0.131 \\
\hline R111-S038-.01 CIT-5-F & 0.43 & 5.014 & 0.002 & 0.150 & 0.002 & $70 \%$ & 6.736 & 0.131 \\
\hline R111-S038-.01 CIT-5-F/C & 0.43 & 5.014 & 0.002 & 0.150 & 0.002 & $70 \%$ & 6.736 & 0.131 \\
\hline R111-S038-.01 CIT-5-F-DUP & 0.43 & 5.014 & 0.002 & 0.150 & 0.002 & $70 \%$ & 6.736 & 0.131 \\
\hline R111-S038-.01 CIT-7 & 0.43 & 5.030 & 0.002 & 0.150 & 0.002 & $69 \%$ & 7.734 & 0.132 \\
\hline R111-S038-.01 CIT-7-F & 0.43 & 5.030 & 0.002 & 0.150 & 0.002 & $69 \%$ & 7.734 & 0.132 \\
\hline R111-S038-.01 CIT-7-F/C & 0.43 & 5.030 & 0.002 & 0.150 & 0.002 & $69 \%$ & 7.734 & 0.132 \\
\hline R111-S038-.01 CIT-7-F-DUP & 0.43 & 5.030 & 0.002 & 0.150 & 0.002 & $69 \%$ & 7.734 & 0.132 \\
\hline R111-S039-.01 CIT-3 & 0.43 & 5.008 & 0.002 & 0.150 & 0.002 & $70 \%$ & 6.304 & 0.130 \\
\hline R111-S039-.01 CIT-3-F & 0.43 & 5.008 & 0.002 & 0.150 & 0.002 & $70 \%$ & 6.304 & 0.130 \\
\hline R111-S039-.01 CIT-3-F/C & 0.43 & 5.008 & 0.002 & 0.150 & 0.002 & $70 \%$ & 6.304 & 0.130 \\
\hline R111-S039-.01 CIT-3-F-DUP & 0.43 & 5.008 & 0.002 & 0.150 & 0.002 & $70 \%$ & 6.304 & 0.130 \\
\hline R111-S039-.01 CIT-5 & 0.43 & 5.041 & 0.002 & 0.150 & 0.002 & $69 \%$ & 6.321 & 0.132 \\
\hline R111-S039-.01 CIT-5-F & 0.43 & 5.041 & 0.002 & $0 . \overline{150}$ & 0.002 & $69 \%$ & 6.321 & 0.132 \\
\hline R111-S039-.01 CIT-5-F/C & 0.43 & 5.041 & 0.002 & 0.150 & 0.002 & $69 \%$ & 6.321 & 0.132 \\
\hline R111-S039-.01 CIT-5-F-DUP & 0.43 & 5.041 & 0.002 & 0.150 & 0.002 & $69 \%$ & 6.321 & 0.132 \\
\hline R111-S039-.01 CIT-7 & 0.43 & 5.029 & 0.002 & 0.270 & 0.003 & $125 \%$ & 7.421 & -0.107 \\
\hline R111-S039-.01 ClT-7-F & 0.43 & 5.029 & 0.002 & 0.150 & 0.002 & $69 \%$ & 7.421 & 0.132 \\
\hline Ri11-S039-.01 CIT-7-F/C & 0.43 & 5.029 & 0.002 & 0.150 & 0.002 & $69 \%$ & 7.421 & 0.132 \\
\hline
\end{tabular}


Cr Removed by Batch Shaker Method

\begin{tabular}{|c|c|c|c|c|c|c|c|c|}
\hline & $\mathrm{Cr}$ & Wt. of Soil & Crin & $\mathrm{Cr}$ & $\mathrm{Cr}$ in & $\% \mathrm{Cr}$ & pH of & Cr Remaining \\
\hline SAMPLE \# & $(\mathbf{m g} / \mathbf{k g})$ & (g) & Soil (mg) & $(\mathrm{mg} / \mathrm{L})$ & Sample (mg) & Removed & Sample & in Soil (mg/kg) \\
\hline R111-S039-.01 CIT-7-F-DUP & 0.43 & 5.029 & 0.002 & 0.170 & 0.002 & $79 \%$ & 7.421 & 0.092 \\
\hline R111-S041-.01 CIT-3 & 0.20 & 5.002 & 0.001 & 0.150 & 0.002 & $150 \%$ & 5.861 & -0.100 \\
\hline R111-S041-.01 CIT-3-F & 0.20 & 5.002 & 0.001 & 0.150 & 0.002 & $150 \%$ & 5.861 & -0.100 \\
\hline R111-S041-.01 CIT-3-F/C & 0.20 & 5.002 & 0.001 & 0.170 & 0.002 & $170 \%$ & 5.861 & -0.140 \\
\hline R111-S041-.01 CIT-3-F-DUP & 0.20 & 5.002 & 0.001 & 0.220 & 0.002 & $220 \%$ & 5.861 & -0.240 \\
\hline R111-S041-.01 CIT-5 & 0.20 & 5.036 & 0.001 & 0.150 & 0.002 & $149 \%$ & 6.498 & -0.098 \\
\hline R111-S041-.01 CIT-5-F & 0.20 & 5.036 & 0.001 & 0.150 & 0.002 & $149 \%$ & 6.498 & -0.098 \\
\hline R111-S041-.01 CIT-5-F/C & 0.20 & 5.036 & 0.001 & 0.150 & 0.002 & $149 \%$ & 6.498 & -0.098 \\
\hline R111-S041-.01 CIT-5-F-DUP & 0.20 & 5.036 & 0.001 & 0.150 & 0.002 & $149 \%$ & 6.498 & -0.098 \\
\hline R111-S041-.01 CIT-7 & 0.20 & 5.041 & 0.001 & 0.240 & 0.002 & $238 \%$ & 7.601 & -0.276 \\
\hline R111-S041-.01 CIT-7-F & 0.20 & 5.041 & 0.001 & 0.150 & 0.002 & $149 \%$ & 7.601 & -0.098 \\
\hline R111-S041-.01 CIT-7-F/C & 0.20 & 5.041 & 0.001 & 0.150 & 0.002 & $149 \%$ & 7.601 & -0.098 \\
\hline R111-S041-.01 CIT-7-F-DUP & 0.20 & 5.041 & 0.001 & 0.150 & 0.002 & $149 \%$ & 7.601 & -0.098 \\
\hline R111-S044-.01 CIT-3 & 0.20 & 5.021 & 0.001 & 0.150 & 0.002 & $149 \%$ & 6.432 & -0.099 \\
\hline R111-S044-.01 CIT-3-F & 0.20 & 5.021 & 0.001 & 0.150 & 0.002 & $149 \%$ & 6.432 & -0.099 \\
\hline R111-S044-.01 CIT-3-F/C & 0.20 & 5.021 & 0.001 & 0.150 & 0.002 & $149 \%$ & 6.432 & -0.099 \\
\hline R111-S044-.01 CIT-3-F-DUP & 0.20 & 5.021 & 0.001 & 0.150 & 0.002 & $149 \%$ & 6.432 & -0.099 \\
\hline R111-S044-.01 CIT-5 & 0.20 & 5.021 & 0.001 & 0.150 & 0.002 & $149 \%$ & 6.747 & -0.099 \\
\hline R111-S044-.01 CIT-5-F & 0.20 & 5.021 & 0.001 & 0.150 & 0.002 & $149 \%$ & 6.747 & -0.099 \\
\hline R111-S044-.01 CIT-5-F/C & 0.20 & 5.021 & 0.001 & 0.150 & 0.002 & $149 \%$ & 6.747 & -0.099 \\
\hline R111-S044-.01 ClT-5-F-DUP & 0.20 & 5.021 & 0.001 & 0.150 & 0.002 & $149 \%$ & 6.747 & -0.099 \\
\hline R111-S044-.01 CIT-7 & 0.20 & 5.041 & 0.001 & 0.160 & 0.002 & $159 \%$ & 7.261 & -0.117 \\
\hline R111-S044-.01 CIT-7-F & 0.20 & 5.041 & 0.001 & 0.150 & 0.002 & $149 \%$ & 7.261 & -0.098 \\
\hline R111-S044-.01 CIT-7-F/C & 0.20 & 5.041 & 0.001 & 0.150 & 0.002 & $149 \%$ & 7.261 & -0.098 \\
\hline R111-S044-.01 CIT-7-F-DUP & 0.20 & 5.041 & 0.001 & 0.150 & 0.002 & $149 \%$ & 7.261 & -0.098 \\
\hline R111-S049-.01 ClT-3 & 0.20 & 5.030 & 0.001 & 0.150 & 0.002 & $149 \%$ & 3.257 & -0.098 \\
\hline R111-S049-.01 CIT-3-F & 0.20 & 5.030 & 0.001 & 0.150 & 0.002 & $149 \%$ & 3.257 & -0.098 \\
\hline R111-S049-.01 CIT-3-F/C & 0.20 & 5.030 & 0.001 & 0.150 & 0.002 & $149 \%$ & 3.257 & -0.098 \\
\hline R111-S049-.01 CIT-3-F-DUP & 0.20 & 5.030 & 0.001 & 0.150 & 0.002 & $149 \%$ & 3.257 & -0.098 \\
\hline R111-S049-.01 CIT-5 & 0.20 & 5.009 & 0.001 & 0.150 & 0.002 & $150 \%$ & 5.163 & -0.099 \\
\hline R111-S049-.01 CIT-5-F & 0.20 & 5.009 & 0.001 & 0.150 & 0.002 & $150 \%$ & 5.163 & -0.099 \\
\hline R111-S049-.01 CIT-5-F/C & 0.20 & 5.009 & 0.001 & 0.150 & 0.002 & $150 \%$ & 5.163 & -0.099 \\
\hline R111-S049-.01 CIT-5-F-DUP & 0.20 & 5.009 & 0.001 & 0.150 & 0.002 & $150 \%$ & 5.163 & -0.099 \\
\hline R111-S049-.01 CIT-7 & 0.20 & 5.008 & 0.001 & 0.150 & 0.002 & $150 \%$ & 7.093 & -0.100 \\
\hline R111-S049-.01 CIT-7-F & 0.20 & 5.008 & 0.001 & 0.150 & 0.002 & $150 \%$ & 7.093 & -0.100 \\
\hline
\end{tabular}


Cr Removed by Batch Shaker Method

\begin{tabular}{|c|c|c|c|c|c|c|c|c|}
\hline & $\mathrm{Cr}$ & Wt. of Soil & Crin & $\mathrm{Cr}$ & Cr in & $\% \mathrm{Cr}$ & $\mathrm{pH}$ of & Cr Remaining \\
\hline SAMPLE \# & (mg/kg) & (g) & Soil (mg) & $(\mathrm{mg} / \mathrm{L})$ & Sample (mg) & Removed & Sample & in Soil ( $\mathrm{mg} / \mathbf{k g}$ ) \\
\hline R111-S049-.01 CIT-7-F/C & 0.20 & 5.008 & 0.001 & 0.150 & 0.002 & $150 \%$ & 7.093 & -0.100 \\
\hline R111-S049-.01 ClT-7-F-DUP & 0.20 & 5.008 & 0.001 & 0.150 & 0.002 & $150 \%$ & 7.093 & -0.100 \\
\hline R111-S037-.01 EDTA-3 & 0.43 & 5.008 & 0.002 & 0.150 & 0.002 & $70 \%$ & 6.715 & 0.130 \\
\hline R111-S037-.01 EDTA-3-F & 0.43 & 5.008 & 0.002 & 0.150 & 0.002 & $70 \%$ & 6.715 & 0.130 \\
\hline R111-S037-.01 EDTA-3-F/C & 0.43 & 5.008 & 0.002 & 0.150 & 0.002 & $70 \%$ & 6.715 & 0.130 \\
\hline R111-S037-.01 EDTA-3-F-DUP & 0.43 & 5.008 & 0.002 & 0.150 & 0.002 & $70 \%$ & 6.715 & 0.130 \\
\hline R111-S037-.01 EDTA-5 & 0.43 & 5.007 & 0.002 & 0.150 & 0.002 & $70 \%$ & 7.113 & 0.130 \\
\hline R111-S037-.01 EDTA-5-F & 0.43 & 5.007 & 0.002 & 0.150 & 0.002 & $70 \%$ & 7.113 & 0.130 \\
\hline R111-S037-.01 EDTA-5-F/C & 0.43 & 5.007 & 0.002 & 0.150 & 0.002 & $70 \%$ & 7.113 & 0.130 \\
\hline R111-S037-.01 EDTA-5-F-DUP & 0.43 & 5.007 & 0.002 & 0.150 & 0.002 & $70 \%$ & 7.113 & 0.130 \\
\hline R111-S037-.01 EDTA-7 & 0.43 & 5.010 & 0.002 & 0.150 & 0.002 & $70 \%$ & 7.229 & 0.131 \\
\hline R111-S037-.01 EDTA-7-F & 0.43 & 5.010 & 0.002 & 0.150 & 0.002 & $70 \%$ & 7.229 & 0.131 \\
\hline R111-S037-.01 EDTA-7-F/C & 0.43 & 5.010 & 0.002 & 0.150 & 0.002 & $70 \%$ & 7.229 & 0.131 \\
\hline R111-S037-.01 EDTA-7-F-DUP & 0.43 & 5.010 & 0.002 & 0.150 & 0.002 & $70 \%$ & 7.229 & 0.131 \\
\hline R111-S038-.01 EDTA-3 & 0.43 & 5.024 & 0.002 & 0.150 & 0.002 & $69 \%$ & 6.884 & 0.131 \\
\hline R111-S038-.01 EDTA-3-F & 0.43 & 5.024 & 0.002 & 0.150 & 0.002 & $69 \%$ & 6.884 & 0.131 \\
\hline R111-S038-.01 EDTA-3-F/C & 0.43 & 5.024 & 0.002 & 0.150 & 0.002 & $69 \%$ & 6.884 & 0.131 \\
\hline R111-S038-.01 EDTA-3-F-DUP & 0.43 & 5.024 & 0.002 & 0.150 & 0.002 & $69 \%$ & 6.884 & 0.131 \\
\hline R111-S038-.01 EDTA-5 & 0.43 & 5.009 & 0.002 & 0.150 & 0.002 & $70 \%$ & 6.982 & 0.131 \\
\hline R111-S038-.01 EDTA-5-F & 0.43 & 5.009 & 0.002 & 0.150 & 0.002 & $70 \%$ & 6.982 & 0.131 \\
\hline R111-S038-.01 EDTA-5-F/C & 0.43 & 5.009 & 0.002 & 0.150 & 0.002 & $70 \%$ & 6.982 & 0.131 \\
\hline R111-S038-.01 EDTA-5-F-DUP & 0.43 & 5.009 & 0.002 & 0.150 & 0.002 & $70 \%$ & 6.982 & 0.131 \\
\hline R111-S038-.01 EDTA-7 & 0.43 & 5.019 & 0.002 & 0.150 & 0.002 & $70 \%$ & 7.204 & 0.131 \\
\hline R111-S038-.01 EDTA-7-F & 0.43 & 5.019 & 0.002 & 0.150 & 0.002 & $70 \%$ & 7.204 & 0.131 \\
\hline R111-S038-.01 EDTA-7-F/C & 0.43 & 5.019 & 0.002 & 0.150 & 0.002 & $70 \%$ & 7.204 & 0.131 \\
\hline R111-S038-.01 EDTA-7-F-DUP & 0.43 & 5.019 & 0.002 & 0.150 & 0.002 & $70 \%$ & 7.204 & 0.131 \\
\hline R111-S039-.01 EDTA-3 & 0.43 & 5.026 & 0.002 & 0.150 & 0.002 & $69 \%$ & 6.401 & 0.132 \\
\hline R111-S039-.01 EDTA-3-F & 0.43 & 5.026 & 0.002 & 0.150 & 0.002 & $69 \%$ & 6.401 & 0.132 \\
\hline R111-S039-.01 EDTA-3-F/C & 0.43 & 5.026 & 0.002 & 0.150 & 0.002 & $69 \%$ & 6.401 & 0.132 \\
\hline R111-S039-.01 EDTA-3-F-DUP & 0.43 & 5.026 & 0.002 & 0.150 & 0.002 & $69 \%$ & 6.401 & 0.132 \\
\hline R111-S039-.01 EDTA-5 & 0.43 & 5.041 & 0.002 & 0.150 & 0.002 & $69 \%$ & 6.854 & 0.132 \\
\hline R111-S039-.01 EDTA-5-F & 0.43 & 5.041 & 0.002 & 0.150 & 0.002 & $69 \%$ & 6.854 & 0.132 \\
\hline R111-S039-.01 EDTA-5-F/C & 0.43 & 5.041 & 0.002 & 0.150 & 0.002 & $69 \%$ & 6.854 & 0.132 \\
\hline R111-S039-.01 EDTA-5-F-DUP & 0.43 & 5.041 & 0.002 & 0.150 & 0.002 & $69 \%$ & 6.854 & 0.132 \\
\hline R111-S039-.01 EDTA-7 & 0.43 & 5.031 & 0.002 & 0.150 & 0.002 & $69 \%$ & 7.186 & 0.132 \\
\hline
\end{tabular}


Cr Removed by Batch Shaker Method

\begin{tabular}{|c|c|c|c|c|c|c|c|c|}
\hline & $\mathrm{Cr}$ & Wt. of Soil & Cr in & $\mathrm{Cr}$ & Cr in & $\% \mathbf{C r}$ & $\mathrm{pH}$ of & Cr Remaining \\
\hline SAMPLE \# & $(\mathbf{m g} / \mathbf{k g})$ & (g) & Soil $(\mathrm{mg})$ & $(\mathrm{mg} / \mathrm{L})$ & Sample (mg) & Removed & Sample & in Soil $(\mathrm{mg} / \mathrm{kg})$ \\
\hline R111-S039-.01 EDTA-7-F & 0.43 & 5.031 & 0.002 & 0.150 & 0.002 & $69 \%$ & 7.186 & 0.132 \\
\hline R111-S039-.01 EDTA-7-F/C & 0.43 & 5.031 & 0.002 & 0.150 & 0.002 & $69 \%$ & 7.186 & 0.132 \\
\hline R111-S039-.01 EDTA-7-F-DUP & 0.43 & 5.031 & 0.002 & 0.150 & 0.002 & $69 \%$ & 7.186 & 0.132 \\
\hline R111-S041-.01 EDTA-3 & 0.20 & 5.031 & 0.001 & 0.150 & 0.002 & $149 \%$ & 6.214 & -0.098 \\
\hline R111-S041-.01 EDTA-3-F & 0.20 & 5.031 & 0.001 & 0.150 & 0.002 & $149 \%$ & 6.214 & -0.098 \\
\hline R111-S041-.01 EDTA-3-F/C & 0.20 & 5.031 & 0.001 & 0.150 & 0.002 & $149 \%$ & 6.214 & -0.098 \\
\hline R111-S041-.01 EDTA-3-F-DUP & 0.20 & 5.031 & 0.001 & 0.150 & 0.002 & $149 \%$ & 6.214 & -0.098 \\
\hline R111-S041-.01 EDTA-5 & 0.20 & 5.036 & 0.001 & 0.150 & 0.002 & $149 \%$ & 6.887 & -0.098 \\
\hline R111-S041-.01 EDTA-5-F & 0.20 & 5.036 & 0.001 & 0.150 & 0.002 & $149 \%$ & 6.887 & -0.098 \\
\hline R111-S041-.01 EDTA-5-F/C & 0.20 & 5.036 & 0.001 & 0.150 & 0.002 & $149 \%$ & 6.887 & -0.098 \\
\hline R111-S041-.01 EDTA-5-F-DUP & 0.20 & 5.036 & 0.001 & 0.150 & 0.002 & $149 \%$ & 6.887 & -0.098 \\
\hline R111-S041-.01 EDTA-7 & 0.20 & 5.027 & 0.001 & 0.150 & 0.002 & $149 \%$ & 7.431 & -0.098 \\
\hline R111-S041-.01 EDTA-7-F & 0.20 & 5.027 & 0.001 & 0.150 & 0.002 & $149 \%$ & 7.431 & -0.098 \\
\hline R111-S041-.01 EDTA-7-F/C & 0.20 & 5.027 & 0.001 & 0.150 & 0.002 & $149 \%$ & 7.431 & -0.098 \\
\hline R111-S041-.01 EDTA-7-F-DUP & 0.20 & 5.027 & 0.001 & 0.150 & 0.002 & $149 \%$ & 7.431 & -0.098 \\
\hline R111-S044-.01 EDTA-3 & 0.20 & 5.036 & 0.001 & 0.150 & 0.002 & $149 \%$ & 6.701 & -0.098 \\
\hline R111-S044-.01 EDTA-3-F & 0.20 & 5.036 & 0.001 & 0.150 & 0.002 & $149 \%$ & 6.701 & -0.098 \\
\hline R111-S044-.01 EDTA-3-F/C & 0.20 & 5.036 & 0.001 & 0.150 & 0.002 & $149 \%$ & 6.701 & -0.098 \\
\hline R111-S044-.01 EDTA-3-F-DUP & 0.20 & 5.036 & 0.001 & 0.150 & 0.002 & $149 \%$ & 6.701 & -0.098 \\
\hline R111-S044-.01 EDTA-5 & 0.20 & 5.034 & 0.001 & 0.150 & 0.002 & $149 \%$ & 6.321 & -0.098 \\
\hline R111-S044-.01 EDTA-5-F & 0.20 & 5.034 & 0.001 & 0.150 & 0.002 & $149 \%$ & 6.321 & -0.098 \\
\hline R111-S044-.01 EDTA-5-F/C & 0.20 & 5.034 & 0.001 & 0.150 & 0.002 & $149 \%$ & 6.321 & -0.098 \\
\hline R111-S044-.01 EDTA-5-F-DUP & 0.20 & 5.034 & 0.001 & 0.150 & 0.002 & $149 \%$ & 6.321 & -0.098 \\
\hline R111-S044-.01 EDTA-7 & 0.20 & 5.013 & 0.001 & 0.150 & 0.002 & $150 \%$ & 7.847 & -0.099 \\
\hline R111-S044-.01 EDTA-7-F & 0.20 & 5.013 & 0.001 & 0.150 & 0.002 & $150 \%$ & 7.847 & -0.099 \\
\hline R111-S044-.01 EDTA-7-F/C & 0.20 & 5.013 & 0.001 & 0.150 & 0.002 & $150 \%$ & 7.847 & -0.099 \\
\hline R111-S044-.01 EDTA-7-F-DUP & 0.20 & 5.013 & 0.001 & 0.150 & 0.002 & $150 \%$ & 7.847 & -0.099 \\
\hline R111-S049-.01 EDTA-3 & 0.20 & 5.041 & 0.001 & 0.150 & 0.002 & $149 \%$ & 3.183 & -0.098 \\
\hline R111-S049-.01 EDTA-3-F & 0.20 & 5.041 & 0.001 & 0.150 & 0.002 & $149 \%$ & 3.183 & -0.098 \\
\hline R111-S049-.01 EDTA-3-F/C & 0.20 & 5.041 & 0.001 & 0.150 & 0.002 & $149 \%$ & 3.183 & -0.098 \\
\hline R111-S049-.01 EDTA-3-F-DUP & 0.20 & 5.041 & 0.001 & 0.150 & 0.002 & $149 \%$ & 3.183 & -0.098 \\
\hline R111-S049-.01 EDTA-5 & 0.20 & 5.027 & 0.001 & 0.150 & 0.002 & $149 \%$ & 5.076 & -0.098 \\
\hline R111-S049-.01 EDTA-5-F & 0.20 & 5.027 & 0.001 & 0.150 & 0.002 & $149 \%$ & 5.076 & -0.098 \\
\hline R111-S049-.01 EDTA-5-F/C & 0.20 & 5.027 & 0.001 & 0.150 & 0.002 & $149 \%$ & 5.076 & -0.098 \\
\hline R111-S049-.01 EDTA-5-F-DUP & 0.20 & 5.027 & 0.001 & 0.150 & 0.002 & $149 \%$ & 5.076 & -0.098 \\
\hline
\end{tabular}


Cr Removed by Batch Shaker Method

\begin{tabular}{|c|c|c|c|c|c|c|c|c|}
\hline & $\mathrm{Cr}$ & Wt. of Soil & Cr in & $\mathrm{Cr}$ & Cr in & $\% \mathbf{C r}$ & pH of & Cr Remaining \\
\hline SAMPLE\# & $(\mathrm{mg} / \mathrm{kg})$ & (g) & Soil (mg) & $(\mathrm{mg} / \mathrm{L})$ & Sample (mg) & Removed & Sample & in Soil (mg/kg) \\
\hline R111-S049-.01 EDTA-7 & 0.20 & 5.033 & 0.001 & 0.150 & 0.002 & $149 \%$ & 7.101 & -0.098 \\
\hline R111-S049-.01 EDTA-7-F & 0.20 & 5.033 & 0.001 & 0.150 & 0.002 & $149 \%$ & 7.101 & -0.098 \\
\hline R111-S049-.01 EDTA-7-F/C & 0.20 & 5.033 & 0.001 & 0.150 & 0.002 & $149 \%$ & 7.101 & -0.098 \\
\hline R111-S049-.01 EDTA-7-F-DUP & 0.20 & 5.033 & 0.001 & 0.150 & 0.002 & $149 \%$ & 7.101 & -0.098 \\
\hline
\end{tabular}


Cu Removed by Batch Shaker Method

\begin{tabular}{|c|c|c|c|c|c|c|c|c|}
\hline & $\mathrm{Cu}$ & Wt. of Soil & Cu in & Cu & Cu in & $\% \mathrm{Cu}$ & pH of & Cu Remaining \\
\hline SAMPLE \# & $(\mathrm{mg} / \mathrm{kg})$ & (g) & Soil (mg) & $(\mathrm{mg} / \mathrm{L})$ & Sample (mg) & Removed & Sample & in Soil $(\mathrm{mg} / \mathrm{kg})$ \\
\hline R111-S037-.01 CIT-3 & 18.93 & 5.003 & 0.095 & 9.190 & 0.414 & $437 \%$ & 5.915 & -63.730 \\
\hline R111-S037-.01 CIT-3-F & 18.93 & 5.003 & 0.095 & 8.490 & 0.382 & $403 \%$ & 5.915 & -57.434 \\
\hline R111-S037-.01 CIT-3-F/C & 18.93 & 5.003 & 0.095 & 8.540 & 0.384 & $406 \%$ & 5.915 & -57.884 \\
\hline R111-S037-.01 CIT-3-F-DUP & 18.93 & 5.003 & 0.095 & 8.380 & 0.377 & $398 \%$ & 5.915 & -56.445 \\
\hline R111-S037-.01 CIT-5 & 18.93 & 5.010 & 0.095 & 6.740 & 0.303 & $320 \%$ & 6.409 & -41.609 \\
\hline R111-S037-.01 CIT-5-F & 18.93 & 5.010 & 0.095 & 4.750 & 0.214 & $225 \%$ & 6.409 & -23.735 \\
\hline R111-S037-.01 ClT-5-F/C & 18.93 & 5.010 & 0.095 & 4.640 & 0.209 & $220 \%$ & 6.409 & -22.747 \\
\hline R111-S037-.01 CIT-5-F-DUP & 18.93 & 5.010 & 0.095 & 4.830 & 0.217 & $229 \%$ & 6.409 & -24.453 \\
\hline R111-S037-.01 CIT-7 & 18.93 & 5.036 & 0.095 & 7.230 & 0.325 & $341 \%$ & 7.698 & -45.675 \\
\hline R111-S037-.01 CIT-7-F & 18.93 & 5.036 & 0.095 & 5.270 & 0.237 & $249 \%$ & 7.698 & -28.161 \\
\hline R111-S037-.01 CIT-7-F/C & 18.93 & 5.036 & 0.095 & 5.200 & 0.234 & $245 \%$ & 7.698 & -27.535 \\
\hline R111-S037-.01 CIT-7-F-DUP & 18.93 & 5.036 & 0.095 & 5.440 & 0.245 & $257 \%$ & 7.698 & -29.680 \\
\hline R111-S038-.01 CIT-3 & 25.45 & 5.014 & 0.128 & 12.600 & 0.567 & $444 \%$ & 6.237 & -87.633 \\
\hline R111-S038-.01 CIT-3-F & 25.45 & 5.014 & 0.128 & 8.680 & 0.391 & $306 \%$ & 6.237 & -52.452 \\
\hline R111-S038-.01 CIT-3-F/C & 25.45 & 5.014 & 0.128 & 8.690 & 0.391 & $306 \%$ & 6.237 & -52.542 \\
\hline R111-S038-.01 CIT-3-F-DUP & 25.45 & 5.014 & 0.128 & 9.130 & 0.411 & $322 \%$ & 6.237 & -56.491 \\
\hline R111-S038-.01 CIT-5 & 25.45 & 5.014 & 0.128 & 8.560 & 0.385 & $302 \%$ & 6.736 & -51.375 \\
\hline R111-S038-.01 CIT-5-F & 25.45 & 5.014 & 0.128 & 7.630 & 0.343 & $269 \%$ & 6.736 & -43.028 \\
\hline R111-S038-.01 CIT-5-F/C & 25.45 & 5.014 & 0.128 & 7.250 & 0.326 & $256 \%$ & 6.736 & -39.618 \\
\hline R111-S038-.01 CIT-5-F-DUP & 25.45 & 5.014 & 0.128 & 7.450 & 0.335 & $263 \%$ & 6.736 & -41.413 \\
\hline R111-S038-.01 ClT-7 & 25.45 & 5.030 & 0.128 & 6.110 & 0.275 & $215 \%$ & 7.734 & -29.212 \\
\hline R111-S038-.01 CIT-7-F & 25.45 & 5.030 & 0.128 & 5.590 & 0.252 & $197 \%$ & 7.734 & -24.560 \\
\hline R111-S038-.01 CIT-7-F/C & 25.45 & 5.030 & 0.128 & 5.480 & 0.247 & $193 \%$ & 7.734 & -23.576 \\
\hline R111-S038-.01 CIT-7-F-DUP & 25.45 & 5.030 & 0.128 & 5.560 & 0.250 & $195 \%$ & 7.734 & -24.292 \\
\hline R111-S039-.01 CIT-3 & 73.42 & 5.008 & 0.368 & 12.280 & 0.553 & $150 \%$ & 6.304 & -36.923 \\
\hline R111-S039-.01 CIT-3-F & 73.42 & 5.008 & 0.368 & 11.610 & 0.522 & $142 \%$ & 6.304 & -30.903 \\
\hline R111-S039-.01 CIT-3-F/C & 73.42 & 5.008 & 0.368 & 11.710 & 0.527 & $143 \%$ & 6.304 & -31.802 \\
\hline R111-S039-.01 CIT-3-F-DUP & 73.42 & 5.008 & 0.368 & 11.660 & 0.525 & $143 \%$ & 6.304 & -31.352 \\
\hline R111-S039-.01 CIT-5 & 73.42 & 5.041 & 0.370 & 9.320 & 0.419 & $113 \%$ & 6.321 & -9.778 \\
\hline R111-S039-.01 CIT-5-F & 73.42 & 5.041 & 0.370 & 9.910 & 0.446 & $120 \%$ & 6.321 & -15.045 \\
\hline R111-S039-.01 CIT-5-F/C & 73.42 & 5.041 & 0.370 & 9.810 & 0.441 & $119 \%$ & 6.321 & -14.152 \\
\hline R111-S039-.01 CIT-5-F-DUP & 73.42 & 5.041 & 0.370 & 10.170 & 0.458 & $124 \%$ & 6.321 & -17.366 \\
\hline R111-S039-.01 CIT-7 & 73.42 & 5.029 & 0.369 & 15.470 & 0.696 & $189 \%$ & 7.421 & -65.007 \\
\hline R111-S039-.01 CIT-7-F & 73.42 & 5.029 & 0.369 & 9.510 & 0.428 & $116 \%$ & 7.421 & -11.676 \\
\hline R111-S039-.01 CIT-7-F/C & 73.42 & 5.029 & 0.369 & 9.070 & 0.408 & $111 \%$ & 7.421 & -7.739 \\
\hline
\end{tabular}




\section{Cu Removed by Batch Shaker Method}

\begin{tabular}{|c|c|c|c|c|c|c|c|c|}
\hline & Cu & Wt. of Soil & Cu in & au & Cu in & $\% \mathbf{C u}$ & $\mathrm{pH}$ of & Cu Remaining \\
\hline SAMPLE \# & (mg/kg) & (g) & Soil (mg) & $(\mathrm{mg} / \mathrm{L})$ & Sample (mg) & Removed & Sample & in Soil ( $\mathrm{mg} / \mathrm{kg}$ ) \\
\hline R111-S039-.01 CIT-7-F-DUP & 73.42 & 5.029 & 0.369 & 10.330 & 0.465 & $126 \%$ & 7.421 & -19.014 \\
\hline R111-S041-.01 CIT-3 & 14.61 & 5.002 & 0.073 & 147.460 & 6.636 & $9080 \%$ & 5.861 & -1311.999 \\
\hline R111-S041-.01 CIT-3-F & 14.61 & 5.002 & 0.073 & 140.670 & 6.330 & $8662 \%$ & 5.861 & -1250.914 \\
\hline R111-S041-.01 CIT-3-F/C & 14.61 & 5.002 & 0.073 & 13.640 & 0.614 & $840 \%$ & 5.861 & -108.101 \\
\hline R111-S041-.01 CIT-3-F-DUP & 14.61 & 5.002 & 0.073 & 13.990 & 0.630 & $861 \%$ & 5.861 & -111.250 \\
\hline R111-S041-.01 CIT-5 & 14.61 & 5.036 & 0.074 & 7.660 & 0.345 & $468 \%$ & 6.498 & -53.837 \\
\hline R111-S041-.01 CIT-5-F & 14.61 & 5.036 & 0.074 & 5.020 & 0.226 & $307 \%$ & 6.498 & -30.247 \\
\hline R111-S041-.01 CIT-5-F/C & 14.61 & 5.036 & 0.074 & 4.960 & 0.223 & $303 \%$ & 6.498 & -29.711 \\
\hline R111-S041-.01 CIT-5-F-DUP & 14.61 & 5.036 & 0.074 & 4.940 & 0.222 & $302 \%$ & 6.498 & -29.532 \\
\hline R111-S041-.01 CIT-7 & 14.61 & 5.041 & 0.074 & 155.620 & 7.003 & $9508 \%$ & 7.601 & -1374.579 \\
\hline R111-S041-.01 CIT-7-F & 14.61 & 5.041 & 0.074 & 7.700 & 0.347 & $470 \%$ & 7.601 & -54.126 \\
\hline R111-S041-.01 ClT-7-F/C & 14.61 & 5.041 & 0.074 & 7.060 & 0.318 & $431 \%$ & 7.601 & -48.413 \\
\hline R111-S041-.01 CIT-7-F-DUP & 14.61 & 5.041 & 0.074 & 7.430 & 0.334 & $45.4 \%$ & 7.601 & -51.716 \\
\hline R111-S044-.01 CIT-3 & 7.68 & 5.021 & 0.039 & 8.820 & 0.397 & $1029 \%$ & 6.432 & -71.368 \\
\hline R111-S044-.01 CIT-3-F & 7.68 & 5.021 & 0.039 & 6.650 & 0.299 & $776 \%$ & 6.432 & -51.920 \\
\hline R111-S044-.01 CIT-3-F/C & 7.68 & 5.021 & 0.039 & 6.470 & 0.291 & $755 \%$ & 6.432 & -50.306 \\
\hline R111-S044-.01 CIT-3-F-DUP & 7.68 & 5.021 & 0.039 & 6.610 & 0.297 & $771 \%$ & 6.432 & -51.561 \\
\hline R111-S044-.01 CIT-5 & 7.68 & 5.021 & 0.039 & 3.930 & 0.177 & $459 \%$ & 6.747 & -27.542 \\
\hline R111-S044-.01 CIT-5-F & 7.68 & 5.021 & 0.039 & 3.960 & 0.178 & $462 \%$ & 6.747 & -27.811 \\
\hline R111-S044-.01 CIT-5-F/C & 7.68 & 5.021 & 0.039 & 3.770 & 0.170 & $440 \%$ & 6.747 & -26.108 \\
\hline R111-S044-.01 CIT-5-F-DUP & 7.68 & 5.021 & 0.039 & 3.930 & 0.177 & $459 \%$ & 6.747 & -27.542 \\
\hline R111-S044-.01 CIT-7 & 7.68 & 5.041 & 0.039 & 10.540 & 0.474 & $1225 \%$ & 7.261 & -86.408 \\
\hline R111-S044-.01 CIT-7-F & 7.68 & 5.041 & 0.039 & 5.430 & 0.244 & $631 \%$ & 7.261 & -40.793 \\
\hline R111-S044-.01 CIT-7-F/C & 7.68 & 5.041 & 0.039 & 4.980 & 0.224 & $579 \%$ & 7.261 & -36.775 \\
\hline R111-S044-.01 CIT-7-F-DUP & 7.68 & 5.041 & 0.039 & 5.190 & 0.234 & $603 \%$ & 7.261 & -38.650 \\
\hline R111-S049-.01 CIT-3 & 0.75 & 5.030 & 0.004 & 0.100 & 0.005 & $119 \%$ & 3.257 & -0.145 \\
\hline R111-S049-.01 CIT-3-F & 0.75 & 5.030 & 0.004 & 0.130 & 0.006 & $155 \%$ & 3.257 & -0.413 \\
\hline R111-S049-.01 CIT-3-F/C & 0.75 & 5.030 & 0.004 & 0.120 & 0.005 & $143 \%$ & 3.257 & -0.324 \\
\hline R111-S049-.01 CIT-3-F-DUP & 0.75 & 5.030 & 0.004 & 0.100 & 0.005 & $119 \%$ & 3.257 & -0.145 \\
\hline R111-S049-.01 CIT-5 & 0.75 & 5.009 & 0.004 & 0.250 & 0.011 & $299 \%$ & 5.163 & -1.496 \\
\hline R111-S049-.01 CIT-5-F & 0.75 & 5.009 & 0.004 & 0.110 & 0.005 & $132 \%$ & 5.163 & -0.238 \\
\hline R111-S049-.01 CIT-5-F/C & 0.75 & 5.009 & 0.004 & 0.120 & 0.005 & $144 \%$ & 5.163 & -0.328 \\
\hline R111-S049-.01 CIT-5-F-DUP & 0.75 & 5.009 & 0.004 & 0.130 & 0.006 & $156 \%$ & 5.163 & -0.418 \\
\hline R111-S049-.01 CIT-7 & 0.75 & 5.008 & 0.004 & 0.250 & 0.011 & $300 \%$ & 7.093 & -1.496 \\
\hline R111-S049-.01 CIT-7-F & 0.75 & 5.008 & 0.004 & 0.170 & 0.008 & $204 \%$ & 7.093 & -0.778 \\
\hline
\end{tabular}




\section{Cu Removed by Batch Shaker Method}

\begin{tabular}{|c|c|c|c|c|c|c|c|c|}
\hline & as & Wt. of Soil & Cu in & $\mathrm{Cu}$ & & $\% \mathrm{Cu}$ & $\mathrm{pH}$ of & Cu Remaining \\
\hline SAMPLE \# & $(\mathrm{mg} / \mathrm{kg})$ & (g) & Soil (mg) & $(\mathrm{mg} / \mathrm{L})$ & Sample (mg) & Removed & Sample & in Soil ( $\mathrm{mg} / \mathrm{kg}$ ) \\
\hline R111-S049-.01 CIT-7-F/C & 0.75 & 5.008 & 0.004 & 0.250 & 0.011 & $300 \%$ & 7.093 & -1.496 \\
\hline R111-S049-.01 CIT-7-F-DUP & 0.75 & 5.008 & 0.004 & 0.160 & 0.007 & $192 \%$ & 7.093 & -0.688 \\
\hline R111-S037-.01 EDTA-3 & 18.93 & 5.008 & 0.095 & 11.540 & 0.519 & $548 \%$ & 6.715 & -84.764 \\
\hline R111-S037-.01 EDTA-3-F & 18.93 & 5.008 & 0.095 & 12.710 & 0.572 & $603 \%$ & 6.715 & -95.277 \\
\hline R111-S037-.01 EDTA-3-F/C & 18.93 & 5.008 & 0.095 & 12.110 & 0.545 & $575 \%$ & 6.715 & -89.886 \\
\hline R111-S037-.01 EDTA-3-F-DUP & 18.93 & 5.008 & 0.095 & 12.440 & 0.560 & $590 \%$ & 6.715 & -92.851 \\
\hline R111-S037-.01 EDTA-5 & 18.93 & 5.007 & 0.095 & 9.150 & 0.412 & $434 \%$ & 7.113 & -63.305 \\
\hline R111-S037-.01 EDTA-5-F & 18.93 & 5.007 & 0.095 & 14.480 & 0.652 & $687 \%$ & 7.113 & -111.208 \\
\hline R111-S037-.01 EDTA-5-F/C & 18.93 & 5.007 & 0.095 & 137.700 & 6.197 & $6538 \%$ & 7.113 & -1218.637 \\
\hline R111-S037-.01 EDTA-5-F-DUP & 18.93 & 5.007 & 0.095 & 14.750 & 0.664 & $700 \%$ & 7.113 & -113.634 \\
\hline R111-S037-.01 EDTA-7 & 18.93 & 5.010 & 0.095 & 6.650 & 0.299 & $316 \%$ & 7.229 & -40.801 \\
\hline R111-S037-.01 EDTA-7-F & 18.93 & 5.010 & 0.095 & 9.070 & 0.408 & $430 \%$ & 7.229 & -62.537 \\
\hline R111-S037-.01 EDTA-7-F/C & 18.93 & 5.010 & 0.095 & 9.250 & 0.416 & $439 \%$ & 7.229 & -64.154 \\
\hline R111-S037-.01 EDTA-7-F-DUP & 18.93 & 5.010 & 0.095 & 10.050 & 0.452 & $477 \%$ & 7.229 & -71.339 \\
\hline R111-S038-.01 EDTA-3 & 25.45 & 5.024 & 0.128 & 14.650 & 0.659 & $516 \%$ & 6.884 & -105.770 \\
\hline R111-S038-.01 EDTA-3-F & 25.45 & 5.024 & 0.128 & 174.860 & 7.869 & $6154 \%$ & 6.884 & -1540.772 \\
\hline R111-S038-.01 EDTA-3-F/C & 25.45 & 5.024 & 0.128 & 173.600 & 7.812 & $6110 \%$ & 6.884 & -1529.486 \\
\hline R111-S038-.01 EDTA-3-F-DUP & 25.45 & 5.024 & 0.128 & 176.620 & 7.948 & $6216 \%$ & 6.884 & -1556.536 \\
\hline R111-S038-.01 EDTA-5 & 25.45 & 5.009 & 0.127 & 10.120 & 0.455 & $357 \%$ & 6.982 & -65.466 \\
\hline R111-S038-.01 EDTA-5-F & 25.45 & 5.009 & 0.127 & 13.600 & 0.612 & $480 \%$ & 6.982 & -96.730 \\
\hline R111-S038-.01 EDTA-5-F/C & 25.45 & 5.009 & 0.127 & 13.150 & 0.592 & $464 \%$ & 6.982 & -92.687 \\
\hline R111-S038-.01 EDTA-5-F-DUP & 25.45 & 5.009 & 0.127 & 13.280 & 0.598 & $469 \%$ & 6.982 & -93.855 \\
\hline R111-S038-.01 EDTA-7 & 25.45 & 5.019 & 0.128 & 7.690 & 0.346 & $271 \%$ & 7.204 & -43.498 \\
\hline R111-S038-.01 EDTA-7-F & 25.45 & 5.019 & 0.128 & 11.280 & 0.508 & $397 \%$ & 7.204 & -75.686 \\
\hline R111-S038-.01 EDTA-7-F/C & 25.45 & 5.019 & 0.128 & 11.290 & 0.508 & $398 \%$ & 7.204 & -75.775 \\
\hline R111-S038-.01 EDTA-7-F-DUP & 25.45 & 5.019 & 0.128 & 11.270 & 0.507 & $397 \%$ & 7.204 & -75.596 \\
\hline R111-S039-.01 EDTA-3 & 73.42 & 5.026 & 0.369 & 194.680 & 8.761 & $2374 \%$ & 6.401 & -1669.636 \\
\hline R111-S039-.01 EDTA-3-F & 73.42 & 5.026 & 0.369 & 208.570 & 9.386 & $2543 \%$ & 6.401 & -1793.999 \\
\hline R111-S039-.01 EDTA-3-F/C & 73.42 & 5.026 & 0.369 & 197.710 & 8.897 & $2411 \%$ & 6.401 & -1696.765 \\
\hline R111-S039-.01 EDTA-3-F-DUP & 73.42 & 5.026 & 0.369 & 206.180 & 9.278 & $2514 \%$ & 6.401 & -1772.601 \\
\hline R111-S039-.01 EDTA-5 & 73.42 & 5.041 & 0.370 & 11.820 & 0.532 & $144 \%$ & 6.854 & -32.095 \\
\hline R111-S039-.01 EDTA-5-F & 73.42 & 5.041 & 0.370 & 15.680 & 0.706 & $191 \%$ & 6.854 & -66.552 \\
\hline R111-S039-.01 EDTA-5-F/C & 73.42 & 5.041 & 0.370 & 157.490 & 7.087 & $1915 \%$ & 6.854 & -1332.462 \\
\hline R111-S039-.01 EDTA-5-F-DUP & 73.42 & 5.041 & 0.370 & 16.010 & 0.720 & $195 \%$ & 6.854 & -69.498 \\
\hline R111-S039-.01 EDTA-7 & 73.42 & 5.031 & 0.369 & 9.540 & 0.429 & $116 \%$ & 7.186 & -11.911 \\
\hline
\end{tabular}


Cu Removed by Batch Shaker Method

\begin{tabular}{|c|c|c|c|c|c|c|c|c|}
\hline & au & Wt. of Soil & Cu in & $\mathrm{Cu}$ & Cu in & $\% \mathrm{Cu}$ & $\mathrm{pH}$ of & Cu Remaining \\
\hline SAMPLE \# & $(\mathbf{m g} / \mathbf{k g})$ & (g) & Soil (mg) & $(\mathrm{mg} / \mathrm{L})$ & Sample (mg) & Removed & Sample & in Soil $(\mathbf{m g} / \mathbf{k g})$ \\
\hline R111-S039-.01 EDTA-7-F & 73.42 & 5.031 & 0.369 & 13.950 & 0.628 & $170 \%$ & 7.186 & -51.356 \\
\hline R111-S039-.01 EDTA-7-F/C & 73.42 & 5.031 & 0.369 & 13.990 & 0.630 & $170 \%$ & 7.186 & -51.714 \\
\hline R111-S039-.01 EDTA-7-F-DUP & 73.42 & 5.031 & 0.369 & 14.050 & 0.632 & $171 \%$ & 7.186 & -52.251 \\
\hline R111-S041-.01 EDTA-3 & 14.61 & 5.031 & 0.074 & 151.460 & 6.816 & $9273 \%$ & 6.214 & -1340.131 \\
\hline R111-S041-.01 EDTA-3-F & 14.61 & 5.031 & 0.074 & 166.590 & 7.497 & $10199 \%$ & 6.214 & -1475.462 \\
\hline R111-S041-.01 EDTA-3-F/C & 14.61 & 5.031 & 0.074 & 159.490 & 7.177 & $9764 \%$ & 6.214 & -1411.955 \\
\hline R111-S041-.01 EDTA-3-F-DUP & 14.61 & 5.031 & 0.074 & 16.610 & 0.747 & $1017 \%$ & 6.214 & -133.959 \\
\hline R111-S041-.01 EDTA-5 & 14.61 & 5.036 & 0.074 & 10.360 & 0.466 & $634 \%$ & 6.887 & -77.963 \\
\hline R111-S041-.01 EDTA-5-F & 14.61 & 5.036 & 0.074 & 136.180 & 6.128 & $8329 \%$ & 6.887 & -1202.249 \\
\hline R111-S041-.01 EDTA-5-F/C & 14.61 & 5.036 & 0.074 & 13.140 & 0.591 & $804 \%$ & 6.887 & -102.805 \\
\hline R111-S041-.01 EDTA-5-F-DUP & 14.61 & 5.036 & 0.074 & 13.850 & 0.623 & $847 \%$ & 6.887 & -109.149 \\
\hline R111-S041-.01 EDTA-7 & 14.61 & 5.027 & 0.073 & 7.850 & 0.353 & $481 \%$ & 7.431 & -55.661 \\
\hline R111-S041-.01 EDTA-7-F & 14.61 & 5.027 & 0.073 & 11.840 & 0.533 & $725 \%$ & 7.431 & -91.378 \\
\hline R111-S041-.01 EDTA-7-F/C & 14.61 & 5.027 & 0.073 & 11.530 & 0.519 & $706 \%$ & 7.431 & -88.603 \\
\hline R111-S041-.01 EDTA-7-F-DUP & 14.61 & 5.027 & 0.073 & 11.810 & 0.531 & $724 \%$ & 7.431 & -91.109 \\
\hline R111-S044-.01 EDTA-3 & 7.68 & 5.036 & 0.039 & 11.090 & 0.499 & $1290 \%$ & 6.701 & -91.417 \\
\hline R111-S044-.01 EDTA-3-F & 7.68 & 5.036 & 0.039 & 11.110 & 0.500 & $1293 \%$ & 6.701 & -91.595 \\
\hline R111-S044-.01 EDTA-3-F/C & 7.68 & 5.036 & 0.039 & 10.520 & 0.473 & $1224 \%$ & 6.701 & -86.323 \\
\hline R111-S044-.01 EDTA-3-F-DUP & 7.68 & 5.036 & 0.039 & 11.330 & 0.510 & $1318 \%$ & 6.701 & -93.561 \\
\hline R111-S044-.01 EDTA-5 & 7.68 & 5.034 & 0.039 & 8.080 & 0.364 & $940 \%$ & 6.321 & -64.549 \\
\hline R111-S044-.01 EDTA-5-F & 7.68 & 5.034 & 0.039 & 11.330 & 0.510 & $1319 \%$ & 6.321 & -93.601 \\
\hline R111-S044-.01 EDTA-5-F/C & 7.68 & 5.034 & 0.039 & 10.680 & 0.481 & $1243 \%$ & 6.321 & -87.791 \\
\hline R111-S044-.01 EDTA-5-F-DUP & 7.68 & 5.034 & 0.039 & 11.190 & 0.504 & $1302 \%$ & 6.321 & -92.350 \\
\hline R111-S044-.01 EDTA-7 & 7.68 & 5.013 & 0.038 & 5.110 & 0.230 & $597 \%$ & 7.847 & -38.191 \\
\hline R111-S044-.01 EDTA-7-F & 7.68 & 5.013 & 0.038 & 7.400 & 0.333 & $865 \%$ & 7.847 & -58.747 \\
\hline R111-S044-.01 EDTA-7-F/C & 7.68 & 5.013 & 0.038 & 7.230 & 0.325 & $845 \%$ & 7.847 & -57.221 \\
\hline R111-S044-.01 EDTA-7-F-DUP & 7.68 & 5.013 & 0.038 & 7.280 & 0.328 & $851 \%$ & 7.847 & -57.670 \\
\hline R111-S049-.01 EDTA-3 & 0.75 & 5.041 & 0.004 & 0.190 & 0.009 & $226 \%$ & 3.183 & -0.946 \\
\hline R111-S049-.01 EDTA-3-F & 0.75 & 5.041 & 0.004 & 0.230 & 0.010 & $274 \%$ & 3.183 & -1.303 \\
\hline R111-S049-.01 EDTA-3-F/C & 0.75 & 5.041 & 0.004 & 0.220 & 0.010 & $262 \%$ & 3.183 & -1.214 \\
\hline R111-S049-.01 EDTA-3-F-DUP & 0.75 & 5.041 & 0.004 & 0.250 & 0.011 & $298 \%$ & 3.183 & -1.482 \\
\hline R111-S049-.01 EDTA-5 & 0.75 & 5.027 & 0.004 & 0.160 & 0.007 & $191 \%$ & 5.076 & -0.682 \\
\hline R111-S049-.01 EDTA-5-F & 0.75 & 5.027 & 0.004 & 0.230 & 0.010 & $275 \%$ & 5.076 & -1.309 \\
\hline R111-S049-.01 EDTA-5-F/C & 0.75 & 5.027 & 0.004 & 0.230 & 0.010 & $275 \%$ & 5.076 & -1.309 \\
\hline R111-S049-.01 EDTA-5-F-DUP & 0.75 & 5.027 & 0.004 & 0.240 & 0.011 & $286 \%$ & 5.076 & -1.398 \\
\hline
\end{tabular}


Cu Removed by Batch Shaker Method

\begin{tabular}{|l|c|c|c|c|c|c|c|c|}
\hline & Cu & Wt. of Soll & Cu in & Cu & Cu in & \% Cu & pH of & Cu Remaining \\
\hline \multicolumn{1}{|c|}{ SAMPLE\# } & $(\mathbf{m g} / \mathbf{k g})$ & $\mathbf{( g )}$ & Soil $(\mathbf{m g})$ & (mg/L) & Sample (mg) & Removed & Sample & in Soil (mg/kg) \\
\hline & & & & & & & & \\
\hline R111-S049-.01 EDTA-7 & 0.75 & 5.033 & 0.004 & 0.230 & 0.010 & $274 \%$ & 7.101 & -1.306 \\
\hline R111-S049-.01 EDTA-7-F & 0.75 & 5.033 & 0.004 & 0.220 & 0.010 & $262 \%$ & 7.101 & -1.217 \\
\hline R111-S049-.01 EDTA-7-F/C & 0.75 & 5.033 & 0.004 & 0.260 & 0.012 & $310 \%$ & 7.101 & -1.575 \\
\hline R111-S049-.01 EDTA-7-F-DUP & 0.75 & 5.033 & 0.004 & 0.250 & 0.011 & $298 \%$ & 7.101 & -1.485 \\
\hline
\end{tabular}


Fe Removed by Batch Shaker Method

\begin{tabular}{|c|c|c|c|c|c|c|c|}
\hline & $\mathrm{Fe}$ & Wt. of Soil & Fe in & $\mathrm{Fe}$ & Fe in & $\% \mathrm{Fe}$ & $\mathrm{pH}$ of \\
\hline SAMPLE \# & $(\mathbf{m g} / \mathbf{k g})$ & (g) & Soil (mg) & (mg/L) & Sample (mg) & Removed & Sample \\
\hline R111-S037-.01 CIT-3 & 975.68 & 5.003 & 4.881 & 32.630 & 1.468 & $30 \%$ & 5.915 \\
\hline R111-S037-.01 CIT-3-F & 975.68 & 5.003 & 4.881 & 28.580 & 1.286 & $26 \%$ & 5.915 \\
\hline R111-S037-.01 CIT-3-F/C & 975.68 & 5.003 & 4.881 & 28.060 & 1.263 & $26 \%$ & 5.915 \\
\hline R111-S037-.01 CIT-3-F-DUP & 975.68 & 5.003 & 4.881 & 27.570 & 1.241 & $25 \%$ & 5.915 \\
\hline R111-S037-.01 CIT-5 & 975.68 & 5.010 & 4.888 & 16.550 & 0.745 & $15 \%$ & 6.409 \\
\hline R111-S037-.01 CIT-5-F & 975.68 & 5.010 & 4.888 & 13.970 & 0.629 & $13 \%$ & 6.409 \\
\hline R111-S037-.01 CIT-5-F/C & 975.68 & 5.010 & 4.888 & 13.300 & 0.599 & $12 \%$ & 6.409 \\
\hline R111-S037-.01 ClT-5-F-DUP & 975.68 & 5.010 & 4.888 & 14.210 & 0.639 & $13 \%$ & 6.409 \\
\hline R111-S037-.01 CIT-7 & 975.68 & 5.036 & 4.914 & 36.450 & 1.640 & $33 \%$ & 7.698 \\
\hline R111-S037-.01 CIT-7-F & 975.68 & 5.036 & 4.914 & 6.860 & 0.309 & $6 \%$ & 7.698 \\
\hline R111-S037-.01 CIT-7-F/C & 975.68 & 5.036 & 4.914 & 6.880 & 0.310 & $6 \%$ & 7.698 \\
\hline R111-S037-.01 CIT-7-F-DUP & 975.68 & 5.036 & 4.914 & 6.770 & 0.305 & $6 \%$ & 7.698 \\
\hline R111-S038-.01 ClT-3 & 1523.36 & 5.014 & 7.638 & 53.830 & 2.422 & $32 \%$ & 6.237 \\
\hline R111-S038-.01 CIT-3-F & 1523.36 & 5.014 & 7.638 & 56.660 & 2.550 & $33 \%$ & 6.237 \\
\hline R111-S038-.01 CIT-3-F/C & 1523.36 & 5.014 & 7.638 & 60.940 & 2.742 & $36 \%$ & 6.237 \\
\hline R111-S038-.01 CIT-3-F-DUP & 1523.36 & 5.014 & 7.638 & 115.500 & 5.198 & $68 \%$ & 6.237 \\
\hline R111-S038-.01 CIT-5 & 1523.36 & 5.014 & 7.638 & 15.950 & 0.718 & $9 \%$ & 6.736 \\
\hline R111-S038-.01 CIT-5-F & 1523.36 & 5.014 & 7.638 & 23.810 & 1.071 & $14 \%$ & 6.736 \\
\hline R111-S038-.01 CIT-5-F/C & 1523.36 & 5.014 & 7.638 & 22.750 & 1.024 & $13 \%$ & 6.736 \\
\hline R111-S038-.01 CIT-5-F-DUP & 1523.36 & 5.014 & 7.638 & 24.660 & 1.110 & $15 \%$ & 6.736 \\
\hline R111-S038-.01 CIT-7 & 1523.36 & 5.030 & 7.663 & 8.090 & 0.364 & $5 \%$ & 7.734 \\
\hline R111-S038-.01 CIT-7-F & 1523.36 & 5.030 & 7.663 & 7.890 & 0.355 & $5 \%$ & 7.734 \\
\hline R111-S038-.01 CIT-7-F/C & 1523.36 & 5.030 & 7.663 & 8.020 & 0.361 & $5 \%$ & 7.734 \\
\hline R111-S038-.01 CIT-7-F-DUP & 1523.36 & 5.030 & 7.663 & 7.710 & 0.347 & $5 \%$ & 7.734 \\
\hline R111-S039-.01 CIT-3 & 662.09 & 5.008 & 3.316 & 29.130 & 1.311 & $40 \%$ & 6.304 \\
\hline R111-S039-.01 CIT-3-F & 662.09 & 5.008 & 3.316 & 29.770 & 1.340 & $40 \%$ & 6.304 \\
\hline R111-S039-.01 CIT-3-F/C & 662.09 & 5.008 & 3.316 & 28.590 & 1.287 & $39 \%$ & 6.304 \\
\hline R111-S039-.01 CIT-3-F-DUP & 662.09 & 5.008 & 3.316 & 28.570 & 1.286 & $39 \%$ & 6.304 \\
\hline R111-S039-.01 CIT-5 & 662.09 & 5.041 & 3.338 & 7.210 & 0.324 & $10 \%$ & 6.321 \\
\hline R111-S039-.01 CIT-5-F & 662.09 & 5.041 & 3.338 & 6.870 & 0.309 & $9 \%$ & 6.321 \\
\hline R111-S039-.01 CIT-5-F/C & 662.09 & 5.041 & 3.338 & 7.150 & 0.322 & $10 \%$ & 6.321 \\
\hline R111-S039-.01 ClT-5-F-DUP & 662.09 & 5.041 & 3.338 & 7.070 & 0.318 & $10 \%$ & 6.321 \\
\hline R111-S039-.01 CIT-7 & 662.09 & 5.029 & 3.330 & 112.060 & 5.043 & $151 \%$ & 7.421 \\
\hline R111-S039-.01 CIT-7-F & 662.09 & 5.029 & 3.330 & 30.590 & 1.377 & $41 \%$ & 7.421 \\
\hline R111-S039-.01 CIT-7-F/C & 662.09 & 5.029 & 3.330 & 26.190 & 1.179 & $35 \%$ & 7.421 \\
\hline
\end{tabular}


Fe Removed by Batch Shaker Method

\begin{tabular}{|c|c|c|c|c|c|c|c|}
\hline & $\mathrm{Fe}$ & wt. of soil & $\mathrm{mg} \mathrm{Fe}$ & $\mathrm{Fe}$ & mg Fe & $\% \mathrm{Fe}$ & $\mathrm{pH}$ of \\
\hline SAMPLE\# & $(\mathbf{m g} / \mathbf{k g})$ & (g) & in soil & $(\mathrm{mg} / \mathrm{L})$ & in sample & removed & sample \\
\hline R111-S039-.01 CIT-7-F-DUP & 662.09 & 5.029 & 3.330 & 32.340 & 1.455 & $44 \%$ & 7.421 \\
\hline R111-S041-.01 CIT-3 & 193.56 & 5.002 & 0.968 & 35.040 & 1.577 & $163 \%$ & 5.861 \\
\hline R111-S041-.01 CIT-3-F & 193.56 & 5.002 & 0.968 & 28.400 & 1.278 & $132 \%$ & 5.861 \\
\hline R111-S041-.01 CIT-3-F/C & 193.56 & 5.002 & 0.968 & 34.870 & 1.569 & $162 \%$ & 5.861 \\
\hline R111-S041-.01 CIT-3-F-DUP & 193.56 & 5.002 & 0.968 & 34.390 & 1.548 & $160 \%$ & 5.861 \\
\hline R111-S041-.01 CIT-5 & 193.56 & 5.036 & 0.975 & 10.570 & 0.476 & $49 \%$ & 6.498 \\
\hline R111-S041-.01 CIT-5-F & 193.56 & 5.036 & 0.975 & 6.200 & 0.279 & $29 \%$ & 6.498 \\
\hline R111-S041-.01 CIT-5-F/C & 193.56 & 5.036 & 0.975 & 7.020 & 0.316 & $32 \%$ & 6.498 \\
\hline R111-S041-.01 CIT-5-F-DUP & 193.56 & 5.036 & 0.975 & 6.340 & 0.285 & $29 \%$ & 6.498 \\
\hline R111-S041-.01 CIT-7 & 193.56 & 5.041 & 0.976 & 93.100 & 4.190 & $429 \%$ & 7.601 \\
\hline R111-S041-.01 CIT-7-F & 193.56 & 5.041 & 0.976 & 18.180 & 0.818 & $84 \%$ & 7.601 \\
\hline R111-S041-.01 CIT-7-F/C & 193.56 & 5.041 & 0.976 & 16.740 & 0.753 & $77 \%$ & 7.601 \\
\hline R111-S041-.01 CIT-7-F-DUP & 193.56 & 5.041 & 0.976 & 19.160 & 0.862 & $88 \%$ & 7.601 \\
\hline R111-S044-.01 CIT-3 & 400.10 & 5.021 & 2.009 & 20.610 & 0.927 & $46 \%$ & 6.432 \\
\hline R111-S044-.01 CIT-3-F & 400.10 & 5.021 & 2.009 & 20.650 & 0.929 & $46 \%$ & 6.432 \\
\hline R111-S044-.01 CIT-3-F/C & 400.10 & 5.021 & 2.009 & 21.190 & 0.954 & $47 \%$ & 6.432 \\
\hline R111-S044-.01 CIT-3-F-DUP & 400.10 & 5.021 & 2.009 & 19.410 & 0.873 & $43 \%$ & 6.432 \\
\hline R111-S044-.01 CIT-5 & 400.10 & 5.021 & 2.009 & 15.710 & 0.707 & $35 \%$ & 6.747 \\
\hline R111-S044-.01 CIT-5-F & 400.10 & 5.021 & 2.009 & 7.610 & 0.342 & $17 \%$ & 6.747 \\
\hline R111-S044-.01 ClT-5-F/C & 400.10 & 5.021 & 2.009 & 7.560 & 0.340 & $17 \%$ & 6.747 \\
\hline R111-S044-.01 CIT-5-F-DUP & 400.10 & 5.021 & 2.009 & 7.500 & 0.338 & $17 \%$ & 6.747 \\
\hline R111-S044-.01 CIT-7 & 400.10 & 5.041 & 2.017 & 67.300 & 3.029 & $150 \%$ & 7.261 \\
\hline R111-S044-.01 CIT-7-F & 400.10 & 5.041 & 2.017 & 14.650 & 0.659 & $33 \%$ & 7.261 \\
\hline R111-S044-.01 CIT-7-F/C & 400.10 & 5.041 & 2.017 & 14.690 & 0.661 & $33 \%$ & 7.261 \\
\hline R111-S044-.01 CIT-7-F-DUP & 400.10 & 5.041 & 2.017 & 28.260 & 1.272 & $63 \%$ & 7.261 \\
\hline R111-S049-.01 CIT-3 & 1.68 & 5.030 & 0.008 & 28.680 & 1.291 & $15273 \%$ & 3.257 \\
\hline R111-S049-.01 CIT-3-F & 1.68 & 5.030 & 0.008 & 34.670 & 1.560 & $18462 \%$ & 3.257 \\
\hline R111-S049-.01 CIT-3-F/C & 1.68 & 5.030 & 0.008 & 34.220 & 1.540 & $18223 \%$ & 3.257 \\
\hline R111-S049-.01 CIT-3-F-DUP & 1.68 & 5.030 & 0.008 & 33.930 & 1.527 & $18068 \%$ & 3.257 \\
\hline R111-S049-.01 CIT-5 & 1.68 & 5.009 & 0.008 & 163.400 & 7.353 & $87378 \%$ & 5.163 \\
\hline R111-S049-.01 CIT-5-F & 1.68 & 5.009 & 0.008 & 17.840 & 0.803 & $9540 \%$ & 5.163 \\
\hline R111-S049-.01 CIT-5-F/C & 1.68 & 5.009 & 0.008 & 20.350 & 0.916 & $10882 \%$ & 5.163 \\
\hline R111-S049-.01 CIT-5-F-DUP & 1.68 & 5.009 & 0.008 & 29.580 & 1.331 & $15818 \%$ & 5.163 \\
\hline R111-S049-.01 CIT-7 & 1.68 & 5.008 & 0.008 & 123.540 & 5.559 & $66076 \%$ & 7.093 \\
\hline R111-S049-.01 CIT-7-F & 1.68 & 5.008 & 0.008 & 35.190 & 1.584 & $18822 \%$ & 7.093 \\
\hline
\end{tabular}


Fe Removed by Batch Shaker Method

\begin{tabular}{|c|c|c|c|c|c|c|c|}
\hline & $\mathrm{Fe}$ & wt. of soil & mg Fe & $\mathrm{Fe}$ & mg Fe & $\% \mathrm{Fe}$ & $\mathrm{pH}$ of \\
\hline SAMPLE \# & $(\mathbf{m g} / \mathbf{k g})$ & (g) & in soil & $(\mathrm{mg} / \mathrm{L})$ & in sample & removed & sample \\
\hline R111-S049-.01 CIT-7-F/C & 1.68 & 5.008 & 0.008 & 57.570 & 2.591 & $30792 \%$ & 7.093 \\
\hline R111-S049-.01 CIT-7-F-DUP & 1.68 & 5.008 & 0.008 & 31.880 & 1.435 & $17051 \%$ & 7.093 \\
\hline R111-S037-.01 EDTA-3 & 980.36 & 5.008 & 4.910 & 29.480 & 1.327 & $27 \%$ & 6.715 \\
\hline R111-S037-.01 EDTA-3-F & 980.36 & 5.008 & 4.910 & 29.460 & 1.326 & $27 \%$ & 6.715 \\
\hline R111-S037-.01 EDTA-3-F/C & 975.68 & 5.008 & 4.886 & 28.860 & 1.299 & $27 \%$ & 6.715 \\
\hline R111-S037-.01 EDTA-3-F-DUP & 975.68 & 5.008 & 4.886 & 35.240 & 1.586 & $32 \%$ & 6.715 \\
\hline R111-S037-.01 EDTA-5 & 975.68 & 5.007 & 4.885 & 11.040 & 0.497 & $10 \%$ & 7.113 \\
\hline R111-S037-.01 EDTA-5-F & 975.68 & 5.007 & 4.885 & 9.680 & 0.436 & $9 \%$ & 7.113 \\
\hline R111-S037-.01 EDTA-5-F/C & 975.68 & 5.007 & 4.885 & 10.030 & 0.451 & $9 \%$ & 7.113 \\
\hline R111-S037-.01 EDTA-5-F-DUP & 975.68 & 5.007 & 4.885 & 11.270 & 0.507 & $10 \%$ & 7.113 \\
\hline R111-S037-.01 EDTA-7 & 975.68 & 5.010 & 4.888 & 8.350 & 0.376 & $8 \%$ & 7.229 \\
\hline R111-S037-.01 EDTA-7-F & 975.68 & 5.010 & 4.888 & 4.590 & 0.207 & $4 \%$ & 7.229 \\
\hline R111-S037-.01 EDTA-7-F/C & 975.68 & 5.010 & 4.888 & 4.830 & 0.217 & $4 \%$ & 7.229 \\
\hline R111-S037-.01 EDTA-7-F-DUP & 975.68 & 5.010 & 4.888 & 5.190 & 0.234 & $5 \%$ & 7.229 \\
\hline R111-S038-.01 EDTA-3 & 1523.36 & 5.024 & 7.653 & 36.010 & 1.620 & $21 \%$ & 6.884 \\
\hline R111-S038-.01 EDTA-3-F & 1523.36 & 5.024 & 7.653 & 32.960 & 1.483 & $19 \%$ & 6.884 \\
\hline R111-S038-.01 EDTA-3-F/C & 1523.36 & 5.024 & 7.653 & 31.220 & 1.405 & $18 \%$ & 6.884 \\
\hline R111-S038-.01 EDTA-3-F-DUP & 1523.36 & 5.024 & 7.653 & 31.460 & 1.416 & $18 \%$ & 6.884 \\
\hline R111-S038-.01 EDTA-5 & 1523.36 & 5.009 & 7.631 & 15.320 & 0.689 & $9 \%$ & 6.982 \\
\hline R111-S038-.01 EDTA-5-F & 1523.36 & 5.009 & 7.631 & 14.240 & 0.641 & $8 \%$ & 6.982 \\
\hline R111-S038-.01 EDTA-5-F/C & 1523.36 & 5.009 & 7.631 & 14.340 & 0.645 & $8 \%$ & 6.982 \\
\hline R111-S038-.01 EDTA-5-F-DUP & 1523.36 & 5.009 & 7.631 & 14.430 & 0.649 & $9 \%$ & 6.982 \\
\hline R111-S038-.01 EDTA-7 & 1523.36 & 5.019 & 7.646 & 6.450 & 0.290 & $4 \%$ & 7.204 \\
\hline R111-S038-.01 EDTA-7-F & 1523.36 & 5.019 & 7.646 & 4.550 & 0.205 & $3 \%$ & 7.204 \\
\hline R111-S038-.01 EDTA-7-F/C & 1523.36 & 5.019 & 7.646 & 4.290 & 0.193 & $3 \%$ & 7.204 \\
\hline R111-S038-.01 EDTA-7-F-DUP & 1523.36 & 5.019 & 7.646 & 4.640 & 0.209 & $3 \%$ & 7.204 \\
\hline R111-\$039-.01 EDTA-3 & 662.09 & 5.026 & 3.328 & 130.090 & 5.854 & $176 \%$ & 6.401 \\
\hline R111-S039-.01 EDTA-3-F & 662.09 & 5.026 & 3.328 & 113.050 & 5.087 & $153 \%$ & 6.401 \\
\hline R111-S039-.01 EDTA-3-F/C & 662.09 & 5.026 & 3.328 & 113.400 & 5.103 & $153 \%$ & 6.401 \\
\hline R111-S039-.01 EDTA-3-F-DUP & 662.09 & 5.026 & 3.328 & 70.270 & 3.162 & $95 \%$ & 6.401 \\
\hline R111-S039-.01 EDTA-5 & 662.09 & 5.041 & 3.338 & 15.140 & 0.681 & $20 \%$ & 6.854 \\
\hline R111-S039-.01 EDTA-5-F & 662.09 & 5.041 & $\mathbf{3 . 3 3 8}$ & 14.560 & 0.655 & $20 \%$ & 6.854 \\
\hline R111-S039-.01 EDTA-5-F/C & 662.09 & 5.041 & 3.338 & 14.550 & 0.655 & $20 \%$ & 6.854 \\
\hline R111-S039-.01 EDTA-5-F-DUP & 662.09 & 5.041 & 3.338 & 17.260 & 0.777 & $23 \%$ & 6.854 \\
\hline R111-S039-.01 EDTA-7 & 662.09 & 5.031 & 3.331 & 5.580 & 0.251 & $8 \%$ & 7.186 \\
\hline
\end{tabular}


Fe Removed by Batch Shaker Method

\begin{tabular}{|c|c|c|c|c|c|c|c|}
\hline & $\mathrm{Fe}$ & wt. of soil & $\mathrm{mg} \mathrm{Fe}$ & Fe & mg Fe & $\% \mathrm{Fe}$ & $\mathrm{pH}$ of \\
\hline SAMPLE \# & $(\mathbf{m g} / \mathbf{k g})$ & $(g)$ & in soil & $(\mathrm{mg} / \mathrm{L})$ & in sample & removed & sample \\
\hline R111-S039-.01 EDTA-7-F & 662.09 & 5.031 & 3.331 & 4.630 & 0.208 & $6 \%$ & 7.186 \\
\hline R111-S039-.01 EDTA-7-F/C & 662.09 & 5.031 & 3.331 & 4.540 & 0.204 & $6 \%$ & 7.186 \\
\hline R111-S039-.01 EDTA-7-F-DUP & 662.09 & 5.031 & 3.331 & 5.250 & 0.236 & $7 \%$ & 7.186 \\
\hline R111-S041-.01 EDTA-3 & 193.56 & 5.031 & 0.974 & 57.810 & 2.601 & $267 \%$ & 6.214 \\
\hline R111-S041-.01 EDTA-3-F & 193.56 & 5.031 & 0.974 & 57.250 & 2.576 & $265 \%$ & 6.214 \\
\hline R111-S041-.01 EDTA-3-F/C & 193.56 & 5.031 & 0.974 & 59.320 & 2.669 & $274 \%$ & 6.214 \\
\hline R111-S041-.01 EDTA-3-F-DUP & 193.56 & 5.031 & 0.974 & 32.510 & 1.463 & $150 \%$ & 6.214 \\
\hline R111-S041-.01 EDTA-5 & 193.56 & 5.036 & 0.975 & 14.170 & 0.638 & $65 \%$ & 6.887 \\
\hline R111-S041-.01 EDTA-5-F & 193.56 & 5.036 & 0.975 & 16.470 & 0.741 & $76 \%$ & 6.887 \\
\hline R111-S041-.01 EDTA-5-F/C & 193.56 & 5.036 & 0.975 & 16.660 & 0.750 & $77 \%$ & 6.887 \\
\hline R111-S041-.01 EDTA-5-F-DUP & 193.56 & 5.036 & 0.975 & 17.600 & 0.792 & $81 \%$ & 6.887 \\
\hline R111-S041-.01 EDTA-7 & 193.56 & 5.027 & 0.973 & 4.500 & 0.203 & $21 \%$ & 7.431 \\
\hline R111-S041-.01 EDTA-7-F & 193.56 & 5.027 & 0.973 & 2.920 & 0.131 & $14 \%$ & 7.431 \\
\hline R111-S041-.01 EDTA-7-F/C & 193.56 & 5.027 & 0.973 & 3.020 & 0.136 & $14 \%$ & 7.431 \\
\hline R111-S041-.01 EDTA-7-F-DUP & 193.56 & 5.027 & 0.973 & 3.360 & 0.151 & $16 \%$ & 7.431 \\
\hline R111-S044-.01 EDTA-3 & 400.10 & 5.036 & 2.015 & 50.580 & 2.276 & $113 \%$ & 6.701 \\
\hline R111-S044-.01 EDTA-3-F & 400.10 & 5.036 & 2.015 & 68.240 & 3.071 & $152 \%$ & 6.701 \\
\hline R111-S044-.01 EDTA-3-F/C & 400.10 & 5.036 & 2.015 & 70.710 & 3.182 & $158 \%$ & 6.701 \\
\hline R111-S044-.01 EDTA-3-F-DUP & 400.10 & 5.036 & 2.015 & 62.230 & 2.800 & $139 \%$ & 6.701 \\
\hline R111-S044-.01 EDTA-5 & 400.10 & 5.034 & 2.014 & 16.320 & 0.734 & $36 \%$ & 6.321 \\
\hline R111-S044-.01 EDTA-5-F & 400.10 & 5.034 & 2.014 & 21.300 & 0.959 & $48 \%$ & 6.321 \\
\hline R111-S044-.01 EDTA-5-F/C & 400.10 & 5.034 & 2.014 & 21.800 & 0.981 & $49 \%$ & 6.321 \\
\hline R111-S044-.01 EDTA-5-F-DUP & 400.10 & 5.034 & 2.014 & 21.370 & 0.962 & $48 \%$ & 6.321 \\
\hline R111-S044-.01 EDTA-7 & 400.10 & 5.013 & 2.006 & 7.390 & 0.333 & $17 \%$ & 7.847 \\
\hline R111-S044-.01 EDTA-7-F & 400.10 & 5.013 & 2.006 & 7.470 & 0.336 & $17 \%$ & 7.847 \\
\hline R111-S044-.01 EDTA-7-F/C & 400.10 & 5.013 & 2.006 & 7.740 & 0.348 & $17 \%$ & 7.847 \\
\hline R111-S044-.01 EDTA-7-F-DUP & 400.10 & 5.013 & 2.006 & 7.630 & 0.343 & $17 \%$ & 7.847 \\
\hline R111-S049-.01 EDTA-3 & 1.68 & 5.041 & 0.008 & 17.050 & 0.767 & $9060 \%$ & 3.183 \\
\hline R111-S049-.01 EDTA-3-F & 1.68 & 5.041 & 0.008 & 28.640 & 1.289 & $15218 \%$ & 3.183 \\
\hline R111-S049-.01 EDTA-3-F/C & 1.68 & 5.041 & 0.008 & 28.030 & 1.261 & $14894 \%$ & 3.183 \\
\hline R111-S049-.01 EDTA-3-F-DUP & 1.68 & 5.041 & 0.008 & 34.660 & 1.560 & $18417 \%$ & 3.183 \\
\hline R111-S049-.01 EDTA-5 & 1.68 & 5.027 & 0.008 & 18.410 & 0.828 & $9810 \%$ & 5.076 \\
\hline R111-S049-.01 EDTA-5-F & 1.68 & 5.027 & 0.008 & 32.060 & 1.443 & $17083 \%$ & 5.076 \\
\hline R111-S049-.01 EDTA-5-F/C & 1.68 & 5.027 & 0.008 & 31.550 & 1.420 & $16811 \%$ & 5.076 \\
\hline R111-S049-.01 EDTA-5-F-DUP & 1.68 & 5.027 & 0.008 & 31.830 & 1.432 & $16960 \%$ & 5.076 \\
\hline
\end{tabular}


Fe Removed by Batch Shaker Method

\begin{tabular}{|c|c|c|c|c|c|c|c|}
\hline & $\mathrm{Fe}$ & wt. of soil & mg Fe & $\mathrm{Fe}$ & $\mathrm{mg} \mathrm{Fe}$ & $\% \mathrm{Fe}$ & $\mathrm{pH}$ of \\
\hline SAMPLE\# & (mg/kg) & (g) & in soil & $(\mathrm{mg} / \mathrm{L})$ & in sample & removed & sample \\
\hline R111-S049-.01 EDTA-7 & 1.68 & 5.033 & 0.008 & 103.700 & 4.667 & $55189 \%$ & 7.101 \\
\hline R111-S049-.01 EDTA-7-F & 1.68 & 5.033 & 0.008 & 28.510 & 1.283 & $15173 \%$ & 7.101 \\
\hline R111-S049-.01 EDTA-7-F/C & 1.68 & 5.033 & 0.008 & 30.440 & 1.370 & $16200 \%$ & 7.101 \\
\hline R111-S049-.01 EDTA-7-F-DUP & 1.68 & 5.033 & 0.008 & 28.620 & 1.288 & $15232 \%$ & 7.101 \\
\hline
\end{tabular}


Pb Removed by Batch Shaker Method

\begin{tabular}{|c|c|c|c|c|c|c|c|c|}
\hline & $\mathbf{P b}$ & Wt. of Soil & Pb in & $\mathbf{P b}$ & $\mathbf{P b}$ in & $\% \mathbf{P b}$ & pH of & Pb Remaining \\
\hline SAMPLE\# & $(\mathbf{m g} / \mathbf{k g})$ & (g) & Soil (mg) & (mg/L) & Sample (mg) & Removed & Sample & in Soil (mg/kg) \\
\hline R111-S037-.01 ClT-3 & 12.45 & 5.003 & 0.062 & 1.170 & 0.053 & $85 \%$ & 5.915 & 1.926 \\
\hline R111-S037-.01 CIT-3-F & 12.45 & 5.003 & 0.062 & 0.260 & 0.012 & $19 \%$ & 5.915 & 10.111 \\
\hline R111-S037-.01 CIT-3-F/C & 12.45 & 5.003 & 0.062 & 0.380 & 0.017 & $27 \%$ & 5.915 & 9.032 \\
\hline R111-S037-.01 CIT-3-F-DUP & 12.45 & 5.003 & 0.062 & 0.390 & 0.018 & $28 \%$ & 5.915 & 8.942 \\
\hline R111-S037-.01 CIT-5 & 12.45 & 5.010 & 0.062 & 0.520 & 0.023 & $38 \%$ & 6.409 & 7.779 \\
\hline R111-S037-.01 CIT-5-F & 12.45 & 5.010 & 0.062 & 0.260 & 0.012 & $19 \%$ & 6.409 & 10.115 \\
\hline R111-S037-.01 CIT-5-F/C & 12.45 & 5.010 & 0.062 & 0.250 & 0.011 & $18 \%$ & 6.409 & 10.204 \\
\hline R111-S037-.01 CIT-5-F-DUP & 12.45 & 5.010 & 0.062 & 0.250 & 0.011 & $18 \%$ & 6.409 & 10.204 \\
\hline R111-S037-.01 ClT-7 & 12.45 & 5.036 & 0.063 & 1.570 & 0.071 & $113 \%$ & 7.698 & -1.579 \\
\hline R111-S037-.01 CIT-7-F & 12.45 & 5.036 & 0.063 & 0.390 & 0.018 & $28 \%$ & 7.698 & 8.965 \\
\hline R111-S037-.01 CIT-7-F/C & 12.45 & 5.036 & 0.063 & 0.250 & 0.011 & $18 \%$ & 7.698 & 10.216 \\
\hline R111-S037-.01 CIT-7-F-DUP & 12.45 & 5.036 & 0.063 & 0.260 & 0.012 & $19 \%$ & 7.698 & 10.127 \\
\hline R111-S038-.01 CIT-3 & 15.04 & 5.014 & 0.075 & 1.300 & 0.059 & $78 \%$ & 6.237 & 3.373 \\
\hline R111-S038-.01 CIT-3-F & 15.04 & 5.014 & 0.075 & 0.510 & 0.023 & $30 \%$ & 6.237 & 10.463 \\
\hline R111-S038-.01 CIT-3-F/C & 15.04 & 5.014 & 0.075 & 0.780 & 0.035 & $47 \%$ & 6.237 & 8.040 \\
\hline R111-S038-.01 CIT-3-F-DUP & 15.04 & 5.014 & 0.075 & 0.520 & 0.023 & $31 \%$ & 6.237 & 10.373 \\
\hline R111-S038-.01 CIT-5 & 15.04 & 5.014 & 0.075 & 0.390 & 0.018 & $23 \%$ & 6.736 & 11.540 \\
\hline R111-S038-.01 CIT-5-F & 15.04 & 5.014 & 0.075 & 0.260 & 0.012 & $16 \%$ & 6.736 & 12.707 \\
\hline R111-S038-.01 CIT-5-F/C & 15.04 & 5.014 & 0.075 & 0.250 & 0.011 & $15 \%$ & 6.736 & 12.796 \\
\hline R111-S038-.01 CIT-5-F-DUP & 15.04 & 5.014 & 0.075 & 0.390 & 0.018 & $23 \%$ & 6.736 & 11.540 \\
\hline R111-S038-.01 CIT-7 & 15.04 & 5.030 & 0.076 & 0.260 & 0.012 & $15 \%$ & 7.734 & 12.714 \\
\hline R111-S038-.01 CIT-7-F & 15.04 & 5.030 & 0.076 & 0.250 & 0.011 & $15 \%$ & 7.734 & 12.803 \\
\hline R111-S038-.01 CIT-7-F/C & 15.04 & 5.030 & 0.076 & 0.250 & 0.011 & $15 \%$ & 7.734 & 12.803 \\
\hline R111-S038-.01 CIT-7-F-DUP & 15.04 & 5.030 & 0.076 & 0.250 & 0.011 & $15 \%$ & 7.734 & 12.803 \\
\hline R111-S039-.01 CIT-3 & 15.04 & 5.008 & 0.075 & 0.910 & 0.041 & $54 \%$ & 6.304 & 6.863 \\
\hline R111-S039-.01 CIT-3-F & 15.04 & 5.008 & 0.075 & 0.510 & 0.023 & $30 \%$ & 6.304 & 10.457 \\
\hline R111-S039-.01 CIT-3-F/C & 15.04 & 5.008 & 0.075 & 0.510 & 0.023 & $30 \%$ & 6.304 & 10.457 \\
\hline R111-S039-.01 CIT-3-F-DUP & 15.04 & 5.008 & 0.075 & 0.250 & 0.011 & $15 \%$ & 6.304 & 12.794 \\
\hline R111-S039-.01 CIT-5 & 15.04 & 5.041 & 0.076 & 0.390 & 0.018 & $23 \%$ & 6.321 & 11.559 \\
\hline R111-S039-.01 CIT-5-F & 15.04 & 5.041 & 0.076 & 0.250 & 0.011 & $15 \%$ & 6.321 & 12.808 \\
\hline R111-S039-.01 CIT-5-F/C & 15.04 & 5.041 & 0.076 & 0.510 & 0.023 & $30 \%$ & 6.321 & 10.487 \\
\hline R111-S039-.01 CIT-5-F-DUP & 15.04 & 5.041 & 0.076 & 0.250 & 0.011 & $15 \%$ & 6.321 & 12.808 \\
\hline R111-S039-.01 CIT-7 & 15.04 & 5.029 & 0.076 & 2.880 & 0.130 & $171 \%$ & 7.421 & -10.731 \\
\hline R111-S039-.01 CIT-7-F & 15.04 & 5.029 & 0.076 & 0.770 & 0.035 & $46 \%$ & 7.421 & 8.150 \\
\hline R111-S039-.01 CIT-7-F/C & 15.04 & 5.029 & 0.076 & 0.640 & 0.029 & $38 \%$ & 7.421 & 9.313 \\
\hline
\end{tabular}


Pb Removed by Batch Shaker Method

\begin{tabular}{|c|c|c|c|c|c|c|c|c|}
\hline & $\mathrm{Pb}$ & Wt. of Soil & $\mathrm{Pb}$ in & $\mathrm{Pb}$ & $\mathrm{Pb}$ in & $\% \mathbf{P b}$ & $\mathrm{pH}$ of & Pb Remaining \\
\hline SAMPLE \# & $(\mathbf{m g} / \mathbf{k g})$ & (g) & Soil (mg) & $(\mathrm{mg} / \mathrm{L})$ & Sample (mg) & Removed & Sample & in Soil (mg/kg) \\
\hline R111-S039-.01 CIT-7-F-DUP & 15.04 & 5.029 & 0.076 & 0.920 & 0.041 & $55 \%$ & 7.421 & 6.808 \\
\hline R111-S041-.01 CIT-3 & 2.51 & 5.002 & 0.013 & 1.430 & 0.064 & $513 \%$ & 5.861 & -10.355 \\
\hline R111-S041-.01 CIT-3-F & 2.51 & 5.002 & 0.013 & 0.900 & 0.041 & $323 \%$ & 5.861 & -5.587 \\
\hline R111-S041-.01 ClT-3-F/C & 2.51 & 5.002 & 0.013 & 0.390 & 0.018 & $140 \%$ & 5.861 & -0.999 \\
\hline R111-S041-.01 CIT-3-F-DUP & 2.51 & 5.002 & 0.013 & 0.650 & 0.029 & $233 \%$ & 5.861 & -3.338 \\
\hline R111-S041-.01 CIT-5 & 2.51 & 5.036 & 0.013 & 0.650 & 0.029 & $231 \%$ & 6.498 & -3.298 \\
\hline R111-S041-.01 CIT-5-F & 2.51 & 5.036 & 0.013 & 0.260 & 0.012 & $93 \%$ & 6.498 & 0.187 \\
\hline R111-S041-.01 CIT-5-F/C & 2.51 & 5.036 & 0.013 & 0.250 & 0.011 & $89 \%$ & 6.498 & 0.276 \\
\hline R111-S041-.01 CIT-5-F-DUP & 2.51 & 5.036 & 0.013 & 0.250 & 0.011 & $89 \%$ & 6.498 & 0.276 \\
\hline R111-S041-.01 CIT-7 & 2.51 & 5.041 & 0.013 & 3.000 & 0.135 & $1067 \%$ & 7.601 & -24.270 \\
\hline R111-S041-.01 CIT-7-F & 2.51 & 5.041 & 0.013 & 0.380 & 0.017 & $135 \%$ & 7.601 & -0.882 \\
\hline R111-S041-.01 CIT-7-F/C & 2.51 & 5.041 & 0.013 & 0.250 & 0.011 & $89 \%$ & 7.601 & 0.278 \\
\hline R111-S041-.01 CIT-7-F-DUP & 2.51 & 5.041 & 0.013 & 0.260 & 0.012 & $92 \%$ & 7.601 & 0.189 \\
\hline R111-S044-.01 CIT-3 & 3.77 & 5.021 & 0.019 & 0.780 & 0.035 & $185 \%$ & 6.432 & -3.221 \\
\hline R111-S044-.01 CIT-3-F & 3.77 & 5.021 & 0.019 & 0.260 & 0.012 & $62 \%$ & 6.432 & 1.440 \\
\hline R111-S044-.01 CIT-3-F/C & 3.77 & 5.021 & 0.019 & 0.250 & 0.011 & $59 \%$ & 6.432 & 1.529 \\
\hline R111-S044-.01 CIT-3-F-DUP & 3.77 & 5.021 & 0.019 & 0.250 & 0.011 & $59 \%$ & 6.432 & 1.529 \\
\hline R111-S044-.01 CIT-5 & 3.77 & 5.021 & 0.019 & 0.260 & 0.012 & $62 \%$ & 6.747 & 1.440 \\
\hline R111-S044-.01 CIT-5-F & 3.77 & 5.021 & 0.019 & 0.390 & 0.018 & $93 \%$ & 6.747 & 0.275 \\
\hline R111-S044-.01 CIT-5-F/C & 3.77 & 5.021 & 0.019 & 0.250 & 0.011 & $59 \%$ & 6.747 & 1.529 \\
\hline R111-S044-.01 CIT-5-F-DUP & 3.77 & 5.021 & 0.019 & 0.260 & 0.012 & $62 \%$ & 6.747 & 1.440 \\
\hline R111-S044-.01 CIT-7 & 3.77 & 5.041 & 0.019 & 1.820 & 0.082 & $431 \%$ & 7.261 & -12.477 \\
\hline R111-S044-.01 CIT-7-F & 3.77 & 5.041 & 0.019 & 0.380 & 0.017 & $90 \%$ & 7.261 & 0.378 \\
\hline R111-S044-.01 CIT-7-F/C & 3.77 & 5.041 & 0.019 & 0.390 & 0.018 & $92 \%$ & 7.261 & 0.289 \\
\hline R111-S044-.01 CIT-7-F-DUP & 3.77 & 5.041 & 0.019 & 0.250 & 0.011 & $59 \%$ & 7.261 & 1.538 \\
\hline R111-S049-.01 CIT-3 & 0.50 & 5.030 & 0.003 & 0.250 & 0.011 & $447 \%$ & 3.257 & -1.737 \\
\hline R111-S049-.01 CIT-3-F & 0.50 & 5.030 & 0.003 & 0.260 & 0.012 & $465 \%$ & 3.257 & -1.826 \\
\hline R111-S049-.01 CIT-3-F/C & 0.50 & 5.030 & 0.003 & 0.250 & 0.011 & $447 \%$ & 3.257 & -1.737 \\
\hline R111-S049-.01 CIT-3-F-DUP & 0.50 & 5.030 & 0.003 & 0.250 & 0.011 & $447 \%$ & 3.257 & -1.737 \\
\hline R111-S049-.01 CIT-5 & 0.50 & 5.009 & 0.003 & 0.260 & 0.012 & $467 \%$ & 5.163 & -1.836 \\
\hline A111-S049-.01 CIT-5-F & 0.50 & 5.009 & 0.003 & 0.250 & 0.011 & $449 \%$ & 5.163 & -1.746 \\
\hline R111-S049-.01 CIT-5-F/C & 0.50 & 5.009 & 0.003 & 0.250 & 0.011 & $449 \%$ & 5.163 & -1.746 \\
\hline R111-S049-.01 CIT-5-F-DUP & 0.50 & 5.009 & 0.003 & 0.250 & 0.011 & $449 \%$ & 5.163 & -1.746 \\
\hline R111-S049-.01 CIT-7 & 0.50 & 5.008 & 0.003 & 0.520 & 0.023 & $935 \%$ & 7.093 & -4.173 \\
\hline R111-S049-.01 CIT-7-F & 0.50 & 5.008 & 0.003 & 0.250 & 0.011 & $449 \%$ & 7.093 & -1.746 \\
\hline
\end{tabular}


Pb Removed by Batch Shaker Method

\begin{tabular}{|c|c|c|c|c|c|c|c|c|}
\hline & $\mathbf{P b}$ & Wt. of Soil & $\mathbf{P b}$ in & $\mathbf{P b}$ & $\mathrm{Pb}$ in & $\% \mathbf{P b}$ & $\mathrm{pH}$ of & $\mathrm{Pb}$ Remaining \\
\hline SAMPLE\# & (mg/kg) & (g) & Soil (mg) & $(\mathrm{mg} / \mathrm{L})$ & Sample (mg) & Removed & Sample & in Soil ( $\mathrm{mg} / \mathrm{kg}$ ) \\
\hline R111-S049-.01 CIT-7-F/C & 0.50 & 5.008 & 0.003 & 0.390 & 0.018 & $701 \%$ & 7.093 & -3.004 \\
\hline R111-S049-.01 CIT-7-F-DUP & 0.50 & 5.008 & 0.003 & 0.250 & 0.011 & $449 \%$ & 7.093 & -1.746 \\
\hline R111-S037-.01 EDTA-3 & 12.45 & 5.008 & 0.062 & 4.460 & 0.201 & $322 \%$ & 6.715 & -27.626 \\
\hline R111-S037-.01 EDTA-3-F & 12.45 & 5.008 & 0.062 & 4.850 & 0.218 & $350 \%$ & 6.715 & -31.130 \\
\hline R111-S037-.01 EDTA-3-F/C & 12.45 & 5.008 & 0.062 & 4.810 & 0.216 & $347 \%$ & 6.715 & -30.771 \\
\hline R111-S037-.01 EDTA-3-F-DUP & 12.45 & 5.008 & 0.062 & 4.680 & 0.211 & $338 \%$ & 6.715 & -29.603 \\
\hline R111-S037-.01 EDTA-5 & 12.45 & 5.007 & 0.062 & 3.150 & 0.142 & $227 \%$ & 7.113 & -15.860 \\
\hline R111-S037-.01 EDTA-5-F & 12.45 & 5.007 & 0.062 & 3.890 & 0.175 & $281 \%$ & 7.113 & -22.511 \\
\hline R111-S037-.01 EDTA-5-F/C & 12.45 & 5.007 & 0.062 & 4.010 & 0.180 & $289 \%$ & 7.113 & -23.590 \\
\hline R111-S037-.01 EDTA-5-F-DUP & 12.45 & 5.007 & 0.062 & 3.840 & 0.173 & $277 \%$ & 7.113 & -22.062 \\
\hline R111-S037-.01 EDTA-7 & 12.45 & 5.010 & 0.062 & 3.140 & 0.141 & $227 \%$ & $7.229^{\circ}$ & -15.754 \\
\hline R111-S037-.01 EDTA-7-F & 12.45 & 5.010 & 0.062 & 3.650 & 0.164 & $263 \%$ & 7.229 & -20.334 \\
\hline R111-S037-.01 EDTA-7-F/C & 12.45 & 5.010 & 0.062 & 3.770 & 0.170 & $272 \%$ & 7.229 & -21.412 \\
\hline R111-S037-.01 EDTA-7-F-DUP & 12.45 & 5.010 & 0.062 & 3.600 & 0.162 & $260 \%$ & 7.229 & -19.885 \\
\hline R111-S038-.01 EDTA-3 & 15.04 & 5.024 & 0.076 & 5.540 & 0.249 & $330 \%$ & 6.884 & -34.582 \\
\hline R111-S038-.01 EDTA-3-F & 15.04 & 5.024 & 0.076 & 6.180 & 0.278 & $368 \%$ & 6.884 & -40.314 \\
\hline R111-S038-.01 EDTA-3-F/C & 15.04 & 5.024 & 0.076 & 5.980 & 0.269 & $356 \%$ & 6.884 & -38.523 \\
\hline R111-S038-.01 EDTA-3-F-DUP & 15.04 & 5.024 & 0.076 & 6.020 & 0.271 & $359 \%$ & 6.884 & -38.881 \\
\hline R111-S038-.01 EDTA-5 & 15.04 & 5.009 & 0.075 & 4.220 & 0.190 & $252 \%$ & 6.982 & -22.872 \\
\hline R111-S038-.01 EDTA-5-F & 15.04 & 5.009 & 0.075 & 4.680 & 0.211 & $280 \%$ & 6.982 & -27.004 \\
\hline R111-S038-.01 EDTA-5-F/C & 15.04 & 5.009 & 0.075 & 4.400 & 0.198 & $263 \%$ & 6.982 & -24.489 \\
\hline R111-S038-.01 EDTA-5-F-DUP & 15.04 & 5.009 & 0.075 & 4.270 & 0.192 & $255 \%$ & 6.982 & -23.321 \\
\hline A111-S038-.01 EDTA-7 & 15.04 & 5.019 & 0.075 & 3.260 & 0.147 & $194 \%$ & 7.204 & -14.189 \\
\hline R111-S038-.01 EDTA-7-F & 15.04 & 5.019 & 0.075 & 4.440 & 0.200 & $265 \%$ & 7.204 & -24.769 \\
\hline R111-S038-.01 EDTA-7-F/C & 15.04 & 5.019 & 0.075 & 4.230 & 0.190 & $252 \%$ & 7.204 & -22.886 \\
\hline R111-S038-.01 EDTA-7-F-DUP & 15.04 & 5.019 & 0.075 & 3.730 & 0.168 & $222 \%$ & 7.204 & -18.403 \\
\hline R111-S039-.01 EDTA-3 & 15.04 & 5.026 & 0.076 & 5.700 & 0.257 & $339 \%$ & 6.401 & -35.995 \\
\hline R111-S039-.01 EDTA-3-F & 15.04 & 5.026 & 0.076 & 5.210 & 0.234 & $310 \%$ & 6.401 & -31.607 \\
\hline R111-S039-.01 EDTA-3-F/C & 15.04 & 5.026 & 0.076 & 5.200 & 0.234 & $310 \%$ & 6.401 & -31.518 \\
\hline R111-S039-.01 EDTA-3-F-DUP & 15.04 & 5.026 & 0.076 & 5.070 & 0.228 & $302 \%$ & 6.401 & -30.354 \\
\hline R111-S039-.01 EDTA-5 & 15.04 & 5.041 & 0.076 & 3.660 & 0.165 & $217 \%$ & 6.854 & -17.632 \\
\hline R111-S039-.01 EDTA-5-F & 15.04 & 5.041 & 0.076 & 4.420 & 0.199 & $262 \%$ & 6.854 & -24.416 \\
\hline R111-S039-.01 EDTA-5-F/C & 15.04 & 5.041 & 0.076 & 4.000 & 0.180 & $237 \%$ & 6.854 & -20.667 \\
\hline A111-S039-.01 EDTA-5-F-DUP & 15.04 & 5.041 & 0.076 & 4.110 & 0.185 & $244 \%$ & 6.854 & -21.649 \\
\hline R111-S039-.01 EDTA-7 & 15.04 & 5.031 & 0.076 & 3.020 & 0.136 & $180 \%$ & 7.186 & -11.973 \\
\hline
\end{tabular}


Pb Removed by Batch Shaker Method

\begin{tabular}{|c|c|c|c|c|c|c|c|c|}
\hline & $\mathbf{P b}$ & Wt. of Soil & $\mathrm{Pb}$ in & $\mathbf{P b}$ & $\mathrm{Pb}$ in & $\% \mathbf{P b}$ & pH of & Pb Remaining \\
\hline SAMPLE\# & ( $\mathrm{mg} / \mathrm{kg})$ & (g) & Soil (mg) & $(\mathrm{mg} / \mathrm{L})$ & Sample (mg) & Removed & Sample & in Soil ( $\mathrm{mg} / \mathrm{kg}$ ) \\
\hline R111-S039-.01 EDTA-7-F & 15.04 & 5.031 & 0.076 & 3.790 & 0.171 & $225 \%$ & 7.186 & -18.860 \\
\hline R111-S039-.01 EDTA-7-F/C & 15.04 & 5.031 & 0.076 & 3.920 & 0.176 & $233 \%$ & 7.186 & -20.023 \\
\hline R111-S039-.01 EDTA-7-F-DUP & 15.04 & 5.031 & 0.076 & 3.730 & 0.168 & $222 \%$ & 7.186 & -18.323 \\
\hline R111-S041-.01 EDTA-3 & 2.51 & 5.031 & 0.013 & 4.640 & 0.209 & $1653 \%$ & 6.214 & -38.993 \\
\hline R111-S041-.01 EDTA-3-F & 2.51 & 5.031 & 0.013 & 4.160 & 0.187 & $1482 \%$ & 6.214 & -34.699 \\
\hline R111-S041-.01 EDTA-3-F/C & 2.51 & 5.031 & 0.013 & 4.410 & 0.198 & $1572 \%$ & 6.214 & -36.935 \\
\hline R111-S041-.01 EDTA-3-F-DUP & 2.51 & 5.031 & 0.013 & 4.540 & 0.204 & $1618 \%$ & 6.214 & -38.098 \\
\hline R111-S041-.01 EDTA-5 & 2.51 & 5.036 & 0.013 & 3.940 & 0.177 & $1403 \%$ & 6.887 & -32.697 \\
\hline R111-S041-.01 EDTA-5-F & 2.51 & 5.036 & 0.013 & 3.900 & 0.176 & $1388 \%$ & 6.887 & -32.339 \\
\hline R111-S041-.01 EDTA-5-F/C & 2.51 & 5.036 & 0.013 & 3.870 & 0.174 & $1378 \%$ & 6.887 & -32.071 \\
\hline R111-S041-.01 EDTA-5-F-DUP & 2.51 & 5.036 & 0.013 & 3.710 & 0.167 & $1321 \%$ & 6.887 & -30.641 \\
\hline R111-S041-.01 EDTA-7 & 2.51 & 5.027 & 0.013 & 2.490 & 0.112 & $888 \%$ & 7.431 & -19.780 \\
\hline R111-S041-.01 EDTA-7-F & 2.51 & 5.027 & 0.013 & 3.770 & 0.170 & $1345 \%$ & 7.431 & -31.238 \\
\hline A111-S041-.01 EDTA-7-F/C & 2.51 & 5.027 & 0.013 & 3.670 & 0.165 & $1309 \%$ & 7.431 & -30.343 \\
\hline R111-S041-.01 EDTA-7-F-DUP & 2.51 & 5.027 & 0.013 & 3.470 & 0.156 & $1238 \%$ & 7.431 & -28.552 \\
\hline R111-S044-.01 EDTA-3 & 3.77 & 5.036 & 0.019 & 3.160 & 0.142 & $749 \%$ & 6.701 & -24.467 \\
\hline R111-S044-.01 EDTA-3-F & 3.77 & 5.036 & 0.019 & 3.650 & 0.164 & $865 \%$ & 6.701 & -28.845 \\
\hline A111-S044-.01 EDTA-3-F/C & 3.77 & 5.036 & 0.019 & 3.360 & 0.151 & $796 \%$ & 6.701 & -26.254 \\
\hline R111-S044-.01 EDTA-3-F-DUP & 3.77 & 5.036 & 0.019 & 3.040 & 0.137 & $721 \%$ & 6.701 & -23.394 \\
\hline R111-S044-.01 EDTA-5 & 3.77 & 5.034 & 0.019 & 2.230 & 0.100 & $529 \%$ & 6.321 & -16.164 \\
\hline R111-S044-.01 EDTA-5-F & 3.77 & 5.034 & 0.019 & 2.330 & 0.105 & $552 \%$ & 6.321 & -17.058 \\
\hline R111-S044-.01 EDTA-5-F/C & 3.77 & 5.034 & 0.019 & 2.310 & 0.104 & $548 \%$ & 6.321 & -16.880 \\
\hline R111-S044-.01 EDTA-5-F-DUP & 3.77 & 5.034 & 0.019 & 2.380 & 0.107 & $564 \%$ & 6.321 & -17.505 \\
\hline R111-S044-.01 EDTA-7 & 3.77 & 5.013 & 0.019 & 1.690 & 0.076 & $402 \%$ & 7.847 & -11.401 \\
\hline R111-S044-.01 EDTA-7-F & 3.77 & 5.013 & 0.019 & 2.070 & 0.093 & $493 \%$ & 7.847 & -14.812 \\
\hline R111-S044-.01 EDTA-7-F/C & 3.77 & 5.013 & 0.019 & 2.350 & 0.106 & $560 \%$ & 7.847 & -17.325 \\
\hline R111-S044-.01 EDTA-7-F-DUP & 3.77 & 5.013 & 0.019 & 2.120 & 0.095 & $505 \%$ & 7.847 & -15.261 \\
\hline R111-S049-.01 EDTA-3 & 0.50 & 5.041 & 0.003 & 0.650 & 0.029 & $1160 \%$ & 3.183 & -5.302 \\
\hline R111-S049-.01 EDTA-3-F & 0.50 & 5.041 & 0.003 & 0.640 & 0.029 & $1143 \%$ & 3.183 & -5.213 \\
\hline R111-S049-.01 EDTA-3-F/C & 0.50 & 5.041 & 0.003 & 0.510 & 0.023 & $911 \%$ & 3.183 & -4.053 \\
\hline R111-S049-.01 EDTA-3-F-DUP & 0.50 & 5.041 & 0.003 & 0.260 & 0.012 & $464 \%$ & 3.183 & -1.821 \\
\hline R111-S049-.01 EDTA-5 & 0.50 & 5.027 & 0.003 & 0.260 & 0.012 & $465 \%$ & 5.076 & -1.827 \\
\hline R111-S049-.01 EDTA-5-F & 0.50 & 5.027 & 0.003 & 0.380 & 0.017 & $680 \%$ & 5.076 & -2.902 \\
\hline R111-S049-.01 EDTA-5-F/C & 0.50 & 5.027 & 0.003 & 0.380 & 0.017 & $680 \%$ & 5.076 & -2.902 \\
\hline R111-S049-.01 EDTA-5-F-DUP & 0.50 & 5.027 & 0.003 & 0.520 & 0.023 & $931 \%$ & 5.076 & -4.155 \\
\hline
\end{tabular}




\section{Pb Removed by Batch Shaker Method}

\begin{tabular}{|c|c|c|c|c|c|c|c|c|}
\hline & $\mathbf{P b}$ & Wt. of Soil & $\mathbf{P b}$ in & $\mathbf{P b}$ & $\mathrm{Pb}$ in & $\% \mathbf{P b}$ & $\mathrm{pH}$ of & Pb Remaining \\
\hline SAMPLE\# & $(\mathbf{m g} / \mathbf{k g})$ & (g) & Soil (mg) & ( $\mathrm{mg} / \mathrm{L}$ ) & Sample (mg) & Removed & Sample & in Soil ( $\mathrm{mg} / \mathrm{kg})$ \\
\hline R111-S049-.01 EDTA-7 & 0.50 & 5.033 & 0.003 & 0.780 & 0.035 & $1395 \%$ & 7.101 & -6.474 \\
\hline R111-S049-.01 EDTA-7-F & 0.50 & 5.033 & 0.003 & 0.640 & 0.029 & $1144 \%$ & 7.101 & -5.222 \\
\hline R111-S049-.01 EDTA-7-F/C & 0.50 & 5.033 & 0.003 & 0.390 & 0.018 & $697 \%$ & 7.101 & -2.987 \\
\hline R111-S049-.01 EDTA-7-F-DUP & 0.50 & 5.033 & 0.003 & 0.530 & 0.024 & $948 \%$ & 7.101 & -4.239 \\
\hline
\end{tabular}


Zn Removed by Batch Shaker Method

\begin{tabular}{|c|c|c|c|c|c|c|c|c|}
\hline & Zn & Wt. of Soil & Zn in & Zn & Zn in & $\% \mathbf{Z n}$ & $\mathrm{pH}$ of & Zn Remaining \\
\hline SAMPLE\# & $(\mathbf{m g} / \mathbf{k g})$ & (g) & Soil (mg) & $(\mathrm{mg} / \mathrm{L})$ & Sample (mg) & Pemoved & Sample & in Soil $(\mathrm{mg} / \mathrm{kg})$ \\
\hline R111-S037-.01 CIT-3 & 975.68 & 5.003 & 4.881 & 95.070 & 4.278 & $88 \%$ & 5.915 & 120.563 \\
\hline R111-S037-.01 CIT-3-F & 975.68 & 5.003 & 4.881 & 7.820 & 0.352 & $7 \%$ & 5.915 & 905.342 \\
\hline R111-S037-.01 CIT-3-F/C & 975.68 & 5.003 & 4.881 & 8.230 & 0.370 & $8 \%$ & 5.915 & 901.654 \\
\hline R111-S037-.01 CIT-3-F-DUP & 975.68 & 5.003 & 4.881 & 6.450 & 0.290 & $6 \%$ & 5.915 & 917.665 \\
\hline R111-S037-.01 CIT-5 & 975.68 & 5.010 & 4.888 & 4.510 & 0.203 & $4 \%$ & 6.409 & 935.171 \\
\hline R111-S037-.01 CIT-5-F & 975.68 & 5.010 & 4.888 & 43.700 & 1.967 & $40 \%$ & 6.409 & 583.165 \\
\hline R111-S037-.01 CIT-5-F/C & 975.68 & 5.010 & 4.888 & 39.170 & 1.763 & $36 \%$ & 6.409 & 623.854 \\
\hline R111-S037-.01 CIT-5-F-DUP & 975.68 & 5.010 & 4.888 & 40.040 & 1.802 & $37 \%$ & 6.409 & 616.039 \\
\hline R111-S037-.01 CIT-7 & 975.68 & 5.036 & 4.914 & 47.310 & 2.129 & $43 \%$ & 7.698 & 552.934 \\
\hline R111-S037-.01 CIT-7-F & 975.68 & 5.036 & 4.914 & 23.880 & 1.075 & $22 \%$ & 7.698 & 762.296 \\
\hline R111-S037-.01 CIT-7-F/C & 975.68 & 5.036 & 4.914 & 21.890 & 0.985 & $20 \%$ & 7.698 & 780.078 \\
\hline R111-S037-.01 CIT-7-F-DUP & 975.68 & 5.036 & 4.914 & 22.860 & 1.029 & $21 \%$ & 7.698 & 771.411 \\
\hline R111-S038-.01 CIT-3 & 1523.36 & 5.014 & 7.638 & 13.160 & 0.592 & $8 \%$ & 6.237 & 1405.251 \\
\hline R111-S038-.01 CIT-3-F & 1523.36 & 5.014 & 7.638 & 10.570 & 0.476 & $6 \%$ & 6.237 & 1428.496 \\
\hline R111-S038-.01 CIT-3-F/C & 1523.36 & 5.014 & 7.638 & 15.840 & 0.713 & $9 \%$ & 6.237 & 1381.198 \\
\hline R111-S038-.01 CIT-3-F-DUP & 1523.36 & 5.014 & 7.638 & 10.980 & 0.494 & $6 \%$ & 6.237 & 1424.816 \\
\hline R111-S038-.01 CIT-5 & 1523.36 & 5.014 & 7.638 & 30.540 & 1.374 & $18 \%$ & 6.736 & 1249.267 \\
\hline R111-S038-.01 CIT-5-F & 1523.36 & 5.014 & 7.638 & 5.540 & 0.249 & $3 \%$ & 6.736 & 1473.639 \\
\hline R111-S038-.01 CIT-5-F/C & 1523.36 & 5.014 & 7.638 & 5.010 & 0.225 & $3 \%$ & 6.736 & 1478.396 \\
\hline R111-S038-.01 CIT-5-F-DUP & 1523.36 & 5.014 & 7.638 & 5.680 & 0.256 & $3 \%$ & 6.736 & 1472.383 \\
\hline R111-S038-.01 CIT-7 & 1523.36 & 5.030 & 7.663 & 32.640 & 1.469 & $19 \%$ & 7.734 & 1231.352 \\
\hline R111-S038-.01 CIT-7-F & 1523.36 & 5.030 & 7.663 & 20.510 & 0.923 & $12 \%$ & 7.734 & 1339.871 \\
\hline R111-S038-.01 CIT-7-F/C & 1523.36 & 5.030 & 7.663 & 19.910 & 0.896 & $12 \%$ & 7.734 & 1345.239 \\
\hline R111-S038-.01 CIT-7-F-DUP & 1523.36 & 5.030 & 7.663 & 19.680 & 0.886 & $12 \%$ & 7.734 & 1347.296 \\
\hline A111-S039-.01 CIT-3 & 662.09 & 5.008 & 3.316 & 24.240 & 1.091 & $33 \%$ & 6.304 & 444.278 \\
\hline A111-S039-.01 CIT-3-F & 662.09 & 5.008 & 3.316 & 20.420 & 0.919 & $28 \%$ & 6.304 & 478.604 \\
\hline R111-S039-.01 CIT-3-F/C & 662.09 & 5.008 & 3.316 & 27.670 & 1.245 & $38 \%$ & 6.304 & 413.458 \\
\hline R111-S039-.01 CIT-3-F-DUP & 662.09 & 5.008 & 3.316 & 17.930 & 0.807 & $24 \%$ & 6.304 & 500.978 \\
\hline R111-S039-.01 CIT-5 & 662.09 & 5.041 & 3.338 & 21.830 & 0.982 & $29 \%$ & 6.321 & 467.218 \\
\hline R111-S039-.01 CIT-5-F & 662.09 & 5.041 & 3.338 & 11.230 & 0.505 & $15 \%$ & 6.321 & 561.842 \\
\hline R111-S039-.01 CIT-5-F/C & 662.09 & 5.041 & 3.338 & 11.180 & 0.503 & $15 \%$ & 6.321 & 562.288 \\
\hline R111-S039-.01 CIT-5-F-DUP & 662.09 & 5.041 & 3.338 & 11.260 & 0.507 & $15 \%$ & 6.321 & 561.574 \\
\hline R111-S039-.01 CIT-7 & 662.09 & 5.029 & 3.330 & 38.910 & 1.751 & $53 \%$ & 7.421 & 313.919 \\
\hline R111-S039-.01 CIT-7-F & 662.09 & 5.029 & 3.330 & 12.510 & 0.563 & $17 \%$ & 7.421 & 550.149 \\
\hline $\mathrm{B} 111-5039-.01 \mathrm{CIT}-7-\mathrm{F} / \mathrm{C}$ & 662.09 & 5.029 & 3.330 & 10.500 & 0.473 & $14 \%$ & 7.421 & 568.135 \\
\hline
\end{tabular}


Zn Removed by Batch Shaker Method

\begin{tabular}{|c|c|c|c|c|c|c|c|c|}
\hline & Zn & Wt. of Soil & $\mathrm{Zn}$ in & Zn & $\mathrm{Zn}$ in & $\% \mathbf{Z n}$ & pH of & Zn Remaining \\
\hline SAMPLE \# & $(\mathrm{mg} / \mathrm{kg})$ & (g) & Soil (mg) & $(\mathrm{mg} / \mathrm{L})$ & Sample (mg) & Pemoved & Sample & in Soil $(\mathrm{mg} / \mathrm{kg})$ \\
\hline R111-S039-.01 CIT-7-F-DUP & 662.09 & 5.029 & 3.330 & 15.110 & 0.680 & $20 \%$ & 7.421 & 526.884 \\
\hline R111-S041-.01 CIT-3 & 193.56 & 5.002 & 0.968 & 42.680 & 1.921 & $198 \%$ & 5.861 & -190.406 \\
\hline R111-S041-.01 CIT-3-F & 193.56 & 5.002 & 0.968 & 30.810 & 1.386 & $143 \%$ & 5.861 & -83.619 \\
\hline R111-S041-.01 CIT-3-F/C & 193.56 & 5.002 & 0.968 & 5.850 & 0.263 & $27 \%$ & 5.861 & 140.931 \\
\hline R111-S041-.01 CIT-3-F-DUP & 193.56 & 5.002 & 0.968 & 29.620 & 1.333 & $138 \%$ & 5.861 & -72.913 \\
\hline R111-S041-.01 CIT-5 & 193.56 & 5.036 & 0.975 & 17.030 & 0.766 & $79 \%$ & 6.498 & 41.386 \\
\hline R111-S041-.01 CIT-5-F & 193.56 & 5.036 & 0.975 & 8.260 & 0.372 & $38 \%$ & 6.498 & 119.751 \\
\hline R111-S041-.01 CIT-5-F/C & 193.56 & 5.036 & 0.975 & 7.280 & 0.328 & $34 \%$ & 6.498 & 128.508 \\
\hline R111-S041-.01 CIT-5-F-DUP & 193.56 & 5.036 & 0.975 & 7.040 & 0.317 & $33 \%$ & 6.498 & 130.653 \\
\hline R111-S041-.01 CIT-7 & 193.56 & 5.041 & 0.976 & 40.820 & 1.837 & $188 \%$ & 7.601 & -170.832 \\
\hline R111-S041-.01 CIT-7-F & 193.56 & 5.041 & 0.976 & 9.290 & 0.418 & $43 \%$ & 7.601 & 110.630 \\
\hline R111-S041-.01 CIT-7-F/C & 193.56 & 5.041 & 0.976 & 9.470 & 0.426 & $44 \%$ & 7.601 & 109.023 \\
\hline R111-S041-.01 CIT-7-F-DUP & 193.56 & 5.041 & 0.976 & 8.650 & 0.389 & $40 \%$ & 7.601 & 116.343 \\
\hline R111-S044-.01 CIT-3 & 400.10 & 5.021 & 2.009 & 44.140 & 1.986 & $99 \%$ & 6.432 & 4.502 \\
\hline R111-S044-.01 CIT-3-F & 400.10 & 5.021 & 2.009 & 29.890 & 1.345 & $67 \%$ & 6.432 & 132.215 \\
\hline R111-S044-.01 CIT-3-F/C & 400.10 & 5.021 & 2.009 & 27.580 & 1.241 & $62 \%$ & 6.432 & 152.918 \\
\hline R111-S044-.01 CIT-3-F-DUP & 400.10 & 5.021 & 2.009 & 28.780 & 1.295 & $64 \%$ & 6.432 & 142.163 \\
\hline R111-S044-.01 CIT-5 & 400.10 & 5.021 & 2.009 & 18.570 & 0.836 & $42 \%$ & 6.747 & 233.669 \\
\hline R111-S044-.01 CIT-5-F & 400.10 & 5.021 & 2.009 & 11.630 & 0.523 & $26 \%$ & 6.747 & 295.868 \\
\hline R111-S044-.01 CIT-5-F/C & 400.10 & 5.021 & 2.009 & 11.210 & 0.504 & $25 \%$ & 6.747 & 299.632 \\
\hline R111-S044-.01 CIT-5-F-DUP & 400.10 & 5.021 & 2.009 & 11.010 & 0.495 & $25 \%$ & 6.747 & 301.424 \\
\hline R111-S044-.01 ClT-7 & 400.10 & 5.041 & 2.017 & 45.160 & 2.032 & $101 \%$ & 7.261 & -3.034 \\
\hline R111-S044-.01 CIT-7-F & 400.10 & 5.041 & 2.017 & 13.060 & 0.588 & $29 \%$ & 7.261 & 283.516 \\
\hline R111-S044-.01 ClT-7-F/C & 400.10 & 5.041 & 2.017 & 45.360 & 2.041 & $101 \%$ & 7.261 & -4.820 \\
\hline R111-S044-.01 CIT-7-F-DUP & 400.10 & 5.041 & 2.017 & 12.270 & 0.552 & $27 \%$ & 7.261 & 290.568 \\
\hline R111-S049-.01 CIT-3 & 1.68 & 5.030 & 0.008 & 2.150 & 0.097 & $1145 \%$ & 3.257 & -17.555 \\
\hline R111-S049-.01 CIT-3-F & 1.68 & 5.030 & 0.008 & 0.410 & 0.018 & $218 \%$ & 3.257 & -1.988 \\
\hline R111-S049-.01 CIT-3-F/C & 1.68 & 5.030 & 0.008 & 0.540 & 0.024 & $288 \%$ & 3.257 & -3.151 \\
\hline R111-S049-.01 CIT-3-F-DUP & 1.68 & 5.030 & 0.008 & 0.530 & 0.024 & $282 \%$ & 3.257 & -3.062 \\
\hline R111-S049-.01 CIT-5 & 1.68 & 5.009 & 0.008 & 3.150 & 0.142 & $1684 \%$ & 5.163 & -26.619 \\
\hline R111-S049-.01 CIT-5-F & 1.68 & 5.009 & 0.008 & 0.460 & 0.021 & $246 \%$ & 5.163 & -2.453 \\
\hline R111-S049-.01 CIT-5-F/C & 1.68 & 5.009 & 0.008 & 1.770 & 0.080 & $947 \%$ & 5.163 & -14.221 \\
\hline R111-S049-.01 CIT-5-F-DUP & 1.68 & 5.009 & 0.008 & 0.430 & 0.019 & $230 \%$ & 5.163 & -2.183 \\
\hline R111-S049-.01 CIT-7 & 1.68 & 5.008 & 0.008 & 2.420 & 0.109 & $1294 \%$ & 7.093 & -20.065 \\
\hline R111-S049-.01 CIT-7-F & 1.68 & 5.008 & 0.008 & 1.350 & 0.061 & $722 \%$ & 7.093 & -10.451 \\
\hline
\end{tabular}


Zn Removed by Batch Shaker Method

\begin{tabular}{|c|c|c|c|c|c|c|c|c|}
\hline & $\mathbf{Z n}$ & Wt. of Soil & $\mathrm{Zn}$ in & $Z n$ & $\mathrm{Zn}$ in & $\% \mathbf{Z n}$ & $\mathrm{pH}$ of & Zn Remaining \\
\hline SAMPLE \# & $(\mathrm{mg} / \mathrm{kg})$ & (g) & Soil (mg) & $(\mathrm{mg} / \mathrm{L})$ & Sample (mg) & Removed & Sample & in Soil $(\mathbf{m g} / \mathbf{k g})$ \\
\hline R111-S049-.01 CIT-7-F/C & 1.68 & 5.008 & 0.008 & 7.520 & 0.338 & $4022 \%$ & 7.093 & -65.892 \\
\hline R111-S049-.01 ClT-7-F-DUP & 1.68 & 5.008 & 0.008 & 2.560 & 0.115 & $1369 \%$ & 7.093 & -21.323 \\
\hline R111-S037-.01 EDTA-3 & 980.36 & 5.008 & 4.910 & 10.550 & 0.475 & $10 \%$ & 6.715 & 885.562 \\
\hline R111-S037-.01 EDTA-3-F & 980.36 & 5.008 & 4.910 & 12.470 & 0.561 & $11 \%$ & 6.715 & 868.309 \\
\hline R111-S037-.01 EDTA-3-F/C & 975.68 & 5.008 & 4.886 & 12.730 & 0.573 & $12 \%$ & 6.715 & 861.293 \\
\hline R111-S037-.01 EDTA-3-F-DUP & 975.68 & 5.008 & 4.886 & 12.350 & 0.556 & $11 \%$ & 6.715 & 864.708 \\
\hline R111-S037-.01 EDTA-5 & 975.68 & 5.007 & 4.885 & 5.700 & 0.257 & $5 \%$ & 7.113 & 924.452 \\
\hline R111-S037-.01 EDTA-5-F & 975.68 & 5.007 & 4.885 & 8.300 & 0.374 & $8 \%$ & 7.113 & 901.084 \\
\hline R111-S037-.01 EDTA-5-F/C & 975.68 & 5.007 & 4.885 & 8.200 & 0.369 & $8 \%$ & 7.113 & 901.983 \\
\hline R111-S037-.01 EDTA-5-F-DUP & 975.68 & 5.007 & 4.885 & 8.660 & 0.390 & $8 \%$ & 7.113 & 897.849 \\
\hline R111-S037-.01 EDTA-7 & 975.68 & 5.010 & 4.888 & 40.580 & 1.826 & $37 \%$ & 7.229 & 611.189 \\
\hline R111-S037-.01 EDTA-7-F & 975.68 & 5.010 & 4.888 & 7.030 & 0.316 & $6 \%$ & 7.229 & 912.536 \\
\hline R111-S037-.01 EDTA-7-F/C & 975.68 & 5.010 & 4.888 & 7.820 & 0.352 & $7 \%$ & 7.229 & 905.440 \\
\hline R111-S037-.01 EDTA-7-F-DUP & 975.68 & 5.010 & 4.888 & 6.940 & 0.312 & $6 \%$ & 7.229 & 913.345 \\
\hline R111-S038-.01 EDTA-3 & 1523.36 & 5.024 & 7.653 & 13.220 & 0.595 & $8 \%$ & 6.884 & 1404.948 \\
\hline R111-S038-.01 EDTA-3-F & 1523.36 & 5.024 & 7.653 & 15.140 & 0.681 & $9 \%$ & 6.884 & 1387.751 \\
\hline R111-S038-.01 EDTA-3-F/C & 1523.36 & 5.024 & 7.653 & 15.220 & 0.685 & $9 \%$ & 6.884 & 1387.034 \\
\hline R111-S038-.01 EDTA-3-F-DUP & 1523.36 & 5.024 & 7.653 & 0.620 & 0.028 & $0 \%$ & 6.884 & 1517.807 \\
\hline R111-S038-.01 EDTA-5 & 1523.36 & 5.009 & 7.631 & 8.340 & 0.375 & $5 \%$ & 6.982 & 1448.435 \\
\hline R111-S038-.01 EDTA-5-F & 1523.36 & 5.009 & 7.631 & 11.570 & 0.521 & $7 \%$ & 6.982 & 1419.417 \\
\hline R111-S038-.01 EDTA-5-F/C & 1523.36 & 5.009 & 7.631 & 117.790 & 5.301 & $69 \%$ & 6.982 & 465.155 \\
\hline R111-S038-.01 EDTA-5-F-DUP & 1523.36 & 5.009 & 7.631 & 11.460 & 0.516 & $7 \%$ & 6.982 & 1420.405 \\
\hline R111-S038-.01 EDTA-7 & 1523.36 & 5.019 & 7.646 & 51.450 & 2.315 & $30 \%$ & 7.204 & 1062.063 \\
\hline R111-S038-.01 EDTA-7-F & 1523.36 & 5.019 & 7.646 & 94.920 & 4.271 & $56 \%$ & 7.204 & 672.314 \\
\hline R111-S038-.01 EDTA-7-F/C & 1523.36 & 5.019 & 7.646 & 58.710 & 2.642 & $35 \%$ & 7.204 & 996.970 \\
\hline R111-S038-.01 EDTA-7-F-DUP & 1523.36 & 5.019 & 7.646 & 86.950 & 3.913 & $51 \%$ & 7.204 & 743.772 \\
\hline R111-S039-.01 EDTA-3 & 662.09 & 5.026 & 3.328 & 47.120 & 2.120 & $64 \%$ & 6.401 & 240.204 \\
\hline R111-S039-.01 EDTA-3-F & 662.09 & 5.026 & 3.328 & 51.980 & 2.339 & $70 \%$ & 6.401 & 196.690 \\
\hline R111-S039-.01 EDTA-3-F/C & 662.09 & 5.026 & 3.328 & 47.960 & 2.158 & $65 \%$ & 6.401 & 232.683 \\
\hline R111-S039-.01 EDTA-3-F-DUP & 662.09 & 5.026 & 3.328 & 48.620 & 2.188 & $66 \%$ & 6.401 & 226.774 \\
\hline R111-S039-.01 EDTA-5 & 662.09 & 5.041 & 3.338 & 27.680 & 1.246 & $37 \%$ & 6.854 & 414.996 \\
\hline R111-S039-.01 EDTA-5-F & 662.09 & 5.041 & 3.338 & 36.130 & 1.626 & $49 \%$ & 6.854 & 339.565 \\
\hline R111-S039-.01 EDTA-5-F/C & 662.09 & 5.041 & 3.338 & 35.800 & 1.611 & $48 \%$ & 6.854 & 342.511 \\
\hline R111-S039-.01 EDTA-5-F-DUP & 662.09 & 5.041 & 3.338 & 36.380 & 1.637 & $49 \%$ & 6.854 & 337.333 \\
\hline R111-S039-.01 EDTA-7 & 662.09 & 5.031 & 3.331 & 20.760 & 0.934 & $28 \%$ & 7.186 & 476.401 \\
\hline
\end{tabular}




\section{Zn Removed by Batch Shaker Method}

\begin{tabular}{|c|c|c|c|c|c|c|c|c|}
\hline & Zn & Wt. of Soil & $\mathrm{Zn}$ in & $\mathrm{Zn}$ & $\mathrm{Zn}$ in & $\% \mathrm{Zn}$ & $\mathrm{pH}$ of & Zn Remaining \\
\hline SAMPLE \# & (mg/kg) & (g) & Soil (mg) & $(\mathbf{m g} / \mathrm{L})$ & Sample (mg) & Removed & Sample & in Soil $(\mathrm{mg} / \mathrm{kg})$ \\
\hline R111-S039-.01 EDTA-7-F & 662.09 & 5.031 & 3.331 & 29.760 & 1.339 & $40 \%$ & 7.186 & 395.900 \\
\hline R111-S039-.01 EDTA-7-F/C & 662.09 & 5.031 & 3.331 & 31.480 & 1.417 & $43 \%$ & 7.186 & 380.516 \\
\hline R111-S039-.01 EDTA-7-F-DUP & 662.09 & 5.031 & 3.331 & 30.550 & 1.375 & $41 \%$ & 7.186 & 388.834 \\
\hline R111-S041-.01 EDTA-3 & 193.56 & 5.031 & 0.974 & 42.460 & 1.911 & $196 \%$ & 6.214 & -186.225 \\
\hline R111-S041-.01 EDTA-3-F & 193.56 & 5.031 & 0.974 & 45.090 & 2.029 & $208 \%$ & 6.214 & -209.749 \\
\hline R111-S041-.01 EDTA-3-F/C & 193.56 & 5.031 & 0.974 & 44.160 & 1.987 & $204 \%$ & 6.214 & -201.431 \\
\hline R111-S041-.01 EDTA-3-F-DUP & 193.56 & 5.031 & 0.974 & 46.110 & 2.075 & $213 \%$ & 6.214 & -218.873 \\
\hline R111-S041-.01 EDTA-5 & 193.56 & 5.036 & 0.975 & 21.420 & 0.964 & $99 \%$ & 6.887 & 2.158 \\
\hline R111-S041-.01 EDTA-5-F & 193.56 & 5.036 & 0.975 & 35.150 & 1.582 & $162 \%$ & 6.887 & -120.529 \\
\hline R111-S041-.01 EDTA-5-F/C & 193.56 & 5.036 & 0.975 & 36.680 & 1.651 & $169 \%$ & 6.887 & -134.200 \\
\hline R111-S041-.01 EDTA-5-F-DUP & 193.56 & 5.036 & 0.975 & 37.430 & 1.684 & $173 \%$ & 6.887 & -140.902 \\
\hline R111-S041-.01 EDTA-7 & 193.56 & 5.027 & 0.973 & 18.130 & 0.816 & $84 \%$ & 7.431 & 31.266 \\
\hline R111-S041-.01 EDTA-7-F & 193.56 & 5.027 & 0.973 & 28.370 & 1.277 & $131 \%$ & 7.431 & -60.399 \\
\hline R111-S041-.01 EDTA-7-F/C & 193.56 & 5.027 & 0.973 & 27.990 & 1.260 & $129 \%$ & 7.431 & -56.997 \\
\hline R111-S041-.01 EDTA-7-F-DUP & 193.56 & 5.027 & 0.973 & 28.890 & 1.300 & $134 \%$ & 7.431 & -65.053 \\
\hline R111-S044-.01 EDTA-3 & 400.10 & 5.036 & 2.015 & 48.030 & 2.161 & $107 \%$ & 6.701 & -29.080 \\
\hline R111-S044-.01 EDTA-3-F & 400.10 & 5.036 & 2.015 & 69.820 & 3.142 & $156 \%$ & 6.701 & -223.788 \\
\hline R111-S044-.01 EDTA-3-F/C & 400.10 & 5.036 & 2.015 & 65.230 & 2.935 & $146 \%$ & 6.701 & -182.773 \\
\hline R111-S044-.01 EDTA-3-F-DUP & 400.10 & 5.036 & 2.015 & 61.580 & 2.771 & $138 \%$ & 6.701 & -150.158 \\
\hline R111-S044-.01 EDTA-5 & 400.10 & 5.034 & 2.014 & 37.060 & 1.668 & $83 \%$ & 6.321 & 68.813 \\
\hline R111-S044-.01 EDTA-5-F & 400.10 & 5.034 & 2.014 & 41.660 & 1.875 & $93 \%$ & 6.321 & 27.692 \\
\hline R111-S044-.01 EDTA-5-F/C & 400.10 & 5.034 & 2.014 & 41.440 & 1.865 & $93 \%$ & 6.321 & 29.659 \\
\hline R111-S044-.01 EDTA-5-F-DUP & 400.10 & 5.034 & 2.014 & 41.650 & 1.874 & $93 \%$ & 6.321 & 27.782 \\
\hline R111-S044-.01 EDTA-7 & 400.10 & 5.013 & 2.006 & 20.840 & 0.938 & $47 \%$ & 7.847 & 213.026 \\
\hline R111-S044-.01 EDTA-7-F & 400.10 & 5.013 & 2.006 & 32.110 & 1.445 & $72 \%$ & 7.847 & 111.859 \\
\hline R111-S044-.01 EDTA-7-F/C & 400.10 & 5.013 & 2.006 & 35.270 & 1.587 & $79 \%$ & 7.847 & 83.493 \\
\hline A111-S044-.01 EDTA-7-F-DUP & 400.10 & 5.013 & 2.006 & 32.880 & 1.480 & $74 \%$ & 7.847 & 104.947 \\
\hline R111-S049-.01 EDTA-3 & 1.68 & 5.041 & 0.008 & 0.610 & 0.027 & $324 \%$ & 3.183 & -3.765 \\
\hline R111-S049-.01 EDTA-3-F & 1.68 & 5.041 & 0.008 & 2.100 & 0.095 & $1116 \%$ & 3.183 & -17.066 \\
\hline R111-S049-.01 EDTA-3-F/C & 1.68 & 5.041 & 0.008 & 2.400 & 0.108 & $1275 \%$ & 3.183 & -19.744 \\
\hline R111-S049-.01 EDTA-3-F-DUP & 1.68 & 5.041 & 0.008 & 0.620 & 0.028 & $329 \%$ & 3.183 & -3.855 \\
\hline A111-S049-.01 EDTA-5 & 1.68 & 5.027 & 0.008 & 1.040 & 0.047 & $554 \%$ & 5.076 & -7.630 \\
\hline R111-S049-.01 EDTA-5-F & 1.68 & 5.027 & 0.008 & 1.360 & 0.061 & $725 \%$ & 5.076 & -10.494 \\
\hline R111-S049-.01 EDTA-5-F/C & 1.68 & 5.027 & 0.008 & 1.150 & 0.052 & $613 \%$ & 5.076 & -8.614 \\
\hline R111-S049-.01 EDTA-5-F-DUP & 1.68 & 5.027 & 0.008 & 1.010 & 0.045 & $538 \%$ & 5.076 & -7.361 \\
\hline
\end{tabular}


Zn Removed by Batch Shaker Method

\begin{tabular}{|c|c|c|c|c|c|c|c|c|}
\hline & Zn & Wt. of Soil & $\mathrm{Zn}$ in & $Z n$ & $\mathrm{Zn}$ in & $\% \mathbf{Z n}$ & $\mathrm{pH}$ of & Zn Remaining \\
\hline SAMPLE \# & $(\mathrm{mg} / \mathrm{kg})$ & (g) & Soil (mg) & $(\mathrm{mg} / \mathrm{L})$ & Sample (mg) & Removed & Sample & in Soil (mg/kg) \\
\hline R111-S049-.01 EDTA-7 & 1.68 & 5.033 & 0.008 & 2.540 & 0.114 & $1352 \%$ & 7.101 & -21.030 \\
\hline R111-S049-.01 EDTA-7-F & 1.68 & 5.033 & 0.008 & 2.840 & 0.128 & $1511 \%$ & 7.101 & -23.712 \\
\hline R111-S049-.01 EDTA-7-F/C & 1.68 & 5.033 & 0.008 & 5.810 & 0.261 & $3092 \%$ & 7.101 & -50.267 \\
\hline R111-S049-.01 EDTA-7-F-DUP & 1.68 & 5.033 & 0.008 & 0.680 & 0.031 & $362 \%$ & 7.101 & -4.400 \\
\hline
\end{tabular}


$\mathrm{Ba}, \mathrm{Cd}, \mathrm{Cr}, \mathrm{Cu}, \mathrm{Pb}, \mathrm{Zn}$ Removed by Batch Shaker Method

\begin{tabular}{|c|c|c|c|c|c|c|c|}
\hline & pH & $\% \mathbf{B a}$ & $\% \mathbf{C d}$ & $\% \mathbf{C r}$ & $\% \mathrm{Cu}$ & $\% \mathbf{P b}$ & $\% \mathbf{Z n}$ \\
\hline SAMPLE \# & of Sample & Removed & Removed & Removed & Removed & Removed & Removed \\
\hline R111-S037-.01 CIT-3 & 5.915 & $26 \%$ & $32 \%$ & $70 \%$ & $437 \%$ & $85 \%$ & $88 \%$ \\
\hline R111-S037-.01 CIT-3-F & 5.915 & $72 \%$ & $21 \%$ & $70 \%$ & $403 \%$ & $19 \%$ & $7 \%$ \\
\hline R111-S037-.01 CIT-3-F/C & 5.915 & $79 \%$ & $20 \%$ & $70 \%$ & $406 \%$ & $27 \%$ & $8 \%$ \\
\hline R111-S037-.01 CIT-3-F-DUP & 5.915 & $75 \%$ & $22 \%$ & $70 \%$ & $398 \%$ & $28 \%$ & $6 \%$ \\
\hline R111-S037-.01 CIT-5 & 6.409 & $42 \%$ & $18 \%$ & $70 \%$ & $320 \%$ & $38 \%$ & $4 \%$ \\
\hline R111-S037-.01 CIT-5-F & 6.409 & $37 \%$ & $9 \%$ & $70 \%$ & $225 \%$ & $19 \%$ & $40 \%$ \\
\hline R111-S037-.01 CIT-5-F/C & 6.409 & $35 \%$ & $10 \%$ & $70 \%$ & $220 \%$ & $18 \%$ & $36 \%$ \\
\hline R111-S037-.01 CIT-5-F-DUP & 6.409 & $30 \%$ & $10 \%$ & $70 \%$ & $229 \%$ & $18 \%$ & $37 \%$ \\
\hline R111-S037-.01 CIT-7 & 7.698 & $37 \%$ & $10 \%$ & $69 \%$ & $341 \%$ & $113 \%$ & $43 \%$ \\
\hline R111-S037-.01 CIT-7-F & 7.698 & $28 \%$ & $4 \%$ & $69 \%$ & $249 \%$ & $28 \%$ & $22 \%$ \\
\hline R111-S037-.01 CIT-7-F/C & 7.698 & $30 \%$ & $3 \%$ & $69 \%$ & $245 \%$ & $18 \%$ & $20 \%$ \\
\hline R111-S037-.01 CIT-7-F-DUP & 7.698 & $24 \%$ & $3 \%$ & $69 \%$ & $257 \%$ & $19 \%$ & $21 \%$ \\
\hline R111-S038-.01 CIT-3 & 6.237 & $93 \%$ & $45 \%$ & $70 \%$ & $444 \%$ & $78 \%$ & $8 \%$ \\
\hline R111-S038-.01 CIT-3-F & 6.237 & $87 \%$ & $30 \%$ & $70 \%$ & $306 \%$ & $30 \%$ & $6 \%$ \\
\hline R111-S038-.01 CIT-3-F/C & 6.237 & $107 \%$ & $31 \%$ & $70 \%$ & $306 \%$ & $47 \%$ & $9 \%$ \\
\hline R111-S038-.01 CIT-3-F-DUP & 6.237 & $89 \%$ & $34 \%$ & $70 \%$ & $322 \%$ & $31 \%$ & $6 \%$ \\
\hline R111-S038-.01 CIT-5 & 6.736 & $41 \%$ & $23 \%$ & $70 \%$ & $302 \%$ & $23 \%$ & $18 \%$ \\
\hline R111-S038-.01 CIT-5-F & 6.736 & $46 \%$ & $14 \%$ & $70 \%$ & $269 \%$ & $16 \%$ & $3 \%$ \\
\hline R111-S038-.01 CIT-5-F/C & 6.736 & $49 \%$ & $14 \%$ & $70 \%$ & $256 \%$ & $15 \%$ & $3 \%$ \\
\hline R111-S038-.01 CIT-5-F-DUP & 6.736 & $39 \%$ & $14 \%$ & $70 \%$ & $263 \%$ & $23 \%$ & $3 \%$ \\
\hline R111-S038-.01 CIT-7 & 7.734 & $36 \%$ & $6 \%$ & $69 \%$ & $215 \%$ & $15 \%$ & $19 \%$ \\
\hline R111-S038-.01 CIT-7-F & 7.734 & $36 \%$ & $3 \%$ & $69 \%$ & $197 \%$ & $15 \%$ & $12 \%$ \\
\hline R111-S038-.01 CIT-7-F/C & 7.734 & $37 \%$ & $2 \%$ & $69 \%$ & $193 \%$ & $15 \%$ & $12 \%$ \\
\hline R111-S038-.01 CIT-7-F-DUP & 7.734 & $33 \%$ & $2 \%$ & $69 \%$ & $195 \%$ & $15 \%$ & $12 \%$ \\
\hline R111-S039-.01 CIT-3 & 6.304 & $61 \%$ & $79 \%$ & $70 \%$ & $150 \%$ & $54 \%$ & $33 \%$ \\
\hline R111-S039-.01 CIT-3-F & 6.304 & $63 \%$ & $60 \%$ & $70 \%$ & $142 \%$ & $30 \%$ & $28 \%$ \\
\hline R111-S039-.01 CIT-3-F/C & 6.304 & $67 \%$ & $60 \%$ & $70 \%$ & $143 \%$ & $30 \%$ & $38 \%$ \\
\hline R111-S039-.01 CIT-3-F-DUP & 6.304 & $61 \%$ & $65 \%$ & $70 \%$ & $143 \%$ & $15 \%$ & $24 \%$ \\
\hline R111-S039-.01 CIT-5 & 6.321 & $34 \%$ & $64 \%$ & $69 \%$ & $113 \%$ & $23 \%$ & $29 \%$ \\
\hline R111-S039-.01 CIT-5-F & 6.321 & $36 \%$ & $42 \%$ & $69 \%$ & $120 \%$ & $15 \%$ & $15 \%$ \\
\hline R111-S039-.01 CIT-5-F/C & 6.321 & $40 \%$ & $42 \%$ & $69 \%$ & $119 \%$ & $30 \%$ & $15 \%$ \\
\hline R111-S039-.01 CIT-5-F-DUP & 6.321 & $36 \%$ & $45 \%$ & $69 \%$ & $124 \%$ & $15 \%$ & $15 \%$ \\
\hline R111-S039-.01 CIT-7 & 7.421 & $34 \%$ & $50 \%$ & $125 \%$ & $189 \%$ & $117 \%$ & $53 \%$ \\
\hline R111-S039-.01 CIT-7-F & 7.421 & $29 \%$ & $23 \%$ & $69 \%$ & $116 \%$ & $46 \%$ & $17 \%$ \\
\hline R111-S039-.01 CIT-7-F/C & 7.421 & $30 \%$ & $21 \%$ & $69 \%$ & $111 \%$ & $38 \%$ & $14 \%$ \\
\hline
\end{tabular}


$\mathrm{Ba}, \mathrm{Cd}, \mathrm{Cr}, \mathrm{Cu}, \mathrm{Pb}, \mathrm{Zn}$ Removed by Batch Shaker Method

\begin{tabular}{|c|c|c|c|c|c|c|c|}
\hline & $\mathbf{p H}$ & $\% \mathbf{B a}$ & $\% \mathrm{Cd}$ & $\% \mathrm{Cr}$ & $\% \mathrm{Cu}$ & $\% \mathrm{~Pb}$ & $\% \mathrm{Zn}$ \\
\hline SAMPLE \# & of Sample & Removed & Removed & Removed & Removed & Removed & Removed \\
\hline R111-S039-.01 CIT-7-F-DUP & 7.421 & $25 \%$ & $24 \%$ & $79 \%$ & $126 \%$ & $55 \%$ & $20 \%$ \\
\hline R111-S041-.01 CIT-3 & 5.861 & $145 \%$ & $117 \%$ & $150 \%$ & $9080 \%$ & $513 \%$ & $198 \%$ \\
\hline R111-S041-.01 CIT-3-F & 5.861 & $135 \%$ & $90 \%$ & $150 \%$ & $8662 \%$ & $323 \%$ & $143 \%$ \\
\hline R111-S041-.01 CIT-3-F/C & 5.861 & $154 \%$ & $94 \%$ & $170 \%$ & $840 \%$ & $140 \%$ & $27 \%$ \\
\hline R111-S041-.01 CIT-3-F-DUP & 5.861 & $122 \%$ & $97 \%$ & $220 \%$ & $861 \%$ & $233 \%$ & $138 \%$ \\
\hline R111-S041-.01 CIT-5 & 6.498 & $61 \%$ & $66 \%$ & $149 \%$ & $468 \%$ & $231 \%$ & $79 \%$ \\
\hline R111-S041-.01 CIT-5-F & 6.498 & $29 \%$ & $20 \%$ & $149 \%$ & $307 \%$ & $93 \%$ & $38 \%$ \\
\hline R111-S041-.01 CIT-5-F/C & 6.498 & $33 \%$ & $21 \%$ & $149 \%$ & $303 \%$ & $89 \%$ & $34 \%$ \\
\hline R111-S041-.01 CIT-5-F-DUP & 6.498 & $28 \%$ & $21 \%$ & $149 \%$ & $302 \%$ & $89 \%$ & $33 \%$ \\
\hline R111-S041-.01 CIT-7 & 7.601 & $54 \%$ & $75 \%$ & $238 \%$ & $9508 \%$ & $1067 \%$ & $188 \%$ \\
\hline R111-S041-.01 CIT-7-F & 7.601 & $29 \%$ & $23 \%$ & $149 \%$ & $470 \%$ & $135 \%$ & $43 \%$ \\
\hline R111-S041-.01 ClT-7-F/C & 7.601 & $27 \%$ & $24 \%$ & $149 \%$ & $431 \%$ & $8 \overline{9} \%$ & $44 \%$ \\
\hline R111-S041-.01 CIT-7-F-DUP & 7.601 & $23 \%$ & $21 \%$ & $149 \%$ & $454 \%$ & $92 \%$ & $40 \%$ \\
\hline R111-S044-.01 CIT-3 & 6.432 & $89 \%$ & $59 \%$ & $149 \%$ & $1029 \%$ & $185 \%$ & $99 \%$ \\
\hline R111-S044-.01 CIT-3-F & 6.432 & $74 \%$ & $30 \%$ & $149 \%$ & $776 \%$ & $62 \%$ & $67 \%$ \\
\hline R111-S044-.01 CIT-3-F/C & 6.432 & $85 \%$ & $32 \%$ & $149 \%$ & $755 \%$ & $59 \%$ & $62 \%$ \\
\hline R111-S044-.01 ClT-3-F-DUP & 6.432 & $73 \%$ & $33 \%$ & $149 \%$ & $771 \%$ & $59 \%$ & $64 \%$ \\
\hline R111-S044-.01 CIT-5 & 6.747 & $36 \%$ & $21 \%$ & $149 \%$ & $459 \%$ & $62 \%$ & $42 \%$ \\
\hline R111-S044-.01 CIT-5-F & 6.747 & $39 \%$ & $10 \%$ & $149 \%$ & $462 \%$ & $93 \%$ & $26 \%$ \\
\hline R111-S044-.01 CIT-5-F/C & 6.747 & $38 \%$ & $10 \%$ & $149 \%$ & $440 \%$ & $59 \%$ & $25 \%$ \\
\hline R111-S044-.01 CIT-5-F-DUP & 6.747 & $36 \%$ & $10 \%$ & $149 \%$ & $459 \%$ & $62 \%$ & $25 \%$ \\
\hline R111-S044-.01 CIT-7 & 7.261 & $42 \%$ & $41 \%$ & $159 \%$ & $1225 \%$ & $431 \%$ & $101 \%$ \\
\hline R111-S044-.01 CIT-7-F & 7.261 & $19 \%$ & $18 \%$ & $149 \%$ & $631 \%$ & $90 \%$ & $29 \%$ \\
\hline R111-S044-.01 CIT-7-F/C & 7.261 & $57 \%$ & $19 \%$ & $149 \%$ & $579 \%$ & $92 \%$ & $101 \%$ \\
\hline R111-S044-.01 CIT-7-F-DUP & 7.261 & $18 \%$ & $17 \%$ & $149 \%$ & $603 \%$ & $59 \%$ & $29 \%$ \\
\hline R111-S049-.01 CIT-3 & 3.257 & $18 \%$ & $118 \%$ & $149 \%$ & $119 \%$ & $447 \%$ & $1145 \%$ \\
\hline R111-S049-.01 CIT-3-F & 3.257 & $12 \%$ & $118 \%$ & $149 \%$ & $155 \%$ & $465 \%$ & $218 \%$ \\
\hline R111-S049-.01 CIT-3-F/C & 3.257 & $19 \%$ & $118 \%$ & $149 \%$ & $143 \%$ & $447 \%$ & $288 \%$ \\
\hline R111-S049-.01 CIT-3-F-DUP & 3.257 & $11 \%$ & $118 \%$ & $149 \%$ & $119 \%$ & $447 \%$ & $282 \%$ \\
\hline R111-S049-.01 CIT-5 & 5.163 & $26 \%$ & $118 \%$ & $150 \%$ & $299 \%$ & $467 \%$ & $1684 \%$ \\
\hline R111-S049-.01 CIT-5-F & 5.163 & $11 \%$ & $118 \%$ & $150 \%$ & $132 \%$ & $449 \%$ & $246 \%$ \\
\hline $\mathrm{R} 111-\mathrm{S} 049-.01 \mathrm{CIT}-5-\mathrm{F} / \mathrm{C}$ & 5.163 & $11 \%$ & $118 \%$ & $150 \%$ & $144 \%$ & $449 \%$ & $947 \%$ \\
\hline R111-S049-.01 CIT-5-F-DUP & 5.163 & $11 \%$ & $118 \%$ & $150 \%$ & $156 \%$ & $449 \%$ & $230 \%$ \\
\hline R111-S049-.01 CIT-7 & 7.093 & $39 \%$ & $118 \%$ & $150 \%$ & $300 \%$ & $935 \%$ & $1294 \%$ \\
\hline R111-S049-.01 CIT-7-F & 7.093 & $60 \%$ & $118 \%$ & $150 \%$ & $204 \%$ & $449 \%$ & $722 \%$ \\
\hline
\end{tabular}


$\mathrm{Ba}, \mathrm{Cd}, \mathrm{Cr}, \mathrm{Cu}, \mathrm{Pb}, \mathrm{Zn}$ Removed by Batch Shaker Method

\begin{tabular}{|c|c|c|c|c|c|c|c|}
\hline & $\mathrm{pH}$ & $\% \mathbf{B a}$ & $\% \mathbf{C d}$ & $\% \mathrm{Cr}$ & $\% \mathbf{C u}$ & $\% \mathbf{P b}$ & $\% \mathbf{Z n}$ \\
\hline SAMPLE \# & of Sample & Removed & Removed & Removed & Removed & Removed & Removed \\
\hline R111-S049-.01 CIT-7-F-DUP & 7.093 & $21 \%$ & $118 \%$ & $150 \%$ & $192 \%$ & $449 \%$ & $1369 \%$ \\
\hline R111-S049-.01 ClT-7-F/C & 7.093 & $2747 \%$ & $118 \%$ & $150 \%$ & $300 \%$ & $701 \%$ & $4022 \%$ \\
\hline AVERAGE CITRIC ACID REMOVAL & & $52 \%$ & $42 \%$ & $111 \%$ & $329 \%$ & $131 \%$ & $123 \%$ \\
\hline \multicolumn{8}{|l|}{ (of f/c samples) } \\
\hline pH 3 AVERAGE REMOVAL* & & $85 \%$ & $59 \%$ & $113 \%$ & $432 \%$ & $125 \%$ & $72 \%$ \\
\hline PH 5 AVERAGE REMOVAL* & & $34 \%$ & $36 \%$ & $110 \%$ & $247 \%$ & $110 \%$ & $179 \%$ \\
\hline PH 7 AVERAGE REMOVAL* & & $36 \%$ & $31 \%$ & $109 \%$ & $309 \%$ & $159 \%$ & $38 \%$ \\
\hline \multicolumn{8}{|l|}{ "not including S049 sample } \\
\hline R111-S037-.01 EDTA-3 & 6.715 & $88 \%$ & $48 \%$ & $70 \%$ & $548 \%$ & $322 \%$ & $10 \%$ \\
\hline R111-S037-.01 EDTA-3-F & 6.715 & $73 \%$ & $45 \%$ & $70 \%$ & $603 \%$ & $350 \%$ & $11 \%$ \\
\hline R111-S037-.01 EDTA-3-F/C & 6.715 & $75 \%$ & $48 \%$ & $70 \%$ & $575 \%$ & $347 \%$ & $12 \%$ \\
\hline R111-S037-.01 EDTA-3-F-DUP & 6.715 & $71 \%$ & $47 \%$ & $70 \%$ & $590 \%$ & $338 \%$ & $11 \%$ \\
\hline R111-S037-.01 EDTA-5 & 7.113 & $39 \%$ & $41 \%$ & $70 \%$ & $434 \%$ & $227 \%$ & $5 \%$ \\
\hline R111-S037-.01 EDTA-5-F & 7.113 & $36 \%$ & $45 \%$ & $70 \%$ & $687 \%$ & $281 \%$ & $8 \%$ \\
\hline R111-S037-.01 EDTA-5-F/C & 7.113 & $35 \%$ & $48 \%$ & $70 \%$ & $6538 \%$ & $289 \%$ & $8 \%$ \\
\hline R111-S037-.01 EDTA-5-F-DUP & 7.113 & $36 \%$ & $50 \%$ & $70 \%$ & $700 \%$ & $277 \%$ & $8 \%$ \\
\hline R111-S037-.01 EDTA-7 & 7.229 & $35 \%$ & $28 \%$ & $70 \%$ & $316 \%$ & $227 \%$ & $37 \%$ \\
\hline R111-S037-.01 EDTA-7-F & 7.229 & $28 \%$ & $29 \%$ & $70 \%$ & $430 \%$ & $263 \%$ & $6 \%$ \\
\hline R111-S037-.01 EDTA-7-F/C & 7.229 & $37 \%$ & $29 \%$ & $70 \%$ & $439 \%$ & $272 \%$ & $7 \%$ \\
\hline R111-S037-.01 EDTA-7-F-DUP & 7.229 & $27 \%$ & $29 \%$ & $70 \%$ & $477 \%$ & $260 \%$ & $6 \%$ \\
\hline R111-S038-.01 EDTA-3 & 6.884 & $87 \%$ & $63 \%$ & $69 \%$ & $516 \%$ & $330 \%$ & $8 \%$ \\
\hline R111-S038-.01 EDTA-3-F & 6.884 & $78 \%$ & $61 \%$ & $69 \%$ & $6154 \%$ & $368 \%$ & $9 \%$ \\
\hline R111-S038-.01 EDTA-3-F/C & 6.884 & $78 \%$ & $57 \%$ & $69 \%$ & $6110 \%$ & $356 \%$ & $9 \%$ \\
\hline R111-S038-.01 EDTA-3-F-DUP & 6.884 & $72 \%$ & $61 \%$ & $69 \%$ & $6216 \%$ & $359 \%$ & $0 \%$ \\
\hline R111-S038-.01 EDTA-5 & 6.982 & $44 \%$ & $41 \%$ & $70 \%$ & $357 \%$ & $252 \%$ & $5 \%$ \\
\hline R111-S038-.01 EDTA-5-F & 6.982 & $43 \%$ & $42 \%$ & $70 \%$ & $480 \%$ & $280 \%$ & $7 \%$ \\
\hline R111-S038-.01 EDTA-5-F/C & 6.982 & $43 \%$ & $41 \%$ & $70 \%$ & $464 \%$ & $263 \%$ & $69 \%$ \\
\hline R111-S038-.01 EDTA-5-F-DUP & 6.982 & $36 \%$ & $46 \%$ & $70 \%$ & $469 \%$ & $255 \%$ & $7 \%$ \\
\hline R111-S038-.01 EDTA-7 & 7.204 & $35 \%$ & $33 \%$ & $70 \%$ & $271 \%$ & $194 \%$ & $30 \%$ \\
\hline R111-S038-.01 EDTA-7-F & 7.204 & $30 \%$ & $37 \%$ & $70 \%$ & $397 \%$ & $265 \%$ & $56 \%$ \\
\hline R111-S038-.01 EDTA-7-F/C & 7.204 & $24 \%$ & $41 \%$ & $70 \%$ & $398 \%$ & $252 \%$ & $35 \%$ \\
\hline R111-S038-.01 EDTA-7-F-DUP & 7.204 & $26 \%$ & $36 \%$ & $70 \%$ & $397 \%$ & $222 \%$ & $51 \%$ \\
\hline R111-S039-.01 EDTA-3 & 6.401 & $118 \%$ & $100 \%$ & $69 \%$ & $2374 \%$ & $339 \%$ & $64 \%$ \\
\hline R111-S039-.01 EDTA-3-F & 6.401 & $86 \%$ & $96 \%$ & $69 \%$ & $2543 \%$ & $310 \%$ & $70 \%$ \\
\hline
\end{tabular}


$\mathrm{Ba}, \mathrm{Cd}, \mathrm{Cr}, \mathrm{Cu}, \mathrm{Pb}, \mathrm{Zn}$ Removed by Batch Shaker Method

\begin{tabular}{|c|c|c|c|c|c|c|c|}
\hline & $\mathrm{pH}$ & $\% \mathbf{B a}$ & $\% \mathrm{Cd}$ & $\% \mathrm{Cr}$ & $\% \mathrm{Cu}$ & $\% \mathrm{~Pb}$ & $\% \mathrm{Zn}$ \\
\hline SAMPLE \# & of Sample & Removed & Removed & Removed & Removed & Removed & Removed \\
\hline R111-S039-.01 EDTA-3-F/C & 6.401 & $119 \%$ & $99 \%$ & $69 \%$ & $2411 \%$ & $310 \%$ & $65 \%$ \\
\hline R111-S039-.01 EDTA-3-F-DUP & 6.401 & $95 \%$ & $104 \%$ & $69 \%$ & $2514 \%$ & $302 \%$ & $66 \%$ \\
\hline R111-S039-.01 EDTA-5 & 6.854 & $49 \%$ & $86 \%$ & $69 \%$ & $144 \%$ & $217 \%$ & $37 \%$ \\
\hline R111-S039-.01 EDTA-5-F & 6.854 & $40 \%$ & $84 \%$ & $69 \%$ & $191 \%$ & $262 \%$ & $49 \%$ \\
\hline R111-S039-.01 EDTA-5-F/C & 6.854 & $47 \%$ & $87 \%$ & $69 \%$ & $1915 \%$ & $237 \%$ & $48 \%$ \\
\hline R111-S039-.01 EDTA-5-F-DUP & 6.854 & $40 \%$ & $94 \%$ & $69 \%$ & $195 \%$ & $244 \%$ & $49 \%$ \\
\hline R111-S039-.01 EDTA-7 & 7.186 & $31 \%$ & $77 \%$ & $69 \%$ & $116 \%$ & $180 \%$ & $28 \%$ \\
\hline R111-S039-.01 EDTA-7-F & 7.186 & $40 \%$ & $85 \%$ & $69 \%$ & $170 \%$ & $225 \%$ & $40 \%$ \\
\hline R111-S039-.01 EDTA-7-F/C & 7.186 & $39 \%$ & $79 \%$ & $69 \%$ & $170 \%$ & $233 \%$ & $43 \%$ \\
\hline R111-S039-.01 EDTA-7-F-DUP & 7.186 & $29 \%$ & $78 \%$ & $69 \%$ & $171 \%$ & $222 \%$ & $41 \%$ \\
\hline R111-S041-.01 EDTA-3 & 6.214 & $102 \%$ & $136 \%$ & $149 \%$ & $9273 \%$ & $1653 \%$ & $196 \%$ \\
\hline R111-S041-.01 EDTA-3-F & 6.214 & $108 \%$ & $122 \%$ & $149 \%$ & $10199 \%$ & $1482 \%$ & $208 \%$ \\
\hline R111-S041-.01 EDTA-3-F/C & 6.214 & $105 \%$ & $126 \%$ & $149 \%$ & $9764 \%$ & $1572 \%$ & $204 \%$ \\
\hline R111-S041-.01 EDTA-3-F-DUP & 6.214 & $96 \%$ & $129 \%$ & $149 \%$ & $1017 \%$ & $1618 \%$ & $213 \%$ \\
\hline R111-S041-.01 EDTA-5 & 6.887 & $63 \%$ & $101 \%$ & $149 \%$ & $634 \%$ & $1403 \%$ & $99 \%$ \\
\hline R111-S041-.01 EDTA-5-F & 6.887 & $65 \%$ & $101 \%$ & $149 \%$ & $8329 \%$ & $1388 \%$ & $162 \%$ \\
\hline R111-S041-.01 EDTA-5-F/C & 6.887 & $66 \%$ & $109 \%$ & $149 \%$ & $804 \%$ & $1378 \%$ & $169 \%$ \\
\hline R111-S041-.01 EDTA-5-F-DUP & 6.887 & $60 \%$ & $112 \%$ & $149 \%$ & $847 \%$ & $1321 \%$ & $173 \%$ \\
\hline R111-S041-.01 EDTA-7 & 7.431 & $37 \%$ & $98 \%$ & $149 \%$ & $481 \%$ & $888 \%$ & $84 \%$ \\
\hline R111-S041-.01 EDTA-7-F & 7.431 & $43 \%$ & $94 \%$ & $149 \%$ & $725 \%$ & $1345 \%$ & $131 \%$ \\
\hline R111-S041-.01 EDTA-7-F/C & 7.431 & $43 \%$ & $28 \%$ & $149 \%$ & $706 \%$ & $1309 \%$ & $129 \%$ \\
\hline R111-S041-.01 EDTA-7-F-DUP & 7.431 & $36 \%$ & $100 \%$ & $149 \%$ & $724 \%$ & $1238 \%$ & $134 \%$ \\
\hline R111-S044-.01 EDTA-3 & 6.701 & $79 \%$ & $81 \%$ & $149 \%$ & $1290 \%$ & $749 \%$ & $107 \%$ \\
\hline R111-S044-.01 EDTA-3-F & 6.701 & $89 \%$ & $78 \%$ & $149 \%$ & $1293 \%$ & $865 \%$ & $156 \%$ \\
\hline A111-S044-.01 EDTA-3-F/C & 6.701 & $85 \%$ & $83 \%$ & $149 \%$ & $1224 \%$ & $796 \%$ & $146 \%$ \\
\hline R111-S044-.01 EDTA-3-F-DUP & 6.701 & $86 \%$ & $86 \%$ & $149 \%$ & $1318 \%$ & $721 \%$ & $138 \%$ \\
\hline R111-S044-.01 EDTA-5 & 6.321 & $53 \%$ & $55 \%$ & $149 \%$ & $940 \%$ & $529 \%$ & $83 \%$ \\
\hline R111-S044-.01 EDTA-5-F & 6.321 & $67 \%$ & $53 \%$ & $149 \%$ & $1319 \%$ & $552 \%$ & $93 \%$ \\
\hline A111-S044-.01 EDTA-5-F/C & 6.321 & $58 \%$ & $55 \%$ & $149 \%$ & $1243 \%$ & $548 \%$ & $93 \%$ \\
\hline R111-S044-.01 EDTA-5-F-DUP & 6.321 & $54 \%$ & $55 \%$ & $149 \%$ & $1302 \%$ & $564 \%$ & $93 \%$ \\
\hline R111-S044-.01 EDTA-7 & 7.847 & $39 \%$ & $37 \%$ & $150 \%$ & $597 \%$ & $402 \%$ & $47 \%$ \\
\hline R111-S044-.01 EDTA-7-F & 7.847 & $44 \%$ & $45 \%$ & $150 \%$ & $865 \%$ & $493 \%$ & $72 \%$ \\
\hline R111-S044-.01 EDTA-7-F/C & 7.847 & $41 \%$ & $45 \%$ & $150 \%$ & $845 \%$ & $560 \%$ & $79 \%$ \\
\hline R111-S044-.01 EDTA-7-F-DUP & 7.847 & $33 \%$ & $42 \%$ & $150 \%$ & $851 \%$ & $505 \%$ & $74 \%$ \\
\hline R111-S049-.01 EDTA-3 & 3.183 & $11 \%$ & $117 \%$ & $149 \%$ & $226 \%$ & $1160 \%$ & $324 \%$ \\
\hline
\end{tabular}




\section{$\mathrm{Ba}, \mathrm{Cd}, \mathrm{Cr}, \mathrm{Cu}, \mathrm{Pb}, \mathrm{Zn}$ Removed by Batch Shaker Method}

\begin{tabular}{|c|c|c|c|c|c|c|c|}
\hline & pH & $\% \mathrm{Ba}$ & $\% \mathbf{C d}$ & $\% \mathrm{Cr}$ & $\% \mathrm{Cu}$ & $\% \mathrm{~Pb}$ & $\% \mathbf{Z n}$ \\
\hline SAMPLE \# & of Sample & Removed & Removed & Removed & Removed & Removed & Removed \\
\hline R111-S049-.01 EDTA-3-F & 3.183 & $12 \%$ & $117 \%$ & $149 \%$ & $274 \%$ & $1143 \%$ & $1116 \%$ \\
\hline R111-S049-.01 EDTA-3-F/C & 3.183 & $25 \%$ & $117 \%$ & $149 \%$ & $262 \%$ & $911 \%$ & $1275 \%$ \\
\hline R111-S049-.01 EDTA-3-F-DUP & 3.183 & $11 \%$ & $117 \%$ & $149 \%$ & $298 \%$ & $464 \%$ & $329 \%$ \\
\hline R111-S049-.01 EDTA-5 & 5.076 & $14 \%$ & $118 \%$ & $149 \%$ & $191 \%$ & $465 \%$ & $554 \%$ \\
\hline R111-S049-.01 EDTA-5-F & 5.076 & $13 \%$ & $118 \%$ & $149 \%$ & $275 \%$ & $680 \%$ & $725 \%$ \\
\hline R111-S049-.01 EDTA-5-F/C & 5.076 & $11 \%$ & $118 \%$ & $149 \%$ & $275 \%$ & $680 \%$ & $613 \%$ \\
\hline R111-S049-.01 EDTA-5-F-DUP & 5.076 & $11 \%$ & $118 \%$ & $149 \%$ & $286 \%$ & $931 \%$ & $538 \%$ \\
\hline R111-S049-.01 EDTA-7 & 7.101 & $94 \%$ & $118 \%$ & $149 \%$ & $274 \%$ & $1395 \%$ & $1352 \%$ \\
\hline R111-S049-.01 EDTA-7-F & 7.101 & $96 \%$ & $118 \%$ & $149 \%$ & $262 \%$ & $1144 \%$ & $1511 \%$ \\
\hline R111-S049-.01 EDTA-7-F/C & 7.101 & $137 \%$ & $118 \%$ & $149 \%$ & $310 \%$ & $697 \%$ & $3092 \%$ \\
\hline R111-S049-.01 EDTA-7-F-DUP & 7.101 & $50 \%$ & $118 \%$ & $149 \%$ & $298 \%$ & $948 \%$ & $362 \%$ \\
\hline AVERAGE EDTA REMOVAL* & & $59 \%$ & $74 \%$ & $109 \%$ & $2243 \%$ & $638 \%$ & $74 \%$ \\
\hline \multicolumn{8}{|l|}{ (of $t / c$ samples) } \\
\hline pH 3 AVERAGE REMOVAL* & & $81 \%$ & $88 \%$ & $109 \%$ & $4017 \%$ & $849 \%$ & $87 \%$ \\
\hline PH 5 AVERAGE REMOVAL* & & $43 \%$ & $76 \%$ & $109 \%$ & $2193 \%$ & $543 \%$ & $78 \%$ \\
\hline pH 7 AVERAGE REMOVAL* & & $54 \%$ & $57 \%$ & $110 \%$ & $519 \%$ & $523 \%$ & $58 \%$ \\
\hline
\end{tabular}




\begin{tabular}{|c|c|c|c|c|c|c|}
\hline \multicolumn{7}{|l|}{ BATCH SHAKER METHOD } \\
\hline & $\mathbf{B a}$ & Cd & $\mathrm{Cr}$ & Cu & $\mathbf{P b}$ & $\mathbf{Z n}$ \\
\hline AVERAGE .01M CITRIC ACID REMOVAL* & $52 \%$ & $42 \%$ & $111 \%$ & $329 \%$ & $131 \%$ & $123 \%$ \\
\hline \multicolumn{7}{|l|}{ (of $\mathrm{t} / \mathrm{c}$ samples) } \\
\hline pH 3 AVERAGE REMOVAL* & $85 \%$ & $59 \%$ & $113 \%$ & $432 \%$ & $125 \%$ & $72 \%$ \\
\hline PH 5 AVERAGE REMOVAL* & $34 \%$ & $36 \%$ & $110 \%$ & $247 \%$ & $110 \%$ & $179 \%$ \\
\hline PH 7 AVERAGE REMOVAL* & $36 \%$ & $31 \%$ & $109 \%$ & $309 \%$ & $159 \%$ & $38 \%$ \\
\hline \multicolumn{7}{|l|}{${ }^{*}$ not including S049 sample } \\
\hline AVERAGE .01M EDTA REMOVAL* & $59 \%$ & $74 \%$ & $116 \%$ & $2243 \%$ & $638 \%$ & $74 \%$ \\
\hline \multicolumn{7}{|l|}{ (of $t / c$ samples) } \\
\hline PH 3 AVERAGE REMOVAL* & $81 \%$ & $88 \%$ & $109 \%$ & $4017 \%$ & $849 \%$ & $87 \%$ \\
\hline PH 5 AVERAGE REMOVAL* & $43 \%$ & $76 \%$ & $109 \%$ & $2193 \%$ & $543 \%$ & $78 \%$ \\
\hline pH 7 AVERAGE REMOVAL* & $54 \%$ & $57 \%$ & $110 \%$ & $519 \%$ & $523 \%$ & $58 \%$ \\
\hline \multicolumn{7}{|l|}{${ }^{*}$ not including $\mathbf{S 0 4 9}$ sample } \\
\hline & & & & & & \\
\hline \multirow{2}{*}{\multicolumn{7}{|c|}{ COLUMNAR FLOODING METHOD }} \\
\hline & & & & & & \\
\hline & Cd & Cr & ou & $\mathrm{Fe}$ & $\mathbf{P b}$ & $\mathbf{Z n}$ \\
\hline AVERAGE DISTILLED WATER REMOVAL & $3.72 \%$ & $1.60 \%$ & $0.21 \%$ & $0.03 \%$ & $0.31 \%$ & $1.69 \%$ \\
\hline AVERAGE CITRIC ACID REMOVAL & $11.06 \%$ & $2.37 \%$ & $8.96 \%$ & $0.39 \%$ & $4.25 \%$ & $10.59 \%$ \\
\hline AVERAGE EDTA REMOVAL & $13.00 \%$ & $2.80 \%$ & $1.41 \%$ & $0.51 \%$ & $17.61 \%$ & $4.87 \%$ \\
\hline
\end{tabular}




$$
134
$$


Appendix B:

Amount of Heavy Metals Removed by

Columnar Flooding: $\mathrm{Cd}, \mathrm{Cr}, \mathrm{Cu}, \mathrm{Fe}, \mathrm{Pb}$, and $\mathrm{Zn}$ 
Cd Removed by Columnar Flooding

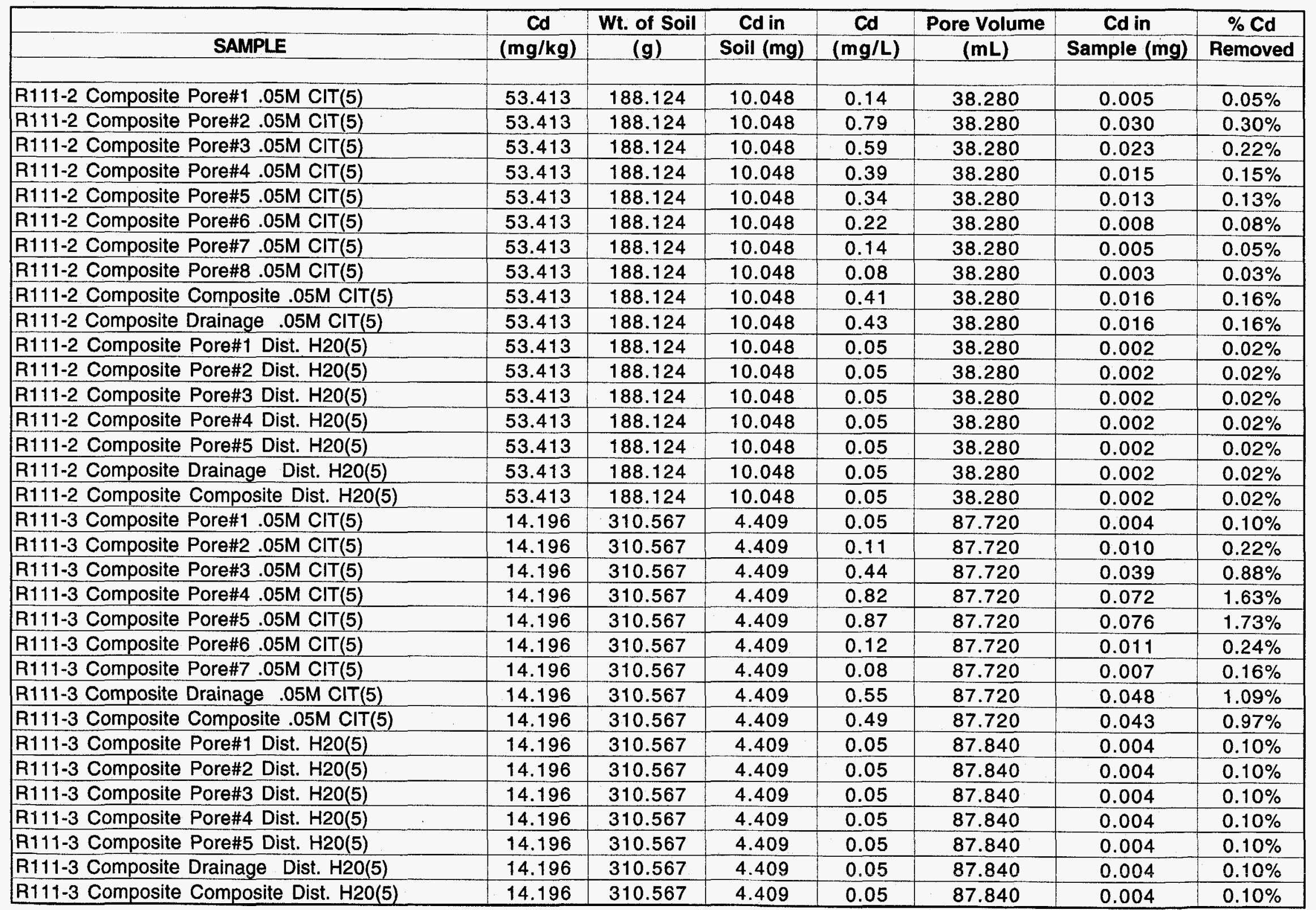


Cd Removed by Columnar Flooding

\begin{tabular}{|c|c|c|c|c|c|c|c|}
\hline & Cd & Wt. of Soil & Cd in & Cd & Pore Volume & Cd in & $\%$ Cd \\
\hline SAMPLE & $(\mathbf{m g} / \mathbf{k g})$ & (g) & Soil (mg) & $(\mathrm{mg} / \mathrm{L})$ & $(\mathrm{mL})$ & Sample (mg) & Removed \\
\hline R111-4 Composite Pore\#1 .05M CIT(5) & 24.392 & 206.100 & 5.027 & 0.11 & 53.550 & 0.006 & $0.12 \%$ \\
\hline R111-4 Composite Pore\#2 .05M CIT(5) & 24.392 & 206.100 & 5.027 & 0,37 & 53.550 & 0.020 & $0.39 \%$ \\
\hline R111-4 Composite Pore\#3 .05M CIT(5) & 24.392 & 206.100 & 5.027 & 0.3 & 53.550 & 0.016 & $0.32 \%$ \\
\hline R111-4 Composite Pore\#4 .05M CIT(5) & 24.392 & 206.100 & 5.027 & 0.11 & 53.550 & 0.006 & $0.12 \%$ \\
\hline R111-4 Composite Pore\#5 .05M CIT(5) & 24.392 & 206.100 & 5.027 & 0.05 & 53.550 & 0.003 & $0.05 \%$ \\
\hline R111-4 Composite Pore\#6 .05M CIT(5) & 24.392 & 206.100 & 5.027 & 0.05 & 53.550 & 0.003 & $0.05 \%$ \\
\hline R111-4 Composite Pore\#7 .05M CIT(5) & 24,392 & 206.100 & 5.027 & 0.05 & 53.550 & 0.003 & $0.05 \%$ \\
\hline R111-4 Composite Pore $\# 8$.05M CIT(5) & 24.392 & 206.100 & 5.027 & 0.05 & 53.550 & 0.003 & $0.05 \%$ \\
\hline R111-4 Composite Drainage .05M CIT(5) & 24.392 & 206.100 & 5.027 & 0.05 & 53.550 & 0.003 & $0.05 \%$ \\
\hline R111-4 Composite Composite .05M CIT(5) & 24.392 & 206.100 & 5.027 & 0.06 & 53.550 & 0.003 & $0.06 \%$ \\
\hline R111-4 Composite Pore\#1 Dist. H2O(5) & 24.392 & 206.100 & 5.027 & 0.05 & 53.770 & 0.003 & $0.05 \%$ \\
\hline R111-4 Composite Pore\#2 Dist. H2O(5) & 24.392 & 206.100 & 5.027 & 0.05 & 53.770 & 0.003 & $0.05 \%$ \\
\hline R111-4 Composite Pore\#3 Dist. H2O(5) & 24.392 & 206.100 & 5.027 & 0.05 & 53.770 & 0.003 & $0.05 \%$ \\
\hline R111-4 Composite Pore\#4 Dist. H2O(5) & 24.392 & 206.100 & 5.027 & 0.05 & 53.770 & 0.003 & $0.05 \%$ \\
\hline R111-4 Composite Pore\#5 Dist. H2O(5) & 24.392 & 206.100 & 5.027 & 0.05 & 53.770 & 0.003 & $0.05 \%$ \\
\hline R111-4 Composite Drainage Dist. $\mathrm{H} 20(5)$ & 24.392 & 206.100 & 5.027 & 0.05 & 53.770 & 0.003 & $0.05 \%$ \\
\hline R111-4 Composite Composite Dist. $\mathrm{H} 2 \mathrm{O}(5)$ & 24.392 & 206.100 & 5.027 & 0.05 & 53.770 & 0.003 & $0.05 \%$ \\
\hline R111-4,3 Composite Pore\#1 .05M CIT(5) & 78.825 & 199.903 & 15.757 & 0.21 & 73.348 & 0.015 & $0.10 \%$ \\
\hline R111-4,3 Composite Pore\#2 .05M CIT(5) & 78.825 & 199.903 & 15.757 & 10.51 & 73.348 & 0.771 & $4.89 \%$ \\
\hline R111-4,3 Composite Pore\#3 .05M CIT(5) & 78.825 & 199.903 & 15.757 & 15.62 & 73.348 & 1.146 & $7.27 \%$ \\
\hline R111-4,3 Composite Pore $\# 4$.05M CIT(5) & 78.825 & 199.903 & 15.757 & 12.47 & 73.348 & 0.915 & $5.80 \%$ \\
\hline R111-4,3 Composite Pore $\# 5$.05M CIT(5) & 78.825 & 199.903 & 15.757 & 8.56 & 73.348 & 0.628 & $3.98 \%$ \\
\hline R111-4,3 Composite Pore\#6 .05M CIT(5) & 78.825 & 199.903 & 15.757 & 6.73 & 73.348 & 0.494 & $3.13 \%$ \\
\hline R111-4,3 Composite Pore\#7 .05M CIT(5) & 78.825 & 199.903 & 15.757 & 5.28 & 73.348 & 0.387 & $2.46 \%$ \\
\hline R111-4,3 Composite Pore $\# 8$.05M CIT(5) & 78.825 & 199.903 & 15.757 & 5.73 & 73.348 & 0.420 & $2.67 \%$ \\
\hline $\mathrm{R} 111-4,3$ Composite Drainage .05M CIT(5) & 78.825 & 199.903 & 15.757 & 1.9 & 73.348 & 0.139 & $0.88 \%$ \\
\hline R111-4,3 Composite Composite .05M CIT(5) & 78.825 & 199.903 & 15.757 & 7.59 & 73.348 & 0.557 & $3.53 \%$ \\
\hline R111-4,3 Composite Pore\#1 Dist. H2O(5) & 78.825 & 199.903 & 15.757 & 0.05 & 73.348 & 0.004 & $0.02 \%$ \\
\hline R111-4,3 Composite Pore\#2 Dist. H2O(5) & 78.825 & 199.903 & 15.757 & 0.05 & 73.348 & 0.004 & $0.02 \%$ \\
\hline R111-4,3 Composite Pore\#3 Dist. H2O(5) & 78.825 & 199.903 & 15.757 & 0.05 & 73.348 & 0.004 & $0.02 \%$ \\
\hline R111-4,3 Composite Pore\#4 Dist. H2O(5) & 78.825 & 199.903 & 15.757 & 0.05 & 73.348 & 0.004 & $0.02 \%$ \\
\hline R111-4,3 Composite Pore\#5 Dist. $\mathrm{H} 2 \mathrm{O}(5)$ & 78.825 & 199.903 & 15.757 & 0.05 & 73.348 & 0.004 & $0.02 \%$ \\
\hline R111-4,3 Composite Drainage Dist. $\mathrm{H} 2 \mathrm{O}(5)$ & 78.825 & 199.903 & 15.757 & 0.05 & 73.348 & 0.004 & $0.02 \%$ \\
\hline
\end{tabular}


Cd Removed by Columnar Flooding

\begin{tabular}{|c|c|c|c|c|c|c|c|}
\hline & Cd & Wt. of Soil & Cd in & $\mathrm{Cd}$ & Pore Volume & Cd in & $\% \mathbf{C d}$ \\
\hline SAMPLE & (mg/kg) & (g) & Soil (mg) & $(\mathrm{mg} / \mathrm{L})$ & $(\mathrm{mL})$ & Sample (mg) & Removed \\
\hline R111-4,3 Composite Composite Dist. H20(5) & 78.825 & 199.903 & 15.757 & 0.05 & 73.348 & 0.004 & $0.02 \%$ \\
\hline R124 Composite Pore\#1 .05M EDTA(5) & 0.626 & 342.551 & 0.214 & 0.05 & 55.770 & 0.003 & $1.30 \%$ \\
\hline R124 Composite Pore\#2 .05M EDTA(5) & 0.626 & 342.551 & 0.214 & 0.05 & 55.770 & 0.003 & $1.30 \%$ \\
\hline R124 Composite Pore\#3 .05M EDTA(5) & 0.626 & 342.551 & 0.214 & 0.05 & 55.770 & 0.003 & $1.30 \%$ \\
\hline R124 Composite Pore\#4 .05M EDTA(5) & 0.626 & 342.551 & 0.214 & 0.05 & 55.770 & 0.003 & $1.30 \%$ \\
\hline R124 Composite Pore\#5 .05M EDTA(5) & 0.626 & 342.551 & 0.214 & 0.05 & 55.770 & 0.003 & $1.30 \%$ \\
\hline R124 Composite Pore\#6 .05M EDTA(5) & 0.626 & 342.551 & 0.214 & 0.05 & 55.770 & 0.003 & $1.30 \%$ \\
\hline R124 Composite Pore\#7 .05M EDTA(5) & 0.626 & 342.551 & 0.214 & 0.05 & 55.770 & 0.003 & $1.30 \%$ \\
\hline R124 Composite Pore\#8 .05M EDTA(5) & 0.626 & 342.551 & 0.214 & 0.05 & 55.770 & 0.003 & $1.30 \%$ \\
\hline R124 Composite Drainage .05M EDTA(5) & 0.626 & 342.551 & 0.214 & 0.05 & 55.770 & 0.003 & $1.30 \%$ \\
\hline R124 Composite Composite .05M EDTA(5) & 0.626 & 342.551 & 0.214 & 0.05 & 55.770 & 0.003 & $1.30 \%$ \\
\hline R124 Composite Pore\#1 Dist. H20(5) & 0.626 & 342.551 & 0.214 & 0.05 & 55.770 & 0.003 & $1.30 \%$ \\
\hline R124 Composite Pore\#2 Dist. H2O(5) & 0.626 & 342.551 & 0.214 & 0.05 & 55.770 & 0.003 & $1.30 \%$ \\
\hline R124 Composite Pore\#3 Dist. H2O(5) & 0.626 & 342.551 & 0.214 & 0.05 & 55.770 & 0.003 & $1.30 \%$ \\
\hline R124 Composite Pore\#4 Dist. H2O(5) & 0.626 & 342.551 & 0.214 & 0.05 & 55.770 & 0.003 & $1.30 \%$ \\
\hline R124 Composite Pore\#5 Dist. H20(5) & 0.626 & 342.551 & 0.214 & 0.05 & 55.770 & 0.003 & $1.30 \%$ \\
\hline R124 CompositeComposite Dist. $\mathrm{H} 20(5)$ & 0.626 & 342.551 & 0.214 & 0.05 & 55.770 & 0.003 & $1.30 \%$ \\
\hline R124 Composite Drainage Dist. $\mathrm{H} 20(5)$ & 0.626 & 342.551 & 0.214 & 0.05 & 55.770 & 0.003 & $1.30 \%$ \\
\hline R124-2 Composite Pore\#1 .05M CIT(5) & 0.476 & 312.744 & 0.149 & 0.05 & 46.880 & 0.002 & $1.58 \%$ \\
\hline R124-2 Composite Pore\#2 .05M CIT(5) & 0.476 & 312.744 & 0.149 & 0.05 & 46.880 & 0.002 & $1.58 \%$ \\
\hline R124-2 Composite Pore\#3 .05M CIT(5) & 0.476 & 312.744 & 0.149 & 0.05 & 46.880 & 0.002 & $1.58 \%$ \\
\hline R124-2 Composite Pore\#4 .05M CIT(5) & 0.476 & 312.744 & 0.149 & 0.05 & 46.880 & 0.002 & $1.58 \%$ \\
\hline R124-2 Composite Pore\#5 .05M CIT(5) & 0.476 & 312.744 & 0.149 & 0.05 & 46.880 & 0.002 & $1.58 \%$ \\
\hline R124-2 Composite Pore\#6 .05M CIT(5) & 0.476 & 312.744 & 0.149 & 0.05 & 46.880 & 0.002 & $1.58 \%$ \\
\hline R124-2 Composite Pore\#7 .05M CIT(5) & 0.476 & 312.744 & 0.149 & 0.05 & 46.880 & 0.002 & $1.58 \%$ \\
\hline R124-2 Composite Pore\#8 .05M CIT(5) & 0.476 & 312.744 & 0.149 & 0.05 & 46.880 & 0.002 & $1.58 \%$ \\
\hline R124-2 Composite Composite .05M CIT(5) & 0.476 & 312.744 & 0.149 & 0.05 & 46.880 & 0.002 & $1.58 \%$ \\
\hline R124-2 Composite Drainage .05M CIT(5) & 0.476 & 312.744 & 0.149 & 0.05 & 46.880 & 0.002 & $1.58 \%$ \\
\hline R124-2 Composite Pore\# 1 Dist. H2O(5) & 0.476 & 312.744 & 0.149 & 0.05 & 46.880 & 0.002 & $1.58 \%$ \\
\hline R124-2 Composite Pore\#2 Dist. $\mathrm{H} 2 \mathrm{O}(5)$ & 0.476 & 312.744 & 0.149 & 0.05 & 46.880 & 0.002 & $1.58 \%$ \\
\hline R124-2 Composite Pore\#3 Dist. H2O(5) & 0.476 & 312.744 & 0.149 & 0.05 & 46.880 & 0.002 & $1.58 \%$ \\
\hline R124-2 Composite Pore\#4 Dist. H2O(5) & 0.476 & 312.744 & 0.149 & 0.05 & 46.880 & 0.002 & $1.58 \%$ \\
\hline R124-2 Composite Pore\#5 Dist. H2O(5) & 0.476 & 312.744 & 0.149 & 0.05 & 46.880 & 0.002 & $1.58 \%$ \\
\hline
\end{tabular}


Cd Removed by Columnar Flooding

\begin{tabular}{|c|c|c|c|c|c|c|c|}
\hline & $\mathbf{C d}$ & Wt. of Soll & Cd in & Cd & Pore Volume & Cd in & $\%$ Cd \\
\hline SAMPLE & $(\mathbf{m g} / \mathbf{k g})$ & (g) & Soil (mg) & (mg/L) & $(\mathbf{m L})$ & Sample (mg) & Removed \\
\hline R124-2 CompositeComposite Dist. H2O(5) & 0.476 & 312.744 & 0.149 & 0.05 & 46.880 & 0.002 & $1.58 \%$ \\
\hline R124-2 Composite Drainage Dist. $\mathrm{H} 20(5)$ & 0.476 & 312.744 & 0.149 & 0.05 & 46.880 & 0.002 & $1.58 \%$ \\
\hline R124-3 Composite Pore\#1 .05M CIT(5) & 2.298 & 213.391 & 0.490 & 0.05 & 63.700 & 0.003 & $0.65 \%$ \\
\hline R124-3 Composite Pore\#2 .05M CIT(5) & 2.298 & 213.391 & 0.490 & 0.05 & 63.700 & 0.003 & $0.65 \%$ \\
\hline R124-3 Composite Pore\#3 .05M CIT(5) & 2.298 & 213.391 & 0.490 & 0.05 & 63.700 & 0.003 & $0.65 \%$ \\
\hline R124-3 Composite Pore\#4 .05M CIT(5) & 2.298 & 213.391 & 0.490 & 0.05 & 63.700 & 0.003 & $0.65 \%$ \\
\hline R124-3 Composite Pore\#5 .05M CIT(5) & 2.298 & 213.391 & 0.490 & 0.05 & 63.700 & 0.003 & $0.65 \%$ \\
\hline R124-3 Composite Pore\#6 .05M CIT(5) & 2.298 & 213.391 & 0.490 & 0.05 & 63.700 & 0.003 & $0.65 \%$ \\
\hline R124-3 Composite Pore\#7 .05M CIT(5) & 2.298 & 213.391 & 0.490 & 0.05 & 63.700 & 0.003 & $0.65 \%$ \\
\hline R124-3 Composite Pore\#8 .05M CIT(5) & 2.298 & 213.391 & 0.490 & 0.05 & 63.700 & 0.003 & $0.65 \%$ \\
\hline R124-3 Composite Composite .05M CIT(5) & 2.298 & 213.391 & 0.490 & 0.05 & 63.700 & 0.003 & $0.65 \%$ \\
\hline R124-3 Composite Drainage .05M CIT(5) & 2.298 & 213.391 & 0.490 & 0.05 & 63.700 & 0.003 & $0.65 \%$ \\
\hline R124-3 Composite Pore\#1 Dist. $\mathrm{H} 20(5)$ & 2.298 & 213.391 & 0.490 & 0.05 & 63.750 & 0.003 & $0.65 \%$ \\
\hline R124-3 Composite Pore\#2 Dist. H20(5) & 2.298 & 213.391 & 0.490 & 0.05 & 63.750 & 0.003 & $0.65 \%$ \\
\hline R124-3 Composite Pore\#3 Dist. H20(5) & 2.298 & 213.391 & 0.490 & 0.05 & 63.750 & 0.003 & $0.65 \%$ \\
\hline R124-3 Composite Pore\#4 Dist. H2O(5) & 2.298 & 213.391 & 0.490 & 0.05 & 63.750 & 0.003 & $0.65 \%$ \\
\hline R124-3 Composite Pore\#5 Dist. H20(5) & 2.298 & 213.391 & 0.490 & 0.05 & 63.750 & 0.003 & $0.65 \%$ \\
\hline R124-3 CompositeComposite Dist. H2O(5) & 2.298 & 213.391 & 0.490 & 0.05 & 63.750 & 0.003 & $0.65 \%$ \\
\hline R124-3 Composite Drainage Dist. $\mathrm{H} 20(5)$ & 2.298 & 213.391 & 0.490 & 0.05 & 63.750 & 0.003 & $0.65 \%$ \\
\hline
\end{tabular}


Cr Removed by Columnar Flooding

\begin{tabular}{|c|c|c|c|c|c|c|c|}
\hline & $\mathbf{C r}$ & Wt. of Soil & Crin & $\mathrm{Cr}$ & Pore Volume & Crin & $\% \mathrm{Cr}$ \\
\hline SAMPLE & $(\mathbf{m g} / \mathbf{k g})$ & (g) & Soil (mg) & $(\mathrm{mg} / \mathrm{L})$ & (ml) & Sample (mg) & Removed \\
\hline R111-2 Composite Pore\#1 .05M CIT(5) & 46.741 & 188.124 & 8.793 & 0.15 & 38.280 & 0.006 & $0.07 \%$ \\
\hline R111-2 Composite Pore\#3 .05M CIT(5) & 46.741 & 188.124 & 8.793 & 0.15 & 38.280 & 0.006 & $0.07 \%$ \\
\hline R111-2 Composite Pore\#4 .05M CIT(5) & 46.741 & 188.124 & 8.793 & 0.15 & 38.280 & 0.006 & $0.07 \%$ \\
\hline R111-2 Composite Pore\#5 .05M CIT(5) & 46.741 & 188.124 & 8.793 & 0.15 & 38.280 & 0.006 & $0.07 \%$ \\
\hline R111-2 Composite Pore\#6 .05M CIT(5) & 46.741 & 188.124 & 8.793 & 0.15 & 38.280 & 0.006 & $0.07 \%$ \\
\hline R111-2 Composite Composite .05M CIT(5) & 46.741 & 188.124 & 8.793 & 0.17 & 38.280 & 0.007 & $0.07 \%$ \\
\hline R111-2 Composite Drainage .05M CIT(5) & 46.741 & 188.124 & 8.793 & 0.2 & 38.280 & 0.008 & $0.09 \%$ \\
\hline R111-2 Composite Pore\#1 Dist. H20(5) & 46.741 & 188.124 & 8.793 & 0.15 & 38.280 & 0.006 & $0.07 \%$ \\
\hline R111-2 Composite Pore\#2 Dist. H2O(5) & 46.741 & 188.124 & 8.793 & 0.15 & 38.280 & 0.006 & $0.07 \%$ \\
\hline R111-2 Composite Pore\#3 Dist. H2O(5) & 46.741 & 188.124 & 8.793 & 0.15 & 38.280 & 0.006 & $0.07 \%$ \\
\hline R111-2 Composite Pore\#4 Dist. H2O(5) & 46.741 & 188.124 & 8.793 & 0.15 & 38.280 & 0.006 & $0.07 \%$ \\
\hline R111-3 Composite Pore\#2 .05M CIT(5) & 58.166 & 310.567 & 18.064 & 0.15 & 87.720 & 0.013 & $0.07 \%$ \\
\hline R111-3 Composite Pore\#3 .05M CIT(5) & 58.166 & 310.567 & 18.064 & 0.17 & 87.720 & 0.015 & $0.08 \%$ \\
\hline R111-3 Composite Pore\#4 .05M CIT(5) & 58.166 & 310.567 & 18.064 & 0.22 & 87.720 & 0.019 & $0.11 \%$ \\
\hline R111-3 Composite Pore\#5 .05M CIT(5) & 58.166 & 310.567 & 18.064 & 0.25 & 87.720 & 0.022 & $0.12 \%$ \\
\hline R111-3 Composite Pore $\# 6$.05M CIT(5) & 58.166 & 310.567 & 18.064 & 0.23 & 87.720 & 0.020 & $0.11 \%$ \\
\hline R111-3 Composite Pore\#7 .05M CIT(5) & 58.166 & 310.567 & 18.064 & 0.25 & 87.720 & 0.022 & $0.12 \%$ \\
\hline R111-3 Composite Drainage .05M CIT(5) & 58.166 & 310.567 & 18.064 & 0.31 & 87.720 & 0.027 & $0.15 \%$ \\
\hline R111-3 Composite Composite .05M CIT(5) & 58.166 & 310.567 & 18.064 & 0.2 & 87.720 & 0.018 & $0.10 \%$ \\
\hline R111-3 Composite Pore\#1 Dist. H20(5) & 58.166 & 310.567 & 18.064 & 0.15 & 87.840 & 0.013 & $0.07 \%$ \\
\hline R111-3 Composite Pore\#2 Dist. H2O(5) & 58.166 & 310.567 & 18.064 & 0.15 & 87.840 & 0.013 & $0.07 \%$ \\
\hline R111-3 Composite Pore\#3 Dist. H20(5) & 58.166 & 310.567 & 18.064 & 0.15 & 87.840 & 0.013 & $0.07 \%$ \\
\hline R111-3 Composite Pore\#4 Dist. H20(5) & 58.166 & 310.567 & 18.064 & 0.15 & 87.840 & 0.013 & $0.07 \%$ \\
\hline R111-3 Composite Pore\#5 Dist. H2O(5) & 58.166 & 310.567 & 18.064 & 0.15 & 87.840 & 0.013 & $0.07 \%$ \\
\hline
\end{tabular}


Cr Removed by Columnar Flooding

\begin{tabular}{|c|c|c|c|c|c|c|c|}
\hline & $\mathrm{Cr}$ & Wt. of Soil & Crin & $\mathbf{C r}$ & Pore Volume & Crin & $\% \mathrm{Cr}$ \\
\hline SAMPLE & $(\mathbf{m g} / \mathbf{k g})$ & (g) & Soil $(\mathrm{mg})$ & $(\mathrm{mg} / \mathrm{L})$ & $(\mathrm{ml})$ & Sample (mg) & Removed \\
\hline R111-4 Composite Pore\#1 .05M CIT(5) & 38.358 & 206.100 & 7.905 & 0.15 & 53.550 & 0.008 & $0.10 \%$ \\
\hline R111-4 Composite Pore\#2 .05M CIT(5) & 38.358 & 206.100 & 7.905 & 0.15 & 53.550 & 0.008 & $0.10 \%$ \\
\hline R111-4 Composite Pore\#3 .05M CIT(5) & 38.358 & 206.100 & 7.905 & 0.17 & 53.550 & 0.009 & $0.12 \%$ \\
\hline R111-4 Composite Pore\#4 .05M CIT(5) & 38.358 & 206.100 & 7.905 & 0.23 & 53.550 & 0.012 & $0.16 \%$ \\
\hline R111-4 Composite Pore\#5 .05M CIT(5) & 38.358 & 206.100 & 7.905 & 0.15 & 53.550 & 0.008 & $0.10 \%$ \\
\hline R111-4 Composite Pore\#6 .05M CIT(5) & 38.358 & 206.100 & 7.905 & 0.15 & 53.550 & 0.008 & $0.10 \%$ \\
\hline R111-4 Composite Pore\#7 .05M CIT(5) & 38.358 & 206.100 & 7.905 & 0.15 & 53.550 & 0.008 & $0.10 \%$ \\
\hline R111-4 Composite Pore\#8 .05M CIT(5) & 38.358 & 206.100 & 7.905 & 0.15 & 53.550 & 0.008 & $0.10 \%$ \\
\hline R111-4 Composite Drainage .05M CIT(5) & 38.358 & 206.100 & 7.905 & 0.15 & 53.550 & 0.008 & $0.10 \%$ \\
\hline R111-4 Composite Composite .05M CIT(5) & 38.358 & 206.100 & 7.905 & 0.15 & 53.550 & 0.008 & $0.10 \%$ \\
\hline R111-4 Composite Pore\#1 Dist. H2O(5) & 38.358 & 206.100 & 7.905 & 0.15 & 53.770 & 0.008 & $0.10 \%$ \\
\hline R111-4 Composite Pore\#2 Dist. H2O(5) & 38.358 & 206.100 & 7.905 & 0.15 & 53.770 & 0.008 & $0.10 \%$ \\
\hline R111-4 Composite Pore\#3 Dist. H20(5) & 38.358 & 206.100 & 7.905 & 0.15 & 53.770 & 0.008 & $0.10 \%$ \\
\hline R111-4 Composite Pore\#4 Dist. H20(5) & 38.358 & 206.100 & 7.905 & 0.15 & 53.770 & 0.008 & $0.10 \%$ \\
\hline R111-4 Composite Pore\#5 Dist. H2O(5) & 38.358 & 206.100 & 7.905 & 0.15 & 53.770 & 0.008 & $0.10 \%$ \\
\hline R111-4 Composite Drainage Dist. $\mathrm{H} 20(5)$ & 38.358 & 206.100 & 7.905 & 0.15 & 53.770 & 0.008 & $0.10 \%$ \\
\hline R111-4 Composite Composite Dist. H2O(5) & 38.358 & 206.100 & 7.905 & 0.15 & 53.770 & 0.008 & $0.10 \%$ \\
\hline R111-4,3 Composite Pore\#1 .05M CIT(5) & 38.985 & 199.903 & 7.793 & 0.15 & 73.348 & 0.011 & $0.14 \%$ \\
\hline R111-4,3 Composite Pore\#2 .05M CIT(5) & 38.985 & 199.903 & 7.793 & 0.15 & 73.348 & 0.011 & $0.14 \%$ \\
\hline R111-4,3 Composite Pore\#3 .05M CIT(5) & 38.985 & 199.903 & 7.793 & 0.23 & 73.348 & 0.017 & $0.22 \%$ \\
\hline R111-4,3 Composite Pore\#4 .05M CIT(5) & 38.985 & 199.903 & 7.793 & 0.22 & 73.348 & 0.016 & $0.21 \%$ \\
\hline R111-4,3 Composite Pore\#5 .05M CIT(5) & 38.985 & 199.903 & 7.793 & 0.22 & 73.348 & 0.016 & $0.21 \%$ \\
\hline R111-4,3 Composite Pore\#6 .05M CIT(5) & 38.985 & 199.903 & 7.793 & 0.23 & 73.348 & 0.017 & $0.22 \%$ \\
\hline R111-4,3 Composite Pore\#7 .05M CIT(5) & 38.985 & 199.903 & 7.793 & 0.28 & 73.348 & 0.021 & $0.26 \%$ \\
\hline R111-4,3 Composite Pore\#8 .05M CIT(5) & 38.985 & 199.903 & 7.793 & 0.25 & 73.348 & 0.018 & $0.24 \%$ \\
\hline R111-4,3 Composite Drainage $.05 \mathrm{M}$ CIT(5) & 38.985 & 199.903 & 7.793 & 0.28 & 73.348 & 0.021 & $0.26 \%$ \\
\hline R111-4,3 Composite Composite .05M CIT(5) & 38.985 & 199.903 & 7.793 & 0.2 & 73.348 & 0.015 & $0.19 \%$ \\
\hline R111-4,3 Composite Pore\#1 Dist. $\mathrm{H} 20$ (5) & 38.985 & 199.903 & 7.793 & 0.15 & 73.348 & 0.011 & $0.14 \%$ \\
\hline R111-4,3 Composite Pore\#2 Dist. H2O(5) & 38.985 & 199.903 & 7.793 & 0.15 & 73.348 & 0.011 & $0.14 \%$ \\
\hline R111-4,3 Composite Pore\#3 Dist. H2O(5) & 38.985 & 199.903 & 7.793 & 0.15 & 73.348 & 0.011 & $0.14 \%$ \\
\hline R111-4,3 Composite Pore\#4 Dist. H2O(5) & 38.985 & 199.903 & 7.793 & 0.15 & 73.348 & 0.011 & $0.14 \%$ \\
\hline R111-4,3 Composite Pore\#5 Dist. H2O(5) & 38.985 & 199.903 & 7.793 & 0.15 & 73.348 & 0.011 & $0.14 \%$ \\
\hline R111-4,3 Composite Drainage Dist. $\mathrm{H} 20(5)$ & 38.985 & 199.903 & 7.793 & 0.15 & 73.348 & 0.011 & $0.14 \%$ \\
\hline
\end{tabular}


Cr Removed by Columnar Flooding

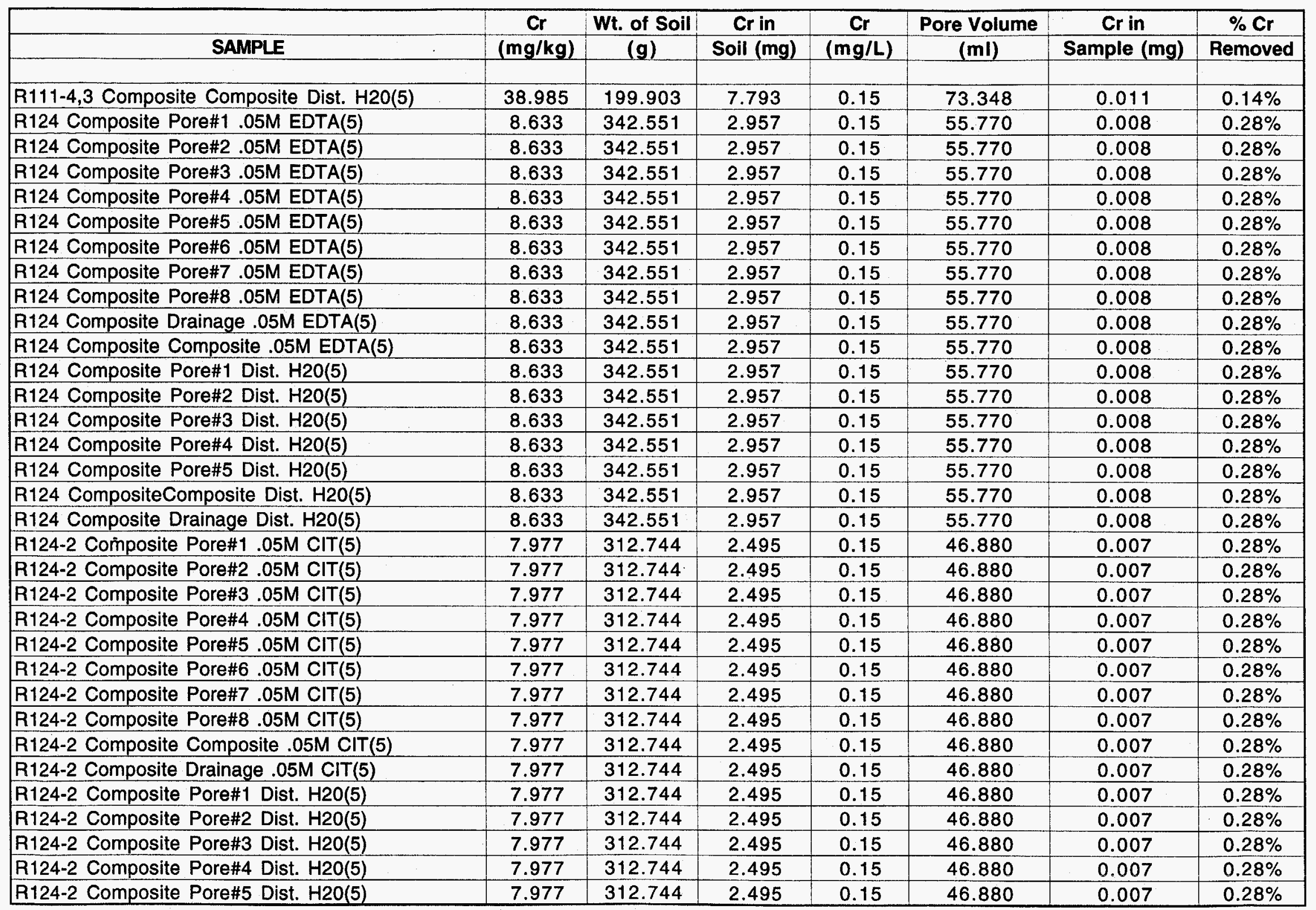


Cr Removed by Columnar Flooding

\begin{tabular}{|c|c|c|c|c|c|c|c|}
\hline & $\mathrm{Cr}$ & Wt. of Soil & Cr in & $\mathrm{Cr}$ & Pore Volume & Crin & $\% \mathrm{Cr}$ \\
\hline SAMPLE & $(\mathbf{m g} / \mathbf{k g})$ & (g) & Soil (mg) & $(\mathrm{mg} / \mathrm{L})$ & $(\mathrm{ml})$ & Sample (mg) & Removed \\
\hline R124-2 CompositeComposite Dist. H20(5) & 7.977 & 312.744 & 2.495 & 0.15 & 46.880 & 0.007 & $0.28 \%$ \\
\hline R124-2 Composite Drainage Dist. $\mathrm{H} 20(5)$ & 7.977 & 312.744 & 2.495 & 0.15 & 46.880 & 0.007 & $0.28 \%$ \\
\hline R124-3 Composite Pore\#1 .05M CIT(5) & 6.788 & 213.391 & 1.448 & 0.15 & 63.700 & 0.010 & $0.66 \%$ \\
\hline R124-3 Composite Pore\#2 .05M CIT(5) & 6.788 & 213.391 & 1.448 & 0.15 & 63.700 & 0.010 & $0.66 \%$ \\
\hline R124-3 Composite Pore\#3 .05M CIT(5) & 6.788 & 213.391 & 1.448 & 0.15 & 63.700 & 0.010 & $0.66 \%$ \\
\hline R124-3 Composite Pore\#4 .05M CIT(5) & 6.788 & 213.391 & 1.448 & 0.15 & 63.700 & 0.010 & $0.66 \%$ \\
\hline R124-3 Composite Pore\#5 .05M CIT(5) & 6.788 & 213.391 & 1.448 & 0.15 & 63.700 & 0.010 & $0.66 \%$ \\
\hline R124-3 Composite Pore\#6 .05M CIT(5) & 6.788 & 213.391 & 1.448 & 0.15 & 63.700 & 0.010 & $0.66 \%$ \\
\hline R124-3 Composite Pore\#7 .05M CIT(5) & 6.788 & 213.391 & 1.448 & 0.15 & 63.700 & 0.010 & $0.66 \%$ \\
\hline R124-3 Composite Pore\#8 .05M CIT(5) & 6.788 & 213.391 & 1.448 & 0.15 & 63.700 & 0.010 & $0.66 \%$ \\
\hline R124-3 Composite Composite .05M CIT(5) & 6.788 & 213.391 & 1.448 & 0.15 & 63.700 & 0.010 & $0.66 \%$ \\
\hline R124-3 Composite Drainage .05M CIT(5) & 6.788 & 213.391 & 1.448 & 0.15 & 63.700 & 0.010 & $0.66 \%$ \\
\hline R124-3 Composite Pore\#1 Dist. H2O(5) & 6.788 & 213.391 & 1.448 & 0.15 & 63.750 & 0.010 & $0.66 \%$ \\
\hline R124-3 Composite Pore\#2 Dist. H2O(5) & 6.788 & 213.391 & 1.448 & 0.15 & 63.750 & 0.010 & $0.66 \%$ \\
\hline R124-3 Composite Pore\#3 Dist. H20(5) & 6.788 & 213.391 & 1.448 & 0.15 & 63.750 & 0.010 & $0.66 \%$ \\
\hline R124-3 Composite Pore\#4 Dist. H2O(5) & 6.788 & 213.391 & 1.448 & 0.15 & 63.750 & 0.010 & $0.66 \%$ \\
\hline R124-3 Composite Pore\#5 Dist. H20(5) & 6.788 & 213.391 & 1.448 & 0.15 & 63.750 & 0.010 & $0.66 \%$ \\
\hline R124-3 CompositeComposite Dist. H2O(5) & 6.788 & 213.391 & 1.448 & 0.15 & 63.750 & 0.010 & $0.66 \%$ \\
\hline R124-3 Composite Drainage Dist. $\mathrm{H} 20(5)$ & 6.788 & 213.391 & 1.448 & 0.15 & 63.750 & 0.010 & $0.66 \%$ \\
\hline
\end{tabular}




\section{Cu Removed by Columnar Flooding}

\begin{tabular}{|c|c|c|c|c|c|c|c|}
\hline & Cu & Wt. of Soil & Cu in & $\mathbf{C u}$ & Pore Volume & Cu in & $\% \mathrm{Cu}$ \\
\hline SAMPLE & $(\mathrm{mg} / \mathrm{kg})$ & (g) & Soil (mg) & $(\mathrm{mg} / \mathrm{L})$ & $(\mathrm{ml})$ & Sample (mg) & Removed \\
\hline R111-2 Composite Pore\#1 .05M CIT(5) & 392.773 & 188.124 & 73.890 & 4.3 & 38.280 & 0.165 & $0.22 \%$ \\
\hline R111-2 Composite Pore\#2 .05M CIT(5) & 392.773 & 188.124 & 73.890 & 8.84 & 38.280 & 0.338 & $0.46 \%$ \\
\hline R111-2 Composite Pore\#3 .05M CIT(5) & 392.773 & 188.124 & 73.890 & 8.73 & 38.280 & 0.334 & $0.45 \%$ \\
\hline R111-2 Composite Pore\#4 .05M CIT(5) & 392.773 & 188.124 & 73.890 & 8.62 & 38.280 & 0.330 & $0.45 \%$ \\
\hline R111-2 Composite Pore\#5 .05M CIT(5) & 392.773 & 188.124 & 73.890 & 8.59 & 38.280 & 0.329 & $0.45 \%$ \\
\hline R111-2 Composite Pore\#6 .05M CIT(5) & 392.773 & 188.124 & 73.890 & 7.44 & 38.280 & 0.285 & $0.39 \%$ \\
\hline R111-2 Composite Pore\#7 .05M CIT(5) & 392.773 & 188.124 & 73.890 & 6.59 & 38.280 & 0.252 & $0.34 \%$ \\
\hline R111-2 Composite Pore\#8 .05M CIT(5) & 392.773 & 188.124 & 73.890 & 6 & 38.280 & 0.230 & $0.31 \%$ \\
\hline R111-2 Composite Composite .05M CIT(5) & 392.773 & 188.124 & 73.890 & 9.04 & 38.280 & 0.346 & $0.47 \%$ \\
\hline R111-2 Composite Drainage .05M CIT(5) & 392.773 & 188.124 & 73.890 & 10.92 & 38.280 & 0.418 & $0.57 \%$ \\
\hline A111-2 Composite Pore\#1 Dist. H2O(5) & 392.773 & 188.124 & 73.890 & 0.79 & 38.280 & 0.030 & $0.04 \%$ \\
\hline R111-2 Composite Pore\#2 Dist. H2O(5) & 392.773 & 188.124 & 73.890 & 0.72 & 38.280 & 0.028 & $0.04 \%$ \\
\hline R111-2 Composite Pore\#3 Dist. H20(5) & 392.773 & 188.124 & 73.890 & 0.87 & 38.280 & 0.033 & $0.05 \%$ \\
\hline R111-2 Composite Pore\#4 Dist. H2O(5) & 392.773 & 188.124 & 73.890 & 0.72 & 38.280 & 0.028 & $0.04 \%$ \\
\hline R111-2 Composite Pore\#5 Dist. H2O(5) & 392.773 & 188.124 & 73.890 & 0.39 & 38.280 & 0.015 & $0.02 \%$ \\
\hline R111-2 Composite Drainage Dist. $\mathrm{H} 20(5)$ & 392.773 & 188.124 & 73.890 & 0.38 & 38.280 & 0.015 & $0.02 \%$ \\
\hline R111-2 Composite Composite Dist. H2O(5) & 392.773 & 188.124 & 73.890 & 0.61 & 38.280 & 0.023 & $0.03 \%$ \\
\hline R111-3 Composite Pore\#1 .05M CIT(5) & 335.786 & 310.567 & 104.284 & 1.36 & 87.720 & 0.119 & $0.11 \%$ \\
\hline R111-3 Composite Pore\#2 .05M CIT(5) & 335.786 & 310.567 & 104.284 & 17.43 & 87.720 & 1.529 & $1.47 \%$ \\
\hline R111-3 Composite Pore\#3 :05M CIT(5) & 335.786 & 310.567 & 104.284 & 17.45 & 87.720 & 1.531 & $1.47 \%$ \\
\hline R111-3 Composite Pore\#4 .05M CIT(5) & 335.786 & 310.567 & 104.284 & 24.97 & 87.720 & 2.190 & $2.10 \%$ \\
\hline R111-3 Composite Pore\#5 .05M CIT(5) & 335.786 & 310.567 & 104.284 & 24.86 & 87.720 & 2.181 & $2.09 \%$ \\
\hline R111-3 Composite Pore\#6 .05M CIT(5) & 335.786 & 310.567 & 104.284 & 19.65 & 87.720 & 1.724 & $1.65 \%$ \\
\hline R111-3 Composite Pore\#7 .05M CIT(5) & 335.786 & 310.567 & 104.284 & 17.45 & 87.720 & 1.531 & $1.47 \%$ \\
\hline R111-3 Composite Drainage .05M CIT(5) & 335.786 & 310.567 & 104.284 & 20.33 & 87.720 & 1.783 & $1.71 \%$ \\
\hline R111-3 Composite Composite .05M CIT(5) & 335.786 & 310.567 & 104.284 & 19.91 & 87.720 & 1.747 & $1.67 \%$ \\
\hline R111-3 Composite Pore\#1 Dist. H2O(5) & 335.786 & 310.567 & 104.284 & 0.42 & 87.840 & 0.037 & $0.04 \%$ \\
\hline R111-3 Composite Pore\#2 Dist. H2O(5) & 335.786 & 310.567 & 104.284 & 0.41 & 87.840 & 0.036 & $0.03 \%$ \\
\hline R111-3 Composite Pore\#3 Dist. H2O(5) & 335.786 & 310.567 & 104.284 & 0.39 & 87.840 & 0.034 & $0.03 \%$ \\
\hline R111-3 Composite Pore\#4 Dist. H2O(5) & 335.786 & 310.567 & 104.284 & 0.51 & 87.840 & 0.045 & $0.04 \%$ \\
\hline R111-3 Composite Pore\#5 Dist. H20(5) & 335.786 & 310.567 & 104.284 & 0.34 & 87.840 & 0.030 & $0.03 \%$ \\
\hline R111-3 Composite Drainage Dist. $\mathrm{H} 20(5)$ & 335.786 & 310.567 & 104.284 & 0.28 & 87.840 & 0.025 & $0.02 \%$ \\
\hline R111-3 Composite Composite Dist. $\mathrm{H} 2 \mathrm{O}(5)$ & 335.786 & 310.567 & 104.284 & 0.38 & 87.840 & 0.033 & $0.03 \%$ \\
\hline
\end{tabular}


Cu Removed by Columnar Flooding

\begin{tabular}{|c|c|c|c|c|c|c|c|}
\hline & au & Wt. of Soil & Cu in & au & Pore Volume & $\mathrm{Cu}$ in & $\% \mathrm{Cu}$ \\
\hline SAMPLE & $(\mathrm{mg} / \mathrm{kg})$ & (g) & Soil (mg) & $(\mathrm{mg} / \mathrm{L})$ & $(\mathrm{ml})$ & Sample (mg) & Removed \\
\hline R111-4 Composite Pore\#1 .05M ClT(5) & 258.584 & 206.100 & 53.294 & 7.86 & 53.550 & 0.421 & $0.79 \%$ \\
\hline R111-4 Composite Pore\#2 .05M CIT(5) & 258.584 & 206.100 & 53.294 & 11.52 & 53.550 & 0.617 & $1.16 \%$ \\
\hline R111-4 Composite Pore\#3 .05M CIT(5) & 258.584 & 206.100 & 53.294 & 11.46 & 53.550 & 0.614 & $1.15 \%$ \\
\hline R111-4 Composite Pore\#4 .05M CIT(5) & 258.584 & 206.100 & 53.294 & 8.44 & 53.550 & 0.452 & $0.85 \%$ \\
\hline R111-4 Composite Pore\#5 .05M CIT(5) & 258.584 & 206.100 & 53.294 & 6.9 & 53.550 & 0.369 & $0.69 \%$ \\
\hline R111-4 Composite Pore $\# 6.05 \mathrm{M} \mathrm{ClT(5)}$ & 258.584 & 206.100 & 53.294 & 5.79 & 53.550 & 0.310 & $0.58 \%$ \\
\hline R111-4 Composite Pore\#7 .05M CIT(5) & 258.584 & 206.100 & 53.294 & 5.27 & 53.550 & 0.282 & $0.53 \%$ \\
\hline R111-4 Composite Pore $\# 8$.05M CIT(5) & 258.584 & 206.100 & 53.294 & 5.26 & 53.550 & 0.282 & $0.53 \%$ \\
\hline R111-4 Composite Drainage .05M CIT(5) & 258.584 & 206.100 & 53.294 & 13.73 & 53.550 & 0.735 & $1.38 \%$ \\
\hline R111-4 Composite Composite .05M CIT(5) & 258.584 & 206.100 & 53.294 & 8.81 & 53.550 & 0.472 & $0.89 \%$ \\
\hline R111-4 Composite Pore\#1 Dist. H2O(5) & 258.584 & 206.100 & 53.294 & 0.64 & 53.770 & 0.034 & $0.06 \%$ \\
\hline R111-4 Composite Pore\#2 Dist. H2O(5) & 258.584 & 206.100 & 53.294 & 0.75 & 53.770 & 0.040 & $0.08 \%$ \\
\hline R111-4 Composite Pore\#3 Dist. H2O(5) & 258.584 & 206.100 & 53.294 & 0.48 & 53.770 & 0.026 & $0.05 \%$ \\
\hline R111-4 Composite Pore\#4 Dist. $\mathrm{H} 2 \mathrm{O}(5)$ & 258.584 & 206.100 & 53.294 & 0.38 & 53.770 & 0.020 & $0.04 \%$ \\
\hline R111-4 Composite Pore\#5 Dist. H2O(5) & 258.584 & 206.100 & 53.294 & 0.31 & 53.770 & 0.017 & $0.03 \%$ \\
\hline R111-4 Composite Drainage Dist. $\mathrm{H} 20(5)$ & 258.584 & 206.100 & 53.294 & 0.31 & 53.770 & 0.017 & $0.03 \%$ \\
\hline R111-4 Composite Composite Dist. $\mathrm{H} 20(5)$ & 258.584 & 206.100 & 53.294 & 0.4 & 53.770 & 0.022 & $0.04 \%$ \\
\hline R111-4,3 Composite Pore\#1 .05M CIT(5) & 419.777 & 199.903 & 83.915 & 7.1 & 73.348 & 0.521 & $0.62 \%$ \\
\hline R111-4,3 Composite Pore\#2 .05M CIT(5) & 419.777 & 199.903 & 83.915 & 34.45 & 73.348 & 2.527 & $3.01 \%$ \\
\hline R111-4,3 Composite Pore\#3 .05M CIT(5) & 419.777 & 199.903 & 83.915 & 28.45 & 73.348 & 2.087 & $2.49 \%$ \\
\hline R111-4,3 Composite Pore $\# 4$.05M CIT(5) & 419.777 & 199.903 & 83.915 & 21 & 73.348 & 1.540 & $1.84 \%$ \\
\hline R111-4,3 Composite Pore\#5 .05M CIT(5) & 419.777 & 199.903 & 83.915 & 16.75 & 73.348 & 1.229 & $1.46 \%$ \\
\hline R111-4,3 Composite Pore $\# 6$.05M CIT(5) & 419.777 & 199.903 & 83.915 & 13.17 & 73.348 & 0.966 & $1.15 \%$ \\
\hline R111-4,3 Composite Pore\#7 .05M CIT(5) & 419.777 & 199.903 & 83.915 & 13.88 & 73.348 & 1.018 & $1.21 \%$ \\
\hline R111-4,3 Composite Pore\#8 .05M CIT(5) & 419.777 & 199.903 & 83.915 & 16.22 & 73.348 & 1.190 & $1.42 \%$ \\
\hline R111-4,3 Composite Drainage .05M CIT(5) & 419.777 & 199.903 & 83.915 & 12.51 & 73.348 & 0.918 & $1.09 \%$ \\
\hline R111-4,3 Composite Composite .05M CIT(5) & 419.777 & 199.903 & 83.915 & 19.05 & 73.348 & 1.397 & $1.67 \%$ \\
\hline R111-4,3 Composite Pore\#1 Dist. H2O(5) & 419.777 & 199.903 & 83.915 & 0.33 & 73.348 & 0.024 & $0.03 \%$ \\
\hline R111-4,3 Composite Pore\#2 Dist. $\mathrm{H} 20(5)$ & 419.777 & 199.903 & 83.915 & 0.5 & 73.348 & 0.037 & $0.04 \%$ \\
\hline R1 $11-4,3$ Composite Pore\#3 Dist. H2O(5) & 419.777 & 199.903 & 83.915 & 0.48 & 73.348 & 0.035 & $0.04 \%$ \\
\hline R111-4,3 Composite Pore\#4 Dist. H2O(5) & 419.777 & 199.903 & 83.915 & 0.4 & 73.348 & 0.029 & $0.03 \%$ \\
\hline R111-4,3 Composite Pore\#5 Dist. H2O(5) & 419.777 & 199.903 & 83.915 & 0.39 & 73.348 & 0.029 & $0.03 \%$ \\
\hline R111-4,3 Composite Drainage Dist. H2O(5) & 419.777 & 199.903 & 83.915 & 0.38 & 73.348 & 0.028 & $0.03 \%$ \\
\hline
\end{tabular}


Cu Removed by Columnar Flooding

\begin{tabular}{|c|c|c|c|c|c|c|c|}
\hline & Cu & Wt. of Soil & Cu in & $\mathrm{Cu}$ & Pore Volume & Cu in & $\% \mathrm{Cu}$ \\
\hline SAMPLE & (mg/kg) & (g) & Soil (mg) & $(\mathrm{mg} / \mathrm{L})$ & $(\mathrm{ml})$ & Sample (mg) & Removed \\
\hline R111-4,3 Composite Composite Dist. H2O(5) & 419.777 & 199.903 & 83.915 & 0.5 & 73.348 & 0.037 & $0.04 \%$ \\
\hline R124 Composite Pore\#1 .05M EDTA(5) & 3259.614 & 342.551 & 1116.583 & 34.52 & 55.770 & 1.925 & $0.17 \%$ \\
\hline R124 Composite Pore\#2 .05M EDTA(5) & 3259.614 & 342.551 & 1116.583 & 36.05 & 55.770 & 2.011 & $0.18 \%$ \\
\hline R124 Composite Pore\#3 .05M EDTA(5) & 3259.614 & 342.551 & 1116.583 & 33.52 & 55.770 & 1.869 & $0.17 \%$ \\
\hline R124 Composite Pore\#4 .05M EDTA(5) & 3259.614 & 342.551 & 1116.583 & 31.14 & 55.770 & 1.737 & $0.16 \%$ \\
\hline R124 Composite Pore\#5 .05M EDTA(5) & 3259.614 & 342.551 & 1116.583 & 25.44 & 55.770 & 1.419 & $0.13 \%$ \\
\hline R124 Composite Pore\#6 .05M EDTA(5) & 3259.614 & 342.551 & 1116.583 & 26.28 & 55.770 & 1.466 & $0.13 \%$ \\
\hline R124 Composite Pore\#7 .05M EDTA(5) & 3259.614 & 342.551 & 1116.583 & 22.34 & 55.770 & 1.246 & $0.11 \%$ \\
\hline R124 Composite Pore\#8 .05M EDTA(5) & 3259.614 & 342.551 & 1116.583 & 22.29 & 55.770 & 1.243 & $0.11 \%$ \\
\hline R124 Composite Drainage .05M EDTA(5) & 3259.614 & 342.551 & 1116.583 & 22.59 & 55.770 & 1.260 & $0.11 \%$ \\
\hline R124 Composite Composite .05M EDTA(5) & 3259.614 & 342.551 & 1116.583 & 27.93 & 55.770 & 1.558 & $0.14 \%$ \\
\hline R124 Composite Pore\#1 Dist. H2O(5) & 3259.614 & 342.551 & 1116.583 & 0.42 & 55.770 & 0.023 & $0.00 \%$ \\
\hline R124 Composite Pore\#2 Dist. H2O(5) & 3259.614 & 342.551 & 1116.583 & 0.36 & 55.770 & 0.020 & $0.00 \%$ \\
\hline R124 Composite Pore\#3 Dist. H2O(5) & 3259.614 & 342.551 & 1116.583 & 0.26 & 55.770 & 0.015 & $0.00 \%$ \\
\hline R124 Composite Pore\#4 Dist. H2O(5) & 3259.614 & 342.551 & 1116.583 & 0.24 & 55.770 & 0.013 & $0.00 \%$ \\
\hline R124 Composite Pore\#5 Dist. H2O(5) & 3259.614 & 342.551 & 1116.583 & 0.18 & 55.770 & 0.010 & $0.00 \%$ \\
\hline R124 CompositeComposite Dist. H20(5) & 3259.614 & 342.551 & 1116.583 & 0.28 & 55.770 & 0.016 & $0.00 \%$ \\
\hline R124 Composite Drainage Dist. H2O(5) & 3259.614 & 342.551 & 1116.583 & 0.28 & 55.770 & 0.016 & $0.00 \%$ \\
\hline R124-2 Composite Pore\#1 .05M CIT(5) & 518.894 & 312.744 & 162.281 & 12.89 & 46.880 & 0.604 & $0.37 \%$ \\
\hline R124-2 Composite Pore\#2 .05M CIT(5) & 518.894 & 312.744 & 162.281 & 19.59 & 46.880 & 0.918 & $0.57 \%$ \\
\hline R124-2 Composite Pore\#3 .05M CIT(5) & 518.894 & 312.744 & 162.281 & 15.21 & 46.880 & 0.713 & $0.44 \%$ \\
\hline R124-2 Composite Pore\#4 .05M CIT(5) & 518.894 & 312.744 & 162.281 & 15.33 & 46.880 & 0.719 & $0.44 \%$ \\
\hline R124-2 Composite Pore\#5 .05M CIT(5) & 518.894 & 312.744 & 162.281 & 16.8 & 46.880 & 0.788 & $0.49 \%$ \\
\hline R124-2 Composite Pore\#6 .05M CIT(5) & 518.894 & 312.744 & 162.281 & 21.06 & 46.880 & 0.987 & $0.61 \%$ \\
\hline R124-2 Composite Pore\#7 .05M CIT(5) & 518.894 & 312.744 & 162.281 & 21.31 & 46.880 & 0.999 & $0.62 \%$ \\
\hline R124-2 Composite Pore \#8 .05M CIT(5) & 518.894 & 312.744 & 162.281 & 19.42 & 46.880 & 0.910 & $0.56 \%$ \\
\hline R124-2 Composite Composite .05M CIT(5) & 518.894 & 312.744 & 162.281 & 16.14 & 46.880 & 0.757 & $0.47 \%$ \\
\hline R124-2 Composite Drainage .05M CIT(5) & 518.894 & 312.744 & 162.281 & 16.97 & 46.880 & 0.796 & $0.49 \%$ \\
\hline R124-2 Composite Pore\#1 Dist. H2O(5) & 518.894 & 312.744 & 162.281 & 1.29 & 46.880 & 0.060 & $0.04 \%$ \\
\hline R124-2 Composite Pore\#2 Dist. H2O(5) & 518.894 & 312.744 & 162.281 & 1.01 & 46.880 & 0.047 & $0.03 \%$ \\
\hline R124-2 Composite Pore\#3 Dist. H2O(5) & 518.894 & 312.744 & 162.281 & 0.5 & 46.880 & 0.023 & $0.01 \%$ \\
\hline R124-2 Composite Pore\#4 Dist. H2O(5) & 518.894 & 312.744 & 162.281 & 0.39 & 46.880 & 0.018 & $0.01 \%$ \\
\hline R124-2 Composite Pore\#5 Dist. H2O(5) & 518.894 & 312.744 & 162.281 & 0.4 & 46.880 & 0.019 & $0.01 \%$ \\
\hline
\end{tabular}




\section{Cu Removed by Columnar Flooding}

\begin{tabular}{|c|c|c|c|c|c|c|c|}
\hline & $\mathrm{Cu}$ & Wt. of Soll & Cu in & $\mathrm{Cu}$ & Pore Volume & Cu in & $\% \mathrm{Cu}$ \\
\hline SAMPLE & $(\mathbf{m g} / \mathbf{k g})$ & (g) & Soil (mg) & $(\mathrm{mg} / \mathrm{L})$ & $(\mathrm{ml})$ & Sample (mg) & Removed \\
\hline R124-2 CompositeComposite Dist. H20(5) & 518.894 & 312.744 & 162.281 & 0.56 & 46.880 & 0.026 & $0.02 \%$ \\
\hline R124-2 Composite Drainage Dist. H20(5) & 518.894 & 312.744 & 162.281 & 0.39 & 46.880 & 0.018 & $0.01 \%$ \\
\hline R124-3 Composite Pore\#1 .05M CIT(5) & 647.430 & 213.391 & 138.155 & 1.65 & 63.700 & 0.105 & $0.08 \%$ \\
\hline R124-3 Composite Pore\#2 .05M CIT(5) & 647.430 & 213.391 & 138.155 & 15.13 & 63.700 & 0.964 & $0.70 \%$ \\
\hline R124-3 Composite Pore\#3 .05M CIT(5) & 647.430 & 213.391 & 138.155 & 24.68 & 63.700 & 1.572 & $1.14 \%$ \\
\hline R124-3 Composite Pore\#4 .05M CIT(5) & 647.430 & 213.391 & 138.155 & 18.89 & 63.700 & 1.203 & $0.87 \%$ \\
\hline R124-3 Composite Pore\#5 .05M CIT(5) & 647.430 & 213.391 & 138.155 & 15.85 & 63.700 & 1.010 & $0.73 \%$ \\
\hline R124-3 Composite Pore\#6 .05M CIT(5) & 647.430 & 213.391 & 138.155 & 15.62 & 63.700 & 0.995 & $0.72 \%$ \\
\hline R124-3 Composite Pore\#7 .05M CIT(5) & 647.430 & 213.391 & 138.155 & 15.12 & 63.700 & 0.963 & $0.70 \%$ \\
\hline R124-3 Composite Pore\#8 .05M CIT(5) & 647.430 & 213.391 & 138.155 & 13.47 & 63.700 & 0.858 & $0.62 \%$ \\
\hline R124-3 Composite Composite .05M CIT(5) & 647.430 & 213.391 & 138.155 & 16.45 & 63.700 & 1.048 & $0.76 \%$ \\
\hline R124-3 Composite Drainage .05M CIT(5) & 647.430 & 213.391 & 138.155 & 12.15 & 63.700 & 0.774 & $0.56 \%$ \\
\hline R124-3 Composite Pore\#1 Dist. H20(5) & 647.430 & 213.391 & 138.155 & 1.19 & 63.750 & 0.076 & $0.05 \%$ \\
\hline R124-3 Composite Pore\#2 Dist. H20(5) & 647.430 & 213.391 & 138.155 & 0.91 & 63.750 & 0.058 & $0.04 \%$ \\
\hline R124-3 Composite Pore\#3 Dist. H20(5) & 647.430 & 213.391 & 138.155 & 0.88 & 63.750 & 0.056 & $0.04 \%$ \\
\hline R124-3 Composite Pore\#4 Dist. H20(5) & 647.430 & 213.391 & 138.155 & 0.79 & 63.750 & 0.050 & $0.04 \%$ \\
\hline R124-3 Composite Pore\#5 Dist. H20(5) & 647.430 & 213.391 & 138.155 & 0.76 & 63.750 & 0.048 & $0.04 \%$ \\
\hline R124-3 CompositeComposite Dist. H2O(5) & 647.430 & 213.391 & 138.155 & 0.84 & 63.750 & 0.054 & $0.04 \%$ \\
\hline R124-3 Composite Drainage Dist. H2O(5) & 647.430 & 213.391 & 138.155 & 0.74 & 63.750 & 0.047 & $0.03 \%$ \\
\hline
\end{tabular}


Fe Removed by Columnar Flooding

\begin{tabular}{|c|c|c|c|c|c|c|c|}
\hline & Fe & Wt. of Soil & $\mathrm{Fe}$ in & $\mathbf{F e}$ & Pore Volume & Fe in & $\% \mathrm{Fe}$ \\
\hline SAMPLE & $(\mathrm{mg} / \mathrm{kg})$ & (g) & Soil (mg) & (mg/L) & $(\mathrm{ml})$ & Sample (mg) & Removed \\
\hline R111-2 Composite Pore\#1 .05M CIT(5) & 16852.850 & 188.124 & 3170.431 & 5.95 & 38.280 & 0.228 & $0.01 \%$ \\
\hline R111-2 Composite Pore\#2 .05M CIT(5) & 16852.850 & 188.124 & 3170.431 & 10.28 & 38.280 & 0.394 & $0.01 \%$ \\
\hline R111-2 Composite Pore\#3 .05M CIT(5) & 16852.850 & 188.124 & 3170.431 & 12.87 & 38.280 & 0.493 & $0.02 \%$ \\
\hline R111-2 Composite Pore\#4 .05M CIT(5) & 16852.850 & 188.124 & 3170.431 & 15.94 & 38.280 & 0.610 & $0.02 \%$ \\
\hline R111-2 Composite Pore\#5 .05M CIT(5) & 16852.850 & 188.124 & 3170.431 & 16.28 & 38.280 & 0.623 & $0.02 \%$ \\
\hline R111-2 Composite Pore\#6 .05M CIT(5) & 16852.850 & 188.124 & 3170.431 & 18.38 & 38.280 & 0.704 & $0.02 \%$ \\
\hline R111-2 Composite Pore\#7 .05M CIT(5) & 16852.850 & 188.124 & 3170.431 & 18.57 & 38.280 & 0.711 & $0.02 \%$ \\
\hline R111-2 Composite Pore\#8 .05M CIT(5) & 16852.850 & 188.124 & 3170.431 & 19.39 & 38.280 & 0.742 & $0.02 \%$ \\
\hline R111-2 Composite Composite .05M CIT(5) & 16852.850 & 188.124 & 3170.431 & 17.69 & 38.280 & 0.677 & $0.02 \%$ \\
\hline R111-2 Composite Drainage $.05 \mathrm{M} \mathrm{CIT(5)}$ & 16852.850 & 188.124 & 3170.431 & 41.11 & 38.280 & 1.574 & $0.05 \%$ \\
\hline R111-2 Composite Pore\#1 Dist. H2O(5) & 16852.850 & 188.124 & 3170.431 & 6.97 & 38.280 & 0.267 & $0.01 \%$ \\
\hline R111-2 Composite Pore\#2 Dist. H2O(5) & 16852.850 & 188.124 & 3170.431 & 7.64 & 38.280 & 0.292 & $0.01 \%$ \\
\hline R111-2 Composite Pore\#3 Dist. H20(5) & 16852.850 & 188.124 & 3170.431 & 11.14 & 38.280 & 0.426 & $0.01 \%$ \\
\hline R111-2 Composite Pore\#4 Dist. H20(5) & 16852.850 & 188.124 & 3170.431 & 14.62 & 38.280 & 0.560 & $0.02 \%$ \\
\hline R111-2 Composite Pore\#5 Dist. H20(5) & 16852.850 & 188.124 & 3170.431 & 13.57 & 38.280 & 0.519 & $0.02 \%$ \\
\hline R111-2 Composite Drainage Dist. $\mathrm{H} 20(5)$ & 16852.850 & 188.124 & 3170.431 & 9.45 & 38.280 & 0.362 & $0.01 \%$ \\
\hline R111-2 Composite Composite Dist. $\mathrm{H} 2 \mathrm{O}(5)$ & 16852.850 & 188.124 & 3170.431 & 10.97 & 38.280 & 0.420 & $0.01 \%$ \\
\hline R111-3 Composite Pore\#1 .05M CIT(5) & 20954.455 & 310.567 & 6507.754 & 1.87 & 87.720 & 0.164 & $0.00 \%$ \\
\hline R111-3 Composite Pore\#2 .05M CIT(5) & 20954.455 & 310.567 & 6507.754 & 7.64 & 87.720 & 0.670 & $0.01 \%$ \\
\hline R111-3 Composite Pore\#3 .05M CIT(5) & 20954.455 & 310.567 & 6507.754 & 18.52 & 87.720 & 1.625 & $0.02 \%$ \\
\hline R111-3 Composite Pore\#4 .05M CIT(5) & 20954.455 & 310.567 & 6507.754 & 18.9 & 87.720 & 1.658 & $0.03 \%$ \\
\hline R111-3 Composite Pore\#5 .05M CIT(5) & 20954.455 & 310.567 & 6507.754 & 31.48 & 87.720 & 2.761 & $0.04 \%$ \\
\hline R111-3 Composite Pore\#6 .05M CIT(5) & 20954.455 & 310.567 & 6507.754 & 31.52 & 87.720 & 2.765 & $0.04 \%$ \\
\hline R111-3 Composite Pore\#7 .05M CIT(5) & 20954.455 & 310.567 & 6507.754 & 41.19 & 87.720 & 3.613 & $0.06 \%$ \\
\hline R111-3 Composite Drainage $.05 \mathrm{M} \mathrm{CIT(5)}$ & 20954.455 & 310.567 & 6507.754 & 46.23 & 87.720 & 4.055 & $0.06 \%$ \\
\hline R111-3 Composite Composite .05M CIT(5) & 20954.455 & 310.567 & 6507.754 & 30.19 & 87.720 & 2.648 & $0.04 \%$ \\
\hline R111-3 Composite Pore\#1 Dist. H2O(5) & 20954.455 & 310.567 & 6507.754 & 1.13 & 87.840 & 0.099 & $0.00 \%$ \\
\hline R111-3 Composite Pore\#2 Dist. H2O(5) & 20954.455 & 310.567 & 6507.754 & 1.17 & 87.840 & 0.103 & $0.00 \%$ \\
\hline R111-3 Composite Pore\#3 Dist. H2O(5) & 20954.455 & 310.567 & 6507.754 & 1.5 & 87.840 & 0.132 & $0.00 \%$ \\
\hline R111-3 Composite Pore\#4 Dist. H2O(5) & 20954.455 & 310.567 & 6507.754 & 3.22 & 87.840 & 0.283 & $0.00 \%$ \\
\hline R111-3 Composite Pore\#5 Dist. H2O(5) & 20954.455 & 310.567 & 6507.754 & 0.78 & 87.840 & 0.069 & $0.00 \%$ \\
\hline R111-3 Composite Drainage Dist. H2O(5) & 20954.455 & 310.567 & 6507.754 & 0.58 & 87.840 & 0.051 & $0.00 \%$ \\
\hline R111-3 Composite Composite Dist. $\mathrm{H} 2 \mathrm{O}(5)$ & 20954.455 & 310.567 & 6507.754 & 1.32 & 87.840 & 0.116 & $0.00 \%$ \\
\hline
\end{tabular}


Fe Removed by Columnar Flooding

\begin{tabular}{|c|c|c|c|c|c|c|c|}
\hline & $\mathrm{Fe}$ & Wt. of Soil & Fe in & $\mathrm{Fe}$ & Pore Volume & Fe in & $\% \mathrm{Fe}$ \\
\hline SAMPLE & $(\mathrm{mg} / \mathrm{kg})$ & (g) & Soil (mg) & $(\mathrm{mg} / \mathrm{L})$ & (ml) & Sample (mg) & Removed \\
\hline R111-4 Composite Pore\#1 .05M CIT(5) & 17551.639 & 206.100 & 3617.393 & 5.69 & 53.550 & 0.305 & $0.01 \%$ \\
\hline R111-4 Composite Pore\#2 .05M CIT(5) & 17551.639 & 206.100 & 3617.393 & 11.23 & 53.550 & 0.601 & $0.02 \%$ \\
\hline R111-4 Composite Pore\#3 .05M CIT(5) & 17551.639 & 206.100 & 3617.393 & 15.43 & 53.550 & 0.826 & $0.02 \%$ \\
\hline R111-4 Composite Pore\#4 .05M CIT(5) & 17551.639 & 206.100 & 3617.393 & 16.64 & 53.550 & 0.891 & $0.02 \%$ \\
\hline R111-4 Composite Pore\#5 .05M CIT(5) & 17551.639 & 206.100 & 3617.393 & 17.51 & 53.550 & 0.938 & $0.03 \%$ \\
\hline R111-4 Composite Pore\#6 .05M CIT(5) & 17551.639 & 206.100 & 3617.393 & 17.39 & 53.550 & 0.931 & $0.03 \%$ \\
\hline R111-4 Composite Pore\#7 .05M CIT(5) & 17551.639 & 206.100 & 3617.393 & 17.45 & 53.550 & 0.934 & $0.03 \%$ \\
\hline R111-4 Composite Pore\#8 .05M CIT(5) & 17551.639 & 206.100 & 3617.393 & 18.14 & 53.550 & 0.971 & $0.03 \%$ \\
\hline R111-4 Composite Drainage .05M CIT(5) & 17551.639 & 206.100 & 3617.393 & 16.76 & 53.550 & 0.897 & $0.02 \%$ \\
\hline R111-4 Composite Composite .05M CIT(5) & 17551.639 & 206.100 & 3617.393 & 16.31 & 53.550 & 0.873 & $0.02 \%$ \\
\hline R111-4 Composite Pore\#1 Dist. $\mathrm{H} 2 \mathrm{O}(5)$ & 17551.639 & 206.100 & 3617.393 & 2.13 & 53.770 & 0.115 & $0.00 \%$ \\
\hline R111-4 Composite Pore\#2 Dist. H2O(5) & 17551.639 & 206.100 & 3617.393 & 1.91 & 53.770 & 0.103 & $0.00 \%$ \\
\hline R111-4 Composite Pore\#3 Dist. H2O(5) & 17551.639 & 206.100 & 3617.393 & 1.21 & 53.770 & 0.065 & $0.00 \%$ \\
\hline R111-4 Composite Pore\#4 Dist. $\mathrm{H} 2 \mathrm{O}(5)$ & 17551.639 & 206.100 & 3617.393 & 0.87 & 53.770 & 0.047 & $0.00 \%$ \\
\hline R111-4 Composite Pore\#5 Dist. H2O(5) & 17551.639 & 206.100 & 3617.393 & 0.58 & 53.770 & 0.031 & $0.00 \%$ \\
\hline R111-4 Composite Drainage Dist. H2O(5) & 17551.639 & 206.100 & 3617.393 & 0.5 & 53.770 & 0.027 & $0.00 \%$ \\
\hline R111-4 Composite Composite Dist. H2O(5) & 17551.639 & 206.100 & 3617.393 & 0.76 & 53.770 & 0.041 & $0.00 \%$ \\
\hline R111-4,3 Composite Pore\#1 .05M CIT(5) & 13675.318 & 199.903 & 2733.739 & 6.34 & 73.348 & 0.465 & $0.02 \%$ \\
\hline R111-4,3 Composite Pore\#2 .05M CIT(5) & 13675.318 & 199.903 & 2733.739 & 15.16 & 73.348 & 1.112 & $0.04 \%$ \\
\hline R111-4,3 Composite Pore\#3 .05M CIT(5) & 13675.318 & 199.903 & 2733.739 & 18.83 & 73.348 & 1.381 & $0.05 \%$ \\
\hline R111-4,3 Composite Pore\#4 .05M CIT(5) & 13675.318 & 199.903 & 2733.739 & 18.16 & 73.348 & 1.332 & $0.05 \%$ \\
\hline R111-4,3 Composite Pore\#5 .05M CIT(5) & 13675.318 & 199.903 & 2733.739 & 19.67 & 73.348 & 1.443 & $0.05 \%$ \\
\hline R111-4,3 Composite Pore\#6 .05M CIT(5) & 13675.318 & 199.903 & 2733.739 & 30.14 & 73.348 & 2.211 & $0.08 \%$ \\
\hline R111-4,3 Composite Pore\#7 .05M CIT(5) & 13675.318 & 199.903 & 2733.739 & 35.67 & 73.348 & 2.616 & $0.10 \%$ \\
\hline R111-4,3 Composite Pore $\# 8$.05M CIT(5) & 13675.318 & 199.903 & 2733.739 & 43.13 & 73.348 & 3.163 & $0.12 \%$ \\
\hline R111-4,3 Composite Drainage $.05 \mathrm{M}$ CIT(5) & 13675.318 & 199.903 & 2733.739 & 46.48 & 73.348 & 09 & $0.12 \%$ \\
\hline R111-4,3 Composite Composite .05M CIT(5) & 13675.318 & 199.903 & 2733.739 & 18.5 & 73.348 & 1.357 & $0.05 \%$ \\
\hline R111-4,3 Composite Pore\#1 Dist. H2O(5) & 13675.318 & 199.903 & 2733.739 & 3.64 & 73.348 & 0.267 & $0.01 \%$ \\
\hline R111-4,3 Composite Pore\#2 Dist. H20(5) & 13675.318 & 199.903 & 2733.739 & 1.8 & 73.348 & 0.132 & $0.00 \%$ \\
\hline R111-4,3 Composite Pore\#3 Dist. H20(5) & 13675.318 & 199.903 & 2733.739 & 1.25 & 73.348 & 0.092 & $0.00 \%$ \\
\hline R111-4,3 Composite Pore\#4 Dist. H20(5) & 13675.318 & 199.903 & 2733.739 & 0.77 & 73.348 & 0.056 & $0.00 \%$ \\
\hline R111-4,3 Composite Pore\#5 Dist. H20(5) & 13675.318 & 199.903 & 2733.739 & 0.54 & 73.348 & 0.040 & $0.00 \%$ \\
\hline R111-4,3 Composite Drainage Dist. H2O(5) & 13675.318 & 199.903 & 2733.739 & 1.12 & 73.348 & 0.082 & $0.00 \%$ \\
\hline
\end{tabular}


Fe Removed by Columnar Flooding

\begin{tabular}{|c|c|c|c|c|c|c|c|}
\hline & Fe & Wt. of Soil & Fe in & $\mathrm{Fe}$ & Pore Volume & Fe in & $\% \mathrm{Fe}$ \\
\hline SAMPLE & $(\mathrm{mg} / \mathrm{kg})$ & (g) & Soil (mg) & (mg/L) & $(\mathrm{ml})$ & Sample (mg) & Removed \\
\hline R111-4,3 Composite Composite Dist. H2O(5) & 13675.318 & 199.903 & 2733.739 & 1.35 & 73.348 & 0.099 & $0.00 \%$ \\
\hline R124 Composite Pore\#1 .05M EDTA(5) & 5052.111 & 342.551 & 1730.604 & 16.85 & 55.770 & 0.940 & $0.05 \%$ \\
\hline R124 Composite Pore\#2 .05M EDTA(5) & 5052.111 & 342.551 & 1730.604 & 17.72 & 55.770 & 0.988 & $0.06 \%$ \\
\hline R124 Composite Pore\#3 .05M EDTA(5) & 5052.111 & 342.551 & 1730.604 & 16.41 & 55.770 & 0.915 & $0.05 \%$ \\
\hline R124 Composite Pore\#4 .05M EDTA(5) & 5052.111 & 342.551 & 1730.604 & 14.98 & 55.770 & 0.835 & $0.05 \%$ \\
\hline R124 Composite Pore\#5 .05M EDTA(5) & 5052.111 & 342.551 & 1730.604 & 15.47 & 55.770 & 0.863 & $0.05 \%$ \\
\hline R124 Composite Pore\#6 .05M EDTA(5) & 5052.111 & 342.551 & 1730.604 & 15.51 & 55.770 & 0.865 & $0.05 \%$ \\
\hline R124 Composite Pore\#7 .05M EDTA(5) & 5052.111 & 342.551 & 1730.604 & 14.8 & 55.770 & 0.825 & $0.05 \%$ \\
\hline R124 Composite Pore\#8 .05M EDTA(5) & 5052.111 & 342.551 & 1730.604 & 14.35 & 55.770 & 0.800 & $0.05 \%$ \\
\hline R124 Composite Drainage .05M EDTA(5) & 5052.111 & 342.551 & 1730.604 & 14.48 & 55.770 & 0.808 & $0.05 \%$ \\
\hline R124 Composite Composite .05M EDTA(5) & 5052.111 & 342.551 & 1730.604 & 14.95 & 55.770 & 0.834 & $0.05 \%$ \\
\hline R124 Composite Pore\#1 Dist. H2O(5) & 5052.111 & 342.551 & 1730.604 & 1.31 & 55.770 & 0.073 & $0.00 \%$ \\
\hline R124 Composite Pore\#2 Dist. H2O(5) & 5052.111 & 342.551 & 1730.604 & 1.56 & 55.770 & 0.087 & $0.01 \%$ \\
\hline R124 Composite Pore\#3 Dist. H2O(5) & 5052.111 & 342.551 & 1730.604 & 1.64 & 55.770 & 0.091 & $0.01 \%$ \\
\hline R124 Composite Pore\#4 Dist. H2O(5) & 5052.111 & 342.551 & 1730.604 & 1.31 & 55.770 & 0.073 & $0.00 \%$ \\
\hline R124 Composite Pore\#5 Dist. H2O(5) & 5052.111 & 342.551 & 1730.604 & 1.11 & 55.770 & 0.062 & $0.00 \%$ \\
\hline R124 CompositeComposite Dist. H20(5) & 5052.111 & 342.551 & 1730.604 & 1.12 & 55.770 & 0.062 & $0.00 \%$ \\
\hline R124 Composite Drainage Dist. H20(5) & 5052.111 & 342.551 & 1730.604 & 1.36 & 55.770 & 0.076 & $0.00 \%$ \\
\hline R124-2 Composite Pore\#1 .05M CIT(5) & 4225.295 & 312.744 & 1321.437 & 11.52 & 46.880 & 0.540 & $0.04 \%$ \\
\hline R124-2 Composite Pore\#2 .05M CIT(5) & 4225.295 & 312.744 & 1321.437 & 13 & 46.880 & 0.609 & $0.05 \%$ \\
\hline R124-2 Composite Pore\#3 .05M CIT(5) & 4225.295 & 312.744 & 1321.437 & 13.93 & 46.880 & 0.653 & $0.05 \%$ \\
\hline R124-2 Composite Pore\#4 .05M CIT(5) & 4225.295 & 312.744 & 1321.437 & 14.78 & 46.880 & 0.693 & $0.05 \%$ \\
\hline R124-2 Composite Pore\#5 .05M CIT(5) & 4225.295 & 312.744 & 1321.437 & 13.76 & 46.880 & 0.645 & $0.05 \%$ \\
\hline R124-2 Composite Pore\#6 .05M CIT(5) & 4225.295 & 312.744 & 1321.437 & 13.98 & 46.880 & 0.655 & $0.05 \%$ \\
\hline R124-2 Composite Pore\#7 .05M CIT(5) & 4225.295 & 312.744 & 1321.437 & 15.28 & 46.880 & 0.716 & $0.05 \%$ \\
\hline R124-2 Composite Pore\#8 .05M CIT(5) & 4225.295 & 312.744 & 1321.437 & 17.32 & 46.880 & 0.812 & $0.06 \%$ \\
\hline R124-2 Composite Composite .05M CIT(5) & 4225.295 & 312.744 & 1321.437 & 14.62 & 46.880 & 0.685 & $0.05 \%$ \\
\hline R124-2 Composite Drainage .05M CIT(5) & 4225.295 & 312.744 & 1321.437 & 17.46 & 46.880 & 0.819 & $0.06 \%$ \\
\hline R124-2 Composite Pore\#1 Dist. $\mathrm{H} 20(5)$ & 4225.295 & 312.744 & 1321.437 & 7.83 & 46.880 & 0.367 & $0.03 \%$ \\
\hline R124-2 Composite Pore\#2 Dist. H20(5) & 4225.295 & 312.744 & 1321.437 & 5.88 & 46.880 & 0.276 & $0.02 \%$ \\
\hline R124-2 Composite Pore\#3 Dist. H20(5) & 4225.295 & 312.744 & 1321.437 & 3.14 & 46.880 & 0.147 & $0.01 \%$ \\
\hline R124-2 Composite Pore\#4 Dist. H2O(5) & 4225.295 & 312.744 & 1321.437 & 2.87 & 46.880 & 0.135 & $0.01 \%$ \\
\hline R124-2 Composite Pore\#5 Dist. $\mathrm{H} 20(5)$ & 4225.295 & 312.744 & 1321.437 & 4.28 & 46.880 & 0.201 & $0.02 \%$ \\
\hline
\end{tabular}


Fe Removed by Columnar Flooding

\begin{tabular}{|c|c|c|c|c|c|c|c|}
\hline & Fe & Wt. of Soil & $\mathrm{Fe}$ in & $\mathrm{Fe}$ & Pore Volume & Fe in & $\% \mathrm{Fe}$ \\
\hline SAMPLE & $(\mathrm{mg} / \mathrm{kg})$ & (g) & Soll (mg) & $(\mathrm{mg} / \mathrm{L})$ & $(\mathrm{ml})$ & Sample (mg) & Removed \\
\hline R124-2 CompositeComposite Dist. H20(5) & 4225.295 & 312.744 & 1321.437 & 4.2 & 46.880 & 0.197 & $0.01 \%$ \\
\hline R124-2 Composite Drainage Dist. H2O(5) & 4225.295 & 312.744 & 1321.437 & 3.51 & 46.880 & 0.165 & $0.01 \%$ \\
\hline R124-3 Composite Pore\#1 .05M CIT(5) & 3886.913 & 213.391 & 829.431 & 0.75 & 63.700 & 0.048 & $0.01 \%$ \\
\hline R124-3 Composite Pore\#2 .05M CIT(5) & 3886.913 & 213.391 & 829.431 & 3.68 & 63.700 & 0.234 & $0.03 \%$ \\
\hline R124-3 Composite Pore\#3 .05M CIT(5) & 3886.913 & 213.391 & 829.431 & 6.79 & 63.700 & 0.433 & $0.05 \%$ \\
\hline R124-3 Composite Pore\#4 .05M CIT(5) & 3886.913 & 213.391 & 829.431 & 6.67 & 63.700 & 0.425 & $0.05 \%$ \\
\hline R124-3 Composite Pore\#5 .05M CIT(5) & 3886.913 & 213.391 & 829.431 & 6.43 & 63.700 & 0.410 & $0.05 \%$ \\
\hline R124-3 Composite Pore\#6 .05M CIT(5) & 3886.913 & 213.391 & 829.431 & 6.35 & 63.700 & 0.404 & $0.05 \%$ \\
\hline R124-3 Composite Pore\#7 .05M CIT(5) & 3886.913 & 213.391 & 829.431 & 6.21 & 63.700 & 0.396 & $0.05 \%$ \\
\hline R124-3 Composite Pore\#8 .05M CIT(5) & 3886.913 & 213.391 & 829.431 & 6.11 & 63.700 & 0.389 & $0.05 \%$ \\
\hline R124-3 Composite Composite .05M CIT(5) & 3886.913 & 213.391 & 829.431 & 5.81 & 63.700 & 0.370 & $0.04 \%$ \\
\hline R124-3 Composite Drainage .05M CIT(5) & 3886.913 & 213.391 & 829.431 & 6.87 & 63.700 & 0.438 & $0.05 \%$ \\
\hline R124-3 Composite Pore\#1 Dist. H2O(5) & 3886.913 & 213.391 & 829.431 & 0.66 & 63.750 & 0.042 & $0.01 \%$ \\
\hline R124-3 Composite Pore\#2 Dist. H2O(5) & 3886.913 & 213.391 & 829.431 & 0.5 & 63.750 & 0.032 & $0.00 \%$ \\
\hline R124-3 Composite Pore\#3 Dist. H20(5) & 3886.913 & 213.391 & 829.431 & 0.63 & 63.750 & 0.040 & $0.00 \%$ \\
\hline R124-3 Composite Pore\#4 Dist. H20(5) & 3886.913 & 213.391 & 829.431 & 0.5 & 63.750 & 0.032 & $0.00 \%$ \\
\hline R124-3 Composite Pore\#5 Dist. H2O(5) & 3886.913 & 213.391 & 829.431 & 0.5 & 63.750 & 0.032 & $0.00 \%$ \\
\hline R124-3 CompositeComposite Dist. H20(5) & 3886.913 & 213.391 & 829.431 & 0.5 & 63.750 & 0.032 & $0.00 \%$ \\
\hline R124-3 Composite Drainage Dist. H2O(5) & 3886.913 & 213.391 & 829.431 & 0.52 & 63.750 & 0.033 & $0.00 \%$ \\
\hline
\end{tabular}


Pb Removed by Columnar Flooding

\begin{tabular}{|c|c|c|c|c|c|c|c|}
\hline & $\overline{\mathrm{Pb}}$ & Wt. of Soil & $\mathrm{Pb}$ in & $\mathbf{P b}$ & Pore Volume & $\mathrm{Pb}$ in & $\% \mathbf{P b}$ \\
\hline SAMPLE & $(\mathrm{mg} / \mathrm{kg})$ & (g) & Soil (mg) & $(\mathrm{mg} / \mathrm{L})$ & $(\mathrm{ml})$ & Sample (mg) & Removed \\
\hline Dist. $\mathrm{H} 2 \mathrm{O}$ Pore \#1 Aberdeen 5000ppm $\mathrm{Pb}(\mathrm{NO} 3) 2$ & 5000 & 503.699 & 2518.496 & 0.91 & 113.400 & 3 & $0.00 \%$ \\
\hline Dist. H2O Pore \#2 Aberdeen 5000ppm Pb(NO3)2 & 5000 & 503.699 & 2518.496 & 4.83 & 113.400 & 0.548 & $0.02 \%$ \\
\hline Dist. $\mathrm{H} 2 \mathrm{O}$ Pore \#3 Aberdeen 5000ppm $\mathrm{Pb}(\mathrm{NO} 3) 2$ & 5000 & 503.699 & 2518.496 & 1.22 & 113.400 & .138 & $0.01 \%$ \\
\hline Dist. $\mathrm{H} 2 \mathrm{O}$ Pore $\# 4$ Aberdeen 5000ppm $\mathrm{Pb}(\mathrm{NO} 3) 2$ & 5000 & 503.699 & 2518.496 & 3.66 & 113.400 & 415 & $0.02 \%$ \\
\hline Dist. $\mathrm{H} 2 \mathrm{O}$ Pore \#5 Aberdeen 5000ppm $\mathrm{Pb}(\mathrm{NO} 3) 2$ & 5000 & 503.699 & 2518.496 & 5.52 & 113.400 & 0.626 & $0.02 \%$ \\
\hline Dist. $\mathrm{H} 2 \mathrm{O}$ Drainage Aberdeen $5000 \mathrm{ppm} \mathrm{Pb}(\mathrm{NO} 3) 2$ & 5000 & 503.699 & 2518.496 & 0.91 & 113.400 & 0.103 & $0.00 \%$ \\
\hline Dist. $\mathrm{H} 2 \mathrm{O}$ Composite Aberdeen 5000ppm $\mathrm{Pb}(\mathrm{NO} 3) 2$ & 5000 & 503.699 & 2518.496 & 3.05 & 113.400 & 0.346 & $0.01 \%$ \\
\hline .01 EDTA Pore \#1 Aberdeen 5000ppm Pb(NO3)2 & 5000 & 503.699 & 2518.496 & 19.91 & 113.400 & 2.258 & $0.09 \%$ \\
\hline .01 EDTA Pore \#2 Aberdeen 5000ppm Pb(NO3)2 & 5000 & 503.699 & 2518.496 & 166.94 & 113.400 & 18.931 & $0.75 \%$ \\
\hline .01 EDTA Pore \#3 Aberdeen 5000ppm Pb(NO3)2 & 5000 & 503.699 & 2518.496 & 144.47 & 113.400 & 16.383 & $0.65 \%$ \\
\hline .01 EDTA Pore \#4 Aberdeen 5000ppm Pb(NO3)2 & 5000 & 503.699 & 2518.496 & 106.50 & 113.400 & 12.077 & $0.48 \%$ \\
\hline .01 EDTA Pore \#5 Aberdeen 5000ppm Pb(NO3)2 & 5000 & 503.699 & 2518.496 & 83.33 & 113.400 & 9.450 & $0.38 \%$ \\
\hline .01 EDTA Pore \#6 Aberdeen 5000ppm Pb(NO3)2 & 5000 & 503.699 & 2518.496 & 59.73 & 113.400 & 6.773 & $0.27 \%$ \\
\hline .01 EDTA Pore \#7 Aberdeen 5000ppm $\mathrm{Pb}(\mathrm{NO} 3) 2$ & 5000 & 503.699 & 2518.496 & 63.93 & 113.400 & 7.250 & $0.29 \%$ \\
\hline .01 EDTA Pore \#8 Aberdeen 5000ppm $\mathrm{Pb}(\mathrm{NO} 3) 2$ & 5000 & 503.699 & 2518.496 & 59.86 & 113.400 & 6.788 & $0.27 \%$ \\
\hline .01 EDTA Drainage Aberdeen 5000ppm $\mathrm{Pb}(\mathrm{NO} 3) 2$ & 5000 & 503.699 & 2518.496 & 17.87 & 113.400 & 2.026 & $0.08 \%$ \\
\hline .01 EDTA Composite Aberdeen 5000ppm Pb(NO3)2 & 5000 & 503.699 & 2518.496 & 116.30 & 113.400 & 13.188 & $0.52 \%$ \\
\hline Dist. $\mathrm{H} 2 \mathrm{O}$ Pore \#1 FT. MEAD 5000ppm Pb(NO3)2. & 5000 & 453.897 & 2269.485 & 0.50 & 106.640 & 53 & $0.00 \%$ \\
\hline Dist. $\mathrm{H} 2 \mathrm{O}$ Pore \#2 FT. MEAD 5000ppm $\mathrm{Pb}(\mathrm{NO} 3) 2$ & 5000 & 453.897 & 2269.485 & 0.50 & 106.640 & 53 & $0.00 \%$ \\
\hline Dist. H2O Pore \#3 FT. MEAD 5000ppm Pb(NO3)2 & 5000 & 453.897 & 2269.485 & 0.50 & 106.640 & .053 & $0.00 \%$ \\
\hline Dist. H2O Pore \#4 FT. MEAD 5000ppm Pb(NO3)2 & 5000 & 453.897 & 2269.485 & 0.50 & 106.640 & 0.053 & $0.00 \%$ \\
\hline Dist. H2O Pore \#5 FT. MEAD 5000ppm Pb(NO3)2 & 5000 & 453.897 & 2269.485 & 0.50 & 106.640 & 0.053 & $0 \%$ \\
\hline Dist. H2O Drainage FT. MEAD 5000ppm Pb(NO3)2 & 5000 & 453.897 & 2269.485 & 2.13 & 106.640 & 0.227 & $1 \%$ \\
\hline Dist. $\mathrm{H} 2 \mathrm{O}$ Composite FT. MEAD 5000ppm $\mathrm{Pb}(\mathrm{NO} 3) 2$ & 5000 & 453.897 & 2269.485 & 0.91 & 106.640 & 0.097 & $0 \%$ \\
\hline .01 EDTA Pore \#1 FT. MEAD 5000ppm Pb(NO3)2 & 5000 & 453.897 & 2269.485 & 121.22 & 106 & 12.927 & $0.57 \%$ \\
\hline .01 EDTA Pore \#2 FT. MEAD 5000ppm Pb(NO3)2 & 5000 & 45 & 2269.485 & 538.57 & 10 & 433 & $3 \%$ \\
\hline .01 EDTA Pore \#3 FT. MEAD 5000ppm Pb(NO3)2 & 5000 & 453.897 & 2269.485 & 829.15 & 10 & 88.421 & $3.90 \%$ \\
\hline .01 EDTA Pore \#4 FT. MEAD 5000ppm Pb(NO3)2 & 5000 & 453.897 & 2269.485 & 72.74 & 106.640 & 7.757 & $0.34 \%$ \\
\hline .01 EDTA Pore \#5 FT. MEAD 5000ppm Pb(NO3)2 & 5000 & 453.897 & 2269.485 & 431.40 & 106.640 & 46.004 & $2.03 \%$ \\
\hline .01 EDTA Pore \#6 FT. MEAD 5000ppm Pb(NO3)2 & 5000 & 453.897 & 2269.485 & 325.92 & 106.640 & 34.756 & $1.53 \%$ \\
\hline .01 EDTA Pore \#7 FT. MEAD 5000ppm Pb(NO3)2 & 5000 & 453.897 & 2269.485 & 27.53 & 106.640 & 2.936 & $0.13 \%$ \\
\hline .01 EDTA Pore \#8 FT. MEAD 5000ppm Pb(NO3)2 & 5000 & 453.897 & 2269.485 & 222.48 & 106.640 & 23.725 & $1.05 \%$ \\
\hline .01 EDTA Drainage FT. MEAD 5000ppm Pb(NO3)2 & 5000 & 453.897 & 2269.485 & 188.72 & 106.640 & 20.125 & $0.89 \%$ \\
\hline
\end{tabular}


Pb Removed by Columnar Flooding

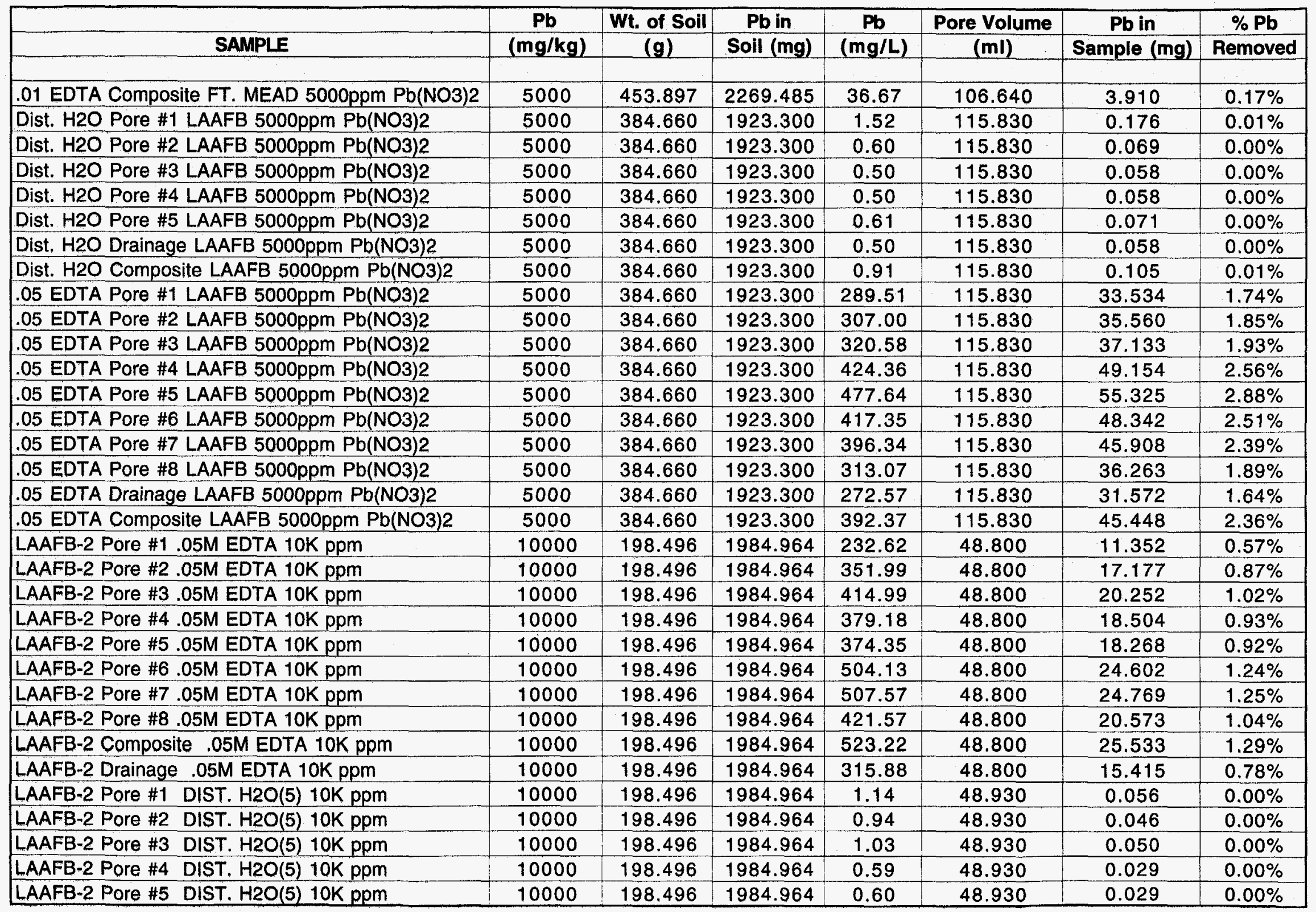


Pb Removed by Columnar Flooding

\begin{tabular}{|c|c|c|c|c|c|c|c|}
\hline & $\mathbf{P b}$ & Wt. of Soil & $\mathrm{Pb}$ in & $\mathbf{P b}$ & Pore Volume & $\mathbf{P b}$ in & $\% \mathbf{P b}$ \\
\hline SAMPLE & $(\mathrm{mg} / \mathrm{kg})$ & (g) & Soil (mg) & $(\mathrm{mg} / \mathrm{L})$ & $(\mathrm{ml})$ & Sample (mg) & Removed \\
\hline LAAFB-2 Composite DIST. H20(5) 10K ppm & 10000 & 198.496 & 1984.964 & 0.67 & 48.930 & 0.033 & $0.00 \%$ \\
\hline LAAFB-2 Drainage DIST. H2O(5) $10 \mathrm{~K}$ ppm & 10000 & 198.496 & 1984.964 & 0.58 & 48.930 & 0.028 & $0.00 \%$ \\
\hline LAAFB-3 Pore \#1 .05M CIT(5) $10 \mathrm{~K} \mathrm{ppm}$ & 10000 & 198.537 & 1985.371 & 137.12 & 52.270 & 7.167 & $0.36 \%$ \\
\hline LAAFB-3 Pore \#2 .05M CIT(5) $10 \mathrm{~K} \mathrm{ppm}$ & 10000 & 198.537 & 1985.371 & 225.26 & 52.270 & 11.774 & $0.59 \%$ \\
\hline LAAFB-3 Pore \#3 .05M CIT(5) $10 \mathrm{~K} \mathrm{ppm}$ & 10000 & 198.537 & 1985.371 & 268.41 & 52.270 & 14.030 & $0.71 \%$ \\
\hline LAAFB-3 Pore \#4 .05M CIT(5) $10 \mathrm{~K} \mathrm{ppm}$ & 10000 & 198.537 & 1985.371 & 366.33 & 52.270 & 19.148 & $0.96 \%$ \\
\hline LAAFB-3 Pore $\# 5.05 \mathrm{M} \mathrm{CIT}(5)$ 10K ppm & 10000 & 198.537 & 1985.371 & 308.12 & 52.270 & 16.105 & $0.81 \%$ \\
\hline LAAFB-3 Pore \#6 .05M CIT(5) $10 \mathrm{~K}$ ppm & 10000 & 198.537 & 1985.371 & 269.92 & 52.270 & 14.109 & $0.71 \%$ \\
\hline LAAFB-3 Pore $\# 7.05 \mathrm{M}$ CIT(5) $10 \mathrm{~K} \mathrm{ppm}$ & 10000 & 198.537 & 1985.371 & 212.12 & 52.270 & 11.088 & $0.56 \%$ \\
\hline LAAFB-3 Pore \#8 .05M CIT(5) $10 \mathrm{~K} \mathrm{ppm}$ & 10000 & 198.537 & 1985.371 & 206.32 & 52.270 & 10.784 & $0.54 \%$ \\
\hline LAAFB-3 Composite $.05 \mathrm{M}$ CIT(5) $10 \mathrm{~K}$ ppm & 10000 & 198.537 & 1985.371 & 188.93 & 52.270 & 9.875 & $0.50 \%$ \\
\hline LAAFB-3 Drainage $.05 \mathrm{M} \mathrm{ClT(5)} 10 \mathrm{~K}$ ppm & 10000 & 198.537 & 1985.371 & 145.40 & 52.270 & 7.600 & $0.38 \%$ \\
\hline LAAFB-3 Pore \#1 DIST. H2O(5) $10 \mathrm{~K}$ ppm & 10000 & 198.537 & 1985.371 & 3.67 & 52.270 & 0.192 & $0.01 \%$ \\
\hline LAAFB-3 Pore \#2 DIST. H2O(5) 10K ppm & 10000 & 198.537 & 1985.371 & 2.74 & 52.270 & 0.143 & $0.01 \%$ \\
\hline LAAFB-3 Pore \#3 DIST. H2O(5) $10 \mathrm{~K}$ ppm & 10000 & 198.537 & 1985.371 & 2.49 & 52.270 & 0.130 & $0.01 \%$ \\
\hline LAAFB-3 Pore \#4 DIST. H2O(5) $10 \mathrm{~K}$ ppm & 10000 & 198.537 & 1985.371 & 1.67 & 52.270 & 0.087 & $0.00 \%$ \\
\hline LAAFB-3 Pore \#5 DIST. H2O(5) 10K ppm & 10000 & 198.537 & 1985.371 & 1.39 & 52.270 & 0.073 & $0.00 \%$ \\
\hline LAAFB-3 Composite DIST. H20(5) $10 \mathrm{~K}$ ppm & 10000 & 198.537 & 1985.371 & 1.92 & 52.270 & 0.100 & $0.01 \%$ \\
\hline LAAFB-3 Drainage DIST. H20(5) $10 \mathrm{~K}$ ppm & 10000 & 198.537 & 1985.371 & 2.02 & 52.270 & 0.106 & $0.01 \%$ \\
\hline R111 Composite Pore \#1 Dist. H2O & 124.169 & 180.861 & 22.457 & 1.10 & 42.080 & 0.046 & $0.21 \%$ \\
\hline R111 Composite Pore \#2 Dist. $\mathrm{H} 2 \mathrm{O}$ & 124.169 & 180.861 & 22.457 & 1.42 & 42.080 & 0.060 & $0.27 \%$ \\
\hline R111 Composite Pore \#3 Dist. H2O & 124.169 & 180.861 & 22.457 & 0.50 & 42.080 & 0.021 & $0.09 \%$ \\
\hline R111 Composite Pore \#4 Dist. H2O & 124.169 & 180.861 & 22.457 & 0.50 & 42.080 & 0.021 & $0.09 \%$ \\
\hline R111 Composite Pore \#5 Dist. H2O & 124.169 & 180.861 & 22.457 & 0.50 & 42.080 & 0.021 & $0.09 \%$ \\
\hline R111 Composite Drainage Dist. $\mathrm{H} 2 \mathrm{O}$ & 124.169 & 180.861 & 22.457 & 1.41 & 42.080 & 0.059 & $0.26 \%$ \\
\hline R111 Composite Composite Dist. $\mathrm{H} 2 \mathrm{O}$ & 124.169 & 180.861 & 22.457 & 0.78 & 42.080 & 0.033 & $0.15 \%$ \\
\hline R111 Composite Pore \#1 .05M EDTA & 124.169 & 180.861 & 22.457 & 0.63 & 42.080 & 0.027 & $0.12 \%$ \\
\hline R111 Composite Pore \#2 .05M EDTA & 124.169 & 180.861 & 22.457 & 3.28 & 42.080 & 0.138 & $0.61 \%$ \\
\hline R111 Composite Pore \#3 .05M EDTA & 124.169 & 180.861 & 22.457 & 9.94 & 42.080 & 0.418 & $1.86 \%$ \\
\hline R111 Composite Pore \#4 .05M EDTA & 124.169 & 180.861 & 22.457 & 12.79 & 42.080 & 0.538 & $2.40 \%$ \\
\hline R111 Composite Pore \#5 .05M EDTA & 124.169 & 180.861 & 22.457 & 9.94 & 42.080 & 0.418 & $1.86 \%$ \\
\hline R111 Composite Pore \#6 .05M EDTA & 124.169 & 180.861 & 22.457 & 7.11 & 42.080 & 0.299 & $1.33 \%$ \\
\hline R111 Composite Pore \#7 .05M EDTA & 124.169 & 180.861 & 22.457 & 5.55 & 42.080 & 0.234 & $1.04 \%$ \\
\hline
\end{tabular}


$\mathrm{Pb}$ Removed by Columnar Flooding

\begin{tabular}{|c|c|c|c|c|c|c|c|}
\hline & $\mathbf{P b}$ & Wt. of Soil & $\mathrm{Pb}$ in & $\mathbf{P b}$ & Pore Volume & $\mathrm{Pb}$ in & $\% \mathbf{P b}$ \\
\hline SAMPLE & $(\mathbf{m g} / \mathbf{k g})$ & (g) & Soil (mg) & $(\mathrm{mg} / \mathrm{L})$ & $(\mathbf{m l})$ & Sample (mg) & Removed \\
\hline R111 Composite Pore \#8 .05M EDTA & 124.169 & 180.861 & 22.457 & 4.93 & 42.080 & 0.207 & $0.92 \%$ \\
\hline R111 Composite Drainage .05M EDTA & 124.169 & 180.861 & 22.457 & 6.08 & 42.080 & 0.256 & $1.14 \%$ \\
\hline R111 Composite Composite .05M EDTA & 124.169 & 180.861 & 22.457 & 7.59 & 42.080 & 0.319 & $1.42 \%$ \\
\hline R111-2 Composite Pore\#1 .05M CIT(5) & 150.237 & 188.124 & 28.263 & 0.89 & 38.280 & 0.034 & $0.12 \%$ \\
\hline R111-2 Composite Pore\#2 .05M CIT(5) & 150.237 & 188.124 & 28.263 & 1.48 & 38.280 & 0.057 & $0.20 \%$ \\
\hline R111-2 Composite Pore\#3 .05M CIT(5) & 150.237 & 188.124 & 28.263 & 1.07 & 38.280 & 0.041 & $0.14 \%$ \\
\hline R111-2 Composite Pore\#4 .05M CIT(5) & 150.237 & 188.124 & 28.263 & 1.41 & 38.280 & 0.054 & $0.19 \%$ \\
\hline R111-2 Composite Pore\#5 .05M CIT(5) & 150.237 & 188.124 & 28.263 & 1.38 & 38.280 & 0.053 & $0.19 \%$ \\
\hline R111-2 Composite Pore\#6 .05M CIT(5) & 150.237 & 188.124 & 28.263 & 1.67 & 38.280 & 0.064 & $0.23 \%$ \\
\hline R111-2 Composite Pore\#7 .05M CIT(5) & 150.237 & 188.124 & 28.263 & 1.18 & 38.280 & 0.045 & $0.16 \%$ \\
\hline R111-2 Composite Pore \#8 .05M CIT(5) & 150.237 & 188.124 & 28.263 & 1.11 & 38.280 & 0.042 & $0.15 \%$ \\
\hline R111-2 Composite Composite .05M CIT(5) & 150.237 & 188.124 & 28.263 & 1.62 & 38.280 & 0.062 & $0.22 \%$ \\
\hline R111-2 Composite Drainage .05M CIT(5) & 150.237 & 188.124 & 28.263 & 2.81 & 38.280 & 0.108 & $0.38 \%$ \\
\hline R111-2 Composite Pore\#1 Dist. $\mathrm{H} 2 \mathrm{O}(5)$ & 150.237 & 188.124 & 28.263 & 1.15 & 38.280 & 0.044 & $0.16 \%$ \\
\hline R111-2 Composite Pore\#2 Dist. H2O(5) & 150.237 & 188.124 & 28.263 & 0.45 & 38.280 & 0.017 & $0.06 \%$ \\
\hline R111-2 Composite Pore\#3 Dist. H2O(5) & 150.237 & 188.124 & 28.263 & 0.56 & 38.280 & 0.021 & $0.08 \%$ \\
\hline R111-2 Composite Pore\#4 Dist. H2O(5) & 150.237 & 188.124 & 28.263 & 1.11 & 38.280 & 0.042 & $0.15 \%$ \\
\hline R111-2 Composite Pore\#5 Dist. H2O(5) & 150.237 & 188.124 & 28.263 & 0.25 & 38.280 & 0.010 & $0.03 \%$ \\
\hline R111-2 Composite Drainage Dist. H20(5) & 150.237 & 188.124 & 28.263 & 0.25 & 38.280 & 0.010 & $0.03 \%$ \\
\hline R111-2 Composite Composite Dist. H20(5) & 150.237 & 188.124 & 28.263 & 0.33 & 38.280 & 0.013 & $0.04 \%$ \\
\hline R111-3 Composite Pore\#1 .05M CIT(5) & 74.351 & 310.567 & 23.091 & 0.67 & 87.720 & 0.059 & $0.25 \%$ \\
\hline R111-3 Composite Pore\#2 .05M CIT(5) & 74.351 & 310.567 & 23.091 & 0.25 & 87.720 & 0.022 & $0.09 \%$ \\
\hline R111-3 Composite Pore\#3 .05M CIT(5) & 74.351 & 310.567 & 23.091 & 0.56 & 87.720 & 0.049 & $0.21 \%$ \\
\hline R111-3 Composite Pore\#4 .05M CIT(5) & 74.351 & 310.567 & 23.091 & 1.02 & 87.720 & 0.089 & $0.39 \%$ \\
\hline R111-3 Composite Pore\#5 .05M CIT(5) & 74.351 & 310.567 & 23.091 & 1.81 & 87.720 & 0.159 & $0.69 \%$ \\
\hline R111-3 Composite Pore\#6 .05M CIT(5) & 74.351 & 310.567 & 23.091 & 0.81 & 87.720 & 0.071 & $0.31 \%$ \\
\hline R111-3 Composite Pore\#7 .05M CIT(5) & 74.351 & 310.567 & 23.091 & 2.27 & 87.720 & 0.199 & $0.86 \%$ \\
\hline R111-3 Composite Drainage .05M CIT(5) & 74.351 & 310.567 & 23.091 & 1.91 & 87.720 & 0.168 & $0.73 \%$ \\
\hline R111-3 Composite Composite .05M CIT(5) & 74.351 & 310.567 & 23.091 & 1.66 & 87.720 & 0.146 & $0.63 \%$ \\
\hline R111-3 Composite Pore\#1 Dist. H2O(5) & 74.351 & 310.567 & 23.091 & 0.25 & 87.840 & 0.022 & $0.10 \%$ \\
\hline R111-3 Composite Pore\#2 Dist. $\mathrm{H} 2 \mathrm{O}(5)$ & 74.351 & 310.567 & 23.091 & 0.35 & 87.840 & 0.031 & $0.13 \%$ \\
\hline R111-3 Composite Pore\#3 Dist. $\mathrm{H} 20(5)$ & 74.351 & 310.567 & 23.091 & 0.25 & 87.840 & 0.022 & $0.10 \%$ \\
\hline R111-3 Composite Pore\#4 Dist. H2O(5) & 74.351 & 310.567 & 23.091 & 0.45 & 87.840 & 0.040 & $0.17 \%$ \\
\hline
\end{tabular}


$\mathrm{Pb}$ Removed by Columnar Flooding

\begin{tabular}{|c|c|c|c|c|c|c|c|}
\hline & $\mathbf{P b}$ & Wt. of Soil & $\mathrm{Pb}$ in & $\mathbf{P b}$ & Pore Volume & $\mathbf{P b}$ in & $\% \mathbf{P b}$ \\
\hline SAMPLE & $(\mathbf{m g} / \mathbf{k g})$ & (g) & Soil (mg) & $(\mathbf{m g} / \mathrm{L})$ & (ml) & Sample (mg) & Removed \\
\hline R111-3 Composite Pore\#5 Dist. $\mathrm{H} 20(5)$ & 74.351 & 310.567 & 23.091 & 0.57 & 87.840 & 0.050 & $0.22 \%$ \\
\hline R111-3 Composite Drainage Dist. $\mathrm{H} 20(5)$ & 74.351 & 310.567 & 23.091 & 0.35 & 87.840 & 0.031 & $0.13 \%$ \\
\hline R111-3 Composite Composite Dist. $\mathrm{H} 20(5)$ & 74.351 & 310.567 & 23.091 & 0.25 & 87.840 & 0.022 & $0.10 \%$ \\
\hline R111-4 Composite Pore\#1 .05M CIT(5) & 98.018 & 206.100 & 20.202 & 0.82 & 53.550 & 0.044 & $0.22 \%$ \\
\hline R111-4 Composite Pore\#2 .05M CIT(5) & 98.018 & 206.100 & 20.202 & 1.38 & 53.550 & 0.074 & $0.37 \%$ \\
\hline R111-4 Composite Pore\#3 .05M CIT(5) & 98.018 & 206.100 & 20.202 & 0.81 & 53.550 & 0.043 & $0.21 \%$ \\
\hline R111-4 Composite Pore\#4 .05M CIT(5) & 98.018 & 206.100 & 20.202 & 1.66 & 53.550 & 0.089 & $0.44 \%$ \\
\hline R111-4 Composite Pore\#5 .05M CIT(5) & 98.018 & 206.100 & 20.202 & 2.10 & 53.550 & 0.112 & $0.56 \%$ \\
\hline R111-4 Composite Pore\#6 .05M CIT(5) & 98.018 & 206.100 & 20.202 & 1.15 & 53.550 & 0.062 & $0.30 \%$ \\
\hline R111-4 Composite Pore\#7 .05M CIT(5) & 98.018 & 206.100 & 20.202 & 2.06 & 53.550 & 0.110 & $0.55 \%$ \\
\hline R111-4 Composite Pore\#8 .05M CIT(5) & 98.018 & 206.100 & 20.202 & 1.49 & 53.550 & 0.080 & $0.39 \%$ \\
\hline R111-4 Composite Drainage .05M CIT(5) & 98.018 & 206.100 & 20.202 & 1.02 & 53.550 & 0.055 & $0.27 \%$ \\
\hline R111-4 Composite Composite .05M CIT(5) & 98.018 & 206.100 & 20.202 & 1.30 & 53.550 & 0.070 & $0.34 \%$ \\
\hline R111-4 Composite Pore\#1 Dist. H2O(5) & 98.018 & 206.100 & 20.202 & 0.35 & 53.770 & 0.019 & $0.09 \%$ \\
\hline R111-4 Composite Pore\#2 Dist. H2O(5) & 98.018 & 206.100 & 20.202 & 0.25 & 53.770 & 0.013 & $0.07 \%$ \\
\hline R111-4 Composite Pore\#3 Dist. $\mathrm{H} 20(5)$ & 98.018 & 206.100 & 20.202 & 0.25 & 53.770 & 0.013 & $0.07 \%$ \\
\hline R111-4 Composite Pore\#4 Dist. $\mathrm{H} 20(5)$ & 98.018 & 206.100 & 20.202 & 0.25 & 53.770 & 0.013 & $0.07 \%$ \\
\hline R111-4 Composite Pore\#5 Dist. H2O(5) & 98.018 & 206.100 & 20.202 & 0.25 & 53.770 & 0.013 & $0.07 \%$ \\
\hline R111-4 Composite Drainage Dist. H2O(5) & 98.018 & 206.100 & 20.202 & 0.25 & 53.770 & 0.013 & $0.07 \%$ \\
\hline R111-4 Composite Composite Dist. H2O(5) & 98.018 & 206.100 & 20.202 & 0.25 & 53.770 & 0.013 & $0.07 \%$ \\
\hline R111-4,3 Composite Pore\#1 .05M CIT(5) & 137.333 & 199.903 & 27.453 & 0.67 & 73.348 & 0.049 & $0.18 \%$ \\
\hline R111-4,3 Composite Pore\#2 .05M CIT(5) & 137.333 & 199.903 & 27.453 & 0.79 & 73.348 & 0.058 & $0.21 \%$ \\
\hline R111-4,3 Composite Pore\#3 .05M CIT(5) & 137.333 & 199.903 & 27.453 & 2.01 & 73.348 & 0.147 & $0.54 \%$ \\
\hline R111-4,3 Composite Pore\#4 .05M CIT(5) & 137.333 & 199.903 & 27.453 & 3.00 & 73.348 & 0.220 & $0.80 \%$ \\
\hline R111-4,3 Composite Pore\#5 .05M CIT(5) & 137.333 & 199.903 & 27.453 & 3.30 & 73.348 & 0.242 & $0.88 \%$ \\
\hline R111-4,3 Composite Pore\#6 .05M CIT(5) & 137.333 & 199.903 & 27.453 & 2.80 & 73.348 & 0.205 & $0.75 \%$ \\
\hline R111-4,3 Composite Pore\#7 .05M CIT(5) & 137.333 & 199.903 & 27.453 & 15.92 & 73.348 & 1.168 & $4.25 \%$ \\
\hline R111-4,3 Composite Pore\#8 .05M CIT(5) & 137.333 & 199.903 & 27.453 & 3.48 & 73.348 & 0.255 & $0.93 \%$ \\
\hline R111-4,3 Composite Drainage .05M CIT(5) & 137.333 & 199.903 & 27.453 & 2.84 & 73.348 & 0.208 & $0.76 \%$ \\
\hline R111-4,3 Composite Composite .05M CIT(5) & 137.333 & 199.903 & 27.453 & 2.50 & 73.348 & 0.183 & $0.67 \%$ \\
\hline R111-4,3 Composite Pore\#1 Dist. H20(5) & 137.333 & 199.903 & 27.453 & 0.25 & 73.348 & 0.018 & $0.07 \%$ \\
\hline R111-4,3 Composite Pore\#2 Dist. H20(5) & 137.333 & 199.903 & 27.453 & 0.25 & 73.348 & 0.018 & $0.07 \%$ \\
\hline R111-4,3 Composite Pore\#3 Dist. H20(5) & 137.333 & 199.903 & 27.453 & 0.25 & 73.348 & 0.018 & $0.07 \%$ \\
\hline
\end{tabular}


Pb Removed by Columnar Flooding

\begin{tabular}{|c|c|c|c|c|c|c|c|}
\hline & $\overline{\mathrm{Pb}}$ & Wt. of Soil & $\mathrm{Pb}$ in & $\mathbf{P b}$ & Pore Volume & $\mathrm{Pb}$ in & $\% \mathbf{P b}$ \\
\hline SAMPLE & $(\mathbf{m g} / \mathbf{k g})$ & (g) & Soil (mg) & $(\mathrm{mg} / \mathrm{L})$ & $(\mathrm{ml})$ & Sample (mg) & Removed \\
\hline R111-4,3 Composite Pore\#4 Dist. H20(5) & 137.333 & 199.903 & 27.453 & 0.25 & 73.348 & 0.018 & $0.07 \%$ \\
\hline R111-4,3 Composite Pore\#5 Dist. H2O(5) & 137.333 & 199.903 & 27.453 & 0.25 & 73.348 & 0.018 & $0.07 \%$ \\
\hline R111-4,3 Composite Drainage Dist. H20(5) & 137.333 & 199.903 & 27.453 & 0.25 & 73.348 & 0.018 & $0.07 \%$ \\
\hline R111-4,3 Composite Composite Dist. H2O(5) & 137.333 & 199.903 & 27.453 & 0.25 & 73.348 & 0.018 & $0.07 \%$ \\
\hline R122 Composite Pore \#1 Dist. $\mathrm{H} 2 \mathrm{O}$ & 398.929 & 312.096 & 124.504 & 1.56 & 69.600 & 0.109 & $0.09 \%$ \\
\hline R122 Composite Pore \#2 Dist. H2O & 398.929 & 312.096 & 124.504 & 1.40 & 69.600 & 0.097 & $0.08 \%$ \\
\hline R122 Composite Pore \#3 Dist. H2O & 398.929 & 312.096 & 124.504 & 0.62 & 69.600 & 0.043 & $0.03 \%$ \\
\hline R122 Composite Pore \#4 Dist. $\mathrm{H} 2 \mathrm{O}$ & 398.929 & 312.096 & 124.504 & 0.50 & 69.600 & 0.035 & $0.03 \%$ \\
\hline R122 Composite Pore \#5 Dist. H2O & 398.929 & 312.096 & 124.504 & 0.47 & 69.600 & 0.033 & $0.03 \%$ \\
\hline R122 Composite Drainage Dist. $\mathrm{H} 2 \mathrm{O}$ & 398.929 & 312.096 & 124.504 & 1.53 & 69.600 & 0.106 & $0.09 \%$ \\
\hline R122 Composite Composite Dist. $\mathrm{H} 2 \mathrm{O}$ & 398.929 & 312.096 & 124.504 & 0.92 & 69.600 & 0.064 & $0.05 \%$ \\
\hline R122 Composite Pore \#1 .05M EDTA & 398.929 & 312.096 & 124.504 & 2.01 & 69.600 & 0.140 & $0.11 \%$ \\
\hline R122 Composite Pore \#2 .05M EDTA & 398.929 & 312.096 & 124.504 & 51.21 & 69.600 & 3.564 & $2.86 \%$ \\
\hline R122 Composite Pore \#3 .05M EDTA & 398.929 & 312.096 & 124.504 & 214.91 & 69.600 & 14.958 & $12.01 \%$ \\
\hline R122 Composite Pore \#4 .05M EDTA & 398.929 & 312.096 & 124.504 & 196.01 & 69.600 & 13.642 & $10.96 \%$ \\
\hline R122 Composite Pore \#5 .05M EDTA & 398.929 & 312.096 & 124.504 & 118.67 & 69.600 & 8.259 & $6.63 \%$ \\
\hline R122 Composite Pore $\# 6.05 \mathrm{M}$ EDTA & 398.929 & 312.096 & 124.504 & 80.92 & 69.600 & 5.632 & $4.52 \%$ \\
\hline R122 Composite Pore \#7 .05M EDTA & 398.929 & 312.096 & 124.504 & 55.04 & 69.600 & 3.831 & $3.08 \%$ \\
\hline R122 Composite Pore \#8 .05M EDTA & 398.929 & 312.096 & 124.504 & 43.86 & 69.600 & 3.053 & $2.45 \%$ \\
\hline R122 Composite Drainage .05M EDTA & 398.929 & 312.096 & 124.504 & 33.60 & 69.600 & 2.339 & $1.88 \%$ \\
\hline R122 Composite Composite .05M EDTA & 398.929 & 312.096 & 124.504 & 108.64 & 69.600 & 7.561 & $6.07 \%$ \\
\hline R124 Composite Pore\#1 .05M EDTA(5) & 8106.044 & 342.551 & 2776.730 & 778.49 & 55.770 & 43.416 & $1.56 \%$ \\
\hline R124 Composite Pore\#2 .05M EDTA(5) & 8106.044 & 342.551 & 2776.730 & 829.36 & 55.770 & 46.253 & $1.67 \%$ \\
\hline R124 Composite Pore $\# 3$.05M EDTA(5) & 8106.044 & 342.551 & 2776.730 & 770.75 & 55.770 & 42.985 & $1.55 \%$ \\
\hline R124 Composite Pore $\# 4$.05M EDTA(5) & 8106.044 & 342.551 & 2776.730 & 811.64 & 55.770 & 45.265 & $1.63 \%$ \\
\hline R124 Composite Pore\#5 .05M EDTA(5) & 8106.044 & 342.551 & 2776.730 & 505.85 & 55.770 & 28.211 & $1.02 \%$ \\
\hline R124 Composite Pore\#6 .05M EDTA(5) & 8106.044 & 342.551 & 2776.730 & 436.48 & 55.770 & 24.342 & $0.88 \%$ \\
\hline R124 Composite Pore\#7 .05M EDTA(5) & 8106.044 & 342.551 & 2776.730 & 348.82 & 55.770 & 19.454 & $0.70 \%$ \\
\hline R124 Composite Pore \#8 .05M EDTA(5) & 8106.044 & 342.551 & 2776.730 & 309.67 & 55.770 & 17.270 & $0.62 \%$ \\
\hline R124 Composite Drainage .05M EDTA(5) & 8106.044 & 342.551 & 2776.730 & 315.88 & 55.770 & 17.617 & $0.63 \%$ \\
\hline R124 Composite Composite .05M EDTA(5) & 8106.044 & 342.551 & 2776.730 & 567.00 & 55.770 & 31.622 & $1.14 \%$ \\
\hline R124 Composite Pore\#1 Dist. H20(5) & 8106.044 & 342.551 & 2776.730 & 2.94 & 55.770 & 0.164 & $0.01 \%$ \\
\hline R124 Composite Pore\#2 Dist. H20(5) & 8106.044 & 342.551 & 2776.730 & 3.90 & 55.770 & 0.218 & $0.01 \%$ \\
\hline
\end{tabular}


Pb Removed by Columnar Flooding

\begin{tabular}{|c|c|c|c|c|c|c|c|}
\hline & $\mathbf{P b}$ & Wt. of Soil & $\mathrm{Pb}$ in & $\mathrm{Pb}$ & Pore Volume & $\mathrm{Pb}$ in & $\% \mathbf{P b}$ \\
\hline SAMPLE & $(\mathbf{m g} / \mathbf{k g})$ & (g) & Soil (mg) & $(\mathrm{mg} / \mathrm{L})$ & $(\mathrm{ml})$ & Sample (mg) & Removed \\
\hline R124 Composite Pore\#3 Dist. H2O(5) & 8106.044 & 342.551 & 2776.730 & 3.20 & 55.770 & 0.178 & $0.01 \%$ \\
\hline R124 Composite Pore\#5 Dist. H2O(5) & 8106.044 & 342.551 & 2776.730 & 2.22 & 55.770 & 0.124 & $0.00 \%$ \\
\hline R124 CompositeComposite Dist. $\mathrm{H} 20(5)$ & 8106.044 & 342.551 & 2776.730 & 3.07 & 55.770 & 0.171 & $0.01 \%$ \\
\hline R124 Composite Drainage Dist. H2O(5) & 8106.044 & 342.551 & 2776.730 & 3.39 & 55.770 & 0.189 & $0.01 \%$ \\
\hline R124-2 Composite Pore\#1 .05M CIT(5) & 8155.602 & 312.7 .44 & 2550.618 & 38.56 & 46.880 & 1.808 & $0.07 \%$ \\
\hline R124-2 Composite Pore\#4 .05M CIT(5) & 8155.602 & 312.744 & 2550.618 & 128.88 & 46.880 & 6.042 & $0.24 \%$ \\
\hline R124-2 Composite Pore\#5 .05M CIT(5) & 8155.602 & 312.744 & 2550.618 & 132.99 & 46.880 & 6.235 & $0.24 \%$ \\
\hline R124-2 Composite Pore\#6 .05M CIT(5) & 8155.602 & 312.744 & 2550.618 & 120.70 & 46.880 & 5.658 & $0.22 \%$ \\
\hline R124-2 Composite Pore\#7 .05M CIT(5) & 8155.602 & 312.744 & 2550.618 & 167.76 & 46.880 & 7.865 & $0.31 \%$ \\
\hline R124-2 Composite Pore\#8 .05M CIT(5) & 8155.602 & 312.744 & 2550.618 & 155.14 & 46.880 & 7.273 & $0.29 \%$ \\
\hline R124-2 Composite Composite .05M CIT(5) & 8155.602 & 312.744 & 2550.618 & 126.15 & 46.880 & 5.914 & $0.23 \%$ \\
\hline R124-2 Composite Pore\#4 Dist. H2O(5) & 8155.602 & 312.744 & 2550.618 & 3.45 & 46.880 & 0.162 & $0.01 \%$ \\
\hline R124-2 Composite Pore\#5 Dist. H2O(5) & 8155.602 & 312.744 & 2550.618 & 4.15 & 46.880 & 0.195 & $0.01 \%$ \\
\hline R124-2 CompositeComposite Dist. H2O(5) & 8155.602 & 312.744 & 2550.618 & 5.24 & 46.880 & 0.246 & $0.01 \%$ \\
\hline R124-2 Composite Drainage Dist. H2O(5) & 8155.602 & 312.744 & 2550.618 & 3.80 & 46.880 & 0.178 & $0.01 \%$ \\
\hline R124-3 Composite Pore\#1 .05M CIT(5) & 28129.324 & 213.391 & 6002.539 & 5.86 & 63.700 & 0.373 & $0.01 \%$ \\
\hline R124-3 Composite Pore\#2 .05M CIT(5) & 28129.324 & 213.391 & 6002.539 & 103.15 & 63.700 & 6.571 & $0.11 \%$ \\
\hline R124-3 Composite Pore\#3 .05M CIT(5) & 28129.324 & 213.391 & 6002.539 & 194.78 & 63.700 & 12.407 & $0.21 \%$ \\
\hline R124-3 Composite Pore\#4 .05M CIT(5) & 28129.324 & 213.391 & 6002.539 & 190.48 & 63.700 & 12.134 & $0.20 \%$ \\
\hline R124-3 Composite Pore\#5 .05M CIT(5) & 28129.324 & 213.391 & 6002.539 & 181.92 & 63.700 & 11.588 & $0.19 \%$ \\
\hline R124-3 Composite Pore\#6 .05M CIT(5) & 28129.324 & 213.391 & 6002.539 & 167.76 & 63.700 & 10.686 & $0.18 \%$ \\
\hline R124-3 Composite Pore\#7 .05M CIT(5) & 28129.324 & 213.391 & 6002.539 & 160.73 & 63.700 & 10.239 & $0.17 \%$ \\
\hline R124-3 Composite Pore\#8 .05M CIT(5) & 28129.324 & 213.391 & 6002.539 & 160.73 & 63.700 & 10.239 & $0.17 \%$ \\
\hline R124-3 Composite Composite .05M CIT(5) & 28129.324 & 213.391 & 6002.539 & 149.06 & 63.700 & 9.495 & $0.16 \%$ \\
\hline
\end{tabular}


$\mathrm{Pb}$ Removed by Columnar Flooding

\begin{tabular}{|c|c|c|c|c|c|c|c|}
\hline & $\mathbf{P b}$ & Wt. of Soil & $\mathbf{P b}$ in & $\mathbf{P b}$ & Pore Volume & $\mathrm{Pb}$ in & $\% \mathbf{P b}$ \\
\hline SAMPLE & $(\mathrm{mg} / \mathrm{kg})$ & (g) & Soil (mg) & $(\mathrm{mg} / \mathrm{L})$ & $(\mathrm{ml})$ & Sample (mg) & Removed \\
\hline R124-3 Composite Pore\#2 Dist. $\mathrm{H} 2 \mathrm{O}(5)$ & 28129.324 & 213.391 & 6002.539 & 0.83 & 63.750 & 0.053 & $0.00 \%$ \\
\hline R124-3 Composite Pore\#3 Dist. $\mathrm{H} 20(5)$ & 28129.324 & 213.391 & 6002.539 & 1.80 & 63.750 & 0.115 & $0.00 \%$ \\
\hline R124-3 Composite Pore\#4 Dist. H2O(5) & 28129.324 & 213.391 & 6002.539 & 0.94 & 63.750 & 0.060 & $0.00 \%$ \\
\hline R124-3 Composite Pore\#5 Dist. H2O(5) & 28129.324 & 213.391 & 6002.539 & 3.67 & 63.750 & 0.234 & $0.00 \%$ \\
\hline R124-3 CompositeComposite Dist. H2O(5) & 28129.324 & 213.391 & 6002.539 & 0.83 & 63.750 & 0.053 & $0.00 \%$ \\
\hline R124-3 Composite Drainage Dist. $\mathrm{H} 20(5)$ & 28129.324 & 213.391 & 6002.539 & 1.16 & 63.750 & 0.074 & $0.00 \%$ \\
\hline
\end{tabular}


Zn Removed by Columnar Flooding

\begin{tabular}{|c|c|c|c|c|c|c|c|}
\hline & Zn & Wt. of Soil & $\mathrm{Zn}$ in & $\mathbf{Z n}$ & Pore Volume & $\mathrm{Zn}$ in & $\% \mathrm{Zn}$ \\
\hline SAMPLE & $(\mathbf{m g} / \mathbf{k g})$ & (g) & Soil (mg) & (mg/L) & $(\mathrm{ml})$ & Sample (mg) & Removed \\
\hline R111-2 Composite Pore\#1 .05M CIT(5) & 1867.823 & 188.124 & 351.383 & 31.84 & 38.280 & 1.219 & $0.35 \%$ \\
\hline R111-2 Composite Pore\#2 .05M CIT(5) & 1867.823 & 188.124 & 351.383 & 7.32 & 38.280 & 0.280 & $0.08 \%$ \\
\hline R111-2 Composite Pore\#3 .05M CIT(5) & 1867.823 & 188.124 & 351.383 & 9.06 & 38.280 & 0.347 & $0.10 \%$ \\
\hline R111-2 Composite Pore\#4 .05M CIT(5) & 1867.823 & 188.124 & 351.383 & 10.51 & 38.280 & 0.402 & $0.11 \%$ \\
\hline R111-2 Composite Pore\#5 .05M CIT(5) & 1867.823 & 188.124 & 351.383 & 8.18 & 38.280 & 0.313 & $0.09 \%$ \\
\hline R111-2 Composite Pore\#6 .05M CIT(5) & 1867.823 & 188.124 & 351.383 & 7.78 & 38.280 & 0.298 & $0.08 \%$ \\
\hline R111-2 Composite Pore\#7 .05M CIT(5) & 1867.823 & 188.124 & 351.383 & 6.76 & 38.280 & 0.259 & $0.07 \%$ \\
\hline R111-2 Composite Pore $\# 8$.05M CIT(5) & 1867.823 & 188.124 & 351.383 & 5.38 & 38.280 & 0.206 & $0.06 \%$ \\
\hline R111-2 Composite Composite .05M CIT(5) & 1867.823 & 188.124 & 351.383 & 8.87 & 38.280 & 0.340 & $0.10 \%$ \\
\hline R111-2 Composite Drainage .05M CIT(5) & 1867.823 & 188.124 & 351.383 & 10.83 & 38.280 & 0.415 & $0.12 \%$ \\
\hline R111-2 Composite Pore\#1 Dist. H20(5) & 1867.823 & 188.124 & 351.383 & 7.16 & 38.280 & 0.274 & $0.08 \%$ \\
\hline R111-2 Composite Pore\#2 Dist. H20(5) & 1867.823 & 188.124 & 351.383 & 6.58 & 38.280 & 0.252 & $0.07 \%$ \\
\hline R111-2 Composite Pore\#3 Dist. H2O(5) & 1867.823 & 188.124 & 351.383 & 6.22 & 38.280 & 0.238 & $0.07 \%$ \\
\hline R111-2 Composite Pore\#4 Dist. H2O(5) & 1867.823 & 188.124 & 351.383 & 6.74 & 38.280 & 0.258 & $0.07 \%$ \\
\hline R111-2 Composite Pore\#5 Dist. H20(5) & 1867.823 & 188.124 & 351.383 & 5.94 & 38.280 & 0.227 & $0.06 \%$ \\
\hline R111-2 Composite Drainage Dist. $\mathrm{H} 20(5)$ & 1867.823 & 188.124 & 351.383 & 6.29 & 38.280 & 0.241 & $0.07 \%$ \\
\hline R111-2 Composite Composite Dist. H2O(5) & 1867.823 & 188.124 & 351.383 & 5.54 & 38.280 & 0.212 & $0.06 \%$ \\
\hline R111-3 Composite Pore\#1 .05M CIT(5) & 928.272 & 310.567 & 288.290 & 3.64 & 87.720 & 0.319 & $0.11 \%$ \\
\hline R111-3 Composite Pore\#2 .05M CIT(5) & 928.272 & 310.567 & 288.290 & 35.13 & 87.720 & 3.082 & $1.07 \%$ \\
\hline R111-3 Composite Pore\#3 .05M CIT(5) & 928.272 & 310.567 & 288.290 & 14.41 & 87.720 & 1.264 & $0.44 \%$ \\
\hline R111-3 Composite Pore\#4 .05M CIT(5) & 928.272 & 310.567 & 288.290 & 15.29 & 87.720 & 1.341 & $0.47 \%$ \\
\hline R111-3 Composite Pore\#5 .05M CIT(5) & 928.272 & 310.567 & 288.290 & 13.89 & 87.720 & 1.218 & $0.42 \%$ \\
\hline R111-3 Composite Pore\#6 .05M CIT(5) & 928.272 & 310.567 & 288.290 & 10.10 & 87.720 & 0.886 & $0.31 \%$ \\
\hline R111-3 Composite Pore\#7 .05M CIT(5) & 928.272 & 310.567 & 288.290 & 6.05 & 87.720 & 0.531 & $0.18 \%$ \\
\hline R111-3 Composite Drainage .05M CIT(5) & 928.272 & 310.567 & 288.290 & 16.87 & 87.720 & 1.480 & $0.51 \%$ \\
\hline R111-3 Composite Composite .05M CIT(5) & 928.272 & 310.567 & 288.290 & 11.45 & 87.720 & 1.004 & $0.35 \%$ \\
\hline R111-3 Composite Pore\#1 Dist. H2O(5) & 928.272 & 310.567 & 288.290 & 3.94 & 87.840 & 0.346 & $0.12 \%$ \\
\hline R111-3 Composite Pore\#2 Dist. H2O(5) & 928.272 & 310.567 & 288.290 & 4.77 & 87.840 & 0.419 & $0.15 \%$ \\
\hline R111-3 Composite Pore\#3 Dist. H2O(5) & 928.272 & 310.567 & 288.290 & 2.16 & 87.840 & 0.190 & $0.07 \%$ \\
\hline R111-3 Composite Pore\#4 Dist. H20(5) & 928.272 & 310.567 & 288.290 & 3.39 & 87.840 & 0.298 & $0.10 \%$ \\
\hline R111-3 Composite Pore\#5 Dist. H2O(5) & 928.272 & 310.567 & 288.290 & 1.34 & 87.840 & 0.118 & $0.04 \%$ \\
\hline R111-3 Composite Drainage Dist. H2O(5) & 928.272 & 310.567 & 288.290 & 3.43 & 87.840 & 0.301 & $0.10 \%$ \\
\hline R111-3 Composite Composite Dist. H2O(5) & 928.272 & 310.567 & 288.290 & 1.96 & 87.840 & 0.172 & $0.06 \%$ \\
\hline
\end{tabular}


Zn Removed by Columnar Flooding

\begin{tabular}{|c|c|c|c|c|c|c|c|}
\hline & $\mathbf{Z n}$ & Wt. of Soil & $\mathrm{Zn}$ in & $\mathbf{Z n}$ & Pore Volume & $\mathrm{Zn}$ in & $\% \mathbf{Z n}$ \\
\hline SAMPLE & $(\mathbf{m g} / \mathbf{k g})$ & (g) & Soil (mg) & $(\mathrm{mg} / \mathrm{L})$ & $(\mathrm{ml})$ & Sample (mg) & Removed \\
\hline R111-4 Composite Pore\#1 .05M CIT(5) & 1697.747 & 206.100 & 349.906 & 43.12 & 53.550 & 2.309 & $0.66 \%$ \\
\hline R111-4 Composite Pore\#2 .05M CIT(5) & 1697.747 & 206.100 & 349.906 & 9.01 & 53.550 & 0.482 & $0.14 \%$ \\
\hline R111-4 Composite Pore \#3 .05M CIT(5) & 1697.747 & 206.100 & 349.906 & 9.29 & 53.550 & 0.497 & $0.14 \%$ \\
\hline R111-4 Composite Pore\#4 .05M CIT(5) & 1697.747 & 206.100 & 349.906 & 7.72 & 53.550 & 0.413 & $0.12 \%$ \\
\hline R111-4 Composite Pore\#5 .05M CIT(5) & 1697.747 & 206.100 & 349.906 & 48.26 & 53.550 & 2.584 & $0.74 \%$ \\
\hline R111-4 Composite Pore\#6 .05M CIT(5) & 1697.747 & 206.100 & 349.906 & 44.61 & 53.550 & 2.389 & $0.68 \%$ \\
\hline R111-4 Composite Pore\#7 .05M CIT(5) & 1697.747 & 206.100 & 349.906 & 42.98 & 53.550 & 2.302 & $0.66 \%$ \\
\hline R111-4 Composite Pore\#8 .05M CIT(5) & 1697.747 & 206.100 & 349.906 & 42.15 & 53.550 & 2.257 & $0.65 \%$ \\
\hline R111-4 Composite Drainage .05M CIT(5) & 1697.747 & 206.100 & 349.906 & 47.21 & 53.550 & 2.528 & $0.72 \%$ \\
\hline R111-4 Composite Composite .05M CIT(5) & 1697.747 & 206.100 & 349.906 & 74.58 & 53.550 & 3.994 & $1.14 \%$ \\
\hline R111-4 Composite Pore\#1 Dist. H2O(5) & 1697.747 & 206.100 & 349.906 & 7.25 & 53.770 & 0.390 & $0.11 \%$ \\
\hline R111-4 Composite Pore\#2 Dist. H2O(5) & 1697.747 & 206.100 & 349.906 & 9.06 & 53.770 & 0.487 & $0.14 \%$ \\
\hline R111-4 Composite Pore\#3 Dist. H2O(5) & 1697.747 & 206.100 & 349.906 & 6.50 & 53.770 & 0.350 & $0.10 \%$ \\
\hline R111-4 Composite Pore\#4 Dist. H2O(5) & 1697.747 & 206.100 & 349.906 & 3.22 & 53.770 & 0.173 & $0.05 \%$ \\
\hline R111-4 Composite Pore\#5 Dist. H20(5) & 1697.747 & 206.100 & 349.906 & 5.57 & 53.770 & 0.299 & $0.09 \%$ \\
\hline R111-4 Composite Drainage Dist. $\mathrm{H} 2 \mathrm{O}(5)$ & 1697.747 & 206.100 & 349.906 & 4.43 & 53.770 & 0.238 & $0.07 \%$ \\
\hline R111-4 Composite Composite Dist. H20(5) & 1697.747 & 206.100 & 349.906 & 7.48 & 53.770 & 0.402 & $0.11 \%$ \\
\hline R111-4,3 Composite Pore\#1 .05M CIT(5) & 757.267 & 199.903 & 151.380 & 4.71 & 73.348 & 0.345 & $0.23 \%$ \\
\hline R111-4,3 Composite Pore\#2 .05M CIT(5) & 757.267 & 199.903 & 151.380 & 36.33 & 73.348 & 2.665 & $1.76 \%$ \\
\hline R111-4,3 Composite Pore\#3 .05M CIT(5) & 757.267 & 199.903 & 151.380 & 78.08 & 73.348 & 5.727 & $3.78 \%$ \\
\hline R111-4,3 Composite Pore\#4 .05M CIT(5) & 757.267 & 199.903 & 151.380 & 48.86 & 73.348 & 3.584 & $2.37 \%$ \\
\hline R111-4,3 Composite Pore\#5 .05M CIT(5) & 757.267 & 199.903 & 151.380 & 41.71 & 73.348 & 3.059 & $2.02 \%$ \\
\hline R111-4,3 Composite Pore\#6 .05M CIT(5) & 757.267 & 199.903 & 151.380 & 39.69 & 73.348 & 2.911 & $1.92 \%$ \\
\hline R111-4,3 Composite Pore\#7 .05M CIT(5) & 757.267 & 199.903 & 151.380 & 40.83 & 73.348 & 2.995 & $1.98 \%$ \\
\hline R111-4,3 Composite Pore\#8 .05M CIT(5) & 757.267 & 199.903 & 151.380 & 40.36 & 73.348 & 2.960 & $1.96 \%$ \\
\hline R111-4,3 Composite Drainage .05M CIT(5) & 757.267 & 199.903 & 151.380 & 37.37 & 73.348 & 2.741 & $1.81 \%$ \\
\hline R111-4,3 Composite Composite .05M CIT(5) & 757.267 & 199.903 & 151.380 & 39.14 & 73.348 & 2.871 & $1.90 \%$ \\
\hline R111-4,3 Composite Pore\#1 Dist. $\mathrm{H} 2 \mathrm{O}(5)$ & 757.267 & 199.903 & 151.380 & 6.77 & 73.348 & 0.497 & $0.33 \%$ \\
\hline R111-4,3 Composite Pore\#2 Dist. H2O(5) & 757.267 & 199.903 & 151.380 & 4.64 & 73.348 & 0.340 & $0.22 \%$ \\
\hline R111-4,3 Composite Pore\#3 Dist. H2O(5) & 757.267 & 199.903 & 151.380 & 4.78 & 73.348 & 0.351 & $0.23 \%$ \\
\hline R111-4,3 Composite Pore\#4 Dist. H2O(5) & 757.267 & 199.903 & 151.380 & 4.18 & 73.348 & 0.307 & $0.20 \%$ \\
\hline R111-4,3 Composite Pore\#5 Dist. H2O(5) & 757.267 & 199.903 & 151.380 & 1.77 & 73.348 & 0.130 & $0.09 \%$ \\
\hline R111-4,3 Composite Drainage Dist. $\mathrm{H} 20(5)$ & 757.267 & 199.903 & 151.380 & 4.96 & 73.348 & 0.364 & $0.24 \%$ \\
\hline
\end{tabular}


Zn Removed by Columnar Flooding

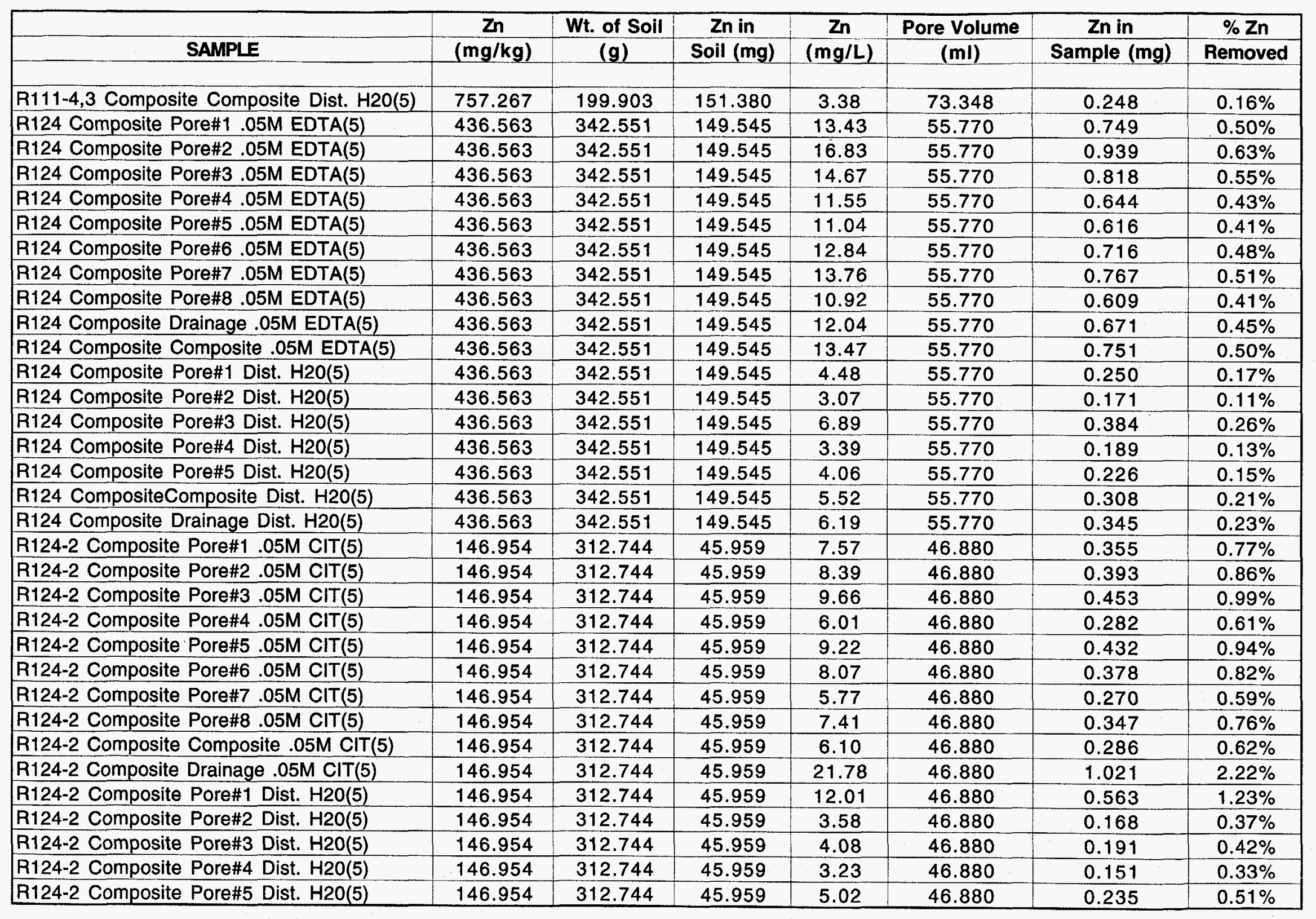


Zn Removed by Columnar Flooding

\begin{tabular}{|c|c|c|c|c|c|c|c|}
\hline & $\mathbf{Z n}$ & Wt. of Soil & Zn in & $\mathbf{Z n}$ & Pore Volume & Zn in & $\% \mathbf{Z n}$ \\
\hline SAMPLE & $(\mathbf{m g} / \mathbf{k g})$ & (g) & Soil (mg) & $(\mathrm{mg} / \mathrm{L})$ & $(\mathrm{ml})$ & Sample (mg) & Removed \\
\hline R124-2 CompositeComposite Dist. H20(5) & 146.954 & 312.744 & 45.959 & 3.54 & 46.880 & 0.166 & $0.36 \%$ \\
\hline R124-3 Composite Pore\#1 .05M CIT(5) & 140.024 & 213.391 & 29.880 & 4.98 & 63.700 & 0.317 & $1.06 \%$ \\
\hline R124-3 Composite Pore $\# 2$.05M CIT(5) & 140.024 & 213.391 & 29.880 & 15.38 & 63.700 & 0.980 & $3.28 \%$ \\
\hline R124-3 Composite Pore\#3 .05M CIT(5) & 140.024 & 213.391 & 29.880 & 18.01 & 63.700 & 1.147 & $3.84 \%$ \\
\hline R124-3 Composite Pore\#4 .05M CIT(5) & 140.024 & 213.391 & 29.880 & 11.63 & 63.700 & 0.741 & $2.48 \%$ \\
\hline R124-3 Composite Pore\#7 .05M CIT(5) & 140.024 & 213.391 & 29.880 & 11.83 & 63.700 & 0.754 & $2.52 \%$ \\
\hline R124-3 Composite Pore\#8 .05M CIT(5) & 140.024 & 213.391 & 29.880 & 10.01 & 63.700 & 0.638 & $2.13 \%$ \\
\hline R124-3 Composite Composite .05M CIT(5) & 140.024 & 213.391 & 29.880 & 9.42 & 63.700 & 0.600 & $2.01 \%$ \\
\hline R124-3 Composite Drainage .05M CIT(5) & 140.024 & 213.391 & 29.880 & 8.61 & 63.700 & 0.548 & $1.84 \%$ \\
\hline R124-3 Composite Pore\#1 Dist. H20(5) & 140.024 & 213.391 & 29.880 & 2.31 & 63.750 & 0.147 & $0.49 \%$ \\
\hline R124-3 Composite Pore\#2 Dist. $\mathrm{H} 2 \mathrm{O}(5)$ & 140.024 & 213.391 & 29.880 & 1.58 & 63.750 & 0.101 & $0.34 \%$ \\
\hline R124-3 Composite Drainage Dist. $\mathrm{H} 20(5)$ & 140.024 & 213.391 & 29.880 & 4.37 & 63.750 & 0.279 & $0.93 \%$ \\
\hline
\end{tabular}


Appendix C:

Percent of Heavy Metals Removed by Columnar Flooding: $\mathrm{Cd}, \mathrm{Cr}, \mathrm{Cu}, \mathrm{Fe}, \mathrm{Pb}$, and $\mathrm{Zn}$ 
\% Cd Removed by Columnar Flooding

\begin{tabular}{|c|c|c|c|c|c|c|c|c|c|c|c|}
\hline & Pore & Pore & Pore & Pore & Pore & Pore & Pore & Pore & & & TOTAL \\
\hline Sample & $\# 1$ & $\# 2$ & \# 3 & $\# 4$ & $\# 5$ & \# 6 & $\# 7$ & $\# 8$ & Drainage & Composite & $\%$ REMOVED \\
\hline R111-2 Composite Dist. $\mathrm{H} 20$ & $0.02 \%$ & $0.02 \%$ & $0.02 \%$ & $0.02 \%$ & $0.02 \%$ & & & & $0.02 \%$ & $0.02 \%$ & $0.14 \%$ \\
\hline R111-2 Composite .05M Cit. & $0.05 \%$ & $0.30 \%$ & $0.22 \%$ & $0.15 \%$ & $0.13 \%$ & $0.08 \%$ & $0.05 \%$ & $0.03 \%$ & $0.16 \%$ & $0.16 \%$ & $1.33 \%$ \\
\hline R111-3 Composite Dist. $\mathrm{H} 2 \mathrm{O}$ & $0.10 \%$ & $0.10 \%$ & $0.10 \%$ & $0.10 \%$ & $0.10 \%$ & & & & $0.10 \%$ & $0.10 \%$ & $0.70 \%$ \\
\hline R111-3 Composite .05M Cit. & $0.10 \%$ & $0.22 \%$ & $1.63 \%$ & $1.73 \%$ & $0.24 \%$ & $0.16 \%$ & $1.09 \%$ & & $0.97 \%$ & $0.63 \%$ & $6.77 \%$ \\
\hline R111-4 Composite Dist. $\mathrm{H} 2 \mathrm{O}$ & $0.05 \%$ & $0.05 \%$ & $0.05 \%$ & $0.05 \%$ & $0.05 \%$ & & & & $0.05 \%$ & $0.05 \%$ & $0.35 \%$ \\
\hline R111-4 Composite .05M Cit. & $0.12 \%$ & $0.39 \%$ & $0.32 \%$ & $0.12 \%$ & $0.05 \%$ & $0.05 \%$ & $0.05 \%$ & $0.05 \%$ & $0.05 \%$ & $0.06 \%$ & $1.26 \%$ \\
\hline R111-4,3 Composite Dist. H2O & $0.02 \%$ & $0.02 \%$ & $0.02 \%$ & $0.02 \%$ & $0.02 \%$ & & & & $0.02 \%$ & $0.02 \%$ & $0.14 \%$ \\
\hline R111-4,3 Composite .05M Cit. & $0.10 \%$ & $4.89 \%$ & $7.27 \%$ & $5.80 \%$ & $3.98 \%$ & $3.13 \%$ & $2.46 \%$ & $2.67 \%$ & $0.88 \%$ & $3.53 \%$ & $34.71 \%$ \\
\hline R124 Composite Dist. H2O & $1.30 \%$ & $1.30 \%$ & $1.30 \%$ & $1.30 \%$ & $1.30 \%$ & & & & $1.30 \%$ & $1.30 \%$ & $9.10 \%$ \\
\hline R124 Composite .05M EDTA & $1.30 \%$ & $1.30 \%$ & $1.30 \%$ & $1.30 \%$ & $1.30 \%$ & $1.30 \%$ & $1.30 \%$ & $1.30 \%$ & $1.30 \%$ & $1.30 \%$ & $13.00 \%$ \\
\hline R124-2 Composite Dist. $\mathrm{H} 20$ & $1.58 \%$ & $1.58 \%$ & $1.58 \%$ & $1.58 \%$ & $1.58 \%$ & & & & $1.58 \%$ & $1.58 \%$ & $11.06 \%$ \\
\hline R124-2 Composite .05M Cit & $1.58 \%$ & $1.58 \%$ & $1.58 \%$ & $1.58 \%$ & $1.58 \%$ & $1.58 \%$ & $1.58 \%$ & $1.58 \%$ & $1.58 \%$ & $1.58 \%$ & $15.80 \%$ \\
\hline R124-3 Composite Dist. H2O & $0.65 \%$ & $0.65 \%$ & $0.65 \%$ & $0.65 \%$ & $0.65 \%$ & & & & $0.65 \%$ & $0.65 \%$ & $4.55 \%$ \\
\hline R124-3 Composite .05M Cit & $0.65 \%$ & $0.65 \%$ & $0.65 \%$ & $0.65 \%$ & $0.65 \%$ & $0.65 \%$ & $0.65 \%$ & $0.65 \%$ & $0.65 \%$ & $0.65 \%$ & $6.50 \%$ \\
\hline AVERAGE REMOVAL FOR DIST. H2O & $3.72 \%$ & & & & & & & & & & \\
\hline AVERAGE REMOVAL FOR CITRIC ACID & $11.06 \%$ & & & & & & & & & & \\
\hline AVERAGE REMOVAL FOR EDTA & $13.00 \%$ & & & & & & & & & & \\
\hline
\end{tabular}


$\%$ Cr Removed by Columnar Flooding

\begin{tabular}{|c|c|c|c|c|c|c|c|c|c|c|c|}
\hline & Pore & Pore & Pore & Pore & Pore & Pore & Pore & Pore & & & TOTAL \\
\hline Sample & $\# 1$ & $\# 2$ & $\# 3$ & $\# 4$ & $\# 5$ & $\# 6$ & $\# 7$ & $\# 8$ & Drainage & Composite & $\%$ REMOVED \\
\hline R111-2 Composite Dist. $\mathrm{H} 2 \mathrm{O}$ & $0.07 \%$ & $0.07 \%$ & $0.07 \%$ & $0.07 \%$ & $0.07 \%$ & & & & $0.07 \%$ & $0.07 \%$ & $0.49 \%$ \\
\hline R111-2 Composite .05M Cit. & $0.07 \%$ & $0.07 \%$ & $0.07 \%$ & $0.07 \%$ & $0.07 \%$ & $0.07 \%$ & $0.07 \%$ & $0.07 \%$ & $0.09 \%$ & $0.07 \%$ & $0.72 \%$ \\
\hline R111-3 Composite Dist. H2O & $0.07 \%$ & $0.07 \%$ & $0.07 \%$ & $0.07 \%$ & $0.07 \%$ & & & & $0.07 \%$ & $0.07 \%$ & $0.49 \%$ \\
\hline R111-3 Composite .05M Cit. & $0.07 \%$ & $0.07 \%$ & $0.08 \%$ & $0.11 \%$ & $0.12 \%$ & $0.11 \%$ & $0.12 \%$ & & $0.15 \%$ & $0.10 \%$ & $0.93 \%$ \\
\hline R111-4 Composite Dist. $\mathrm{H} 20$ & $0.10 \%$ & $0.10 \%$ & $0.10 \%$ & $0.10 \%$ & $0.10 \%$ & & & & $0.10 \%$ & $0.10 \%$ & $0.70 \%$ \\
\hline R111-4 Composite .05M Cit. & $0.10 \%$ & $0.10 \%$ & $0.12 \%$ & $0.16 \%$ & $0.10 \%$ & $0.10 \%$ & $0.10 \%$ & $0.10 \%$ & $0.10 \%$ & $0.10 \%$ & $1.08 \%$ \\
\hline R111-4,3 Composite Dist. H2O & $0.14 \%$ & $0.14 \%$ & $0.14 \%$ & $0.14 \%$ & $0.14 \%$ & & & & $0.14 \%$ & $0.14 \%$ & $0.98 \%$ \\
\hline R111-4,3 Composite .05M Cit. & $0.14 \%$ & $0.14 \%$ & $0.22 \%$ & $0.21 \%$ & $0.21 \%$ & $0.22 \%$ & $0.26 \%$ & $0.24 \%$ & $0.26 \%$ & $0.19 \%$ & $2.09 \%$ \\
\hline R124 Composite Dist. $\mathrm{H} 20$ & $0.28 \%$ & $0.28 \%$ & $0.28 \%$ & $0.28 \%$ & $0.28 \%$ & & & & $0.28 \%$ & $0.28 \%$ & $1.96 \%$ \\
\hline R124 Composite .05M EDTA & $0.28 \%$ & $0.28 \%$ & $0.28 \%$ & $0.28 \%$ & $0.28 \%$ & $0.28 \%$ & $0.28 \%$ & $0.28 \%$ & $0.28 \%$ & $0.28 \%$ & $2.80 \%$ \\
\hline R124-2 Composite Dist. H2O & $0.28 \%$ & $0.28 \%$ & $0.28 \%$ & $0.28 \%$ & $0.28 \%$ & & & & $0.28 \%$ & $0.28 \%$ & $1.96 \%$ \\
\hline R124-2 Composite .05M Cit & $0.28 \%$ & $0.28 \%$ & $0.28 \%$ & $0.28 \%$ & $0.28 \%$ & $0.28 \%$ & $0.28 \%$ & $0.28 \%$ & $0.28 \%$ & $0.28 \%$ & $2.80 \%$ \\
\hline R124-3 Composite Dist. $\mathrm{H} 20$ & $0.66 \%$ & $0.66 \%$ & $0.66 \%$ & $0.66 \%$ & $0.66 \%$ & & & & $0.66 \%$ & $0.66 \%$ & $4.62 \%$ \\
\hline R124-3 Composite .05M Cit & $0.66 \%$ & $0.66 \%$ & $0.66 \%$ & $0.66 \%$ & $0.66 \%$ & $0.66 \%$ & $0.66 \%$ & $0.66 \%$ & $0.66 \%$ & $0.66 \%$ & $6.60 \%$ \\
\hline AVERAGE REMOVAL FOR DIST. H2O & $1.60 \%$ & & & & & & & & & & \\
\hline AVERAGE REMOVAL FOR CITRIC ACID & $2.37 \%$ & & & & & & & & & & \\
\hline AVERAGE REMOVAL FOR EDTA & $2.80 \%$ & & & & & & & & & & \\
\hline
\end{tabular}


\% Cu Removed by Columnar Flooding

\begin{tabular}{|c|c|c|c|c|c|c|c|c|c|c|c|}
\hline & Pore & Pore & Pore & Pore & Pore & Pore & Pore & Pore & & & TOTAL \\
\hline Sample & $\# 1$ & $\# 2$ & $\# 3$ & $\# 4$ & $\# 5$ & \# 6 & $\# 7$ & $\# 8$ & Drainage & Composite & $\%$ REMOVED \\
\hline R111-2 Composite Dist. H2O & $0.04 \%$ & $0.04 \%$ & $0.05 \%$ & $0.04 \%$ & $0.02 \%$ & & & & $0.02 \%$ & $0.03 \%$ & $0.24 \%$ \\
\hline R111-2 Composite .05M Cit. & $0.22 \%$ & $0.46 \%$ & $0.45 \%$ & $0.45 \%$ & $0.45 \%$ & $0.39 \%$ & $0.34 \%$ & $0.31 \%$ & $0.57 \%$ & $0.47 \%$ & $4.11 \%$ \\
\hline R111-3 Composite Dist. H2O & $0.04 \%$ & $0.03 \%$ & $0.03 \%$ & $0.04 \%$ & $0.03 \%$ & & & & $0.02 \%$ & $0.03 \%$ & $0.22 \%$ \\
\hline R111-3 Composite .05M Cit. & $0.11 \%$ & $1.47 \%$ & $1.47 \%$ & $2.10 \%$ & $2.09 \%$ & $1.65 \%$ & $1.47 \%$ & & $1.17 \%$ & $1.67 \%$ & $13.20 \%$ \\
\hline R111-4 Composite Dist. H2O & $0.06 \%$ & $0.08 \%$ & $0.05 \%$ & $0.04 \%$ & $0.03 \%$ & & & & $0.03 \%$ & $0.04 \%$ & $0.33 \%$ \\
\hline R111-4 Composite .05M Cit. & $0.79 \%$ & $1.16 \%$ & $1.15 \%$ & $0.85 \%$ & $0.69 \%$ & $0.58 \%$ & $0.53 \%$ & $0.53 \%$ & $1.38 \%$ & $0.89 \%$ & $8.55 \%$ \\
\hline R111-4,3 Composite Dist. $\mathrm{H} 20$ & $0.03 \%$ & $0.04 \%$ & $0.04 \%$ & $0.03 \%$ & $0.03 \%$ & & & & $0.03 \%$ & $0.04 \%$ & $0.24 \%$ \\
\hline R111-4,3 Composite .05M Cit. & $0.62 \%$ & $3.01 \%$ & $2.49 \%$ & $1.84 \%$ & $1.46 \%$ & $1.15 \%$ & $1.21 \%$ & $1.42 \%$ & $1.09 \%$ & $1.67 \%$ & $15.96 \%$ \\
\hline R124 Composite Dist. H2O & $0.00 \%$ & $0.00 \%$ & $0.00 \%$ & $0.00 \%$ & $0.00 \%$ & & & & $0.00 \%$ & $0.00 \%$ & $0.00 \%$ \\
\hline R124 Composite .05M EDTA & $0.17 \%$ & $0.18 \%$ & $0.17 \%$ & $0.16 \%$ & $0.13 \%$ & $0.13 \%$ & $0.11 \%$ & $0.11 \%$ & $0.11 \%$ & $0.14 \%$ & $1.41 \%$ \\
\hline R124-2 Composite Dist. $\mathrm{H} 2 \mathrm{O}$ & $0.04 \%$ & $0.03 \%$ & $0.01 \%$ & $0.01 \%$ & $0.01 \%$ & & & & $0.02 \%$ & $0.01 \%$ & $0.13 \%$ \\
\hline R124-2 Composite .05M Cit & $0.37 \%$ & $0.57 \%$ & $0.44 \%$ & $0.44 \%$ & $0.49 \%$ & $0.61 \%$ & $0.62 \%$ & $0.56 \%$ & $0.47 \%$ & $0.49 \%$ & $5.06 \%$ \\
\hline R124-3 Composite Dist. H2O & $0.05 \%$ & $0.04 \%$ & $0.04 \%$ & $0.04 \%$ & $0.04 \%$ & & & & $0.03 \%$ & $0.04 \%$ & $0.28 \%$ \\
\hline R124-3 Composite .05M Cit & $0.08 \%$ & $0.70 \%$ & $1.14 \%$ & $0.87 \%$ & $0.73 \%$ & $0.72 \%$ & $0.70 \%$ & $0.62 \%$ & $0.56 \%$ & $0.76 \%$ & $6.88 \%$ \\
\hline AVERAGE REMOVAL FOR DIST. H2O & $0.21 \%$ & & & & & & & & & & \\
\hline AVERAGE REMOVAL FOR CITRIC ACID & $8.96 \%$ & & & & & & & & & & \\
\hline AVERAGE REMOVAL FOR EDTA & $1.41 \%$ & & & & & & & & & & \\
\hline
\end{tabular}


\% Fe Removed by Columnar Flooding

\begin{tabular}{|c|c|c|c|c|c|c|c|c|c|c|c|}
\hline & Pore & Pore & Pore & Pore & Pore & Pore & Pore & Pore & & & TOTAL \\
\hline Sample & $\# 1$ & \#2 & \#3 & $\# 4$ & $\# 5$ & \#6 & $\# 7$ & $\# 8$ & Drainage & Composite & $\%$ REMOVED \\
\hline R111-2 Composite Dist. H2O & $0.01 \%$ & $0.01 \%$ & $0.01 \%$ & $0.02 \%$ & $0.02 \%$ & & & & $0.01 \%$ & $0.01 \%$ & $0.09 \%$ \\
\hline R111-2 Composite .05M Cit. & $0.01 \%$ & $0.01 \%$ & $0.02 \%$ & $0.02 \%$ & $0.02 \%$ & $0.02 \%$ & $0.02 \%$ & $0.02 \%$ & $0.05 \%$ & $0.02 \%$ & $0.21 \%$ \\
\hline R111-3 Composite Dist. H2O & $0.00 \%$ & $0.00 \%$ & $0.00 \%$ & $0.00 \%$ & $0.00 \%$ & & & & $0.00 \%$ & $0.00 \%$ & $0.00 \%$ \\
\hline R111-3 Composite .05M Cit. & $0.00 \%$ & $0.01 \%$ & $0.02 \%$ & $0.03 \%$ & $0.04 \%$ & $0.04 \%$ & $0.06 \%$ & & $0.06 \%$ & $0.04 \%$ & $0.30 \%$ \\
\hline R111-4 Composite Dist. $\mathrm{H} 20$ & $0.00 \%$ & $0.00 \%$ & $0.00 \%$ & $0.00 \%$ & $0.00 \%$ & & & & $0.00 \%$ & $0.00 \%$ & $0.00 \%$ \\
\hline R111-4 Composite .05M Cit. & $0.01 \%$ & $0.02 \%$ & $0.02 \%$ & $0.02 \%$ & $0.03 \%$ & $0.03 \%$ & $0.03 \%$ & $0.03 \%$ & $0.02 \%$ & $0.02 \%$ & $0.23 \%$ \\
\hline R111-4,3 Composite Dist. H2O & $0.01 \%$ & $0.00 \%$ & $0.00 \%$ & $0.00 \%$ & $0.00 \%$ & & & & $0.00 \%$ & $0.00 \%$ & $0.01 \%$ \\
\hline R111-4,3 Composite .05M Cit. & $0.02 \%$ & $0.04 \%$ & $0.05 \%$ & $0.05 \%$ & $0.05 \%$ & $0.08 \%$ & $0.10 \%$ & $0.12 \%$ & $0.12 \%$ & $0.05 \%$ & $0.68 \%$ \\
\hline R124 Composite Dist. H2O & $0.00 \%$ & $0.01 \%$ & $0.01 \%$ & $0.00 \%$ & $0.00 \%$ & & & & $0.00 \%$ & $0.00 \%$ & $0.02 \%$ \\
\hline R124 Composite .05M EDTA & $0.05 \%$ & $0.06 \%$ & $0.05 \%$ & $0.05 \%$ & $0.05 \%$ & $0.05 \%$ & $0.05 \%$ & $0.05 \%$ & $0.05 \%$ & $0.05 \%$ & $0.51 \%$ \\
\hline R124-2 Composite Dist. $\mathrm{H} 2 \mathrm{O}$ & $0.03 \%$ & $0.02 \%$ & $0.01 \%$ & $0.01 \%$ & $0.02 \%$ & & & & $0.01 \%$ & $0.01 \%$ & $0.11 \%$ \\
\hline R124-2 Composite .05M Cit & $0.04 \%$ & $0.05 \%$ & $0.05 \%$ & $0.05 \%$ & $0.05 \%$ & $0.05 \%$ & $0.05 \%$ & $0.06 \%$ & $0.06 \%$ & $0.05 \%$ & $0.51 \%$ \\
\hline R124-3 Composite Dist. $\mathrm{H} 20$ & $0.01 \%$ & $0.00 \%$ & $0.00 \%$ & $0.00 \%$ & $0.00 \%$ & & & & $0.00 \%$ & $0.00 \%$ & $0.01 \%$ \\
\hline R124-3 Composite .05M Cit & $0.01 \%$ & $0.03 \%$ & $0.05 \%$ & $0.05 \%$ & $0.05 \%$ & $0.05 \%$ & $0.05 \%$ & $0.05 \%$ & $0.05 \%$ & $0.04 \%$ & $0.43 \%$ \\
\hline AVERAGE REMOVAL FOR DIST. H2O & $0.03 \%$ & & & & & & & & & & \\
\hline AVERAGE REMOVAL FOR CITRIC ACID & $0.39 \%$ & & & & & & & & & & \\
\hline AVERAGE REMOVAL FOR EDTA & $0.51 \%$ & & & & & & & & & & \\
\hline
\end{tabular}


\% Pb Removed by Columnar Flooding

\begin{tabular}{|c|c|c|c|c|c|c|c|c|c|c|c|}
\hline & Pore & Pore & Pore & Pore & Pore & Pore & Pore & Pore & & & TOTAL \\
\hline Sample & $\# 1$ & $\# 2$ & $\# 3$ & $\# 4$ & $\# 5$ & \#6 & $\# 7$ & $\# 8$ & Drainage & Composite & $\%$ REMOVED \\
\hline Aberdeen Dist. H2O 5000 ppm Pb(NO3)2 & $0.00 \%$ & $0.02 \%$ & $0.01 \%$ & $0.02 \%$ & $0.02 \%$ & & & & $0.00 \%$ & $0.01 \%$ & $0.08 \%$ \\
\hline Aberdeen .01M EDTA 5000 ppm Pb(NO3)2 & $0.09 \%$ & $0.75 \%$ & $0.65 \%$ & $0.48 \%$ & $0.38 \%$ & $0.27 \%$ & $0.29 \%$ & $0.27 \%$ & $0.08 \%$ & $0.52 \%$ & $3.78 \%$ \\
\hline Ft. Mead Dist. H20 5000 ppm Pb(NO3)2 & $0.00 \%$ & $0.00 \%$ & $0.00 \%$ & $0.00 \%$ & $0.00 \%$ & $0.00 \%$ & & & $0.01 \%$ & $0.00 \%$ & $0.01 \%$ \\
\hline Ft. Mead .01M EDTA $5000 \mathrm{ppm} \mathrm{Pb(NO3)2}$ & $0.57 \%$ & $2.53 \%$ & $3.90 \%$ & $0.34 \%$ & $2.03 \%$ & $1.53 \%$ & $0.13 \%$ & $1.05 \%$ & $0.89 \%$ & $0.17 \%$ & $13.14 \%$ \\
\hline LAAFB Dist. $\mathrm{H} 205000$ ppm Pb(NO3)2 & $0.01 \%$ & $0.00 \%$ & $0.00 \%$ & $0.00 \%$ & $0.00 \%$ & & & & $0.00 \%$ & $0.01 \%$ & $0.02 \%$ \\
\hline LAAFB .05M EDTA 5000 ppm $\mathrm{Pb}(\mathrm{NO} 3) 2$ & $1.74 \%$ & $1.85 \%$ & $1.93 \%$ & $2.56 \%$ & $2.88 \%$ & $2.51 \%$ & $2.39 \%$ & $1.89 \%$ & $1.64 \%$ & $2.36 \%$ & $21.75 \%$ \\
\hline LAAFB-2 Dist. H20 10000 ppm Pb(NO3)2 & $0.00 \%$ & $0.00 \%$ & $0.00 \%$ & $0.00 \%$ & $0.00 \%$ & & & & $0.00 \%$ & $0.00 \%$ & $0.00 \%$ \\
\hline LAAFB-2 .05M EDTA $10000 \mathrm{ppm} \mathrm{Pb}(\mathrm{NO} 3) 2$ & $0.57 \%$ & $0.87 \%$ & $1.02 \%$ & $0.93 \%$ & $0.92 \%$ & $1.24 \%$ & $1.25 \%$ & $1.04 \%$ & $1.29 \%$ & $0.78 \%$ & $9.91 \%$ \\
\hline LAAFB-3 Dist. H20 10000 ppm Pb(NO3)2 & $0.01 \%$ & $0.01 \%$ & $0.01 \%$ & $0.00 \%$ & $0.00 \%$ & & & & $0.01 \%$ & $0.01 \%$ & $0.05 \%$ \\
\hline LAAFB-3 .05M CIT. $10000 \mathrm{ppm} \mathrm{Pb}(\mathrm{NO} 3) 2$ & $0.36 \%$ & $0.59 \%$ & $0.71 \%$ & $0.96 \%$ & $0.81 \%$ & $0.71 \%$ & $0.56 \%$ & $0.54 \%$ & $0.38 \%$ & $0.50 \%$ & $6.12 \%$ \\
\hline R111 Composite Dist. H2O & $0.21 \%$ & $0.27 \%$ & $0.09 \%$ & $0.09 \%$ & $0.09 \%$ & & & & $0.26 \%$ & $0.15 \%$ & $1.16 \%$ \\
\hline R111 Composite .05M EDTA & $0.12 \%$ & $0.61 \%$ & $1.86 \%$ & $2.40 \%$ & $1.86 \%$ & $1.33 \%$ & $1.04 \%$ & $0.92 \%$ & $1.14 \%$ & $1.42 \%$ & $12.70 \%$ \\
\hline R111-2 Composite Dist. $\mathrm{H} 20$ & $0.16 \%$ & $0.06 \%$ & $0.08 \%$ & $0.15 \%$ & $0.03 \%$ & & & & $0.03 \%$ & $0.04 \%$ & $0.55 \%$ \\
\hline R111-2 Composite .05M Cit. & $0.12 \%$ & $0.20 \%$ & $0.14 \%$ & $0.19 \%$ & $0.19 \%$ & $0.23 \%$ & $0.16 \%$ & $0.15 \%$ & $0.38 \%$ & $0.22 \%$ & $1.98 \%$ \\
\hline R111-3 Composite Dist. H2O & $0.10 \%$ & $0.13 \%$ & $0.10 \%$ & $0.17 \%$ & $0.22 \%$ & & & & $0.13 \%$ & $0.10 \%$ & $0.95 \%$ \\
\hline R111-3 Composite .05M Cit. & $0.25 \%$ & $0.09 \%$ & $0.21 \%$ & $0.39 \%$ & $0.69 \%$ & $0.31 \%$ & $0.86 \%$ & & $0.73 \%$ & $0.63 \%$ & $4.16 \%$ \\
\hline R111-4 Composite Dist. H20 & $0.09 \%$ & $0.07 \%$ & $0.07 \%$ & $0.07 \%$ & $0.07 \%$ & & & & $0.07 \%$ & $0.07 \%$ & $0.51 \%$ \\
\hline R111-4 Composite .05M Cit. & $0.22 \%$ & $0.37 \%$ & $0.21 \%$ & $0.44 \%$ & $0.56 \%$ & $0.30 \%$ & $0.55 \%$ & $0.39 \%$ & $0.27 \%$ & $0.34 \%$ & $3.65 \%$ \\
\hline R111-4,3 Composite Dist. H2O & $0.07 \%$ & $0.07 \%$ & $0.07 \%$ & $0.07 \%$ & $0.07 \%$ & & & & $0.07 \%$ & $0.07 \%$ & $0.49 \%$ \\
\hline R111-4,3 Composite .05M Cit. & $0.18 \%$ & $0.21 \%$ & $0.54 \%$ & $0.80 \%$ & $0.88 \%$ & $0.75 \%$ & $4.25 \%$ & $0.93 \%$ & $0.76 \%$ & $0.67 \%$ & $9.97 \%$ \\
\hline R122 Composite Dist. H2O & $0.09 \%$ & $0.08 \%$ & $0.03 \%$ & $0.03 \%$ & $0.03 \%$ & & & & $0.09 \%$ & $0.05 \%$ & $0.40 \%$ \\
\hline R122 Composite .05M EDTA & $0.11 \%$ & $2.86 \%$ & $12.01 \%$ & $10.96 \%$ & $6.63 \%$ & $4.52 \%$ & $3.08 \%$ & $2.45 \%$ & $1.88 \%$ & $6.07 \%$ & $50.57 \%$ \\
\hline R124 Composite Dist. H2O & $0.01 \%$ & $0.01 \%$ & $0.01 \%$ & $0.00 \%$ & $0.00 \%$ & & & & $0.01 \%$ & $0.01 \%$ & $0.05 \%$ \\
\hline R124 Composite .05M EDTA & $1.56 \%$ & $1.67 \%$ & $1.55 \%$ & $1.63 \%$ & $1.02 \%$ & $0.88 \%$ & $0.70 \%$ & $0.62 \%$ & $0.63 \%$ & $1.14 \%$ & $11.40 \%$ \\
\hline R124-2 Composite Dist. H20 & $0.03 \%$ & $0.02 \%$ & $0.01 \%$ & $0.01 \%$ & $0.01 \%$ & & & & $0.01 \%$ & $0.01 \%$ & $0.10 \%$ \\
\hline R124-2 Composite .05M Cit & $0.07 \%$ & $0.19 \%$ & $0.22 \%$ & $0.24 \%$ & $0.24 \%$ & $0.22 \%$ & $0.31 \%$ & $0.29 \%$ & $0.23 \%$ & $0.29 \%$ & $2.30 \%$ \\
\hline R124-3 Composite Dist. H2O & $0.00 \%$ & $0.00 \%$ & $0.00 \%$ & $0.00 \%$ & $0.00 \%$ & & & & $0.00 \%$ & $0.00 \%$ & $0.00 \%$ \\
\hline R124-3 Composite .05M Cit & $0.01 \%$ & $0.11 \%$ & $0.21 \%$ & $0.20 \%$ & $0.19 \%$ & $0.18 \%$ & $0.17 \%$ & $0.17 \%$ & $0.14 \%$ & $0.16 \%$ & $1.54 \%$ \\
\hline AVERAGE REMOVAL FOR DIST. H2O & $0.31 \%$ & & & & & & & & & & \\
\hline AVERAGE REMOVAL FOR CITRIC ACID & $4.25 \%$ & & & & & & & & & & \\
\hline AVERAGE REMOVAL FOR EDTA & $17.61 \%$ & & & & & & & & & & \\
\hline
\end{tabular}


\% Zn Removed by Columnar Flooding

\begin{tabular}{|c|c|c|c|c|c|c|c|c|c|c|c|}
\hline & Pore & Pore & Pore & Pore & Pore & Pore & Pore & Pore & & & TOTAL \\
\hline Sample & $\# 1$ & $\# 2$ & \#3 & $\# 4$ & $\# 5$ & $\# 6$ & $\# 7$ & $\# 8$ & Drainage & Composite & \% REMOVED \\
\hline R111-2 Composite Dist. $\mathrm{H} 20$ & $0.08 \%$ & $0.07 \%$ & $0.07 \%$ & $0.07 \%$ & $0.06 \%$ & & & & $0.07 \%$ & $0.06 \%$ & $0.48 \%$ \\
\hline R111-2 Composite .05M Cit. & $0.35 \%$ & $0.08 \%$ & $0.10 \%$ & $0.11 \%$ & $0.09 \%$ & $0.08 \%$ & $0.07 \%$ & $0.06 \%$ & $0.12 \%$ & $0.10 \%$ & $1.16 \%$ \\
\hline R111-3 Composite Dist. H2O & $0.12 \%$ & $0.15 \%$ & $0.07 \%$ & $0.10 \%$ & $0.04 \%$ & & & & $0.10 \%$ & $0.06 \%$ & $0.64 \%$ \\
\hline R111-3 Composite .05M Cit. & $0.11 \%$ & $1.07 \%$ & $0.44 \%$ & $0.47 \%$ & $0.42 \%$ & $0.31 \%$ & $0.18 \%$ & & $0.51 \%$ & $0.35 \%$ & $3.86 \%$ \\
\hline R111-4 Composite Dist. $\mathrm{H} 2 \mathrm{O}$ & $0.11 \%$ & $0.14 \%$ & $0.10 \%$ & $0.05 \%$ & $0.09 \%$ & & & & $0.07 \%$ & $0.11 \%$ & $0.67 \%$ \\
\hline R111-4 Composite .05M Cit. & $0.66 \%$ & $0.14 \%$ & $0.14 \%$ & $0.12 \%$ & $0.74 \%$ & $0.68 \%$ & $0.66 \%$ & $0.65 \%$ & $0.72 \%$ & $1.14 \%$ & $5.65 \%$ \\
\hline R111-4,3 Composite Dist. $\mathrm{H} 20$ & $0.33 \%$ & $0.22 \%$ & $0.23 \%$ & $0.20 \%$ & $0.09 \%$ & & & & $0.24 \%$ & $0.16 \%$ & $1.47 \%$ \\
\hline R111-4,3 Composite .05M Cit. & $0.23 \%$ & $1.76 \%$ & $3.78 \%$ & $2.37 \%$ & $2.02 \%$ & $1.92 \%$ & $1.98 \%$ & $1.96 \%$ & $1.81 \%$ & $1.90 \%$ & $19.73 \%$ \\
\hline R124 Composite Dist. H2O & $0.17 \%$ & $0.11 \%$ & $0.26 \%$ & $0.13 \%$ & $0.15 \%$ & & & & $0.21 \%$ & $0.23 \%$ & $1.26 \%$ \\
\hline R124 Composite :05M EDTA & $0.50 \%$ & $0.63 \%$ & $0.55 \%$ & $0.43 \%$ & $0.41 \%$ & $0.48 \%$ & $0.51 \%$ & $0.41 \%$ & $0.45 \%$ & $0.50 \%$ & $4.87 \%$ \\
\hline R124-2 Composite Dist. $\mathrm{H} 2 \mathrm{O}$ & $1.23 \%$ & $0.37 \%$ & $0.42 \%$ & $0.33 \%$ & $0.51 \%$ & & & & $0.27 \%$ & $0.36 \%$ & $3.49 \%$ \\
\hline R124-2 Composite .05M Cit & $0.77 \%$ & $0.86 \%$ & $0.99 \%$ & $0.61 \%$ & $0.94 \%$ & $0.82 \%$ & $0.59 \%$ & $0.76 \%$ & $2.22 \%$ & $0.62 \%$ & $9.18 \%$ \\
\hline R124-3 Composite Dist. $\mathrm{H} 20$ & $0.49 \%$ & $0.34 \%$ & $0.38 \%$ & $0.69 \%$ & $0.62 \%$ & & & & $0.93 \%$ & $0.35 \%$ & $3.80 \%$ \\
\hline R124-3 Composite .05M Cit & $1.06 \%$ & $3.28 \%$ & $3.84 \%$ & $2.48 \%$ & $3.39 \%$ & $1.40 \%$ & $2.52 \%$ & $2.13 \%$ & $1.84 \%$ & $2.01 \%$ & $23.95 \%$ \\
\hline AVERAGE REMOVAL FOR DIST. H2O & $1.69 \%$ & & & & & & & & & & \\
\hline AVERAGE REMOVAL FOR CITRIC ACID & $10.59 \%$ & & & & & & & & & & \\
\hline AVERAGE REMOVAL FOR EDTA & $4.87 \%$ & & & & & & & & & & \\
\hline
\end{tabular}

